\title{
Instrumentação para o Ensino de Física III
}

Vera Lucia Mello

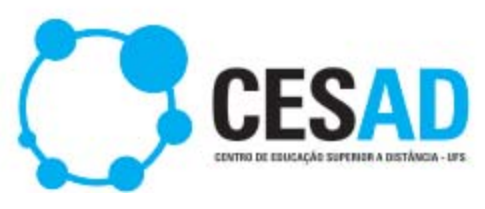

São Cristóvão/SE 2011 


\title{
Instrumentação para o Ensino de Física III
}

\author{
Elaboração de Conteúdo
}

Vera Lucia Mello

\author{
Projeto Gráfico \\ Neverton Correia da Silva \\ Nycolas Menezes Melo \\ Capa \\ Hermeson Alves de Menezes \\ Diagramação \\ Neverton Correia da Silva
}

Copyright $\odot$ 2011, Universidade Federal de Sergipe / CESAD.

Nenhuma parte deste material poderá ser reproduzida, transmitida e gravada por qualquer meio eletrônico, mecânico, por fotocópia e outros, sem a prévia autorização por escrito da UFS.

Ficha catalográfica produzida pela Biblioteca Central

Universidade Federal de Sergipe
Mello, Vera Lucia
M527i
Instrumentação para o Ensino de Física III / Vera Lúcia Mello. - São Cristóvão : Universidade Federal de Sergipe, CESAD, 2011.

1. Física - Estudo e ensino. 2. Física - Instrumentos.

I. Título. 


\section{Presidente da República}

Dilma Vana Rousseff

\section{Ministro da Educação \\ Fernando Haddad}

\section{Secretário de Educação a Distância}

Carlos Eduardo Bielschowsky

Reitor

Josué Modesto dos Passos Subrinho
Chefe de Gabinete

Ednalva Freire Caetano

\section{Coordenador Geral da UAB/UFS \\ Diretor do CESAD \\ Antônio Ponciano Bezerra}

Vice-coordenador da UAB/UFS

Vice-diretor do CESAD

Fábio Alves dos Santos

Vice-Reitor

Angelo Roberto Antoniolli

\section{Diretoria Pedagógica \\ Clotildes Farias de Sousa (Diretora) \\ Diretoria Administrativa e Financeira \\ Edélzio Alves Costa Júnior (Diretor) \\ Sylvia Helena de Almeida Soares \\ Valter Siqueira Alves \\ Coordenação de Cursos \\ Djalma Andrade (Coordenadora) \\ Núcleo de Formação Continuada \\ Rosemeire Marcedo Costa (Coordenadora) \\ Núcleo de Avaliação \\ Hérica dos Santos Matos (Coordenadora) \\ Carlos Alberto Vasconcelos}

\section{Núcleo de Serviços Gráficos e Audiovisuais Giselda Barros}

\section{Núcleo de Tecnologia da Informação João Eduardo Batista de Deus Anselmo Marcel da Conceição Souza \\ Raimundo Araujo de Almeida Júnior}

\section{Assessoria de Comunicação \\ Edvar Freire Caetano \\ Guilherme Borba Gouy}

\section{Coordenadores de Curso}

Denis Menezes (Letras Português)

Eduardo Farias (Administração)

Haroldo Dorea (Química)

Hassan Sherafat (Matemática)

Hélio Mario Araújo (Geografia)

Lourival Santana (História)

Marcelo Macedo (Física)

Silmara Pantaleão (Ciências Biológicas)
Coordenadores de Tutoria

Edvan dos Santos Sousa (Física)

Geraldo Ferreira Souza Júnior (Matemática)

Ayslan Jorge Santos de Araujo (Administração)

Priscila Viana Cardozo (História)

Rafael de Jesus Santana (Química)

Gleise Campos Pinto Santana (Geografia)

Trícia C. P. de Sant'ana (Ciências Biológicas)

Laura Camila Braz de Almeida (Letras Português)

Lívia Carvalho Santos (Presencial)

\section{NÚCLEO DE MATERIAL DIDÁTICO}

\section{Hermeson Menezes (Coordenador)} Marcio Roberto de Oliveira Mendoça
Neverton Correia da Silva

Nycolas Menezes Melo 



\section{Sumário}

AULA 1

Eletrização e carga elétrica 07

AULA 2

Força elétrica e o Pssc. 29

AULA 3

Campo elétrico 55

AULA 4

Potencial elétrico 75

AULA 5

Corrente e resistência elétrica. 95

AULA 6

O Projeto pef e o efeito Joule. 123

AULA 7

Campo e força magnética. 151

AULA 8

Campo magnético 175

AULA 9

Campo magnético produzido por uma corrente elétrica. 195

AULA 10

Corrente e fem induzida. 213 



\section{Aula 1}

\section{ELETRIZAÇÃO E CARGA ELÉTRICA}

META

Fazer com que o estudante comece a pensar no ensino de ciências como algo "orgânico"

que está em profunda transformação.

Fazer com que os alunos percebam, através de um texto básico complementado com atividades lúdicas, applets de ensino, vídeos, e com materiais de baixo custo, que o conceito de eletrização e carga elétrica pode ser apreendido de forma simples e divertida. Analisar dois textos sobre o tema de eletrização de modo que o aluno possa analisar duas

formas de se apresentar este conceito. Apresentar o curso de instrumentação III.

OBJETIVOS

Ao final desta aula, o aluno deverá: estar ciente das novas possibilidades, dos desafios que envolvem o ensino de ciências em geral e das dificuldades de se ministrar um curso de eletricidade e magnetismo. Ter compreendido que as ciências naturais estão baseadas na experimentação e que esta é feita de ensaios, experiências e medidas e que estas levam a compreensão e matematização dos conceitos físicos (naturais em geral). Compreender que pode usar o conceito de átomo ou não, no ensino do conceito de eletrização.

Os estudantes devem compreender que o curso de instrumentação III está centrado na

explicação da Física dos eletrodomésticos (Física das coisas) e na discussão se o livro didático é o produto de vários projetos de ensino de ciências e da transposição didática de livros universitários.

\section{PRÉ-REQUISITOS}

Os alunos deverão ter cursado as disciplinas Psicologia da Educação, Física A, Física B e Instrumentação I.

\section{Vera Lucia Mello}




\section{INTRODUÇÃO}

O tema de estudo da disciplina Instrumentação III é de como ministrar um curso de Eletricidade e Magnetismo. As teorias eletromagnéticas foram desenvolvidas e completadas no século XIX e marcaram a virada do século XX com eletrificação das primeiras cidades americanas (Chicago). Hoje em dia não saberíamos mais viver sem os eletrodomésticos. Apesar disso o curso de eletromagnetismo faz pouca referência a estes dispositivos e do papel fundamental da ciência no seu desenvolvimento.

Por esta razão e outras que o grupo de ensino de Física da USP, através do projeto GREF, lançou o projeto de ensino de "Física das coisas" e não se ensinar as "coisas da Física". Ou seja, eles pregam que devemos ensinar a partir da Física envolvida no funcionamento dos objetos que usamos no nosso cotidiano (a Física das coisas) e não devemos ensinar Física através da formulação de teorias e fórmulas e depois sairmos a procura de exemplos que se encaixem na nossa teoria (as coisas de Física).

Assim, nesse curso vamos apresentar de forma mais detalhada os principais projetos de ensino de Física e vamos fazer uma análise comparativa entre o material didático produzido por eles e o material didático que temos à nossa disposição, principalmente o livro didático. Deste modo, alguns temas serão tratados fora da ordem que estamos habituados em nossos cursos de Física, mas terá que ser assim, pois, não temos a tradução completa de todas as aulas desses projetos.

Trataremos agora do tema dessa aula. Quando iniciamos um curso de eletricidade e magnetismo, naturalmente começamos com o conceito de eletrização e de carga elétrica. Historicamente, se determinou as propriedades das cargas elétricas muito antes de qualquer conhecimento experimental sobre a estrutura da matéria, apesar dos filósofos atomistas pressuporem que a matéria deveria ser composta de átomos. Mas, a maioria dos textos atuais começa explicando a existência das cargas elétricas através do modelo atômico da matéria. Colocamos abaixo um texto sobre eletrização, que usa o modelo atômico e em seguida fazemos uma adaptação desse mesmo texto tirando o modelo atômico de sua explicação para que você avalie as vantagens e desvantagens de se fazer uma abordagem mais próxima dos fatos históricos e de uma que leve em conta mais os fatos atuais.

\section{PROCESSOS DE ELETRIZAÇÃO TEXTO ORIGINAL INTRODUÇÃO HISTÓRICA}

O primeiro registro histórico da propriedade de eletrização foi feita pelo sábio grego Tales de Mileto (640-546 AC) que observou que um pedaço de 
âmbar (substância resinosa, amarela e fossilizada) atritado com um pano atraia certos corpos de massa pequena como fio de cabelo e fio de lã. Até os dias de William Gilbert (1540-1603), não se fazia distinção entre magnetização e eletrização. Gilbert fazendo experiências verificou que muitas outras substâncias apresentavam tal propriedade e todos os fenômenos relacionados foram chamados de elétricos (âmbar em grego é elektron).

\section{CARGA E FORÇA ELÉTRICA}

No século XVIII, o físico francês Charles François Du Fay (1698-1739) publicou um trabalho acerca da existência de dois tipos de eletricidade:

- Vitrosa, chamada assim porque é a carga que adquire uma barra de vidro depois de atritada com seda.

- Resinosa, que é a carga da borracha quando atritada com lã.

Posteriormente, o físico americano Benjamin Franklin (1706-1790), sem conhecer os trabalhos de Du Fay, atribuiu os nomes de positiva e negativa aos dois tipos de eletricidade. Até o século XIX se considerava que as forças elétricas eram fenômenos particulares que não tinha relação com a gravitação nem com o magnetismo. Em nossos dias se considera que a força elétrica é uma das quatro forças fundamentais da natureza; as outras são a gravidade e as forças nucleares, forte e fraca.

Força nuclear é a força que mantém unido o núcleo de um átomo. Afeta as partículas do núcleo: nêutrons, prótons e mésons. Força nuclear é a força que se manifesta nos núcleos de átomos instáveis com mais de 89 prótons através de emissões beta.

A força elétrica é uma propriedade das cargas elétricas. A carga elétrica é uma propriedade fundamental da matéria como a massa e o volume e estas podem ser de dois tipos, positivas ou negativas. O conceito de carga elétrica, ainda que um pouco abstrato, é tão importante que não se pode deixar de mencioná-la na descrição do mundo físico. No princípio, dito conceito físico era somente um artifício inventado para descrever uma situação, porém depois adquiriu realidade ao se descobrir a origem e a unidade natural da carga elétrica. No começo do século passado se mediu a unidade de carga do elétron como sendo igual, em módulo, a carga do próton e esta vale aproximadamente 1,6x10-19C.

Quando duas cargas elétricas interagem a direção das forças é dada pela Lei de $D u$ Fay: cargas de sinais iguais se repelem e cargas de sinais diferentes se atraem. A unidade para medir a carga no SI é o Coulomb (C), em homenagem ao físico francês Charles Augustin de Coulomb (1736-1806), quem descobriu a relação matemática entre a força elétrica e as cargas elétricas. 


\section{PROCESSOS DE ELETRIZAÇÃO}

Os átomos e a matéria são eletricamente neutros em estado natural apesar de terem cargas positivas e negativas. Isto porque nos átomos e moléculas em geral há o mesmo número de prótons e elétrons. Para alterar tal situação, ou seja, para eletrizar um corpo é necessário fazer certo trabalho ou esforço. Dizemos que um corpo está eletrizado ou carregado quando o número de prótons é diferente do número de elétrons. Para eletrizar um corpo é necessário retirar ou acrescentar elétrons em um corpo.

Experimentalmente, verifica-se que os elétrons localizados nas últimas camadas eletrônicas de certos átomos podem ser facilmente deslocados de suas posições e ainda transferidos para outros átomos. A maior ou menor dificuldade encontrada em movimentar os elétrons dentro de um material determina se esse material é um condutor de elétrons ou um isolante.....

\section{TEXTO MODIFICADO INTRODUÇÃO HISTÓRICA}

Eletrização é o fenômeno físico que quando atritamos (esfregamos) certos materiais como pente no cabelo, estes adquirem a propriedade de atrair pequenos pedaços de papel ou lã. O primeiro registro histórico da propriedade de eletrização foi feita pelo sábio grego Tales de Mileto (640-546 $\mathrm{AC}$ ) que observou que um pedaço de âmbar (substância resinosa, amarela e fossilizada) atritado com um pano atraia certos corpos de massa pequena como fio de cabelo e fio de lã. Depois descobriu-se que mais materiais possuem esta propriedade. Até os dias de William Gilbert (1540-1603), não se fazia distinção entre magnetização e eletrização. Gilbert fazendo experiências verificou que muitas outras substâncias apresentavam tal propriedade e todos os fenômenos relacionados foram chamados de elétricos (âmbar em grego é elektron).

\section{CARGA E FORÇA ELÉTRICA}

No século XVIII, o físico francês Charles François Du Fay (1698-1739) publicou um trabalho acerca da existência de dois tipos de eletricidade:

- Vitrosa, chamada assim porque é a carga que adquire uma barra de vidro depois de atritada com seda.

- Resinosa, que é a carga da borracha quando atritada com lã.

Posteriormente, o físico americano Benjamin Franklin (1706-1790), sem conhecer os trabalhos de Du Fay, atribuiu os nomes de positiva e negativa aos dois tipos de eletricidade. Quando duas cargas elétricas interagem, a 
direção das forças é dada pela Lei de Du Fay: cargas de sinais iguais (ou mesmo tipo) se repelem e cargas de sinais diferentes (tipo diferentes) se atraem. A unidade para medir a carga no SI é o Coulomb (C), em homenagem ao físico francês Charles Augustin de Coulomb (1736-1806), quem descobriu a relação matemática entre a força elétrica e as cargas elétricas.

A força elétrica é uma propriedade das cargas elétricas. A carga elétrica é uma propriedade fundamental da matéria como a massa e o volume e estas podem ser de dois tipos, positivas ou negativas. O conceito de carga elétrica, ainda que um pouco abstrato, é tão importante que não se pode deixar de mencioná-la na descrição das propriedades da matéria. No princípio, dito conceito físico era somente um artifício inventado para descrever o fenômeno de atração e repulsão entre dois corpos, porém depois adquiriu uma explicação completa no final do século IX ao se descobrir a origem e a unidade natural da carga elétrica. No começo do século passado se mediu a unidade de carga do elétron como sendo igual, em módulo, a carga do próton e esta vale aproximadamente 1,6x10-19C.

$\mathrm{Na}$ época de Du Fay e de Coulomb se imaginava que quando atritávamos duas substâncias diferentes elas trocavam matéria ou um fluído entre si. Não havia o conceito de átomo ainda.

\section{PROCESSOS DE ELETRIZAÇÃO}

A matéria é eletricamente neutra em estado natural apesar de ter cargas positivas e negativas. Isto porque nos átomos e moléculas que as compõe há o mesmo número de prótons e elétrons. Para alterar tal situação, ou seja, para eletrizar um corpo é necessário fazer certo trabalho ou esforço. Dizemos que um corpo está eletrizado ou carregado quando o número de prótons é diferente do número de elétrons. Para eletrizar um corpo é necessário retirar ou acrescentar elétrons em um corpo.

Historicamente, antes da teoria atômica, pensava-se que a carga elétrica fosse uma espécie de fluído que passava de um corpo para outro.

Experimentalmente, verifica-se que os elétrons localizados nas últimas camadas eletrônicas de certos átomos podem ser facilmente deslocados de suas posições e ainda transferidos para outros átomos. A maior ou menor dificuldade encontrada em movimentar os elétrons dentro de um material determina se esse material é um condutor de elétrons ou um Isolante. 
Existem três tipos de Eletrização de corpos:

1. por atrito;

2. por contato;

3. por indução.

\section{Eletrização por Atrito:}

Tem-se a eletrização por atrito quando se fricciona dois corpos. $\grave{A}$ medida que um corpo perde elétrons, este vai apresentando uma predominância de cargas elementares positivas equivalentes a quantidade de elétrons perdida, enquanto que o outro recebe elétrons ficando com uma quantidade de cargas elementares negativas em excesso.

Ex.: pegando-se um canudinho de refrigerante e atritando-o com um pedaço de papel (pode ser higiênico); observa-se através de experimentos que ambos ficam carregados com a mesma quantidade de cargas, porém de sinais contrários.

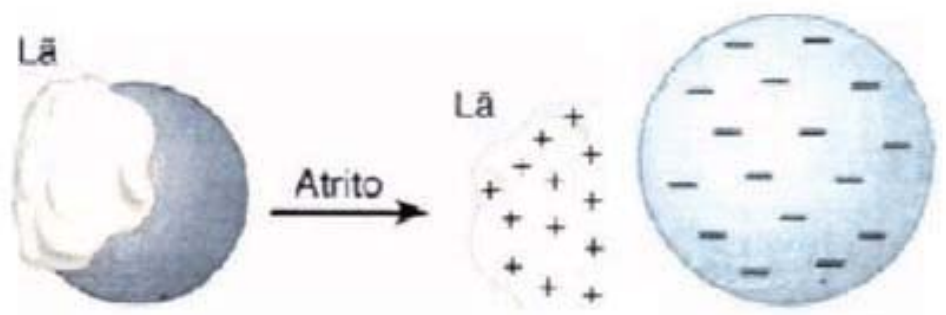

Disponível em: < http://fisica.uems.br/arquivos/labfis2/eletrizar.pdf>

\section{Eletrização por Contato:}

Quando colocamos um material condutor carregado eletricamente (por exemplo, uma esfera) em contato com um condutor neutro, observase que ambos ficam carregados com cargas de mesmo sinal. Ex.: tendo-se um bastão (ou outra esfera) carregado e uma esfera neutra inicialmente, ao tocar a esfera com este bastão, verifica-se que a esfera adquire a carga de mesmo sinal daquela presente no bastão.
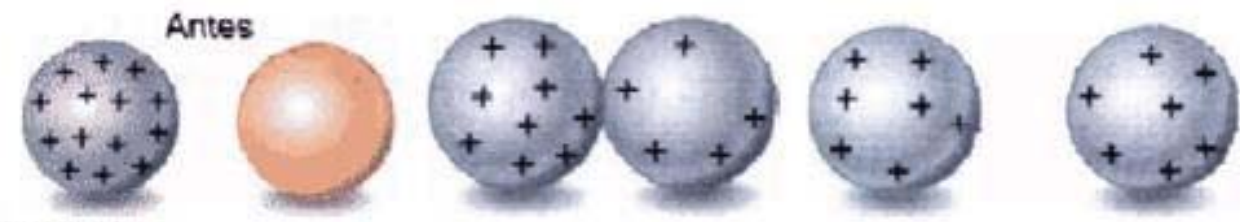

Disponível em: < http://fisica.uems.br/arquivos/labfis2/eletrizar.pdf> 


\section{Eletrização por Indução:}

A indução ocorre quando se tem um corpo que está inicialmente eletrizado e é colocado próximo a um corpo condutor neutro. Com isso, a configuração das cargas do corpo neutro se modifica de forma que cargas de sinal contrário a do bastão tendem a se aproximar do mesmo, e as de sinais iguais tendem a ficar o mais afastado possível. Ou seja, na indução ocorre a separação entre algumas cargas positivas e negativas do corpo neutro ou corpo induzido.
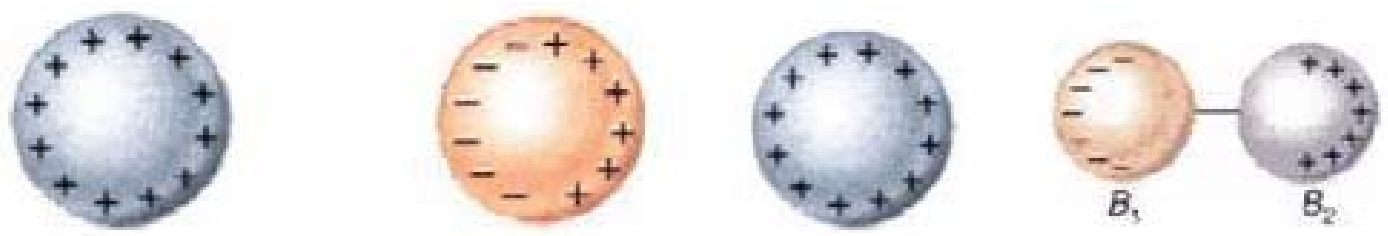

Disponível em: < http://fisica.uems.br/arquivos/labfis2/eletrizar.pdf $>$

O processo de indução, simplesmente, não eletriza um corpo. $\mathrm{O}$ que ocorre é um rearranjo no posicionamento das cargas. Podemos, dentro deste procedimento, fazer uma ligação à terra do corpo induzido e eletrizá-lo. Ligando o corpo Induzido à terra, teremos, neste caso, o deslocamento de elétrons da terra para o corpo.
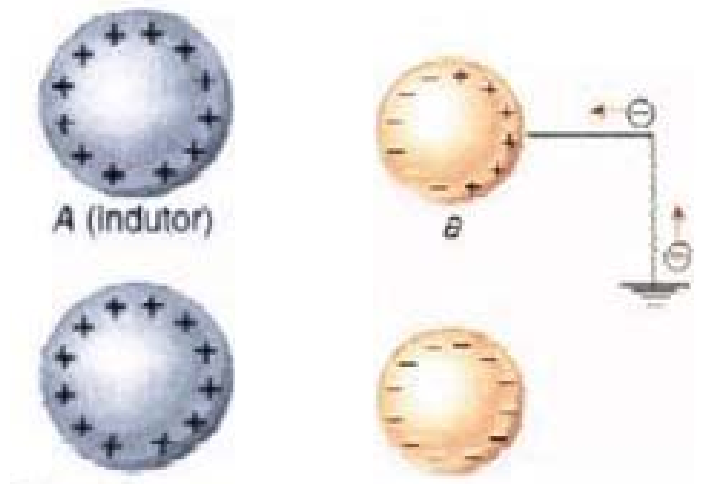

Disponível em: <http://fisica.uems.br/arquivos/labfis2/eletrizar.pdf>

\subsection{ELETROSCÓPIOS}

Para constatar se um corpo está ou não eletrizado, utilizamos dispositivos denominados eletroscópios. Existem os eletroscópios de folhas e o de pêndulo. O eletroscópio de pêndulo é baseado no processo de indução para detectar se um corpo está ou não eletrizado. Ele possui um fio isolante amarrado a uma esfera metálica. 


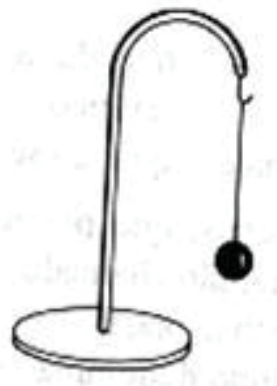

Disponível em <http://www.idesa. com.br/disciplinas/fisica/apostilas/ Eletro.pdf>

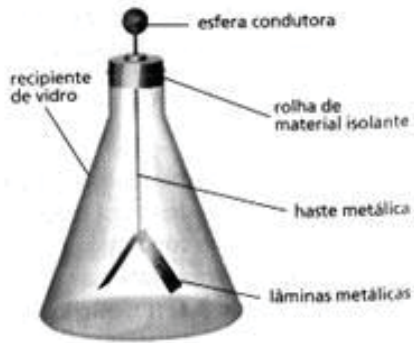

Disponível em < http:/ /www.idesa. com.br/disciplinas/fisica/apostilas/Eletro.pdf $>$

O eletroscópio de folhas também se utiliza do processo de indução para detectar se um corpo está ou não eletrizado. Caso seja aproximado um corpo eletrizado positivamente da esfera condutora, as cargas negativas serão atraídas para a esfera, já as cargas positivas se acumularão nas lâminas metálicas que irão abrir devido a repulsão de cargas iguais.

\section{PRINCÍPIOS BÁSICOS DO ELETROMAGNETISMO}

Das experiências com carga elétrica chegou-se aos dois princípios básicos do eletromagnetismo:

a. Princípio da conservação de cargas: a carga total (que é a soma algébrica de todas as cargas, sejam elas positivas ou negativas) deve ser conservada. Assim, em um processo de eletrificação de corpos as cargas são transferidas de um corpo ao outro, ao invés de serem criadas ou destruídas. Esse processo torna-se ligeiramente diferente quando da aniquilação de um elétron com um pósitron, gerando radiação gama. Observe que a carga total permanece nula em todo o processo. b. Princípio de quantização de carga. Esse princípio afirma que toda a carga é múltiplo inteiro de uma carga elementar e, que é, em módulo, igual à carga do elétron. Não existe um valor de carga menor que e, e nem um múltiplo não inteiro desse valor. $\mathrm{O}$ valor de e vale $1,602 \times 10-19 \mathrm{C}$.

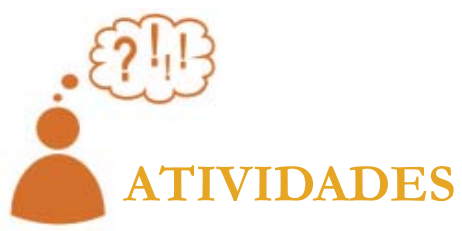

1. Para se explicar o fenômeno de eletrização temos que lançar mão do conceito de carga elétrica?

2. Qual dos textos 1 ou 2 você acha que é mais simples para estudantes do ensino médio e do fundamental?

3. Informar que historicamente se explicava a transferência de carga entre substâncias através do conceito de troca de fluído irá ilustrar mais o conceito de carga elétrica ou vai confundir os alunos? 
4. Existem muitos experimentos simples sobre eletrização. Por exemplo, o do pente no cabelo. Pesquise na bibliografia dois experimentos simples sobre esse assunto.

5. Assista ao vídeo que demonstra algumas experiências de eletrização de fácil reprodução e também utilizando um gerador de Van Graaff, através do link <http://www.pontociencia.org.br/experimentos-interna.php?expe rimento $=223 \&$ PROCESSOS + DE + ELETRIZACAO ++ PARTE $+12>$ 6. Acesse o link < http://www2.fc.unesp.br/experimentosdefisica/>, clique em Eletricidade e leia as experiências que mostram a existência de cargas elétricas (Bexigas Carregadas e Eletroscópio)

Detector de cargas "Eletroscópio de folhas"

Experiência realizada no dia 13 de Agosto de 2009 na Universidade Estadual de Mato Grosso do Sul, no Laboratório de Ensino de Física pelas acadêmicas: Liliane do Nascimento Pereira do terceiro ano noturno e Ana Paula Langaro do primeiro ano noturno, do curso de Licenciatura em Física com orientação do professor Nilson Oliveira da Silva. Todos os materiais utilizados na experiência são de fácil acesso e manuseio, para qualquer pessoa consiga realizar o experimento.

Material utilizado:

- $13 \mathrm{~cm}$ de arame fino;

- $1 \mathrm{~cm}$ de fio de cobre (número 28);

- Folha de alumínio;

- Um vidro;

- 1 bolinha de isopor;

- Adesivo epóxi;

- 1 canudo de plástico;

- Papel higiênico;

- Régua e tesoura;

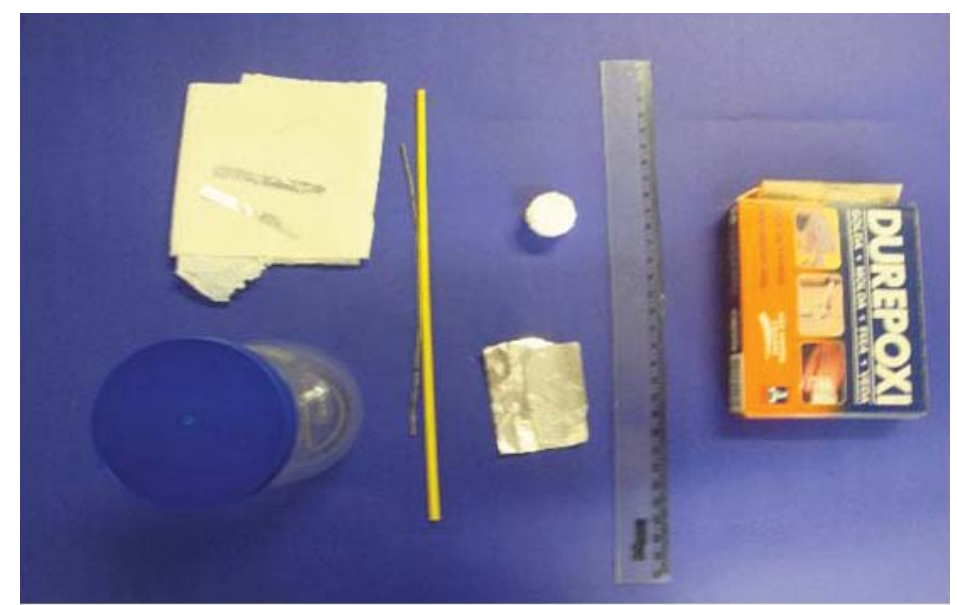

Material utilizado na experiência, começando da direita temos o adesivo epóxi, régua, folha de papel alumínio, bola de isopor, canudo de plástico, $13 \mathrm{~cm}$ de arame fino, um vidro, duas folhas de papel alumínio com $3 \mathrm{~cm}$ cada, $1 \mathrm{~cm}$ de fio de cobre (número 28) e por fim o papel higiênico. 


\section{Procedimento experimental}

$1^{\circ}$ passo:

- Faça um furo na tampa do vidro com a mesma espessura do arame. Para isso, esquente o arame e faça o furo com auxilio de um adulto.

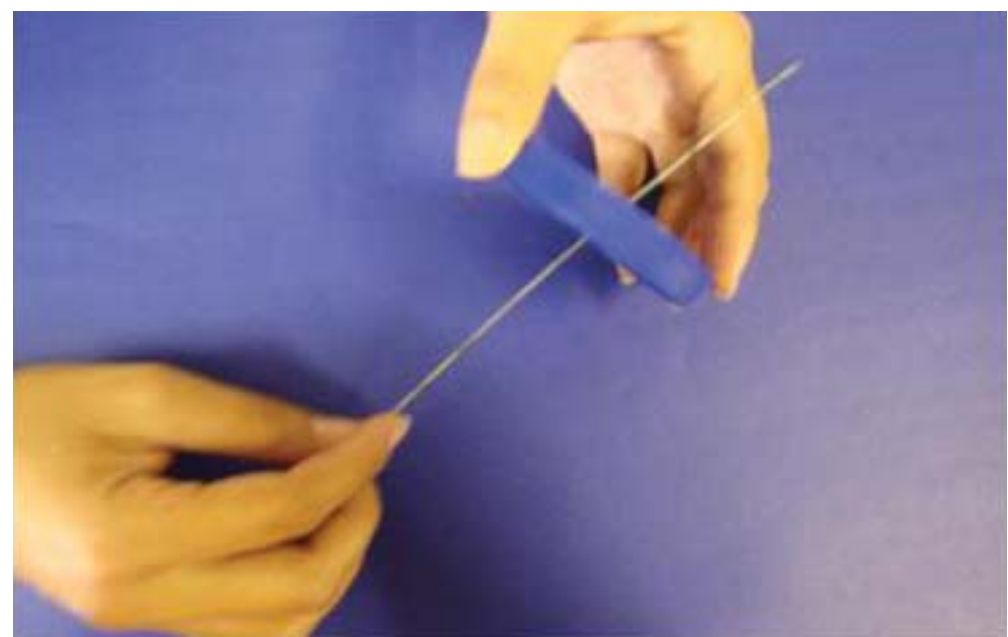

Processo realizado para furar a tampa do vidro utilizando o próprio arame.

- Dobre-o na forma de um gancho, fixe-o na tampa com adesivo epóxi e espere secar (duas horas para ela secar).

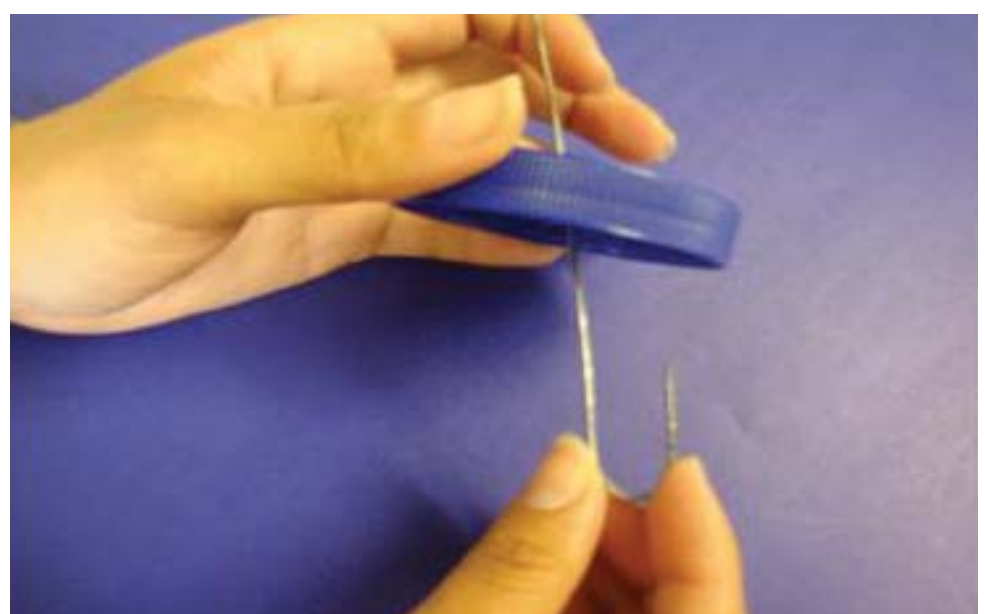

Arame dobrado em forma de um gancho.

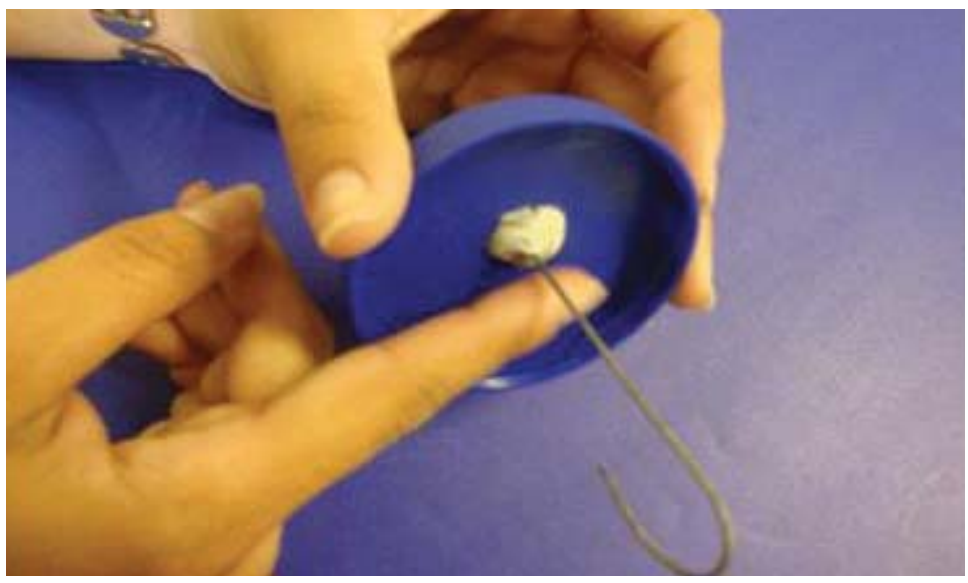

Fixação do arame na tampa com o adesivo epóxi. 
- Corte duas tiras finas de papel alumínio de $3 \mathrm{~cm}$ de comprimento e prenda-as com o fio de cobre. Depois que a cola estiver seca, coloque as tiras de papel alumínio no gancho.

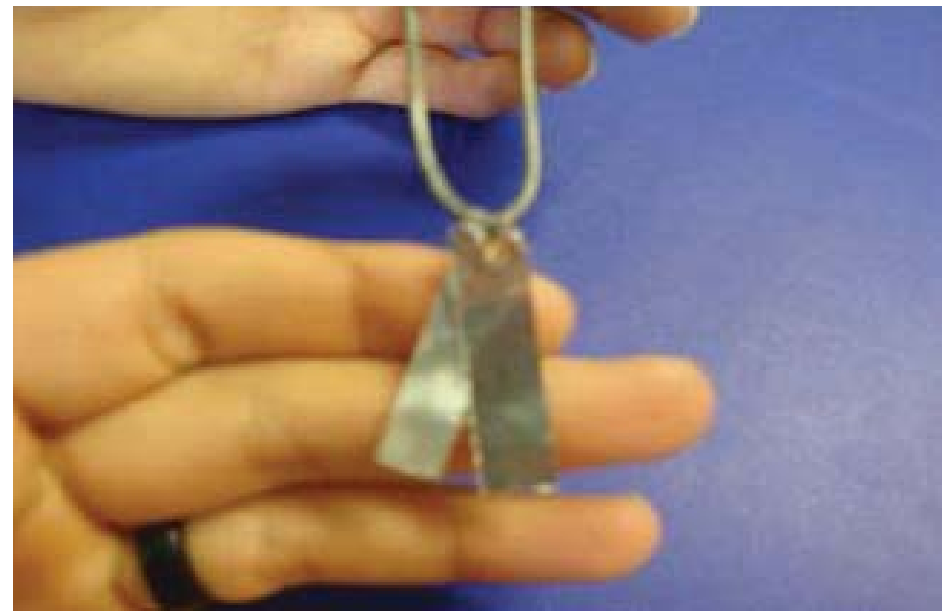

Duas tiras de papel alumínio com $3 \mathrm{~cm}$ de comprimento cada, presas com $1 \mathrm{~cm}$ de fio de cobre (número 28), colocadas no gancho.

- Tampe o vidro. Por último, encape uma bola de isopor com papel alumínio e fixe-o no arame.

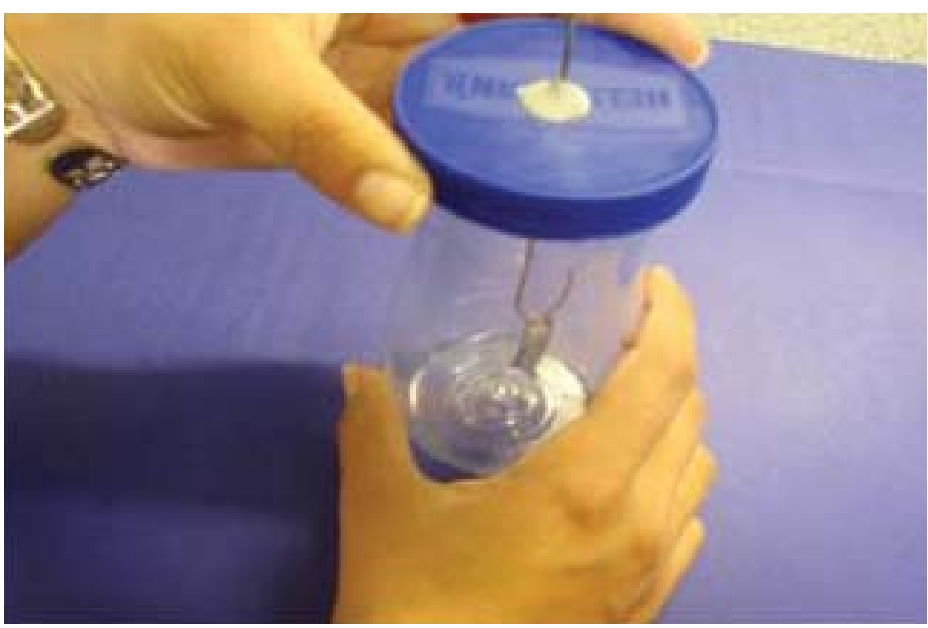

Tampando o vidro.

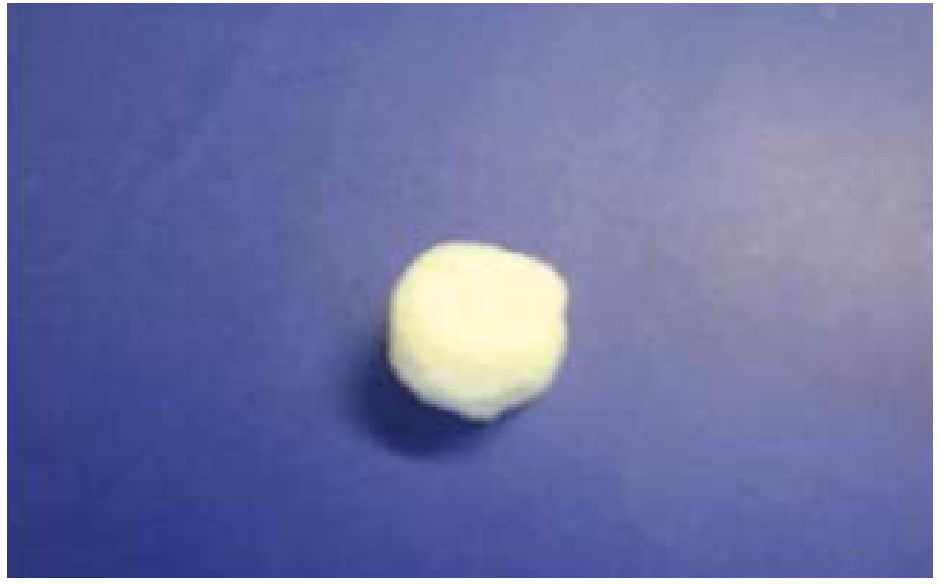

Bola de isopor antes de ser encapada com papel alumínio 


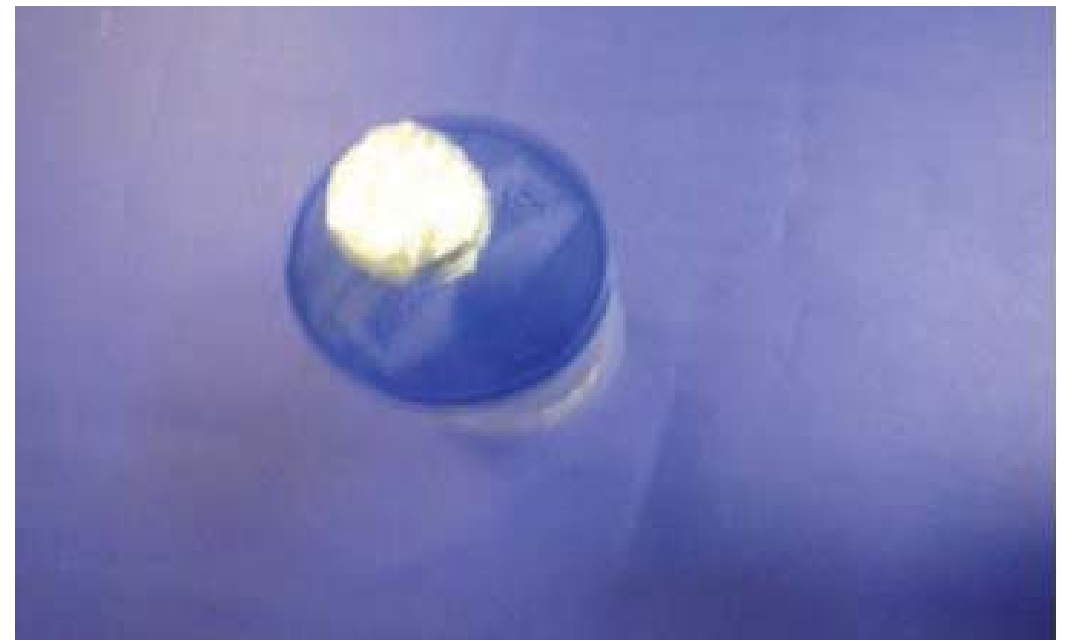

Fixação da bola de isopor encapada com papel alumínio no arame.

\section{$2^{\circ}$ passo:}

- Atrite o canudo com um pedaço de papel higiênico (lembrando, que este processo deve ser feito algumas vezes para que o canudo fique bem eletrizado), e aproxime e afaste o canudo da esfera, sem tocá-la. Observe o que acontece com as tiras de alumínio.

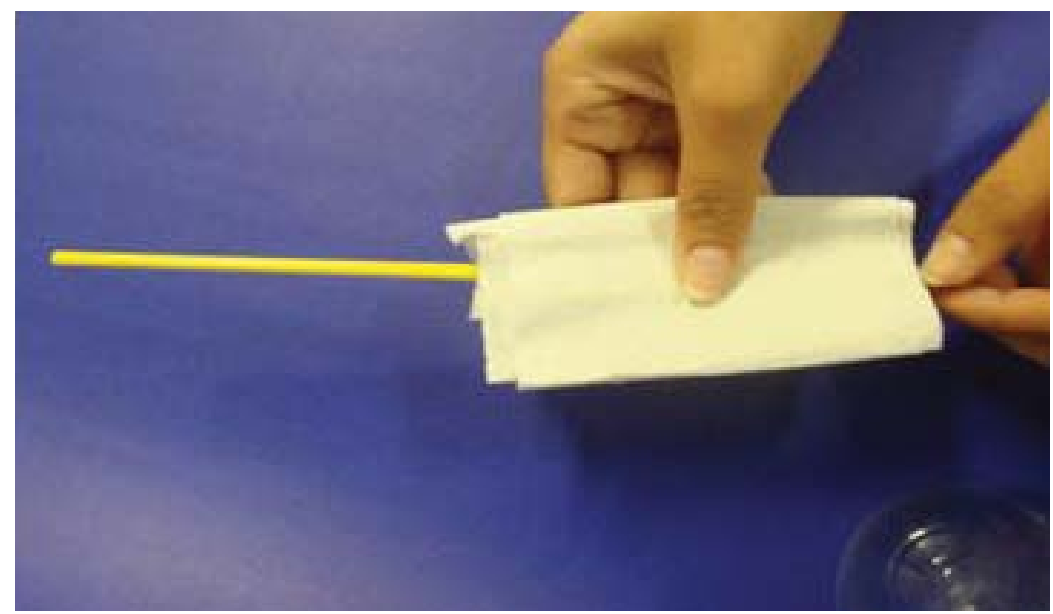

Começo do processo de atrito do canudo

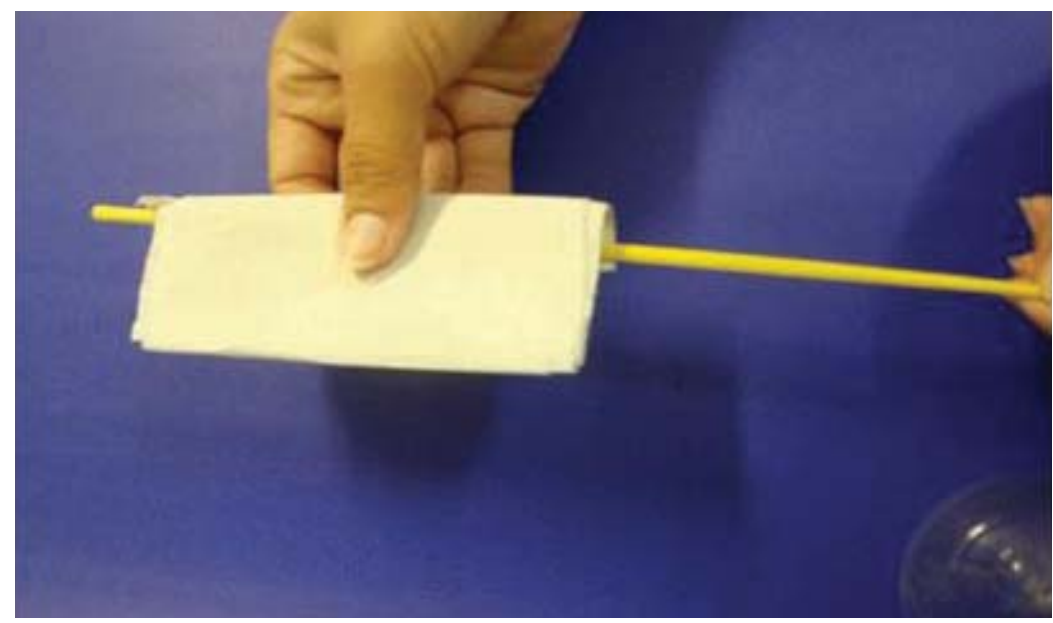

Término do processo de atrito do canudo 


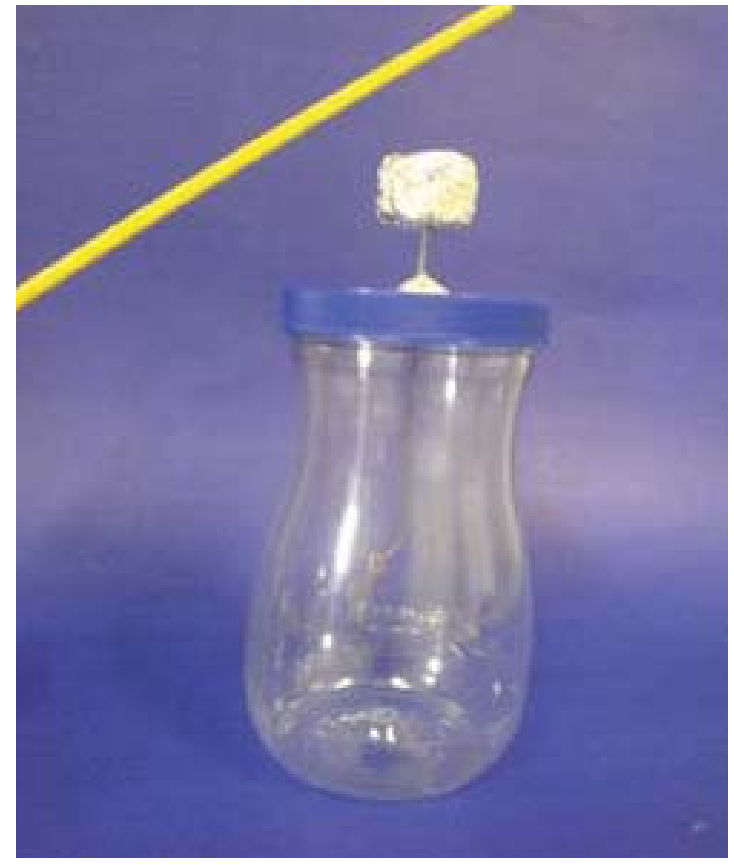

Aproximação do canudo eletrizado da esfera.

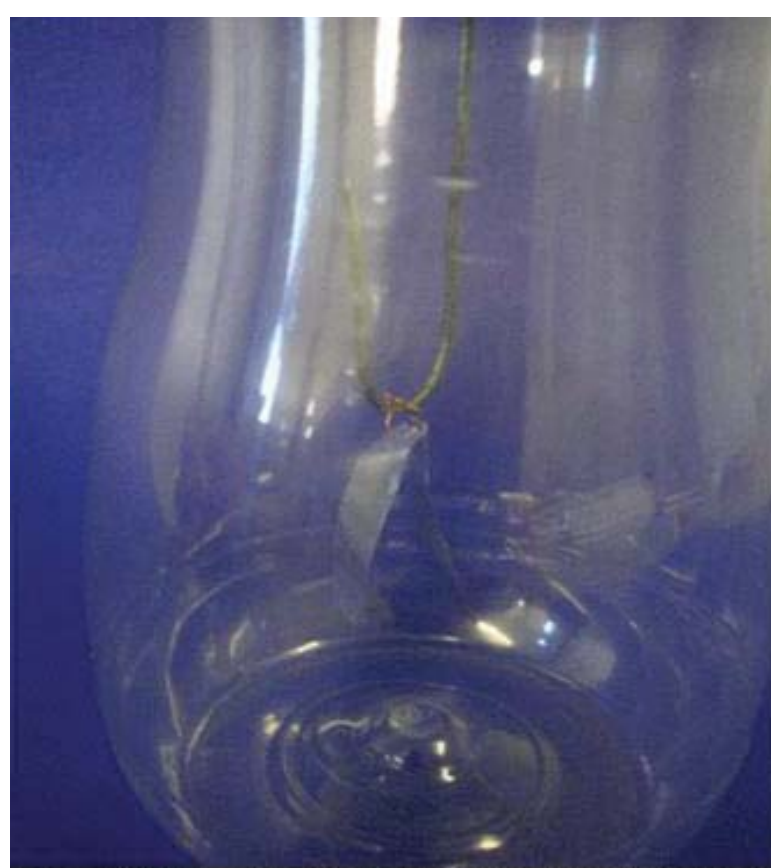

Foto retirada na hora da aproximação do canudo eletrizado na esfera

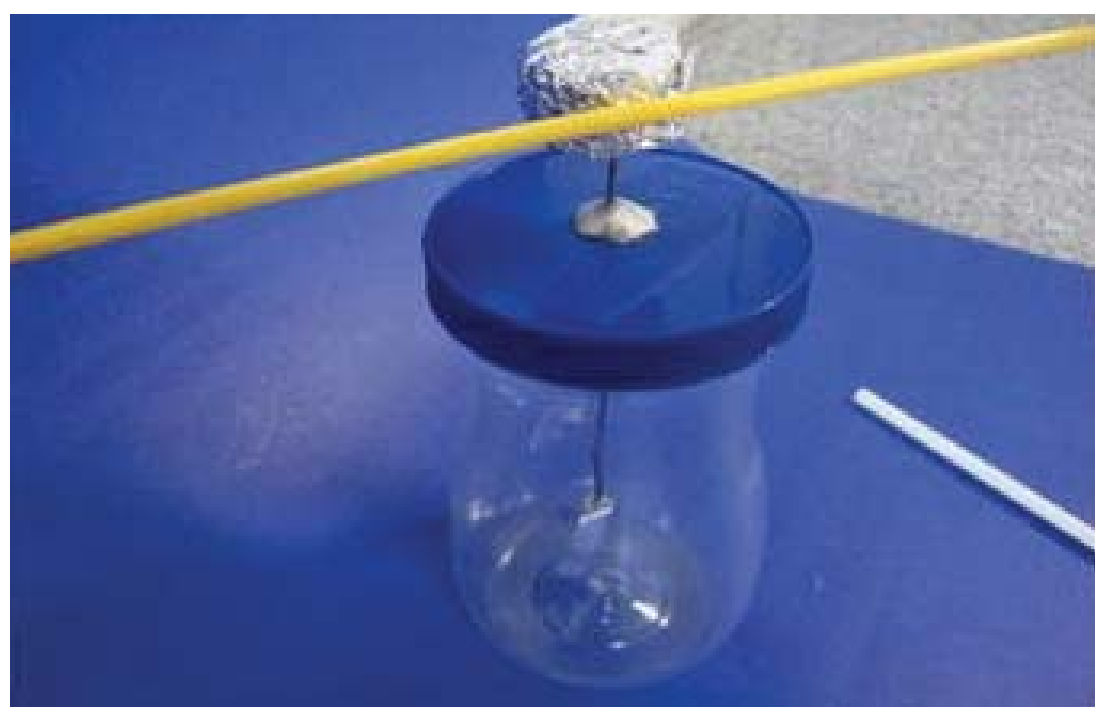

Foto retirada na hora do afastamento do canudo eletrizado da esfera.

\section{$3^{\circ}$ passo:}

Agora encoste o canudo eletrizado na esfera. Observe o que acontece com as tiras de alumínio. 


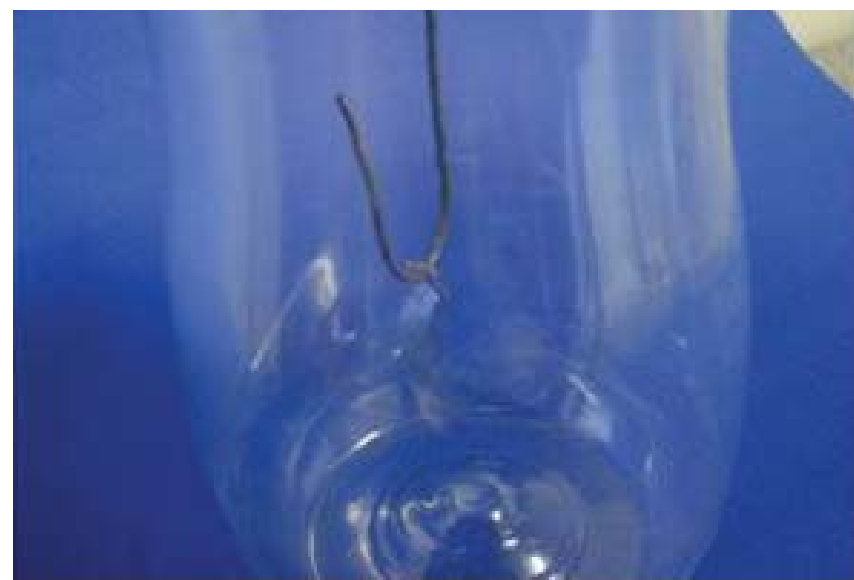

Encostando o canudo eletrizado na esfera.

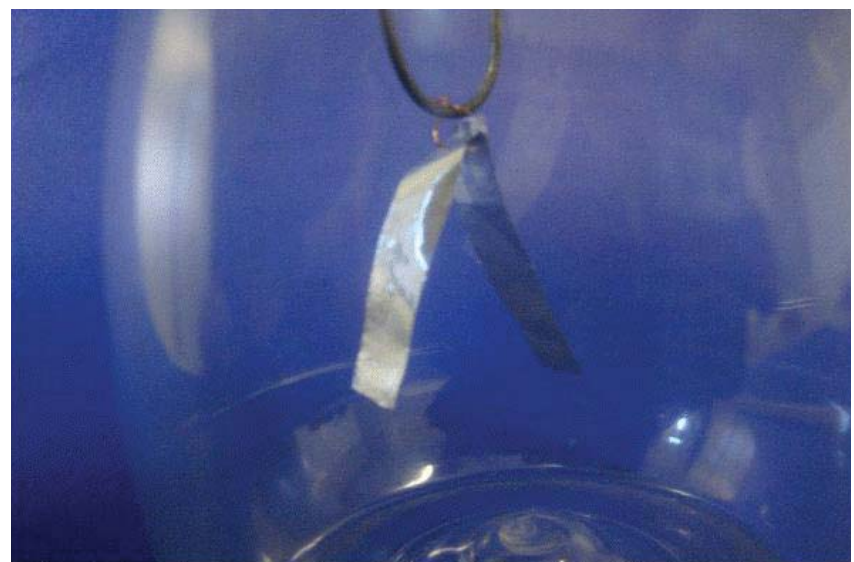

Foto retirada no momento em que é encostado o canudo eletrizado na esfera

Após os três passos concluídos, observa-se que ao aproximar ou encostar o canudo eletrizado na esfera encapada com alumínio as tiras de papel alumínio afastam-se umas das outras.

Por que isto ocorre?

Quando aproximamos o canudo eletrizado negativamente da esfera, as cargas negativas da esfera são repelidas e acumulam-se nas tiras de alumínio. A esfera então apresenta excesso de cargas positivas e as tiras excesso de cargas negativas. Como as duas tiras ficam eletrizadas com cargas iguais, elas se repelem. Ao afastar o canudo eletrizado do eletroscópio, as tiras juntam-se novamente, porque as cargas se redistribuem voltando às posições anteriores à aproximação do canudo.

Já quando encostamos o canudo eletrizado negativamente na esfera, cargas negativas do canudo são transferidas para ela. Com isso, tanto a esfera quanto as tiras ficam com excesso de cargas negativas e, conseqüentemente, as tiras se separam. Observe que afastando o canudo, as tiras continuam separadas porque eletrizamos o eletroscópio por contato, isto é, houve transferência de carga do canudo para a esfera e dela para as tiras de alumínio. 
Perguntas e respostas:

1. Depois que o eletroscópio estiver eletrizado, o que fazer para as tiras se juntarem novamente?

Basta que você encoste a mão na esfera, pois quando isso é feito, os elétrons em excesso, escoam pelo seu corpo até a Terra, assim a esfera ficará neutra.

2. Mais aí a Terra ficará eletrizada?

Não. Como o planeta Terra possui uma enorme superfície, o efeito das mesmas torna-se imperceptível, pois o excesso de cargas vai se espalhar por toda superfície da Terra.

3. E se o eletroscópio estivesse eletrizado positivamente, como neutralizá-lo?

Da mesma forma, encostando a mão na esfera, porém, neste caso, os elétrons livres da Terra passariam através do seu corpo até a esfera, neutralizando-a.

4. Com esse eletroscópio podemos determinar o sinal da carga de um objeto eletrizado?

Sim. Como exemplo temos a eletrização de um canudo de plástico com papel higiênico, o canudo fica eletrizado negativamente. Por outro lado, se eletrizarmos um bastão de vidro com papel higiênico, ele ficará eletrizado positivamente.

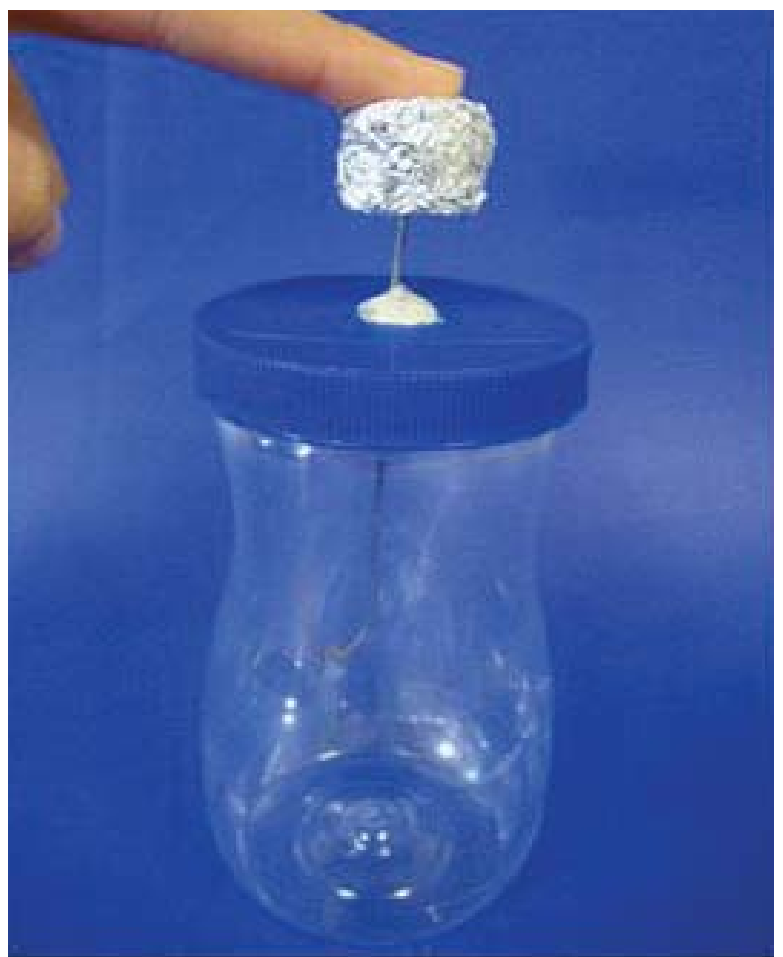

Processo realizado para fazer com que a esfera fique neutra novamente. 
Observações:

- Ao montar o "Eletroscópio de Folhas" o vidro não poderá estar úmido, pois se isso acontecer o ar no seu interior se tornará condutor impedindo que as tiras de folhas de alumínio se afastem;

- Pode-se fazer uma bolinha apenas de folha de alumínio, isso não impedirá de observar o fenômeno das folhas de alumínio se afastando;

- Observe que quando se aproxima o canudo eletrizado negativamente da esfera as tiras de alumínio se afastam, uma da outra e, quando afastamos o canudo da mesma, as tiras de alumínio volta ao seu estado normal;

- Pede-se que realize a experiência com o eletroscópio de folhas dentro do vidro, pois isso impedirá com que haja a interferência do ar no mesmo. Porém, se você realizar a experiência num local fechado sem interferência do ar o eletroscópio de folhas funciona fora do vidro;

- Realizei a experiência num dia seco e chuvoso e pude concluir que no dia chuvoso o experimento não funcionou, pois a umidade do ar e a densidade aumentam e a pressão diminui fazendo com que o ar se torne condutor e conseqüentemente fazendo com que o experimento não funcione. E no dia seco (de sol) o experimento funcionou, fazendo com que conclú́sse que o dia favorável de realizar o experimento é num dia seco (de sol).

\section{APPLETS DE ENSINO}

7. Acesse "O gerador de Van der Graaff" disponível no link: < http:/ /www. fisica.ufs.br/egsantana/elecmagnet/campo_electrico/graaf/graaf.htm>. Ver as explicações sobre força eletromotriz e eletrização.

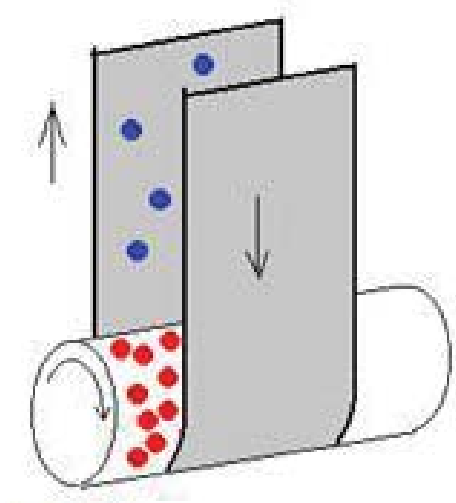

Disponível em <http://www.fisica.ufs.br/egsantana/elecmagnet/ campo_electrico/graaf/graaf.htm\#El generador de Van de Graaf> 


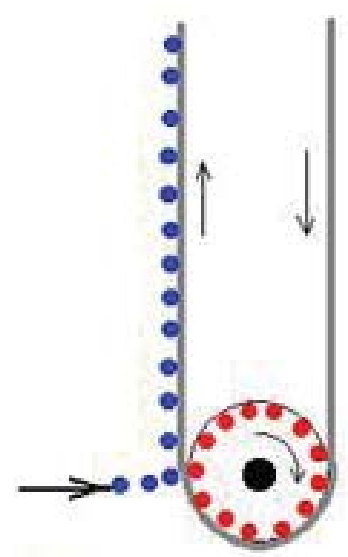

Disponível em < http://www.fisica.ufs.br/egsantana/elecmagnet/campo_electrico/graaf/graaf.htm\#El generador de Van de Graaf>

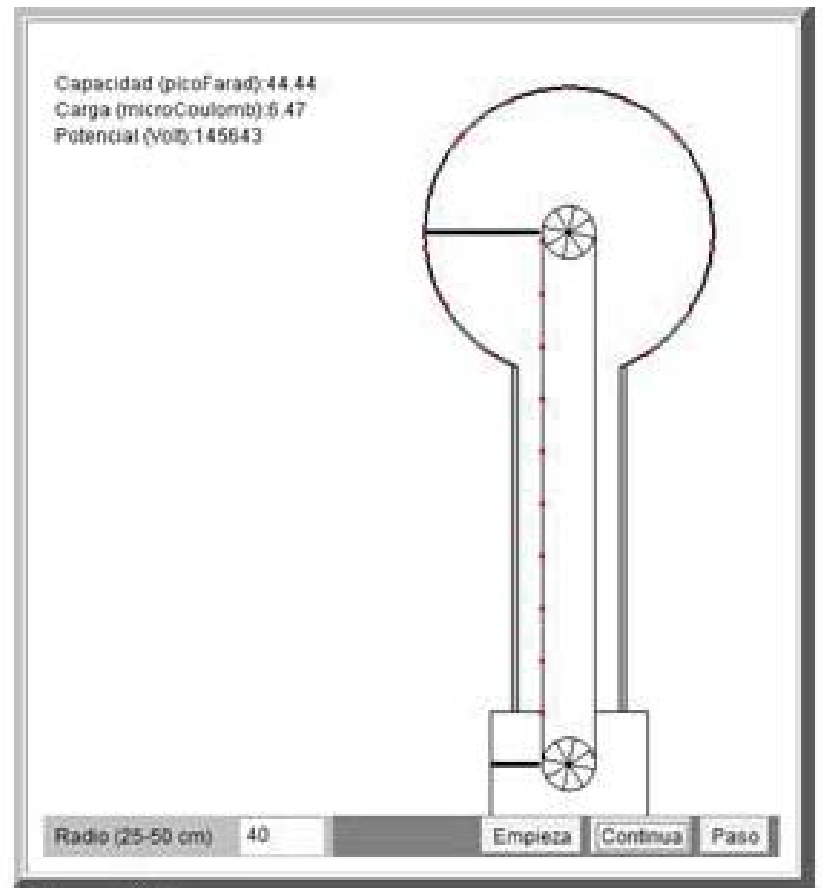

Disponível em <http://www.fisica.ufs.br/egsantana/elecmagnet/ campo_electrico/graaf/graaf.htm\#El generador de Van de Graaf>

8. Explore o projeto Cabrillo disponível no link: <http://www.cabrillo. edu/ jmccullough/physlets/electrostatics/electrostatics_9.html> 


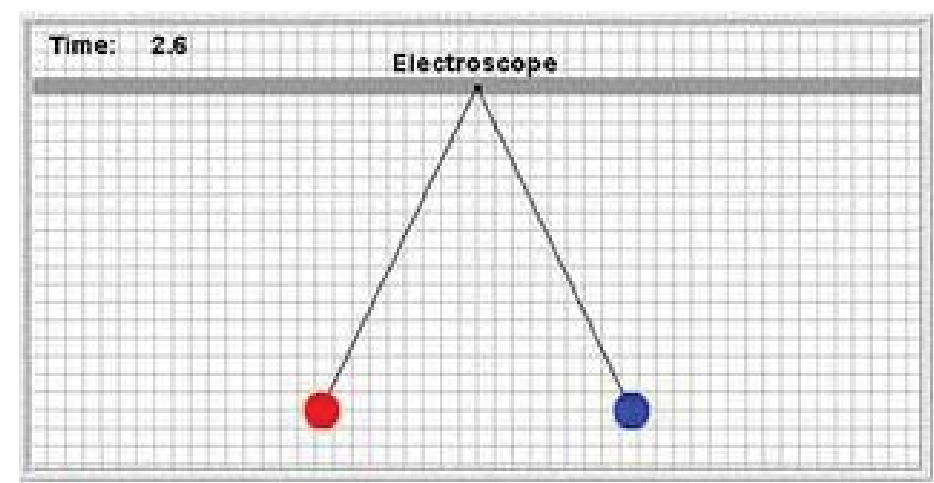

Disponível em < http://www.cabrillo.edu/ jmccullough/physlets/ electrostatics/electrostatics_9.html>

\section{Descrição:}

Duas esferas carregadas iguais de massa igual a $500 \mathrm{~g}$, fixas a bastõe rígidos, formam um eletroscópio (posição em $\mathrm{cm}$ e tempo em s). Você pode arrastar as esperas para qualquer posição desejada, antes ou durante a animação. Você também pode amortecer o movimento clicando no botão "Damp velocity" (Amorteça a velocidade).

Pergunta:

Determine a carga de cada esfera.

\section{VÍDEOS DE ENSINO}

9. Assista aos vídeos selecionados abaixo e depois da exibição faça uma análise globalizante, enfatizando os seguintes aspectos:

- positivos

- negativos

- principais ideias transmitidas

- elementos que chamam mais atenção

- conseqüências e aplicações na nossa vida

- o que vocês mudariam neste vídeo

- Vídeo sobre eletricidade estática da série “O Universo Mecânico”. Pode ser visto no link < http:/ /www.youtube.com/watch?v=XPXm76NpiZA>

- Aula com duração de $9 \mathrm{~min} 57 \mathrm{seg}$ sobre eletrização. Pode ser visto no link: <http://www.youtube.com/watch?v=LtjCMn99xgA>

- Aula com duração de 10min. Pode ser visto no link < http://youtu. be/MKmvAjm3YJ4>

- Aula com duração de 11 min sobre corrente elétrica, entrevistas, definição, aplicações, analogias, exercícios e trechos de vídeos. Pode ser visto no link < http://youtu.be/0vTq12VCygo> 


\section{CONCLUSÃO}

O estudante e futuro professor deve ter ficado ciente e alerta para os problemas da transposição didática. Alerta para o fato de que, muitas vezes, ao se ministrar uma disciplina estamos usando conceitos externos (fora do escopo) desta para ilustrá-la ou explicá-la. Depois desta aula, poderá surgir o questionamento de como podemos ficar alerta para este fato, já que este pode estar influenciando no grau de dificuldade do aprendizado do aluno.

Com a análise dos experimentos de baixo custo e dos recursos de multimídias que colocamos no final da aula o futuro professor deve ter ficado com algumas boas idéias de como este pode enriquecer uma aula sobre o tema eletrização e carga elétrica.

\section{COMENTÁRIOS SOBRE AS ATIVIDADES}

Em geral os alunos que fazem o curso de Licenciatura em Física tiveram um curso muito superficial ou não tiveram nenhuma aula de Física. Se tiveram, usaram algum livro texto tradicional, onde a Física é apresentada como uma coleção de definições e fórmulas para ser aplicada em problemas e exercícios. Assim, a maioria deles só possui o conhecimento de Física dado na universidade. Com a discussão que trouxemos, procuramos mostrar que temos sempre que avaliar quais são os conceitos utilizados ao ensinar um tema da física e que sempre podemos simplificar e ilustrar ao máximo cada aula de física.

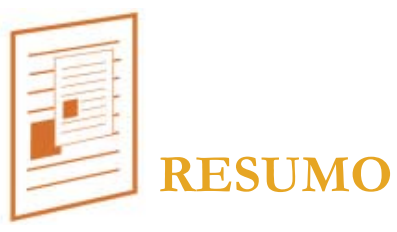

Nesta $1^{a}$ aula começamos a avaliar o problema da transposição didática na disciplina de Física. Para isso apresentamos um texto sobre eletrização que usa o modelo atômico e em seguida fazemos uma adaptação desse mesmo texto tirando o modelo atômico de sua explicação para que você avalie as vantagens e desvantagens de se fazer uma abordagem mais próxima dos fatos históricos e de uma que leve em conta mais os fatos atuais.

Em seguida, apresentamos vários experimentos de baixo custo para que $o$ aluno explore as possibilidades que estes oferecem para se ministrar um curso usando mais ferramentas fenomenológicas e menos formais. Colocamos dois excelentes applets de ensino como recurso de simulação de fenômeno físico para ser explorado pelo futuro professor. Não colocamos mais, pois a maioria deles serve mais para explicar a lei de Coulomb do que o fenômeno da eletrização. 
Como há ótimos vídeos de ensino colocamos alguns deles como referência e deixamos sua exploração como atividade para os estudantes. No curso de Instrumentação I não usamos os vídeos didáticos como ferramenta didática principal.

\section{RESPOSTA ÀS A'TIVIIDADES}

1. Não, pois como fizemos no texto dois podemos explicar o fenômeno da eletrização somente usando os fatos fenomenológicos.

2 .O texto 1 , pois apresenta menos conceitos.

3. Certamente confundir.

4. Tem que fazer.

\section{REFERÊNCIAS}

ALUNOS ONLINE, Seu Portal de Educação. Isolantes e Condutores. Disponível em: <http://www.alunosonline.com.br/fisica/isolantes-econdutores/>. Acesso em: 18 de Junho de 2009.

FEIJO, Luiz Alberto. Experimentos com Alta Tensão: Eletroscópios Construção de Eletroscópio de Folhas. 08 de Junho de 2007. Disponível em: <http://www.teclas.org/chispas/Eletroscopios>. Acesso em: 09 de Junho de 2009.

FISLET, Física com Applets. Disponível em: < http:// fislet.blogspot. com/2011/04/11-carga-eletrica.html>. Acesso em: 15/10/2011.

GARCIA, A. F.; SANTANA, E. G. O gerador de Van der Graaff. Universidade Federal de Sergipe - UFS. Disponível em: <http://www.fisica. ufs.br/egsantana/elecmagnet/campo_electrico/graaf/graaf.htm $>$. Acesso em 15/10/2011.

LEMES, Maurício Ruy - Eletricidade. P. 26. Disponível em:

<http://www.idesa.com.br/disciplinas/fisica/apostilas/Eletro.pdf $>$. Acesso em: 15/10/2011.

MARTINS, José Eduardo; PINTO, Kelson Rosa; E SILVA, Wander de Moura - Universidade de Brasília - UNB. Eletroscópio de Folhas - Guia de Construção - O que é? Instituto de Física - Licenciatura em Física - Noturno. Materiais Didáticos para o Ensino de Física. Disponível em: <http://servlab.fis.unb.br/matdid/12000/kelwan/eletro/eletroscopio. html>. Acesso em: 09 de Junho de 2009.

NUNES, Luiz Antônio de Oliveira; ARANTES, Alessandra Riposati. Física em casa. São Carlos: USP/Instituto de Física, 2006.

PONTO CIÊNCIA, Várias experiências em um só lugar-Experimentos - Processos de Eletrização - Cadastrada por Amadeu Albino Júnior em 31/03/09, atualizado em 10/04/09. Disponível em: <http://www. pontociencia.org.br/experimentos-interna.php? experimento $=223 \& \mathrm{PROC}$ 
ESSOS+DE+ELETRIZACAO++PARTE+12>. Acesso em: 15/10/2011. PROJETO CABRILLO. Electrostatics Problem 9. Disponível no link: $<$ http://www.cabrillo.edu/ jmccullough/physlets/electrostatics/electrostatics_9.html>. Acesso em 15/10/2011.

SILVA, Nilson Oliveira da; PEREIRA, Liliane do Nascimento; e LANGARO, Ana Paula - Universidade Estadual do Mato Grosso do Sul - UMS. Feira de Ciências - Detector de cargas "Eletroscópio de folhas" Licenciatura em Física - Noturno, 26/08/2009. Disponível em: <http:// fisica.uems.br/aprenda/eletroscopio/>. Acesso em 15/10/2011.

VIEIRA, Emerson Canato - Universidade Estadual do Mato Grosso do Sul - UMS. Laboratório de Física II - Curso de Física - Processos de Eletrização, 26/09/2009. Disponível em: <http:// fisica.uems.br/arquivos/labfis2/eletrizar.pdf>. Acesso em: 15/10/2011.

YOUTUBE. 28 - O Universo Mecânico - Eletricidade Estática (4:3). Disponível em: <http://www.youtube.com/watch?v=XPXm76NpiZA $>$. Acesso em: 15/10/2011.

Física - Eletrização e força eletrostática - Parte 1 e 2. Disponível em: <http:/ www.youtube.com/watch?v=LtjCMn99xgA>. Acesso em: 15/10/2011.

. Física - Carga e Corrente Elétrica - Parte 1 - 2. Disponível em:<http://youtu.be/MKmvAjm3YJ4>. Acesso em: 15/10/2011.

Física 52 - Corrente elétrica Parte 1. Disponível em: <http:/ / youtu. be/0vTq12VCygo > . Acesso em: 15/10/2011.

WIKIPÉDIA, A enciclopédia livre. Disponível em: < http://pt.wikipedia. org/wiki/Eletrosc ${ }^{\circ} /{ }^{\circ} \mathrm{C} 3{ }^{\circ} /{ }^{\circ}$ B3pio $>$. Acesso em: 09 de Junho de 2009.

- Redirecionado de Francis Hauksbee. Disponível em: $<$ http:/ / translate.google.com.br/translate?hl=pt-BR\&sl=en\&u=http: / / en.wikipedia.org/wiki/FrancisHauksbee\&ei>. Acesso em: 10 de Junho de 2009. 



\section{Aula 2}

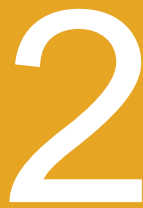

\section{FORÇA ELÉTRICA E O PSSC}

META

Fazer que o estudante comece a pensar no ensino de ciências como algo "orgânico" que está em profunda transformação.

Fazer com que os alunos percebam através de um texto básico complementado com atividades lúdicas, applets de ensino, vídeos, que o conceito de força elétrica pode ser apreendido de forma simples e divertida.

Fazer uma analise comparativa entre o texto produzido para o projeto de ensino PSSC e o projeto Gref sobre o tema força elétrica, de modo que, o aluno possa analisar duas formas de se apresentar este conceito e como a forma de se ensinar física evoluiu até o presente. Levantar a questão da importância dos projetos de ensino de Física (ciência).

OBJETIVOS

Ao final desta aula, o aluno deverá: estar ciente das novas possibilidades e dos desafios que envolvem o ensino de ciências em geral e das dificuldades de se ministrar um curso de eletricidade e magnetismo.

Ter compreendido que as ciências naturais estão baseadas na experimentação e que esta é feita de ensaios, experiências e medidas e que estas levam a compreensão e matematização dos conceitos físicos (naturais em geral).

Ficar ciente das vantagens e desvantagens de se apresentar um conteúdo de forma resumida e de uma forma mais extensa e histórica. Mostrar aos estudantes que os livros didáticos são frutos dos projetos de ensino de física.

PRÉ-REQUISITOS

Os alunos deverão ter cursado as disciplinas Psicologia da Educação, Física A, Física B e Instrumentação I. 


\section{INTRODUÇÃO}

Estudamos na aula anterior, como podemos carregar um material eletricamente e as propriedades das cargas elétricas. Neste capítulo, estudaremos como podemos medir a força que aparece entre dois materiais carregados eletricamente, ou seja, a força elétrica ou Lei de Coulomb. Também veremos como se pode expressar a lei matemática que descreve essa força. $\mathrm{Na}$ aula anterior, discutimos se precisamos usar os conhecimentos modernos sobre a estrutura da matéria para podermos explicar a física da eletrização. Nessa aula, usaremos o material didático produzido para o projeto de ensino PSSC para discutirmos a questão de que os livros textos devem ou não ensinar Física dentro do contexto histórico, com muito texto e experiências de apoio.

No curso de Instrumentação para o Ensino de Física I, introduzimos um resumo sobre os projetos de ensino. Chegou o momento de analisarmos com mais cuidado o material confeccionado para estes projetos e sua filosofia de aprendizado. Nesta aula iniciaremos com o projeto do Physical Science Study Committee (PSSC), pois, este foi o projeto pioneiro e seguiremos as próximas aulas apresentando o projeto Harvard, o PEF e o Gref. Analisaremos o material elaborado para ministrar o tema força elétrica e iremos compará-lo com o texto do projeto Gref para podermos visualizar o que ocorreu com o ensino no Brasil nas últimas décadas.

Antes de introduzir os textos faremos um breve resumo da história do PSSC para ficar claro o contexto em que foi criado e o contexto em que este material de ensino está inserido.

\section{CONTEXTO HISTÓRICO E SURGIMENTO DO PROJE'TO}

O contexto social, econômico e político sempre influenciou, e influenciará as concepções e perspectivas envolvidas no ensino de ciências. Não há como falar do ensino de Física no Brasil sem falar do ensino de Física internacional e do contexto histórico que ele esteve inserido.

No início da década de 50 do século passado, nos EUA, os integrantes do N.S.F. (National Science Foundation) começaram a perceber que o ensino de ciências aos jovens americanos mostrava-se deficitário: os estudantes terminavam sua formação inicial com pouco, ou quase nenhum, conhecimento específico em Matemática, Física, Química e Biologia. Com isso iniciou um movimento de renovação do ensino de ciências, que se estendeu, posteriormente, à Europa e aos demais continentes.

Em 1956, um grupo de professores universitários, de professores de Física em nível secundário (bigh school) e do Instituto de Tecnologia de Massachusetts (MIT), liderados por Jerrold Zacharias e Francis Friedman, formou o Physical Science Study Committee (PSSC) para pensar e propor ma- 
neiras de reformular o ensino de Física em cursos introdutórios. O grupo reuniu cientistas, professores, psicólogos, escritores, fotógrafos, técnicos em filmagem e outros, num total de 282 pessoas, cujos esforços estavam voltados para produzir um novo curso de Física para a escola secundária norte-americana. Aqueles educadores decidiram que livros textos adequados poderiam estimular, pelo menos em parte, o interesse dos estudantes pelo assunto, levá-los a pensar como cientistas e disponibilizar oportunidades para que resolvessem problemas da mesma forma que um físico.

Poderíamos dizer que o projeto de Física PSSC foi um dos maiores representantes do movimento inovador no ensino de ciências. Ele foi uma das primeiras iniciativas de pensar e efetivar um ensino de física atualizado, motivador e eficiente.

Até esta época, o ensino de Física era baseado principalmente nos livros-textos (paradigma dos livros), com muita matematização e pouca discussão dos conceitos envolvidos. O PSSC representa uma mudança do paradigma dos livros para o paradigma dos projetos.

Acontecimentos como a corrida armamentista, a escassez de profissionais atuantes na área de ciências exatas e o desânimo dos jovens perante o prosseguimento de uma carreira cientifica, juntamente com o advento do lançamento do Sputnik, serviram como incentivo de financiamentos para o desenvolvimento do projeto PSSC. Em especial, o lançamento em 1957 do primeiro satélite artificial da Terra, o Sputnik I, pela antiga União Soviética, fato este que foi atribuído ao avanço tecnológico e científico soviético e também ao seu ensino, causou um grande impacto na sociedade americana e promoveu uma mobilização nacional para reverter este quadro, o que resultou em grandes investimentos financeiros para o PSSC.

$\mathrm{Na}$ verdade, criou-se um programa nacional de desenvolvimento tecnológico, em que o PSSC e outros projetos na área de ciências estavam incluídos, no qual também fez parte a criação da NASA. Por esses e outros motivos, inicialmente cinco milhões de dólares foram disponibilizados, valor significantemente alto e revolucionário para o período. Neste âmbito, pode-se dizer que o PSSC é uma referência na história dos projetos de ensino, pois foi o primeiro desenvolvido em larga escala, além de ser um dos precursores na preparação de material didático específico para o ensino de Física.

Para muitos historiadores, essa pressão da Guerra Fria foi o que possibilitou o desenvolvimento do PSSC, pois nada além de uma crise de segurança nacional justificaria o esforço investido, que custou ao longo dos anos mais de 200 milhões de dólares. O apoio financeiro foi dado inicialmente pela N.S.F., sendo que, também contribuíram na manutenção do programa, a Fundação Ford e a Fundação Alfred P. Sloan.

A primeira edição do PSSC Physics foi publicada em 1960, pela D.C. HeatheCo. Embora tenha sido desenvolvido nos Estados Unidos, o curso 
de Física do PSSC (Physical Science Study Committee) é um bom ponto de partida para uma breve análise retrospectiva do ensino de Física, no ensino médio e em nível internacional. Sua tradução para o português foi liderada por uma equipe do IBECC entre os anos 1961/64 na Universidade de São Paulo e foi publicado no Brasil pela Editora Universidade de Brasília. O material experimental foi produzido pela Funbec (Fundação Brasileira para o Desenvolvimento do Ensino de Ciências), empresa criada em 1966 e que teve na produção desses equipamentos sua principal atividade inicial. Não era, simplesmente, um novo livro de Física para a escola média. Era um projeto curricular completo, com materiais instrucionais, educativos, inovadores e uma filosofia de ensino de Física, destacando procedimentos físicos e a estrutura da Física.

\section{METODOLOGIA E FILOSOFIA DO PSSC}

O PSSC se constituiu em um projeto com uma proposta metodológica revolucionária, utilizando material textual diferenciado, com uma linguagem moderna e uma seqüência conceitual nova, incorporando tópicos conceituais até então pouco explorados. A motivação filosófica do PSSC baseava-se na busca da participação ativa do aluno em todas as atividades. Assim sendo, com os diferentes recursos didáticos buscava sempre uma inter-relação entre situações-problema, prática experimental e desenvolvimento teórico da Física, apresentando ao aluno uma visão diferenciada da ciência escolar, aproximando-a da atividade científica.

O PSSC se compunha de um texto básico que sintetizava a filosofia da proposta, segundo o Guia do Professor "nele a Física é apresentada não como um simples conjunto de fatos, mas basicamente como um processo em evolução, por meio do qual os homens procuram compreender a natureza do mundo físico"

A primeira edição do PSSC surgiu em 1960, seguida por muitas edições subsequentes, o material didático criado pelo PSSC foi projetado para enfatizar os princípios fundamentais da Física, encorajando o engajamento e envolvimento em oposição à memorização, tornando o assunto mais atraente aos estudantes e utilizando todos os meios disponíveis na época como filmes, slides, livros, laboratório, trabalhos de casa e leituras auxiliares. O material de leitura auxiliar incluía o "The Science Study Series" "“Série Estudos de Ciência”, publicado pela EDART - São Paulo), uma série de divulgação cientifica voltada para o público em geral.

O material do PSSC incentivava a participação ativa do estudante através de uma ação pedagógica que deveria promover discussões, estimuladas pelo contato com questões abertas e com a manipulação experimental. Essa manipulação experimental era realizada exigindo que todos os estudantes realizassem o experimento ao mesmo tempo. Os kits de experiência eram 
acompanhados por guias que explicavam o funcionamento do equipamento e que forneciam informações básicas sobre a atividade, sem, contudo, detalhá-las. Os "guias de laboratório" que acompanhavam os experimentos afastavam-se das conhecidas fórmulas "cook-book" (roteiros prontos para a realização dos experimentos, em que o estudante deve seguir instruções detalhadas e sequenciais).

O Guia do Professor orientava a atividade do docente, sobretudo em relação à ênfase a ser dada aos diferentes conteúdos. Apresentava conteúdos suplementares e notas de laboratório em que eram dadas informações auxiliares e indicados os momentos mais adequados para que os alunos realizassem com maior proveito as atividades experimentais sugeridas.

Em síntese, o PSSC estava centrado, de um lado, em uma nova proposta curricular de Física, e de outro, no entendimento de que o aluno só poderia aprender ciência por si, a partir da atividade experimental, como se dizia no prefácio do guia de laboratório incluído no texto básico: "As idéias, os conceitos, e as definições, só têm, na verdade, um sentido efetivo quando baseados em experiências". E essas experiências dariam ao aluno a possibilidade de simular o papel do cientista na descoberta da ciência, como se afirmava logo adiante: "Ao realizar experiências cujo resultado, de antemão, lhe é desconhecido, fica o aluno tomado por uma sensação de participação pessoal nas descobertas científicas; tornam-se-lhe mais significativas a ciência e a importância do cientista."

\section{ESTRUTURA DO CURSO}

O Curso do PSSC compreende quatro partes estreitamente interligadas. São quatro livros textos do aluno com respectivos Guias do Professor, além dos kits de experiência, guias de laboratório, filmes e leituras complementares.

\section{OS LIVROS TEXTOS DOS ALUNOS}

A tabela traz os capítulos presentes nos quatro livros textos dos alunos. A tabela apresenta também a proposta de quais capítulos deveriam ser aplicados a cada um dos 3 anos do curso científico, assim como, o número de aulas teóricas e de aulas prática. 


\begin{tabular}{|c|c|c|c|c|c|c|}
\hline & & Capítulo & Semanas & \begin{tabular}{|c|} 
Aulas \\
teóricas \\
\end{tabular} & $\begin{array}{l}\text { Aulas } \\
\text { práticas }\end{array}$ & $\begin{array}{l}N^{0} \\
\text { de } \\
\text { exp. }\end{array}$ \\
\hline & & 1. O que é física? & 7,5 & 2 & - & - \\
\hline & & 2. Tempo e sua mediçăo & & 4 & 4 & 1 \\
\hline & $\mathscr{W}$ & 3. Espaço e sua medição & & 4 & 5 & 2 \\
\hline & $\stackrel{\Phi}{\geq}$ & 4. Funçס̋es e escalas & & 6 & 5 & 1 \\
\hline & $\stackrel{5}{5}$ & $\begin{array}{l}\text { 5. Movimento ao longo de uma } \\
\text { trajetória }\end{array}$ & 5 & 7 & 5 & 1 \\
\hline 8 & 1 & 6. Vetores & & 8 & - & - \\
\hline 䔍 & $\bar{\Phi}$ & 7. Massa, elementos, átomos & 7 & 4 & 10 & 3 \\
\hline$\frac{\overline{0}}{2}$ & $\frac{\mathrm{t}}{\pi}$ & 8. Átomos e moléculas & & 5 & - & - \\
\hline 0 & & 9. A natureza de um gás & & 4 & 3 & 1 \\
\hline & & 10. Mensuração & & 2 & - & - \\
\hline & & 11. Comportamento da luz & 10,5 & 2 & - & - \\
\hline & & 12. Reflexăo e imagens & & 5 & 8 & 2 \\
\hline & & 13. Refração & & 5 & 4 & 1 \\
\hline & 范 品 & 14. Lentes e instrumentos ópticos & & 5 & 5 & 1 \\
\hline & $1 \frac{\pi}{0}$ & 15. Modelo corpuscular da luz & & 4 & 4 & 2 \\
\hline & $=0$ & 16. Introduçăo às ondas & 9 & 2 & 2 & 1 \\
\hline & & 17. Ondas e luz & & 2 & 10 & 4 \\
\hline & & 18. Interferência & & 3 & 5 & 2 \\
\hline & & 19. Ondas luminosas & & 4 & 7 & 4 \\
\hline & & 20. A lei do movimento de Newton & 10 & 3 & 12 & 4 \\
\hline 道 &.$\stackrel{8}{ }$ & $\begin{array}{l}\text { 21. Movimento na superfície da } \\
\text { Terra }\end{array}$ & & 11 & 6 & 2 \\
\hline$\frac{5}{0}$ & త్ర్ల్ & $\begin{array}{l}\text { 22. Gravitaçăo Universal e o } \\
\text { Sistema Solar }\end{array}$ & & 5 & 3 & 1 \\
\hline$\stackrel{\circ}{\sim}$ & $\stackrel{2}{1}$ & $\begin{array}{l}\text { 23. A quantidade de movimento e } \\
\text { sua conservaçăo }\end{array}$ & 12 & 9 & 8 & 3 \\
\hline & $\underset{\Phi}{ \pm}$ & 24. Trabalho e energia cinética & & 8 & 2 & 1 \\
\hline & $\underset{\pi}{\pi}$ & 25. Energia potencial & & 7 & 5 & 2 \\
\hline & & $\begin{array}{l}\text { 26. Calor, movimento molecular e } \\
\text { conservaçăo de energia }\end{array}$ & & 6 & 2 & 1 \\
\hline & & $\begin{array}{l}\text { 27. Alguns fatos qualitativos sobre } \\
\text { a eletricidade }\end{array}$ & 8 & 5 & 3 & 2 \\
\hline & $\stackrel{0}{0}_{\frac{0}{0}}^{0}$ & $\begin{array}{l}\text { 28. A lei de Coulomb e a carga } \\
\text { elétrica elementar }\end{array}$ & & 8 & 5 & 2 \\
\hline 8 & $\frac{\pi}{\frac{\pi}{0}} \cdot \frac{\mathrm{v}}{\mathrm{O}}$ & $\begin{array}{l}\text { 29. Energia e movimento de } \\
\text { cargas em campos elétricos }\end{array}$ & & 14 & 6 & 2 \\
\hline 窎 & 尝 & 30. O campo magnético & 7 & 14 & 12 & 4 \\
\hline$: \frac{0}{0}$ & 山䎡 & $\begin{array}{l}\text { 31. Indução e ondas } \\
\text { eletromagnéticas }\end{array}$ & & 9 & - & - \\
\hline m & $\geq \frac{5}{\omega}$ & 32. Explorando o átomo & 7 & 10 & 3 & 1 \\
\hline & 壱 & $\begin{array}{l}\text { 33. Fótons e ondas associadas à } \\
\text { matéria }\end{array}$ & & 10 & 3 & 1 \\
\hline & & $\begin{array}{l}\text { 34. Sistemas quânticos e a } \\
\text { estrutura dos átomos }\end{array}$ & & 8 & - & - \\
\hline
\end{tabular}

Tabela resumida do planejamento de tempo para aulas teóricas e aulas práticas.

\begin{tabular}{|c|c|c|c|c|c|}
\hline Ano & $N^{\circ}$ semanas & $\begin{array}{c}\text { Aulas } \\
\text { totais }\end{array}$ & $\begin{array}{c}\text { Aulas } \\
\text { teóricas }\end{array}$ & $\begin{array}{c}\text { Aulas } \\
\text { práticas }\end{array}$ & $\begin{array}{c}\mathrm{N}^{\circ} \text { de } \\
\text { experimentos }\end{array}$ \\
\hline $1^{\circ}$ científico & 30 & 120 & 67 & 53 & 15 \\
\hline $2^{\circ}$ científico & 31 & 122 & 60 & 62 & 25 \\
\hline $3^{\circ}$ científico & $22+8$ & 150 & $78+40$ & 32 & 12 \\
\hline
\end{tabular}

Ao final do $3^{\circ}$ científico o programa incluía, ainda, 8 semanas (com 40 aulas teóricas) para matéria complementar. 


\section{GUIA DO PROFESSOR}

O Guia é dividido em quatro partes, correspondentes às partes I, II, III, IV do texto. Cada parte do Guia inclui uma seção introdutória, discutindo as características importantes de cada capítulo e sugerindo planejamentos dos conteúdos.

A finalidade do Guia do Professor era auxiliar os professores a introduzir o material do PSSC nos programas de classe e de laboratório. O Guia do Professor não trazia o livro texto dos alunos como ocorre hoje em dia e sim fornecia informações básicas e detalhadas sobre todo o conjunto do material, fazia sugestões concretas para atividades de classe e laboratório e discutia sessões selecionadas do curso, num nível dirigido mais aos professores do que aos alunos.

O Guia não pretende estabelecer regras rígidas e imediatas para o ensino do curso, mas sim dar sugestões, das quais algumas serão diretamente úteis e outras estimularão o desenvolvimento de outros assuntos.

Resumidamente, as funções do Guia são:

1. Colocar tópicos individuais, com realce das finalidades e do conteúdo do curso inteiro;

2. Apresentar ao professor certos tópicos do curso num grau mais elevado do que no livro texto dos alunos;

3. Sugerir o uso apropriado do material correlacionado com cada parte do texto: experiências de laboratório; filmes; problemas para casa, classe e laboratório; demonstrações; livros da "Science Study Series"; e ocasionalmente outros assuntos;

4. Providenciar informações detalhadas sobre o uso de experiências e aparelhos de laboratório;

5. Sugerir possíveis planejamentos para o ensino do curso;

6. Apresentar soluções para os problemas das seções para casa, classe e laboratório do texto;

7. Sugerir problemas complementares.

\section{OS EXPERIMENTOS}

Com relação ao programa de laboratório contido no PSSC, observa-se, para a época, um espetacular avanço. O trabalho de laboratório é colocado praticamente no mesmo patamar do trabalho de conteúdo teórico, o que impõe um papel mais ativo para o aluno.

Dos mais de cinqüenta experimentos que compõem seu acervo básico, alguns são de natureza qualitativa e outros são quantitativos. É importante destacar que muitos dos experimentos, do ponto de vista didático, são novidades. Entre eles destaca-se o "tanque de ondas", para o estudo de 
ondas. São experimentos que, além de fugir das tradicionais experiências demonstrativas, são inovadores na concepção do seu "design".

A proposta do PSSC de que os alunos tivessem uma participação ativa nas atividades de Ensino, exigia que todos os alunos realizassem o experimento ao mesmo tempo. Isto casou a necessidade de produzir e oferecer equipamentos para todos os alunos. Estes equipamentos deveriam se caracterizar pela simplicidade e robustez, de forma a diminuir seus custos de confecção e permitir a manipulação pelos próprios alunos. Inicialmente pensou em envolver os alunos na confecção dos equipamentos, ideia que foi posteriormente afastada. A organização final dos equipamentos resultou em pequenos kits.

A precisão nas medidas experimentais não era o mais importante, pois a “(...) precisão exigida é determinada pelo conhecimento que você tinha antes da experiência e pela finalidade da experiência. (...)Se a determinação de um dado valor desconhecido obtido experimentalmente chegar relativamente próximo ao valor aceito como padrão, isto é sinônimo de sucesso, pois para quem desconhece o valor correto, o valor encontrado já se configura no enriquecimento do conhecimento. Porém muitas vezes é desnecessário afinar a precisão das medidas, pois a finalidade da experiência não é o valor numérico encontrado e sim a discussão de sua validade." (retirado do "Guia do Professor para Experiências" contido no Guia do Professor, Parte I).

Somente em raras ocasiões, uma experiência deveria ser escrita em forma de relatório, era recomendado que cada aluno mantivesse suas anotações bem feitas tomando-as durante a experiência.

\section{OS FILMES}

O PSSC utilizava uma série de filmes didáticos, num total de 47 filmes, elaborados com o que existia de melhor em tecnologia audiovisual e técnicas de cinematografia. Os filmes mantinham um rígido programa de Física apresentado através da experimentação e utilizavam os recursos mais modernos da época, envolvendo, por exemplo, técnicas de "slow-motion" e fotografias estroboscópicas em Super-8 (looping), com o objetivo de serem utilizados nas próprias salas de aula, inclusive com a possibilidade concreta de tomada de medidas nos experimentos filmados.

Quem tiver interesse em assistir alguns destes filmes (infelizmente, hoje, a maioria destes filmes não estão mais acessíveis) e analisar a metodologia do PSSC empregada neles, pode acessar o link, www.archive.org/details / frames_of_reference, referente ao filme da parte III "Frames of Reference", ou o link, www.archive.org/details/magnet_laboratory 1959, referente ao filme da parte IV "A Magnet Laboratory". 


\section{RESULTADOS DA IMPLANTAÇÃO DO PSSC}

Os diagramas a seguir mostram a evolução, ao longo dos anos, do número de professores treinados para usar o PSSC e o número de alunos que o usaram nos EUA.
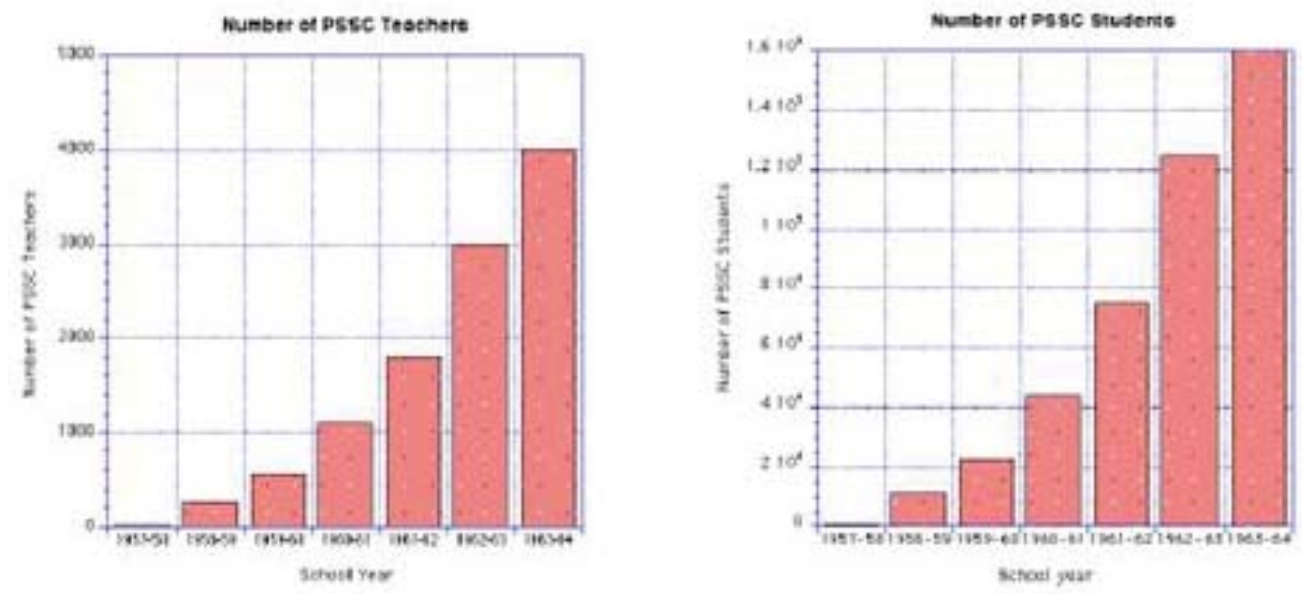

Em 1957-58, 8 escolas e 300 estudantes experimentaram os primeiros materiais do PSSC. Seus comentários e sugestões ajudaram a melhorar e ampliar o conteúdo e o projeto. Depois, em 1958-59, aproximadamente, 300 escolas e 12.500 estudantes valeram-se do curso; em 59-60, quase 600 escolas e 25.000 alunos participaram do terceiro ano de experiência do projeto.

A partir da análise desses resultados, o curso foi cuidadosamente revisto e implementado em mais escolas. Até 1964, alcançou-se a marca de 160.000 estudantes participantes do PSSC nos EUA. Não estão disponíveis estatísticas relativas ao número de estudantes que utilizaram o PSSC no Brasil.

No entanto, os resultados apresentados pela implantação do PSSC não foram animadores nos EUA, nem nos demais países em que foi aplicado. Não se observou uma melhora significativa no ensino de Física, muitos alunos continuaram desmotivados e desinteressados em estudar esta ciência, ou seja, na prática, as coisas não ocorreram exatamente como planejadas no projeto.

Mas, quais as razões para o fracasso de projetos tão sólidos como o do PSSC? Podemos citar a má compreensão do professor sobre seu papel durante o processo de ensino e aprendizagem na aplicação dos projetos. Ou talvez, o seu principal conceito, a participação ativa do aluno, o que pode ter resultado numa ênfase exagerada dada às experiências. O PSSC tratava muito bem dos conceitos físicos, mas não trazia suas implicações sociais e nem aplicações tecnológicas. O livro do aluno, em geral, não era muito atrativo, contendo textos longos com poucas, ou nenhuma relação com o cotidiano do aluno, e também com desenvolvimento matemático. 
Era dada uma grande ênfase na estrutura da Física, o que tornou o material conceitualmente complexo e atrativo apenas para os alunos que já se interessavam pela Física.

No caso do PSSC no Brasil, a aplicação do projeto foi muito restrita, limitada a poucas escolas onde lecionavam alguns professores que dele tomaram conhecimento e sentiram-se capazes de aplicá-lo; alguns, embora o conhecessem não se animaram em aplicá-lo, principalmente pela dificuldade de utilização do material experimental entregue às escolas pela Funbec (Fundação Brasileira para o Desenvolvimento de Ensino de Ciências). Possuía muitos kits incompletos sem identificação adequada ou qualquer instrução auxiliar além do texto. O currículo proposto era desvinculado da nossa realidade educacional e a esmagadora maioria dos professores não estava preparada.

Dificuldades associadas à infra-estrutura precária das escolas brasileiras, à falta de laboratórios, ao difícil acesso e exibição dos filmes, à carga horária reduzida da disciplina podem, pelo menos, parcialmente, explicar a falta de êxito desta proposta em relação ao grande público do Ensino Médio brasileiro. Entretanto, apesar das inovações pedagógicas e tecnológicas, o aluno continuava a ser visto como um pequeno cientista.

Apesar do insucesso em sua aplicação no ensino secundário, fica evidente sua vertente inovadora e revolucionária pela quantidade de traduções que teve e pelo número de trabalhos acadêmicos que o analisaram.

No Brasil este projeto ficou principalmente restrito aos cursos de formação de professores, via disciplina de Instrumentação para o Ensino de Física. Um estudo da pesquisadora Ana Maria P. Carvalho mostrou que os professores tiveram forte influência do PSSC em seu trabalho, embora poucos o tenham adotado. Mesmo sem sua adoção, uma enquete revelou uma melhoria no ensino de Física, seja pelo fato de os professores escolherem com mais cuidado o livro-texto, seja por outras metodologias utilizadas em sala de aula, como o uso mais frequente de laboratório didático e a introdução de técnicas de discussão.

A influência mais duradoura do PSSC no Brasil, segundo a pesquisadora, foi a exercida sobre os docentes que se envolveram em pesquisas em ensino de Física quando da produção dos projetos brasileiros.

\section{LEI DE COULOMB}

\section{LEI DE COULOMB - COMO APRESENTADO NO RAMALHO}

Cap1.8 - Forças entre Cargas Elétricas Puntiformes: Lei de Coulomb Considere duas cargas elétricas puntiformes Q1 e Q2 separadas pela 
distância e situadas no vácuo. Entre elas ocorre atração (se tiverem sinais opostos) ou repulsão (mesmo sinal), com forças de mesma intensidade, mesma direção e sentidos opostos, de acordo com o Princípio de Ação e Reação.

Note que a forma de apresentação do Ramalho é como estivesse formulando um problema: Considere duas cargas elétricas puntiformes Q1 e Q2 separadas pela distância e situadas no vácuo ( $1^{\circ}$ parágrafo). Há uma nota histórica em uma caixa de texto no final da seção que pode ser suprimida deste. A única vantagem que o texto é curto, simples e objetivo. Vejamos como o mesmo tema é abordado no PSSC

\section{MATERIAL APRESENTADO NO PSSC}

Segue abaixo o texto com algumas ilustrações e material de apoio como originalmente apresentado no livro didático do PSSC.

\section{A LEI DE COULOMB E A CARGA ELEMENTAR}

Pelo texto abaixo, vemos que o autor começa contando quem foi o autor da lei e como ele a obteve. Note que a apresentação do tema Lei de Coulomb se dá como se o autor estivesse realizando e descrevendo o experimento em um laboratório. Ele começa descrevendo a lei do inverso do quadrado da distância e fazendo uma analogia com a Lei da Gravitação Universal.

Você pode acessar todo o material no link < http://www.cienciamao. usp.br/dados/pssc/_parteiv-eletricidadeeest_2.arquivopdf.pdf>

\section{CAPITULO 28}

Até agora nosso estudo das forças elétricas foi apenas qualitativo. Vimos que as atrações e repulsões elétricas entre objetos grandes são devidas às atrações e repulsões entre as partículas sub-atômicas de que são feitos esses objetos. Nossa próxima tarefa será descrever experiências que nos forneçam informações quantitativas sobre essas forças.

28 - 1. Força e Distância.

A maneira pela qual a força de atração ou de repulsão entre cargas elétricas depende da distância que as separa foi estabelecida experimentalmente pelo físico francês, Charles Coulomb, em 1785. Em sua experiência, Coulomb utilizou uma balança de torsão, semelhante ao instrumento usado mais tarde por Canendish para estudar a atração gravitacional. (Veja Seção 22-10). A Fig. 28-1 é um esquema desse tipo de aparelho. Quando a esfera carregada A é colocada no lugar, a força elétrica de repulsão que ela exerce 
sobre a esfera carregada B faz girar a haste horizontal. Esta atinge uma nova posição de repouso com o fio de suspensão torcido. Quanto maior a torsão do fio, maior deve ser a força entre as cargas. Assim, pelo ângulo de torsão, Coulomb podia medir a força elétrica. Variando a distância entre as esferas carregadas, mediu a força como função da distância entre elas.

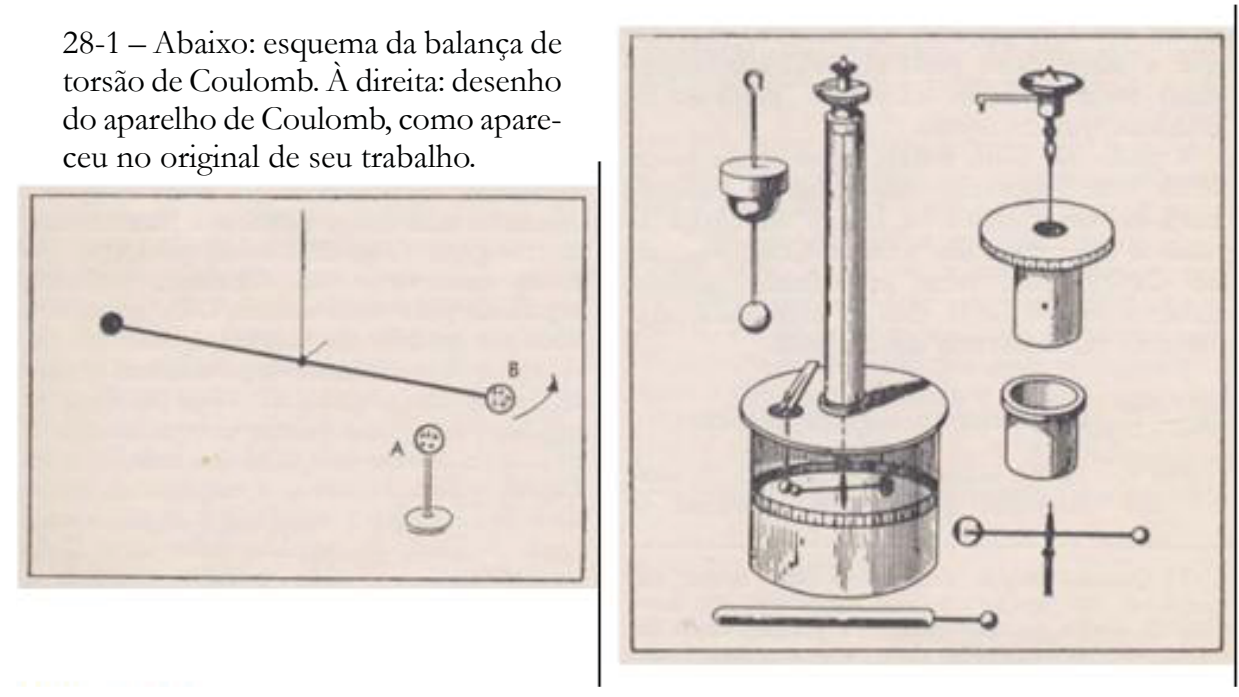

Disponível em: <http://www.cienciamao.usp.br/dados/pssc/_parteiv-eletricidadeeest_2. arquivopdf.pdf $>$

Como as cargas estão distribuídas sobre as esferas, a distância entre elas deve ser suficientemente grande para que pequenas diferenças em distância e direção não sejam importantes.

Utilizando esferas com cargas positivas e negativas, Coulomb mostrou que a força elétrica é sempre inversamente proporcional ao quadrado da distância entre as cargas. Estabeleceu este resultado com uma exatidão da ordem de três por cento. Mais tarde, testes indiretos - utilizando o efeito de blindagem dos condutores - demonstraram a lei com precisão muito maior. Cavendish conseguiu precisão de um por cento e, na segunda metade do século XIX, Markwell estabeleceu o expoente 2 (o "quadrado" na lei do inverso do quadrado), com erro inferior a uma parte em 40.000. Este número é conhecido, hoje em dia, com erro inferior a 1 parte em 109. Note que as forças elétricas e as gravitacionais variam com a distância exatamente da mesma forma. Não conhecemos nenhuma explicação para esta semelhança, mas por causa dela, podemos muitas vezes compreender da mesma maneira os efeitos elétricos e os gravitacionais.

Veja acima a importância que eles dão às medidas e confirmação experimental. Na sequência eles vão apresentar a dependência da força com as cargas do mesmo modo que fizerem com a distância e vão concluir deduzindo (obtendo) a Lei de Coulomb.

Acreditamos que a força de atração ou de repulsão entre dois objetos carregados é a soma vetorial de todas as forças que as partículas elétricas do 
outro. Em todos os casos, verificamos experimentalmente que a força varia na razão inversa do quadrado da distância entre os objetos. Concluímos portanto que a força entre partículas elétricas individuais varia na razão inversa do quadrado da distância que as separa.

A partir de 1910, muitas experiências foram feitas com partículas sub-atômicas. Podemos lançá-las umas contra as outras ou contra os núcleos carregados dos átomos. Como veremos no Capítulo 32, essas experiências também mostram que a força elétrica entre partículas varia na razão inversa da distância.

\section{8 - 2. Carga Elétrica e Fôrça Elétrica.}

Em um corpo eletricamente neutro, os efeitos das partículas positivas e negativas se cancelam. Um corpo dotado de carga positiva ou negativa contém cargas negativas não contrabalançadas. Assim, a carga elétrica de um corpo depende do excesso de partículas positivas ou negativas, medindo a partir do estado neutro.

A força entre dois corpos carregados depende da distância entre eles e cresce com o excesso de partículas positivas ou negativas em cada corpo. De que maneira, exatamente, depende a força do excesso de partículas elétricas? Para responder a esta questão precisamos saber reduzir o excesso de partículas à metade, a um têrço, etc. Suponha que colocamos em contato uma esfera de metal carregada e uma esfera idêntica à primeira, mas descarregada (Fig. 28.2). As partículas elétricas mover-se-ão até ficarem igualmente repartidas pelas duas esferas. Cada esfera terá, então, a metade da carga original.

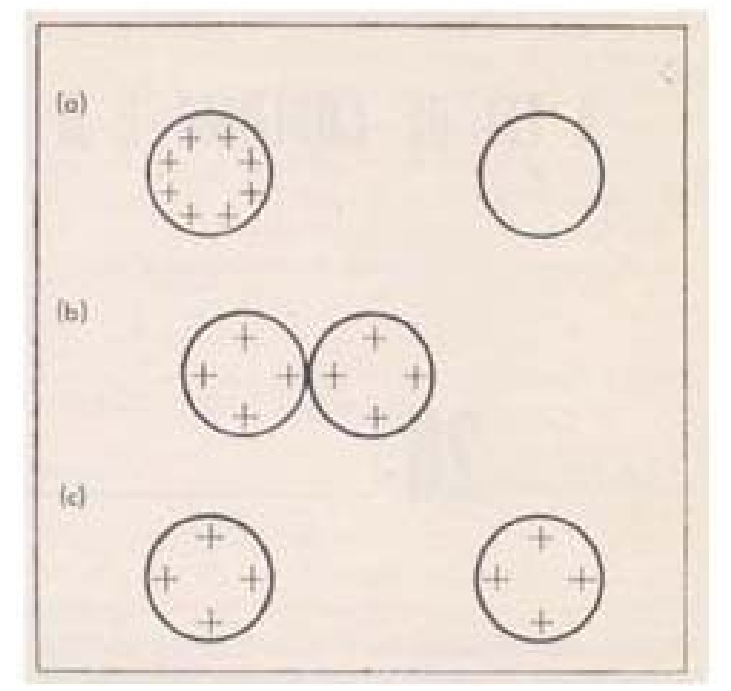

Figura 28-2 - O processo de repartir carga elétrica. Quando encostamos uma esfera carregada em outra, idêntica a ela, mas descarregada, as cargas elétricas que estão em excesso dividem-se igualmente. A distribuição final de cargas deve ser igual nas duas esferas, como se vê em (c).

PSSC, p. 32. Disponível em: <http://www.cienciamao.usp.br/dados/pssc/_parteiv-eletricidadeeest_2. arquivopdf.pdf> 
O que ocorre com as forças elétricas quando as cargas são repartidas? Meça a força de repulsão entre duas esferas carregadas A e C, situadas a determinada distância uma da outra. Depois reduza à metade a carga de $\mathrm{A}$, fazendo-a ceder carga a uma esfera B exatamente igual. A força de repulsão entre $\mathrm{A}$ e $\mathrm{C}$ (a mesma distância) fica também reduzida à metade. Obtemos ainda a mesma força quando A é substituída por B, a esfera com a qual a carga foi repartida. Aparentemente a carga e as forças são proporcionais, conforme poderíamos ter adivinhado.

Experiências desse tipo permitem comparar quantitativamente cargas elétricas. Duas cargas são iguais se sofrem a ação da mesma força quando colocadas a determinada distância de uma terceira carga. Uma carga é o dobro de outra quando fica sob a ação de uma força duas vezes maior. Além do mais, a fôrça a que uma carga fica sujeita e a força que ela exerce sobre outra variam da mesma forma. Quando uma carga é reduzida à metade, a força que ela exerce sobre uma terceira carga fica também reduzida à metade. Em geral, comparam-se cargas comparando-se suas interações com uma terceira carga, a determinada distância. A razão dessas forças não depende da outra carga, nem da distância a que se deram as interações (Fig. 28-3).

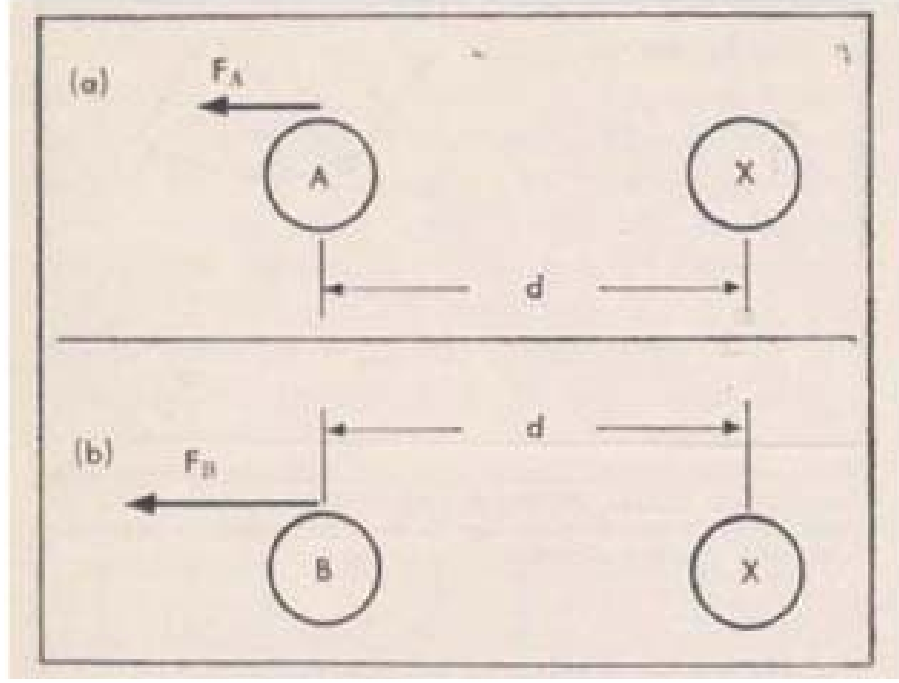

28-3 - Para comparar duas cargas, A e B, colocamos uma de cada vez à mesma distância de uma outra carga $\mathrm{X}$, e medimos as forças. $\mathrm{A}$ razão entre as cargas é a mesma que a razão entre as forças:

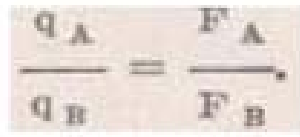

(PSSC, p. 33. Disponível em: < http://www.cienciamao.usp.br/dados/pssc/_ parteiv-eletricidadeeest_2. arquivopdf.pdf $>$ )

$\mathrm{Na}$ sua opinião, qual é a razão entre as forças que atuam sobre X?

Resumindo em linguagem algébrica o que já sabemos sobre cargas elétricas, podemos dizer que a força elétrica sobre uma carga q é proporcional à carga: $\mathrm{F} \alpha$ q. Quando esta força é a interação entre a carga q e outro corpo pequeno com carga $\mathrm{Q}$, a força é proporcional também a outra carga. Podemos indicar esta proporcionalidade pela expressão: F $\alpha$ qQ. 
A carga elétrica tem agora para nós um significado definido e sabemos como exprimir a dependência entre a força elétrica e a carga. Podemos combinar estes dados com o resultado das experiências de Coulomb. Eles nos dizem que a força é inversamente proporcional ao quadrado da distância r entre as cargas. Chegamos, assim, à expressão completa para a força de interação entre duas cargas:

$$
F=\frac{k Q q}{r^{2}}
$$

na qual o fator de proporcionalidade $\mathrm{k}$ depende apenas das unidades adotadas para medir forças, distâncias e cargas. Chamaremos Lei de Coulomb a esta expressão e designaremos a força como força de Coulomb.

Quando, pela primeira vez, falamos em cargas elétricas, demos à palavra um sentido qualitativo. Uma carga elétrica era simplesmente o resultado da adição ou remoção de algumas partículas positivas ou negativas de um objeto neutro. Agora, porém, aprendemos a comparar cargas quantitativamente e podemos falar da carga das partículas individualmente. Diremos que duas partículas têm a mesma carga quando experimentam a mesma força sempre que colocadas à mesma distância de outra carga. Se as forças a que, ficam sujeitas as duas partículas são diferentes, diremos que suas cargas estão na mesma razão que essas forças. A "carga" de um objeto grande, pode ser considerada como o excesso de partículas elétricas de determinado sinal. Mas a carga de uma partícula elétrica só pode ser definida pela força que ela exerce.

Mas falta, ainda, uma coisa. Necessitamos de uma unidade padrão de carga, algo reprodutível, de modo que possamos comparar cargas em qualquer lugar, por mais distantes que sejam. Para essa finalidade muitas unidades arbitrárias têm sido usadas. Felizmente, contudo, como veremos na Seção 28-5, a própria natureza fornece uma unidade fundamental.

(A lei de Coulomb e as carga elétrica elementar. Disponível em <http:/ / www.cienciamao.usp.br/dados/pssc/_parteiv-eletricidadeeest_2.arquivopdf.pdf>, p. 32 e 33)

Note que enquanto o Ramalho (consulte o livro impresso) gasta uma página e meia para expor a lei de Coulomb, o PSSC gasta mais de três. Ele complementa o texto com um experimento simples, ver abaixo, como é o espírito do projeto.

Experimento contido no guia de laboratório. Você pode acessá-lo no link < http://www.cienciamao.usp.br/dados/pssc/_parteiv-eletricidadeeest_9. arquivopdf.pdf $>$ 


\section{A FORÇA ENTRE DUAS ESFERAS CARREGADAS}

A força entre corpos carregados eletricamente depende da distância entre eles e do valor de suas cargas. A natureza da dependência pode ser determinada quantitativamente por vários processos Nesta experiência mediremos a força que age sobre um corpo carregado, equilibrando-a com uma força conhecida - a força da gravidade. Podemos suspender uma pequena esfera carregada por meio de um fio isolante, e aproximar dela outra esfera carregada. Considerando o desvio da esfera suspensa em relação à vertical, podemos medir a força elétrica sobre ela exercida, em função de seu peso. Suspenda uma esfera condutora, A, muito leve, na extremidade de um "V" e de fio de nylon muito fino, de forma que ela possa oscilar num único plano vertical (Fig. 2). Coloque uma fonte de luz de maneira a projetar a sombra da esfera numa escala milimetrada. Leia, na escala, a posição de um dos bordos da sombra da esfera suspensa. Carregue a esfera por indução, e aproxime dela outra esfera $B$, também carregada. Não segure diretamente a esfera $\mathrm{B}$; espete nela um alfinete e espete o alfinete num pequeno bastão de parafina, que é um bom isolante, e mantenha o bastão em pé por meio de um prendedor de roupa, como indica a Fig. 2. Faça leituras das duas sombras na escala, para diversas posições, das esferas, à medida que você vai trazendo B para perto de A, ao longo de uma linha que está no plano de oscilação de A. Certifique-se de que usa o mesmo bordo de cada esfera, todas as vezes em que lê sua posição (P1 e P2 na Fig. 2).

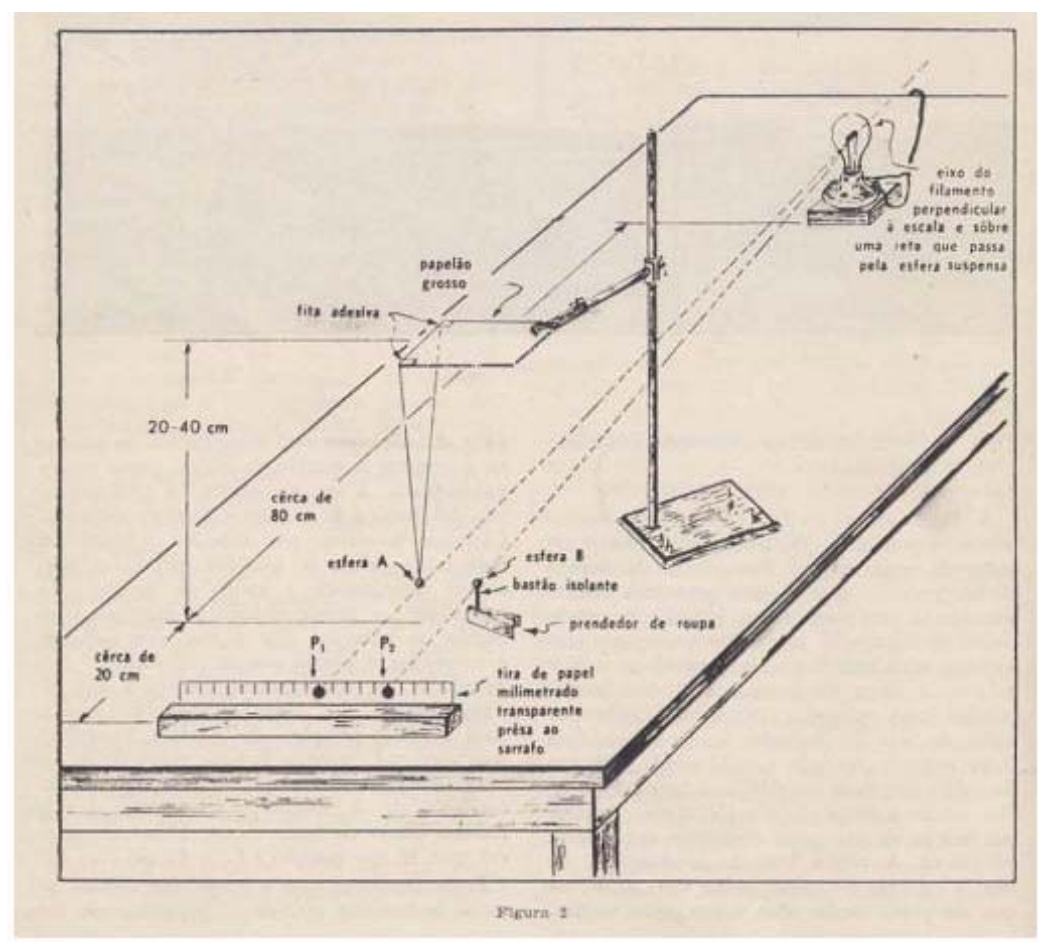

Disponível em http://www.cienciamao.usp.br/dados/pssc/_parteiv-eletricidadeeest_9.arquivopdf.pdf pág. 232 
Pode acontecer que a carga das esferas se escoe lentamente através da superfície do fio e do suporte isolante, introduzindo-se assim, um erro na experiência. Como pode você testar essa perda? Em que momento faria você o teste? Enquanto faz as medidas ou no fim?

Quando a esfera suspensa está em equilíbrio, a força resultante que nela atua é nula; isto é, o vetor soma da tensão T no fio e do peso da esfera, mg é igual e oposto à força elétrica F. Considerando a Fig. 3, pode-se ver que, para pequenos ângulos, a relação entre o módulo da força elétrica e o módulo

do peso, $\frac{F}{m g}$, é igual a $\frac{d}{L}$, que representa a relação entre o deslocamento horizontal da esfera suspensa e o comprimento da suspensão. Portanto:

$$
\mathrm{F}=\frac{m g}{L} \mathrm{X} \mathrm{d}=(\text { constante }) \mathrm{X} \mathrm{d} \text {. }
$$

Como não estamos interessados em considerar unidades especiais de força, podemos medi-la em termos de d. Além disso, o deslocamento horizontal, d, da esfera é proporcional ao deslocamento horizontal D de sua sombra na escala. Analogamente, a distância $r$ entre as duas esferas é proporcional à distância $\mathrm{R}$ entre suas sombras. Podemos, portanto, estudar a relação de dependência entre F e r, representado graficamente D em função de R.

Faça um gráfico da força em função da distância entre as duas esferas (observe que a distância entre as duas sombras é proporcional à distância entre as duas esferas). Como se relaciona a força, quando a distância é r, com a força, quando a distância vale $\frac{1}{2} \mathrm{r}, \frac{2}{3} \mathrm{r}$ ? Que tipo de dependência isto sugere? Faça um gráfico para testá-lo.

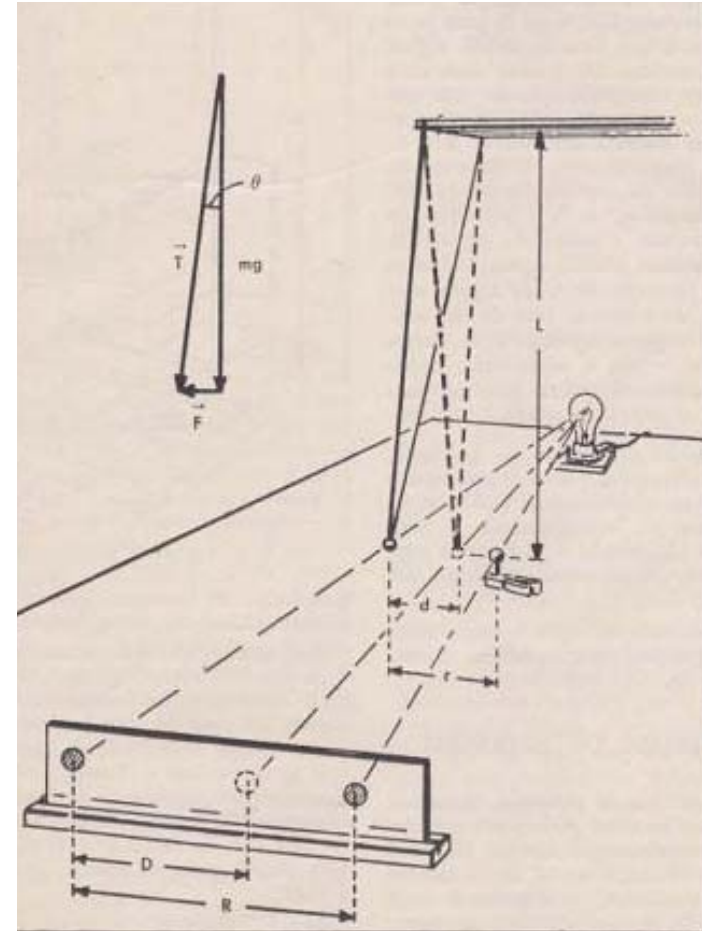

Disponível em <http:// www.cienciamao.usp.br/ dados/pssc/_parteiv-eletricidadeeest_9.arquivopdf.pdf $>$ 
(PSSC. Guia de laboratório. p. 231 a 233)

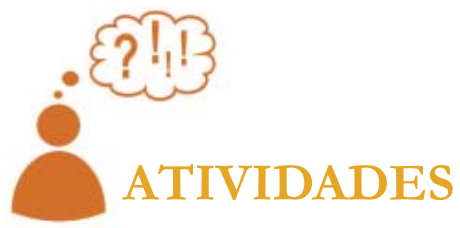

1. Discuta se você adotaria o material do GREF abaixo em vez do Ramalho ou do PSSC.

\section{A Lei de Coulomb}

O campo elétrico de uma carga está associado a sua "capacidade" de poder criar forças elétricas sobre outras cargas elétricas. Essa capacidade está presente em torno de uma carga, independente de existirem ou não outras cargas em torno dela capazes de "sentir" esse campo.

O campo elétrico $\mathrm{E}$ em um ponto $\mathrm{P}$, criado por uma carga $\mathrm{Q}$ puntiforme em repouso, tem as seguintes características:

- a direção é dada pela reta que une o ponto P e a carga Q.

- o sentido de E aponta para P se Q é positiva: e no sentido oposto se Q é negativa.

- o módulo de E é dado pela expressão:

$$
\mathrm{E}=\mathrm{K} \cdot \frac{\mathrm{Q}}{d^{2}}
$$

onde K é uma constante que no SI e vale: $9.10^{9} \mathrm{~N} \cdot \mathrm{m}^{2} / \mathrm{C}^{2}$.

A intensidade da força elétrica entre duas cargas Q e q é dada pela expressão que representa a Lei de Coulomb:

$$
F=K \cdot \frac{Q \cdot q}{d^{2}}
$$

onde d é a distância entre as cargas.

Quando uma carga elétrica Q está imersa num campo elétrico E, e o valor da força elétrica que age sobre ela é dada por:

No sistema internacional de unidades, a força é medida em $N$ ewton $(\mathrm{N})$, a carga elétrica em Coulomb (C) e o campo elétrico em Newton/Coulomb (N/C). exercitando... 
a) Representar as forças elétricas em cada situação:

a.

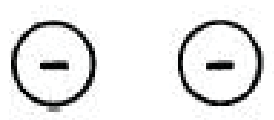

b.

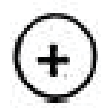

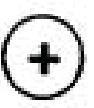

c.

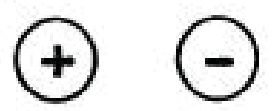

2. Determine a intensidade da força de repulsão entre duas cargas iguais a $1 \mathrm{C}$, que se encontram no vácuo, distanciadas em $1 \mathrm{~m}$.

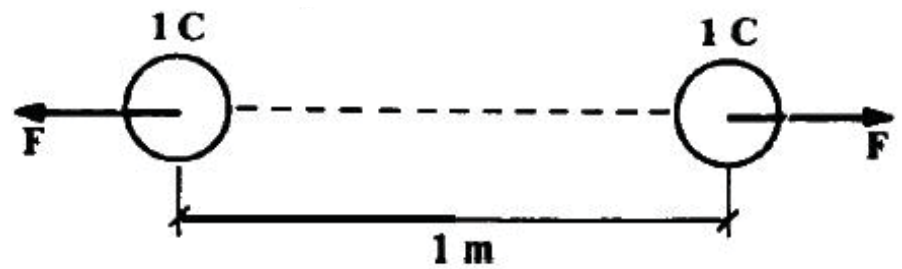

(Gref - Eletromagnetismo para ler, fazer e pensar - versão preliminar 20-29, p. 108. Disponível em: <http://www.if.usp.br/gref/eletro/eletro4.pdf>.

3. Três corpos com cargas elétricas iguais são colocadas como indica a figura abaixo. A intensidade da força elétrica que A exerce em B é de $F=3,0.10^{-6} \mathrm{~N}$ :

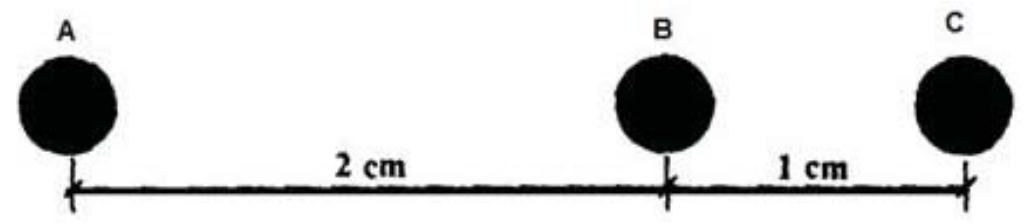

(Gref - Eletromagnetismo para ler, fazer e pensar - versão preliminar 20-29, p. 108. Disponível em: <http://www.if.usp.br/gref/eletro/eletro4.pdf>.

Determinar a intensidade da força elétrica:

a) Que C exerce em B

b) Resultante no corpo B

4. Podemos eletrizar um objeto neutro através do atrito com outro objeto neutro, ou através de um objeto carregado. É possível eletrizarmos um objeto sem atrito ou contato? Como?

5. Analise o texto a seguir e diga se é verdadeiro ou falso:

"O fato de uma carga poder exercer força sobre a outra através do campo está de acordo com o princípio de ação e reação ( $3^{a}$ lei de Newton). Segundo este princípio, podemos considerar as forças F e F' como par de ação e reação que tem, portanto, o mesmo módulo, porém sentidos opostos, além de estarem aplicados a corpos diferentes.." 
(Gref - Eletromagnetismo para ler, fazer e pensar - versão preliminar 20-29, p. 108. Disponível em: <http://www.if.usp.br/gref/eletro/eletro4. pdf $>$.

Na seção 4 desta aula apresentamos os resultados do insucesso do PSSC. Analise respondendo as atividades abaixo.

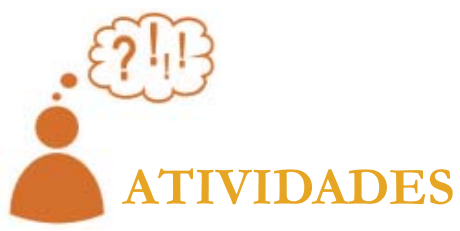

1. Os textos são realmente longos?

2. Excesso de experimentos atrapalha e não exemplifica o conceito?

3. A falta de conexão com o cotidiano do aluno é realmente desmotivante?

4. Você acha que o texto do PSSC é útil para complementar os seus conhecimentos antes de ministrar uma aula?

5. Qual dos dois textos (um livro texto tradicional do tipo Ramalho ou o projeto PSSC), você usaria como referência para ministrar uma aula sobre campo elétrico? Por quê?

6. Você acha que os físicos formados na década de 70 e 80 e que escreveram os nossos livros didáticos foram influenciados por estes projetos de ensino de física?

7. Você acha que os alunos não conseguem ver filmes documentários muito longos?

8. Compare o filme produzido para a série o Universo Mecânico com os de curta duração produzidos para o Youtube como os sugeridos disponíveis nos links <http://youtu.be/TRO0XzLWGvA>; < http://youtu.be/ MURbr0sD8uc>.

\section{APPLETS DE ENSINO}

Sugerimos alguns sites como material de multimídia para você analisar. Segue abaixo um guia de applets de ensino com dicas para vocês analisarem. 1. Explore esse excelente applet do Professor Falstad disponível no link: $<$ http://www.falstad.com/emstatic/>.

Note que você pode arrastar a caixa para visualizar a força de várias posições. 


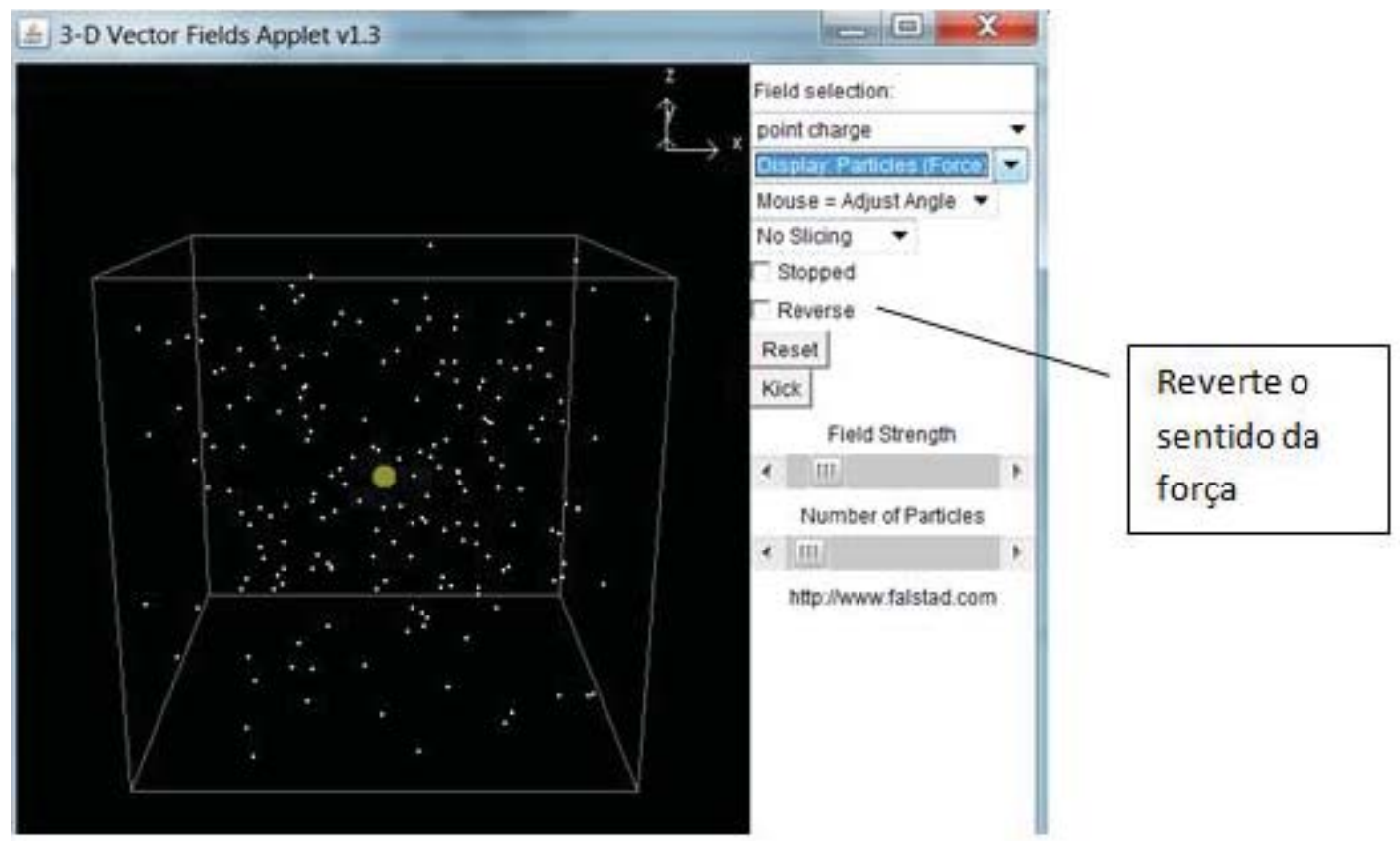

Disponível em <http://www.falstad.com/emstatic/>

2. Explique o princípio de funcionamento do applet do curso da Universidade do Colorado. Acesse através do link: < https://sites.google.com/site/ professorpifer/Home/fisica-mix/eletromagnetismo>.

Você pode colocar quantas cargas você quiser na tela e uma partícula como sensor de campo. Junto com o sensor de campo vai um vetor força elétrica. Arraste-o. Não se esqueça de ativar o campo "Show E-field".

Você pode brincar de determinar o módulo e a direção da força elétrica sobre a carga de prova.

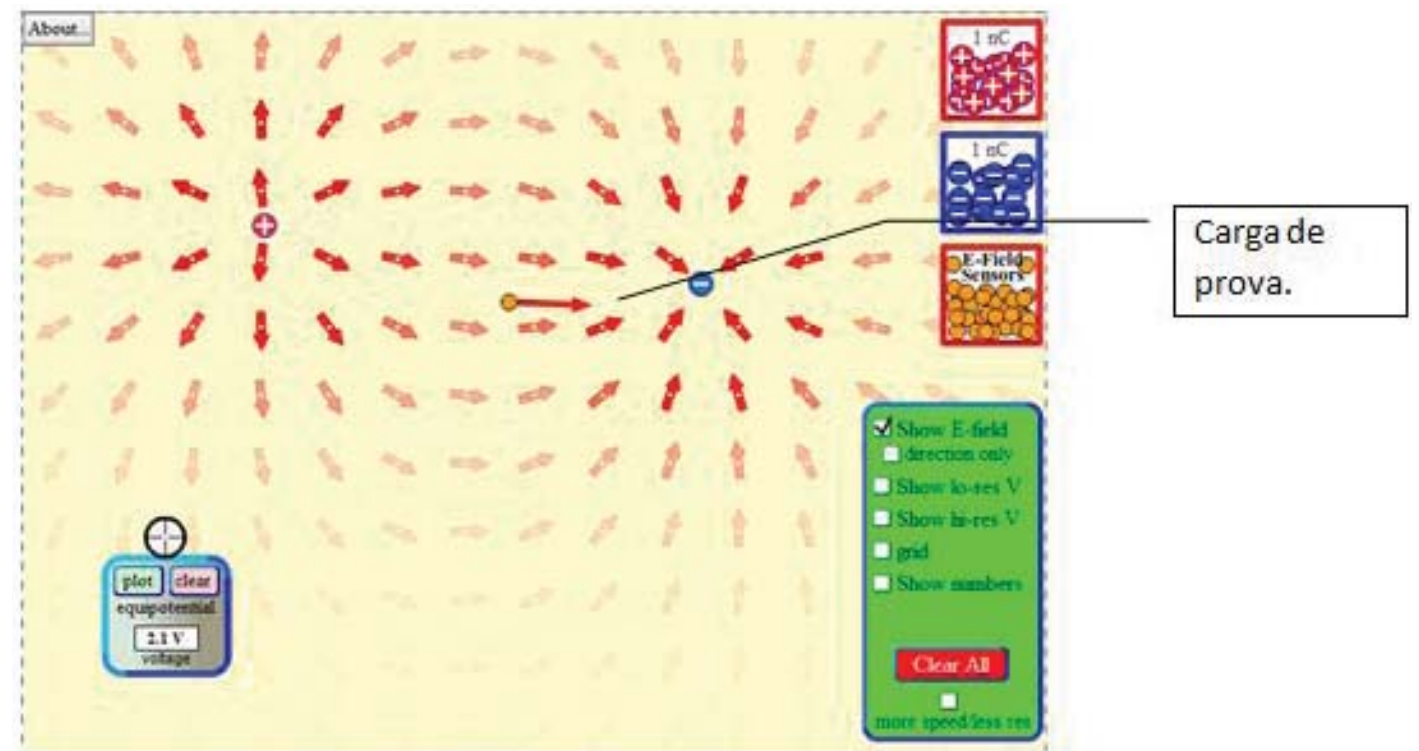

Disponível em < https://sites.google.com/site/professorpifer/Home/fisica-mix/eletromagnetismo > 


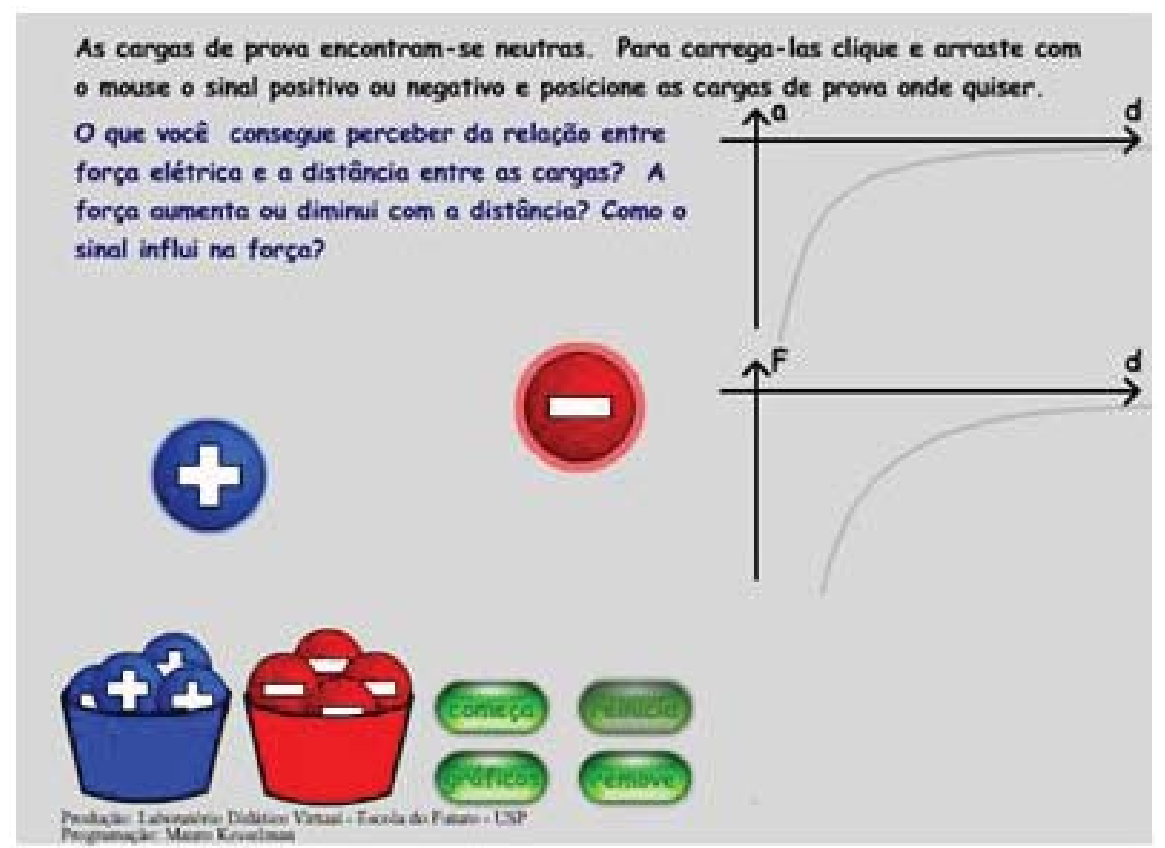

Disponível em < http://www.labvirt.fe.usp.br/simulacoes/fisica/sim_eletromag_forcaeletrica.htm $>$

4. Explore esse excelente applet da Universidade do Colorado, acessando o link: <http://www.labvirt.fe.usp.br/simulacoes/fisica/sim_eletromag_forcaeletrica.htm $>$.

\section{Charges and Fields}

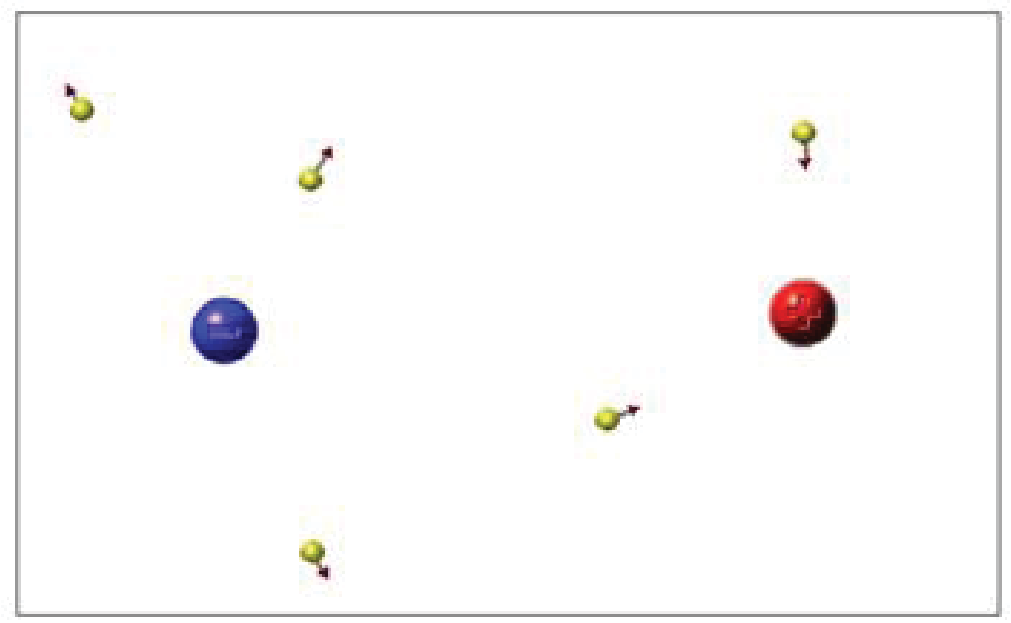

Disponível em < http://www.labvirt.fe.usp.br/simulacoes/fisica/sim_eletromag_forcaeletrica.htm $>$

Adicionar terminais e "cargas teste" e arrastar as coisas ao redor para ver como a mudança nas forças. Dê um duplo clique em qualquer objeto ou sobre o fundo para o menu de opções.

Clique e arraste para mover terminais ou cargas. 


\section{VIDEOS AULAS}

1 - Acesse o vídeo com história da eletricidade, através do link: <http:// www.youtube.com/watch?v $=$ MURbr0sD8uc $>$.

2 - Vídeo aula muito boa. Acesse através do link: <http://www.youtube. $\mathrm{com} /$ watch?v $=$ TRO0XzLWGvA\&feature $=$ related $>$.

\section{EXPERIMENTOS DE BAIXO CUSTO}

1. Tente você mesmo fazer uma balança de torção. Pegue dois canudinho de plástico; três bolinhas de isopor; papel alumínio e bole um aparato para sustentar sua estrutura. Como você faria para carregar as bolinhas de isopor forradas de papel alumínio?
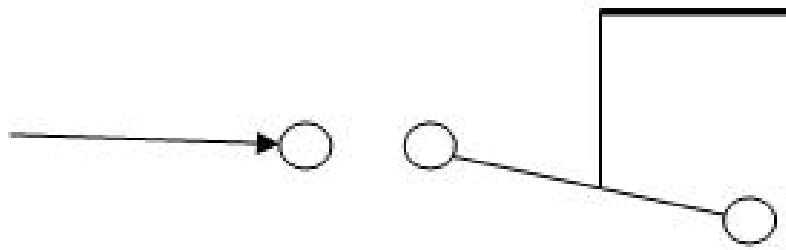

2. Faça um experimento mais simples. Pense nos detalhes.
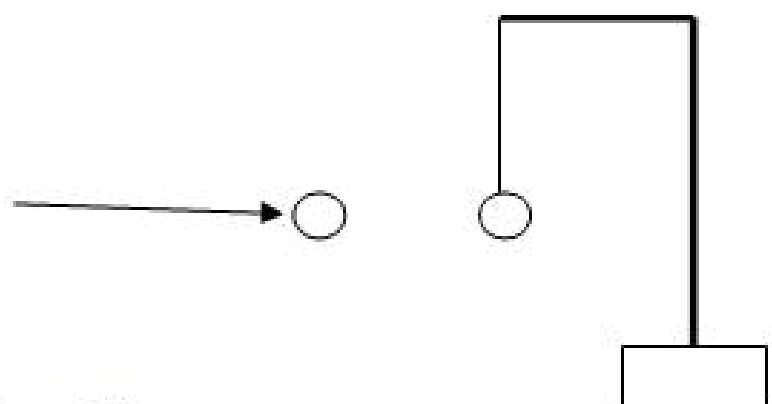


\section{CONCLUSÃO}

Através da leitura do capítulo 28 do livro texto do projeto PSSC, entramos em contato com o material pedagógico e sua filosofia pedagógica. Observamos como se comprovou na história, que textos e filmes longos não são adequados para alunos do Ensino Médio. Por outro lado, vimos também que um texto muito curto e baseado na definiç̧ão de leis e equações, sem uma contextualização histórica e de como a Física se relaciona com o cotidiano, também se torna uma disciplina enfadonha e sem sentido para o aluno. Assim ficou a pergunta: como tornar o curso de Física mais atraente e motivante?

Com a análise dos experimentos de baixo custo e dos recursos de multimídias que colocamos no final da aula o futuro professor deve ter ficado com algumas boas ideias de como este pode enriquecer uma aula sobre o tema Lei de Coulomb.

\section{COMENTÁRIOS SOBRE AS ATIVIDADES}

Em geral os alunos que fazem o curso de licenciatura em Física têm um curso muito superficial ou não têm nenhuma aula de Física. Se têm, usam algum livro texto tradicional, onde a Física é apresentada como uma coleção de definições e fórmulas para serem aplicadas em problemas e exercícios. Assim, a maioria deles só possui o conhecimento de Física dado na universidade. A apresentação do projeto PSSC deve ter dado uma visão geral de toda a complexidade de se montar um curso de Física e como esse pode se tornar mais atraente.

Os futuros professores devem ter compreendido o papel central que eles têm na escolha do conteúdo, da técnica e da didática ser utilizada em sala de aula. Este deve ter adquirido uma ideia de como se deve preparar um curso ou apenas uma aula. Eles devem compreender que uma aula é um processo dinâmico e orgânico.

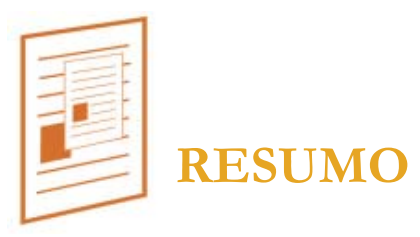

Apresentamos um resumo da história do projeto PSSC e através da análise do capítulo 28, Força Elétrica, começamos a analisar a influência que estes projetos de ensino tiveram sobre a construção do livro didático. Através da leitura deste texto, fizemos uma comparação com um texto padrão de um livro didático, no caso o livro do Ramalho e levantamos a questão sobre o uso de textos longos como recurso didático para a disciplina de Física. 
Em seguida, apresentamos vários experimentos de baixo custo para que o aluno explore as possibilidades que estes oferecem para se ministrar um curso usando mais ferramentas fenomenológicas e menos formais. Colocamos vários e excelentes applets de ensino como recurso de simulação de fenômeno físico para ser explorado pelo futuro professor. Colocamos, também, ótimos experimentos de baixo custo que podem ser usados facilmente em sala de aula.

Como há ótimos vídeos de ensino colocamos alguns deles como referência e deixamos sua exploração como atividade para os estudantes, uma vez que no curso de Instrumentação I não usamos os vídeos didáticos como ferramenta didática principal.

\section{RESPOSTA DAS A'TIVIDADES}

$1-\operatorname{Sim}$

2 - Depende. Na maioria dos casos não.

3 - certamente

4 - Espero que ele responda que sim

5 - Resposta pessoal

6 - Sim

7 - A grande maioria não

8 - São muito melhores, mas são longos

\section{REFERENCIAS}

ALVES FILHO, J.P; Atividades experimentais do método a prática construtiva; Tese de Doutorado apresentada ao Programa de PósGraduação em Educação da UFSC; 2000.

APPLETS-ELETROMAGNETISMO. Universidade do Colorado. Disponível em: <https://sites.google.com/site/professorpifer/Home/ fisica-mix/eletromagnetismo>. Acesso em 15/10/2011.

CARVALHO, A. M. P.; A pesquisa no ensino, sobre o ensino e sobre a reflexão dos professores sobre seus ensinos; Revista Educação e Pesquisa, v. 28, n. 2; 2002.

DISCOVERING THE PSSC: A Personal Memoir, by A. P. French. Disponível em <http://www.compadre.org/portal/pssc/docs/French.pdf > GASPAR, A.; Cinqüenta anos de Ensino de Física: Muitos equívocos, alguns acertos e a necessidade do resgate do papel do professor; artigo apresentado no XV Encontro de Físicos do Norte e Nordeste; 2002. 
GREF - Grupo de Reelaboração do Ensino de Física, Instituto de Física da USP - Leituras de física - Gref - Eletromagnetismo para ler, fazer e pensar - versão preliminar 20-29, p. 108. Disponível em: < http:/ /www. if.usp.br/gref/eletro/eletro1.pdf>. Acesso em 15/10/2011.

LAB VIRT. Laboratório Didático Virtual - Escola do Futuro - USP.

Disponível em: <http://www.labvirt.fe.usp.br/simulacoes/fisica/sim_eletromag_forcaeletrica.htm>. Acesso em 15/10/2011.

MOREIRA, A. M; Ensino de Física no Brasil: Retrospectiva e Perspectivas, apresentação feita na mesa redonda "Retrospectiva de Ensino e Pesquisa"; Universidade de Brasília, 1999.

PERINI ,L. ; FERREIRA, G. K.; CLEMENTE, L.; Projeto de Ensino PSSC: uma análise dos exercícios/problemas; resumo apresentado no XVIII Simpósio Nacional de Ensino de Física; SNEF; Vitória, ES; 2009. PSSC, Física - Parte I, Parte II, Parte III, Parte IV, Editora Universidade de Brasília, tradução autorizada com direitos reservados para o Brasil pelo IBECC-UNESCO.

PSSC, Guia do Professor de Física- Parte I, Parte II, Parte III, Parte IV, EDART, SP, traduzido e adaptado pela Fundação Brasileira para o Desenvolvimento do Ensino de Ciências e pelo Centro de Treinamento de Professores de Ciências de São Paulo(CECISP).

PSSC PHYSICS: A Personal Perspective, by Uri Haber-Schaim. Disponível em <http://www.compadre.org/portal/pssc/docs/Haber-Schaim.pdf> PSSC in Historical Context: Science, National Security, and American Culture during the Cold War, by John L. Rudolph”. Disponível em < http:/ / www. $\neg$ compadre.-org/ $\neg$ portal/ $\neg$ pssc/ $\neg$ docs $/ \neg$ Rudolph. $\neg$ pdf $>$

YOUTUBE. Força Elétrica. Disponível em: <http://youtu.be/TRO0XzLWGvA>. Acesso em 15/10/2011. . Força Elétrica - Lei de Coulomb. Disponível em: < http://youtu.be/ MURbr0sD8uc>. Acesso em 15/10/2011. 


\section{Aula 3 3}

\section{CAMPO ELÉTRICO}

META

Fazer com que o estudante comece a pensar no ensino de ciências como algo "orgânico" que está em profunda transformação.

Fazer com que os alunos percebam, através de um texto básico complementado com atividades lúdicas, applets de ensino, vídeos, e com materiais de baixo custo que o conceito de campo elétrico pode ser apreendido de forma simples e divertida.

Analisar a biografia de Michael Faraday e fazer com que o estudante reflita sobre o que é fazer Física. Introduzir o problema de como se ensinar o conceito de campo.

OBJETIVOS

Ao final desta aula, o aluno deverá: estar ciente das novas possibilidades e dos desafios que envolvem o ensino de ciências em geral e das dificuldades de se ministrar um curso de eletricidade e magnetismo. Ter compreendido que as ciências naturais estão baseadas na experimentação e que esta é feita de ensaios, experiências e medidas e que estas levam à compreensão e matematização dos conceitos físicos (naturais em geral). Trazer a discussão sobre o papel que a Matemática tem na formação e no ensino de Física. Discutir as dificuldades de se trocar o conceito de força pelo de campo nas explicações dos fenômenos físicos.

\section{PRÉ-REQUISITOS} Os alunos deverão ter cursado Psicologia da Educação, Física A e Física B e instrumentação I. 


\section{INTRODUÇÃO}

Devido ao papel fundamental que a Matemática tem e continuará desempenhando na descoberta, construção e evolução das ciências exatas o ensino de Física, principalmente no Ensino Médio, está centrado na metodologia de se apresentar a Física como uma ciência feita de leis expressas por meio de leis matemáticas e com muito pouco contato com a experimentação.

Nos dois cursos de instrumentação anteriores tivemos a oportunidade de introduzir o papel da experimentação no ensino de Física. Nesta instrumentação teremos a oportunidade de apresentar a história de um cientista, Faraday, que apesar de seus parcos conhecimentos e domínio de Matemática se tornou um dos mais importantes e célebres cientistas modernos. Como experimentação e história da Física são partes integrantes do curso de instrumentação, a seguir apresentamos um resumo da biografia de Faraday e depois faremos um resumo da teoria do campo elétrico.

Discutiremos aqui, através de dois textos didáticos, a dificuldade de se ensinar o conceito de campo elétrico. Os educadores que trabalham com aprendizagem significativa concordam que certos conceitos físicos, tais como o princípio da inércia, campo elétrico e outros, exigem certa capacidade de raciocínio abstrato por parte do aluno. É de consenso que a grande maioria dos adolescentes não atingiram este grau de compreensão. Então surge a questão: como ministrar ou abordar estes temas? Não vamos resolver este problema aqui, mas vamos discutir algumas soluções para ele.

\section{BIOGRAFIA}

Michael Faraday nasceu em NewingtonButts, ao sul de Londres. Sua família era pobre e seu pai, James Faraday, era um ferreiro que com a mãe de Faraday, Margaret Hastwell, tinha no começo de 1791 migrado do norte da Inglaterra para NewingtonButts, em busca de trabalho. Eles já tinham dois filhos antes de se mudarem (um menino e uma menina), e Faraday nasceu poucos meses depois dessa mudança. A família logo se mudou de novo, agora para Londres, onde o jovem Michael Faraday, recebeu os rudimentos de uma educação, aprendendo a ler, escrever, e aritmética.

Faraday começou a trabalhar aos 13 anos de idade, como menino de recados de um encadernador e comerciante de livros, George Riebau, um imigrante francês que foi para Londres devido à Revolução Francesa. Em 1805, aos 14 anos, Faraday tornou-se aprendiz de Riebau e leu vários dos livros que encadernou durante seus sete anos de aprendizado.

O primeiro livro que chamou sua atenção foi Conversations of Chemistry (Palestras sobre Química) de Jane Marcet, escrito em 1805. A obra - 
A melhoria da mente - de Isaac Watts, foi a primeira que fez com que ele meditasse. Leu a Enciclopédia Britânica (um exemplar que estava encadernando) e interessou-se muito por um artigo sobre eletricidade.

Como resultado de suas leituras realizou experiências químicas simples: certa vez teve acesso a um livro chamado Experiências Químicas, e com o pouco dinheiro que tinha comprou instrumentos simples e começou a fazer as experiências que estavam no livro. Assim, foi modelando sua inteligência, desenvolvendo sua técnica. Conforme ele progredia, aumentava o seu interesse e a sua curiosidade. Lia todos os livros de ciência que encontrava.

Desde 1810, Faraday assistiu aulas de John Tatum (fundador de uma sociedade filosófica), sobre diversos assuntos. Quando tinha 20 anos, em 1810, Faraday foi convidado para assistir a quatro conferências de Humphry Davy, um importante químico inglês e presidente da Royal Society entre 1820 e 1827. Faraday tomou notas dessas conferências e, mais tarde, redigiu-as em formato mais completo. Então, em 1812, ele escreveu para Humphry Davy mandando cópias dessas notas. Davy respondeu para Faraday quase imediatamente, e muito favoravelmente, além de arranjar um encontro.

Em março de 1813, foi nomeado ajudante de laboratório da Royal Institution por recomendação de Humphry Davy.

Davy precisava fazer uma lâmpada de segurança para ser usada nas minas e Michael pode mostrar seu potencial, dando-lhe sugestões, pois tinha grande capacidade analítica. Suas sugestões foram aceitas. Davy o reconheceu e lhe deu a oportunidade de participar ativamente de suas experiências.

Seis meses depois, Davy o convidou para acompanhá-lo como seu "assessor filosófico" em uma série de conferências. No dia 13 de outubro de 1813, partiram para a Europa. "Esta manhã marca uma época em minha vida", escreveu em seu diário. Como o criado de Davy desistiu de viajar, Michael assumiu este papel. A viagem foi cheia de surpresas para Michael: conheceu o mar, as montanhas, o Vesúvio, viu Napoleão; conheceu Alessandro Volta, André-Marie Ampère, Joseph Gay-Lussac e outros cientistas.

Em 1815, volta à Inglaterra. Michael passa a integrar o Royal Institution, sendo conferencista ocasional. Ele e Davy concluem a lâmpada de segurança que começou a ser usada no ano seguinte. Michael declara que a lâmpada não era perfeitamente segura, o que desagrada ao ego de Davy. Ingressou na Sociedade Filosófica, onde realizava conferências sobre química, utilizando-se do que ouvia de Davy.

As suas contribuições mais importantes e os seus trabalhos mais conhecidos estão intimamente relacionados com os fenômenos da eletricidade e do magnetismo, no entanto, também contribuiu de forma significativa para a evolução da Química enquanto ciência. Faraday foi principalmente um experimentalista, chegando a ser descrito como o "melhor experimentalista na história da ciência", embora não dominasse conhecimentos de Matemática avançada, como o cálculo. 
Tanto as suas contribuições para a ciência, como o impacto que as mesmas tiveram na nossa sociedade, são importantes: as suas descobertas científicas cobrem áreas significativas da Física e da Química modernas, e a tecnologia desenvolvida baseada no seu trabalho está ainda mais presente. As suas descobertas na área do eletromagnetismo constituíram a base para os trabalhos de engenharia do fim do século XIX por pessoas como Edison, Siemens, Tesla e Westinghouse, que tornaram possível a eletrificação das sociedades industrializadas. Por outro lado, os seus trabalhos em eletroquímica são agora amplamente usados em Química industrial.

$\mathrm{Na}$ área da Física, foi um dos primeiros a relacionar a eletricidade e o magnetismo.

Em 1821, logo após Oersted ser o primeiro a descobrir que a eletricidade e o magnetismo eram associados entre si, Faraday publicou o seu trabalho, a que chamou de "Rotação Eletromagnética" (princípio que explica o funcionamento do motor elétrico).

Em 1831, Faraday descobriu a indução eletromagnética, o princípio do funcionamento de um gerador elétrico e de um transformador elétrico.

Suas ideias sobre os campos elétrico e magnético, e a natureza dos campos em geral, inspiraram trabalhos posteriores nessa área (como as equações de Maxwell).

$\mathrm{Na}$ área da Química, ele descobriu o benzeno, produziu os primeiros cloretos de carbono conhecidos $\left(\mathrm{C}_{2} \mathrm{Cl}_{6}\right.$ e $\left.\mathrm{C}_{2} \mathrm{Cl}_{4}\right)$, ajudou a estender as fundações da metalurgia e metalografia, além de ter tido sucesso em liquefazer gases nunca antes liquefeitos (dióxido de carbono e cloro, entre outros), tornando possível métodos de refrigeração que foram muito utilizados. Talvez a sua maior contribuição foi, na fundação virtual da eletroquímica, introduzindo termos como eletrólito, ânodo, cátodo, elétrodo e íon.

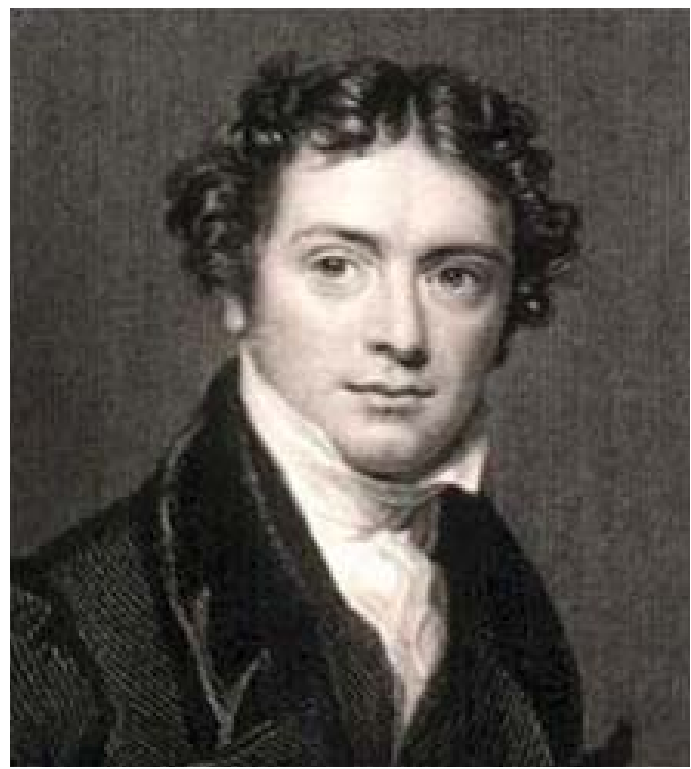

Michael Faraday (1791 - 1867).

Disponível em: <http://www.explicatorium. com/Michael-Faraday.php> 
Pesquisou também algumas ligas de aço e produziu vários tipos novos de vidros. Um desses vidros tornou-se historicamente importante por ser a substância em que Faraday identificou a rotação do plano de polarização da luz quando era colocado num campo magnético e também por ser a primeira substância a ser repelida pelos pólos de um ímã.

Faraday morreu na sua casa em Hampton Court em 25 de Agosto de 1867, aos 75 anos, e foi enterrado na Abadia de Westminster, ao lado de Isaac Newton.

A constante Física fundamental que representa a carga molar elementar, recebeu o nome de constante de Faraday, em homenagem a este cientista britânico, devido aos seus vastos estudos em eletroquímica.

A seguir colocamos um texto didático disponível no Portal São Francisco, produzido por um professor do Ensino Médio para os seus alunos. Este texto apresenta a forma e estrutura de apresentação da maioria dos livros textos antes do advento do PNLEM. Note-se que ele está baseado na introdução direta de conceitos, definições e fórmulas.

\section{CONCEITOS CAMPO ELÉTRICO}

1. O vetor campo elétrico

O campo elétrico pode ser representado, em cada ponto do espaço, por um vetor, usualmente simbolizado por $\mathrm{E}$ que se denomina vetor campo elétrico.

A seguir, encontram-se as características deste vetor.

\subsection{Módulo do vetor}

O módulo do vetor, em um dado ponto, costuma ser denominado intensidade do campo elétrico naquele ponto. Para definir este módulo, consideremos a carga Q, mostrada na fig.02, criando um campo elétrico no espaço em torno dela. Colocando-se uma carga de prova $\mathrm{q}$ em um ponto qualquer, como o ponto P1, por exemplo, uma força elétrica atuará sobre esta carga de prova. A intensidade do campo elétrico em P1 será, por definição, dada pela expressão

$$
\mathrm{E}=\mathrm{F} / \mathrm{q}
$$

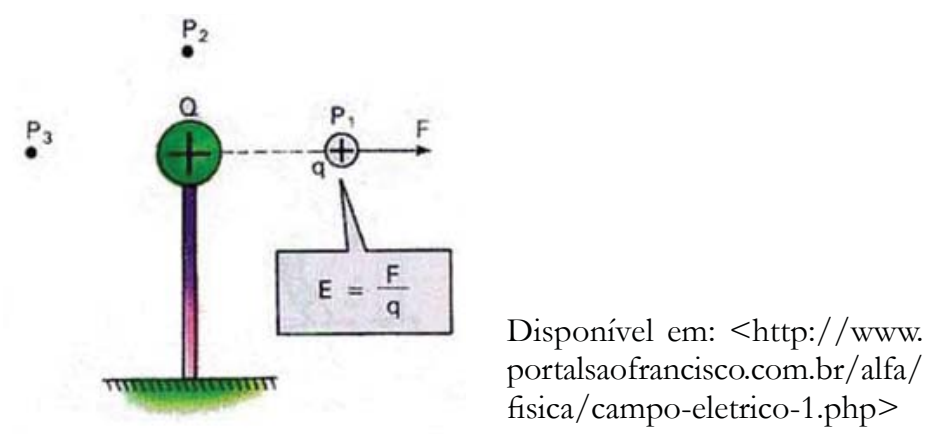


A expressão $\mathrm{E}=\mathrm{F} / \mathrm{q}$ nos permite determinar a intensidade do campo elétrico em qualquer outro ponto, tal como P2, ou P3 etc. De maneira geral, o valor de $E$ será diferente para cada um desses pontos, a não ser em casos especiais. Observe que, de $\mathrm{E}=\mathrm{F} / \mathrm{q}$ obtemos:

$$
\mathrm{F}=\mathrm{qE}
$$

isto é, se conhecermos a intensidade, E, do campo elétrico em um ponto, poderemos calcular, usando a expressão anterior, o módulo da força que atua em uma carga qualquer, q, colocada naquele ponto.

\subsection{Direção e sentido do vetor}

A direção e o sentido do vetor campo elétrico em um ponto são, por definição, dados pela direção e sentido da força que atua em uma carga de prova positiva colocada no ponto.

Por exemplo:

Consideremos o ponto P1 mostrado na fig.03. Se uma carga de prova positiva fosse colocada em P1 ela seria, evidentemente, repelida por Q com uma força horizontal para a direita. Portando, em virtude do exposto, o vetor campo elétrico 1 , naquele ponto, seria também horizontal e dirigido para a direita. De modo análogo, podemos concluir que em P2 temos uma vetor 2 dirigido verticalmente para cima; pois, se uma carga de prova positiva fosse colocada neste ponto, ela ficaria sob a ação de uma força com aquela direção e naquele sentido. Então, podemos verificar que, em P3 e P4 , os vetores 3 e 4 têm as direções e os sentidos indicados na fig.03.

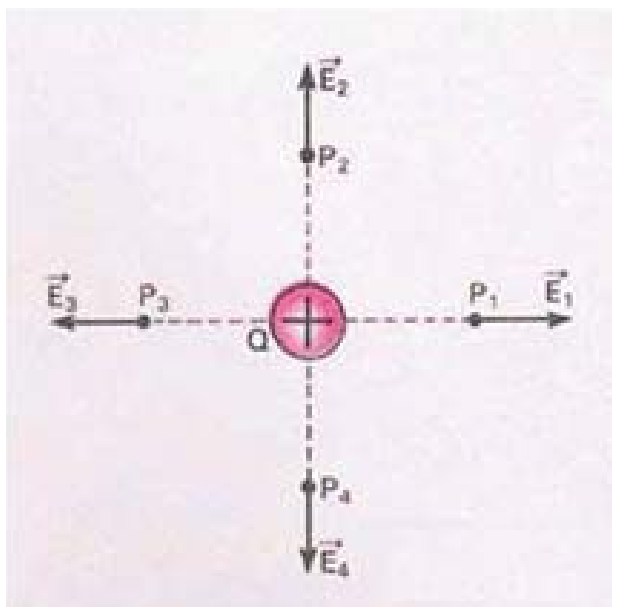

Disponível em: <http://www.portalsaofrancisco.com.br/alfa/fisica/campo-eletrico-1.php>

Suponha, agora, que a carga que cria o campo seja negativa, como mostra a fig. 04. Neste caso, se colocássemos a carga de prova positiva em P1, ela seria atraída por Q com uma força para a esquerda. Portanto, o vetor campo elétrico estaria agora dirigido para a esquerda (sempre no 
mesmo sentido da força que atua na carga de prova positiva). Seguindo esta orientação, podemos concluir que em P2, P3 e P4 o vetor campo elétrico será representado pelos vetores 2,3 e 4 mostrados na fig. 04 .

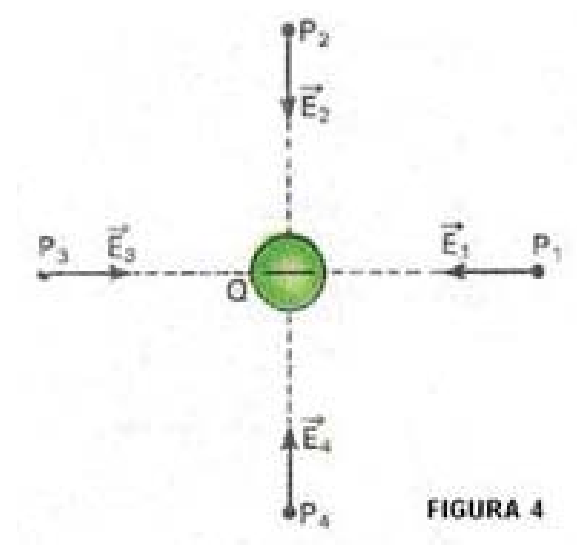

Disponível em: <http://www.portalsaofrancisco.com.br/alfa/fisica/campo-eletrico-1.php>

2. Movimento de cargas em um campo elétrico

Suponha que uma carga positiva q seja colocada no ponto P1 da fig.03, onde existe um campo elétrico 1 criado por Q. A carga q será repelida por Q com uma força dirigida para a direita e, consequentemente, ela tenderá a se deslocar no sentido desta força. Já que, o vetor 1 tem o mesmo sentido desta força, concluímos que a carga positiva q tende a se deslocar no sentido do campo elétrico. Se esta mesma carga positiva q for colocada no ponto P1 da fig.04 (campo criado por carga negativa), ela será atraída pela carga Q e tenderá, também neste caso, a se deslocar no sentido do campo elétrico 1.

De maneira geral podemos verificar que, em qualquer ponto que a carga positiva q for abandonada, ela tenderá a se deslocar no sentido do vetor do campo elétrico existente naquele ponto.

Imagine, agora, que coloquemos no ponto P1 da fig.03 uma carga negativa q (lembremos que em P1, existe um campo elétrico 1 dirigido para a direita, produzido pela carga Q). Nestas condições, a carga q será atraída por Q e tenderá, então, a se deslocar em sentido contrário ao campo 1. Se deslocarmos a carga negativa q no ponto P1 da fig.04, ela será repelida pela carga negativa $\mathrm{Q}$ e, da mesma maneira, tenderá a se deslocar em sentido contrário ao do vetor 1 .

A seguir colocamos um texto didático preparado para o Projeto Educar. Note que nele o autor procura puxar na memória do aluno fatos do seu cotidiano. Em seguida, contextualiza os fatos históricos que levaram a formulação da teoria. Depois descreve os fatos empíricos que levaram à conclusão do princípio físico ou lei. 


\section{CAMPO ELÉTRICO}

No nosso dia a dia convivemos com diferentes tipos de forças, uma das mais comuns são as forças de contato, tal como puxar ou empurrar algum objeto sobre uma mesa ou mesmo chutando uma bola de futebol. Em contra partida, existem duas forças que agem a distância, são elas as forças gravitacional e elétrica, isto quer dizer que, existe força mesmo que dois objetos não estejam em contato.

Forças agindo a distância foram um dos problemas mais complexos tratados pelos nossos pensadores antepassados. Os primeiros passos concretos dados na compreensão e descrição matemática deste problema foi dado por Newton ao estudar a influência da força gravitacional sobre os objetos na face da Terra.

Destes estudos surgiu a lei da gravitação universal. Uma forma extremamente valiosa para entender este fenômeno, vem da proposição de Michael Faraday (1791-1867) em criar o conceito de campo elétrico. Assim, um dos propósitos do uso de campos elétricos é evitar o conceito de ação a distância.

De acordo com Faraday, o campo elétrico emanaria de qualquer carga, tanto das positivas quanto das negativas, e que permearia todo o espaço em torno das mesmas. Ele admitiu ainda que uma segunda carga colocada na presença da primeira sentiria o campo elétrico produzido pela primeira carga. Este campo é que seria o responsável para o aparecimento da força elétrica.

Ora, se isto é verdade, então deve existir uma conexão direta entre o campo elétrico e a força eletrostática de acordo com a lei de Coulomb. A correlação entre estes dois entes pode ser determinada reorganizando a expressão para a força como a seguir

$$
\overrightarrow{\mathrm{F}}=\mathrm{kq}_{0} \sum_{\mathrm{i}=1}^{\mathrm{N}} \frac{\mathrm{q}_{\mathrm{i}}}{\mathrm{r}_{\mathrm{i}}^{2}} \hat{\mathrm{r}}_{\mathrm{i}}=\mathrm{q}_{0}\left(\mathrm{k} \sum_{\mathrm{i}=1}^{\mathrm{N}} \frac{\mathrm{q}_{\mathrm{i}}}{\mathrm{r}_{\mathrm{i}}^{2}} \hat{\mathrm{r}}_{\mathrm{i}}\right)=\mathrm{q}_{0} \overrightarrow{\mathrm{E}}
$$

Disponível em: <http://www.portalsaofrancisco.com.br/alfa/ fisica/campo-eletrico-1.php>

ou simplesmente

$$
\overrightarrow{\mathrm{E}}=\frac{\overrightarrow{\mathrm{F}}}{\mathrm{q}_{0}}
$$

Disponível em: <http://www.portalsaofrancisco.com.br/alfa/fisica/campo-eletrico-1.php> 
onde $\vec{E}$ é um vetor, o qual denominamos de vetor campo elétrico. De acordo com Faraday este campo elétrico é devido a uma distribuição discreta de cargas. Ele permeia todo espaço em torno das cargas. Idealmente, $\overrightarrow{\mathrm{E}}$ é definido como $\overrightarrow{\mathrm{F}} / \mathrm{q}$ para o caso limite de $\mathrm{q} \rightarrow 0$.

Como consequência da definição, do vetor $\vec{E}$, observe que, se uma carga pontual positiva $\left(\mathrm{q}_{0}\right)$ for colocada em um ponto P onde existe campo elétrico, ela ficará sujeita a uma força na mesma direção e sentido do campo elétrico, isto é, ela tende a se mover no sentido do vetor E. Se uma carga negativa for colocada no mesmo ponto, ela tenderá a se mover em sentido contrário ao campo, como estabelece a equação.

Desta maneira, conforme havíamos dito, o vetor $\vec{E}$ caracteriza o campo elétrico. Conhecendo $\vec{E}$ em cada ponto do espaço, podemos prever a ação deste campo sobre cargas colocadas dentro dele, sem que seja necessário conhecermos a distribuição de cargas que criou o campo.

Em suma, podemos dizer que o campo elétrico, em qualquer ponto do espaço, é um vetor cuja direção é a direção da força sobre uma carga de prova positiva e que sua magnitude é a força por unidade de carga. Dessa forma, $\vec{E}$ tem unidades de Newton por Coulomb $(\mathrm{N} / \mathrm{C})$.

É importante ressaltar que, pela definição de $\vec{E}$, o campo elétrico não depende da carga de prova e sim apenas da distribuição que o gerou.

No caso de um campo $\vec{E}$ criado por uma única carga temos que;

$$
\overrightarrow{\mathrm{E}}=\mathrm{k} \frac{\mathrm{q}}{\mathrm{r}^{2}} \hat{\mathrm{r}}
$$

Disponível em: <http://www.portalsaofrancisco. com.br/alfa/fisica/campo-eletrico-1.php>

cujo módulo, denominado algumas vezes por intensidade do campo E, é dado por:

$$
\mathrm{E}=\mathrm{k} \frac{\mathrm{Q}}{\mathrm{r}^{2}}
$$

Disponível em: < http:/ /www.portalsaofrancisco.com. $\mathrm{br} / \mathrm{alfa} /$ fisica/campo-eletrico-1.php $>$

onde r é o ponto do espaço onde está se observando o campo $\overrightarrow{\mathrm{E}}$.

Observe na expressão que o campo elétrico é diretamente proporcional a carga Q e inversamente proporcional ao quadrado de $\mathrm{r}$ (distância do ponto de observação). Os gráficos de E x Q e E x r (Fig.9) são mostrados a seguir: 

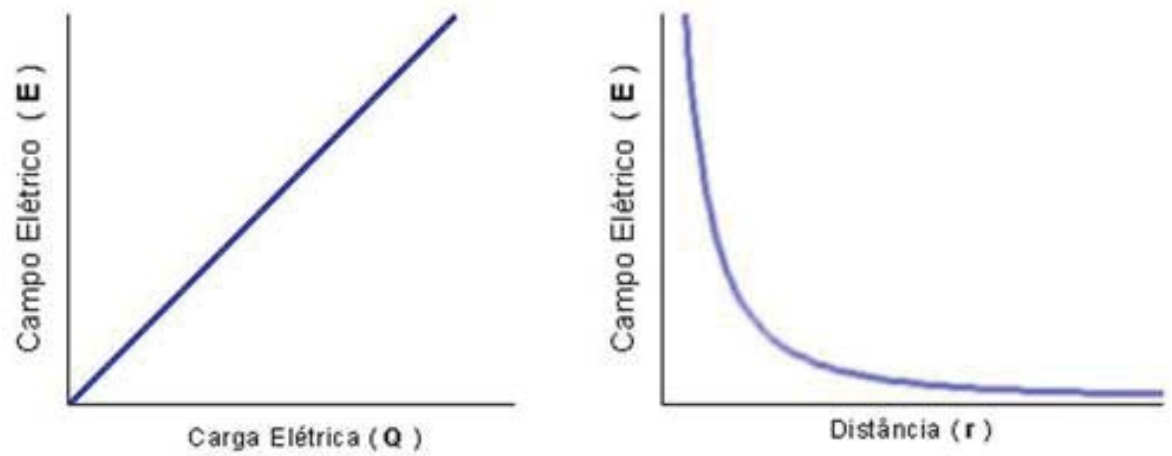

Campo Elétrico em função da carga e da distância

Disponível em: <http://www.portalsaofrancisco.com.br/alfa/fisica/imagens/campoeletrico-007-g.jpg >

Lembramos que, o campo elétrico depende da intensidade de carga, assim como, da forma em que elas estão distribuídas.

Como cada pedaço pequeno do corpo pode ser considerado como uma carga pontual pode-se dai calcular o campo resultante somando vetorialmente as contribuições devido a cada uma destas partes infinitesimais.

Esta soma de um grande número (quase infinito) de parcelas infinitesimais é determinada usando o cálculo integral.

De forma semelhante ao caso da potencial elétrico podemos construir equações para o Campo Elétrico para diferentes distribuições de cargas, como mostraremos a seguir. Vimos também que o campo elétrico produzido por cargas elétricas pode ser escrito em termos da força elétrica pela lei de Coulomb;

$$
\overrightarrow{\mathrm{E}}=\frac{\overrightarrow{\mathrm{F}}}{\mathrm{q}_{0}}
$$

Disponível em: < http://www.portalsaofrancisco.com.br/alfa/ fisica/campo-eletrico-1.php $>$

$$
\overrightarrow{\mathrm{E}}=\mathrm{k} \frac{\mathrm{q}}{\mathrm{r}^{2}} \overrightarrow{\mathrm{r}}
$$

Disponível em: < http://www.portalsaofrancisco.com.br/alfa/fisica/campo-eletrico-1.php $>$ 


\section{TEXTO RETIRADO DO PROJETO LADIF}

$\mathrm{Na}$ nossa infância, apenas os mágicos e os fantasmas conseguiam mover objetos sem tocar. Por essa razão é difícil aceitar que isso aconteça na natureza. Um físico chamado Faraday certamente não gostava da ideia de ação a distância e apresentou outro modelo para explicar essas forças, porque não se deixou enganar pelos seus sentidos. Imaginou que as cargas elétricas e os ímãs deviam criar, na sua vizinhança, uma espécie de 'fantasma', invisível, inodoro e imperceptível ao seu tato. Os puxões e empurrões sobre objetos, outras cargas elétricas e outros ímãs seriam da responsabilidade desses 'fantasmas'. Para isso, o 'fantasma' deve ocupar todo o espaço: só assim ele poderia estar sempre em contato com outras cargas e outros ímãs.

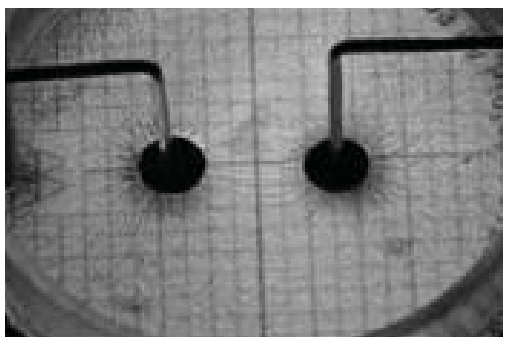

Figura 12A - Terminais condutores com cargas q e $-\mathrm{q}$ imersos em óleo coberto com fubá. (ALMEIDA. P. 22. Disponível em: < http:// omnis.if.ufrj.br/ ladif/tea/fenel/eletrocapitulo2.pdf $>$ )

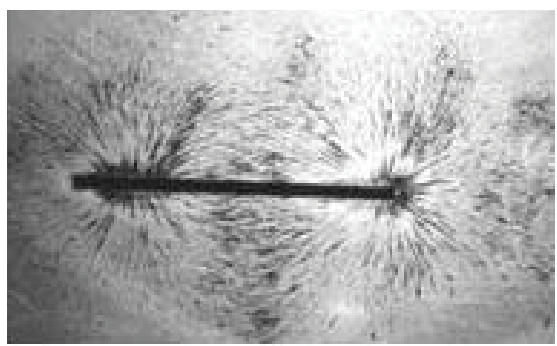

Figura 12B - Limalha de ferro espalhada sobre uma paca de acrílico colocada sobre um imã

(ALMEIDA. P. 22. Disponível em: < http://omnis.if.ufrj. br/ ladif/tea/fenel/eletro-capitulo2.pdf $>$ )

Para visualizar o 'fantasma elétrico', imergimos as cargas elétricas em óleo e jogamos fubá sobre ele (Figuras 12A); para visualizar o 'fantasma magnético', é só jogar limalha de ferro nas vizinhança dos ímãs (veja a Figura 12B). Faraday chamou as linhas observadas de linhas de força elétrica e linhas de força magnética. Para ele, essas linhas tinham as propriedades de elásticos reais.

O fubá se organiza sobre as linhas de força quando é colocado sobre um óleo viscoso. A força viscosa que o óleo exerce sobre o fubá evita 
que ele seja completamente arrastado na direção das cargas elétricas. $\mathrm{Na}$ Figura 13A temos uma camada de óleo coberta por fubá e dois terminais metálicos lineares paralelos e descarregados. O fubá está igualmente distribuído na superfície do óleo. Na Figura 13B, temos uma camada de fubá e dois terminais metálicos lineares carregados. O terminal da direita está com carga elétrica positiva e o da esquerda, com carga elétrica negativa. As distribuições do fubá nas duas imagens são diferentes. Na Figura 13B existem linhas paralelas entre os terminais, linhas curvas nas extremidades dos terminais e nenhuma linha atrás dos terminais.

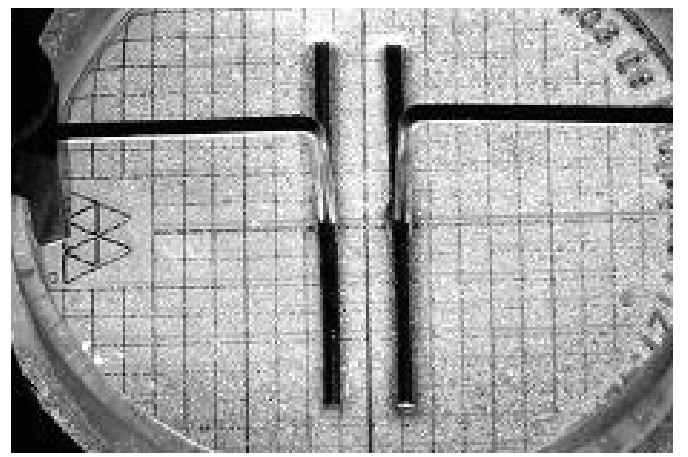

Figura 13A - Terminais lineares descarregados imersos em óleo coberto com fubá

(ALMEIDA. P. 23. Disponível em: <http://omnis.

if.ufrj.br/ ladif/tea/fenel/eletro-capitulo2.pdf $>$ )

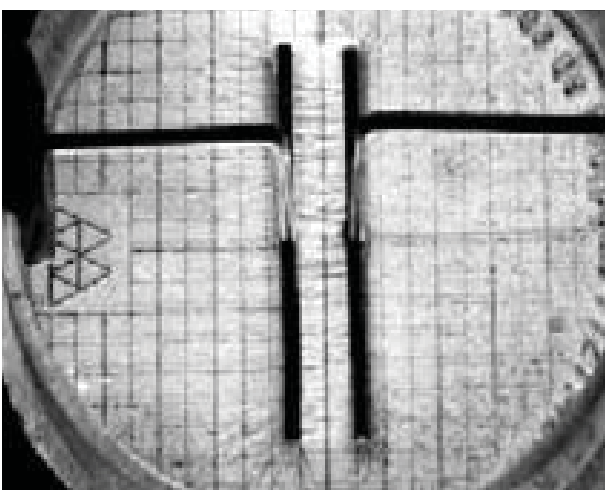

Figura 13B - Terminais lineares com cargas q e $-\mathrm{q}$ imersos em óleo coberto com fubá

(ALMEIDA. P. 23. Disponível em: <http://omnis.if.ufrj. br/ ladif/tea/fenel/eletro-capitulo2.pdf $>$ )Inserir Figura 13A

Para Faraday, as linhas eram elásticos que atuavam nas cargas elétricas. Os terminais positivo e negativo se atraem porque são puxados pelos elásticos. Os terminais não se aproximam porque estão presos na cuba que contém o óleo. A interação entre as linhas e os terminais é de contato. Hoje em dia não se fala mais sobre elásticos e sim em campo elétrico. O campo elétrico é um conjunto de vetores responsáveis pelas forças elétricas. Eles são criados pelas cargas elétricas em todo o espaço. São os vetores do campo elétrico que estão em contato com os terminais que exercem forças sobre eles. 
Os vetores do campo elétrico são sempre tangentes às linhas de força, e são mais intensos onde existe uma concentração maior de linhas de força. Os módulos desses vetores são proporcionais ao número de linhas de força por unidade de área perpendicular a elas.

$\mathrm{Na}$ Figura 13B, na região central, entre os terminais, a concentração de linhas de força é aproximadamente constante e as linhas são perpendiculares aos terminais. Isso significa que nessa região os vetores do campo elétrico são praticamente constantes e perpendiculares aos terminais. As linhas curvas nas extremidades dos terminais indicam que os vetores do campo elétrico são variáveis. A inexistência de linhas atrás dos terminais está associada a vetores do campo elétrico muito fracos ou nulos.

Essas ideias foram estendidas à força gravitacional. Dizemos que as massas criam um campo gravitacional; são os vetores do campo gravitacional que, em contato com outras massas, exercem forças sobre elas.

É difícil aceitar as ideias do modelo de ação a distância e do modelo do campo porque, no primeiro modelo uma carga é capaz de exercer força sobre a outra sem tocá-la, e no segundo modelo que quem exerce a força sobre a carga é o campo elétrico que também não é percebido pelos nossos olhos. A opção por um modelo em Física está na simplicidade dos seus conceitos e na facilidade com que se explicam os fenômenos associados a eles. A dificuldade de explicar a interação entre cargas elétricas em repouso é equivalente nos dois modelos. A diferença entre eles aparece quando se deseja estudar sistemas que têm cargas elétricas ou/e ímãs em movimento. Foi graças às ideias de Faraday que se descobriram os princípios que permitiram construir o walkman, a televisão etc. Hoje em dia, a maioria dos físicos aceita a ideia de campo elétrico sem muita dificuldade. Uma teoria que descreve a interação elétrica com o conceitode campo elétrico não pode ser incompatível com os resultados experimentais. Portanto, é preciso definir o campo elétrico de tal forma que os resultados experimentais sejam respeitados. Quer dizer: a força que os vetores do campo elétrico exercem sobre as cargas elétricas tem que respeitar a Lei de Coulomb e o princípio da superposição.

\section{APPLETS DE ENSINO}

Como nas outras duas instrumentações, sugerimos alguns sites de ensino com material de multimídia para você analisar. Segue abaixo um guia de applets com dicas.

1. Explique o princípio de funcionamento do applet do curso da Universidade do Colorado. Acesse através do link: < https:/ / sites.google.com/site/ professorpifer/Home/fisica-mix/eletromagnetismo $>$.

Você pode colocar quantas cargas você quiser na tela e uma partícula como sensor de campo. Junto com o sensor de campo vai um vetor campo elétrico. Arraste-o. Não se esqueça de ativar o campo "Show E-field". 


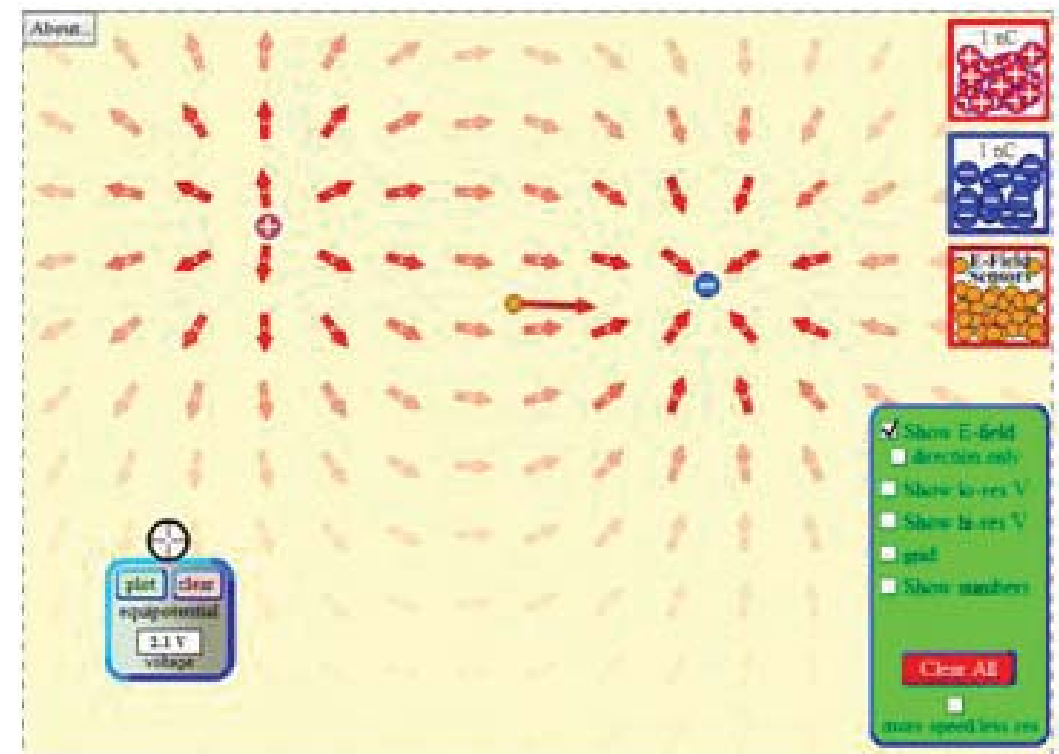

Disponível em <https://sites.google.com/site/professorpifer/Home/fisicamix/eletromagnetismo $>$

2. Explore esse excelente applet do Professor Falstad, acessando o link: $<$ http://www.falstad.com/emstatic/>.

Note que você pode arrastar as cargas e escolher vários tipos de arranjos de carga.

Q1. Que figura você espera obter se selecionar: quadrupole charge.

Q2 . Que figura você espera obter se selecionar: charge + plane.

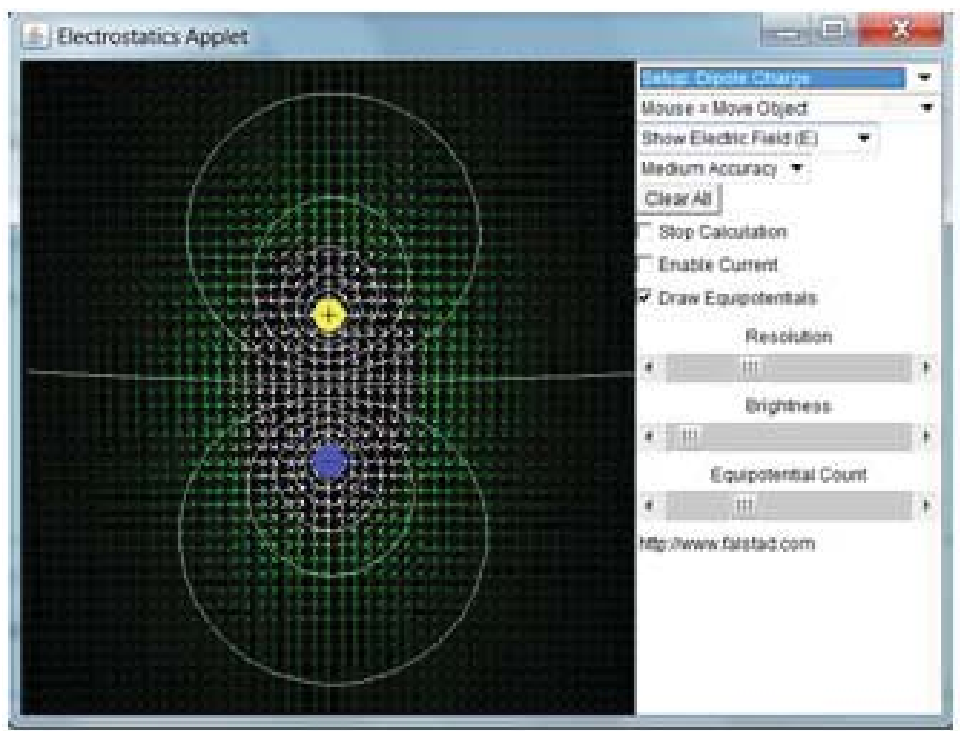

Disponível em < http://www.falstad.com/emstatic/> 


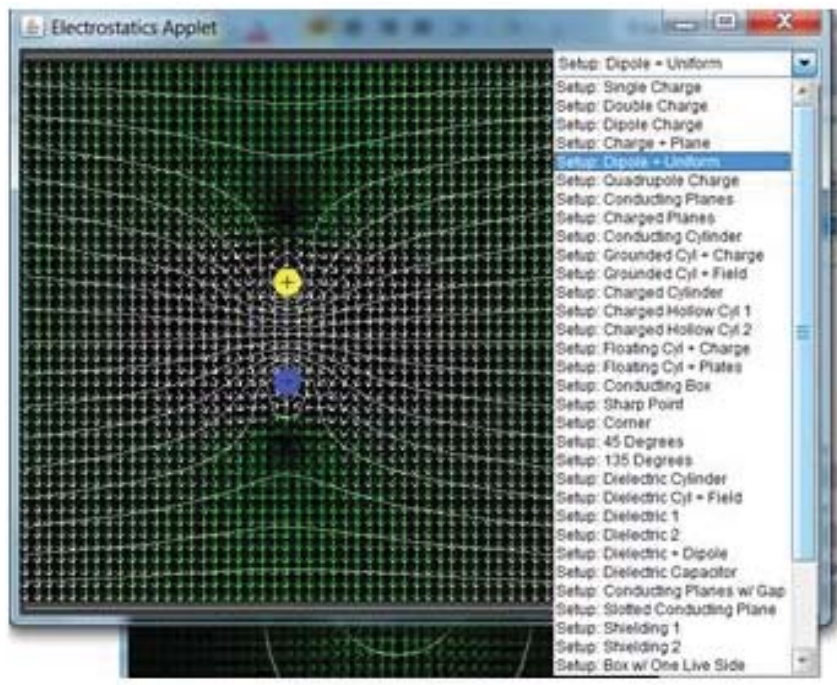

Disponível em <http://www.falstad.com/emstatic/>

3. Explore esse excelente applet do Professor Falstad, acessando o link: $<$ http://www.falstad.com/emstatic/>

Note que você pode arrastar a caixa para visualizar o campo de várias posições.

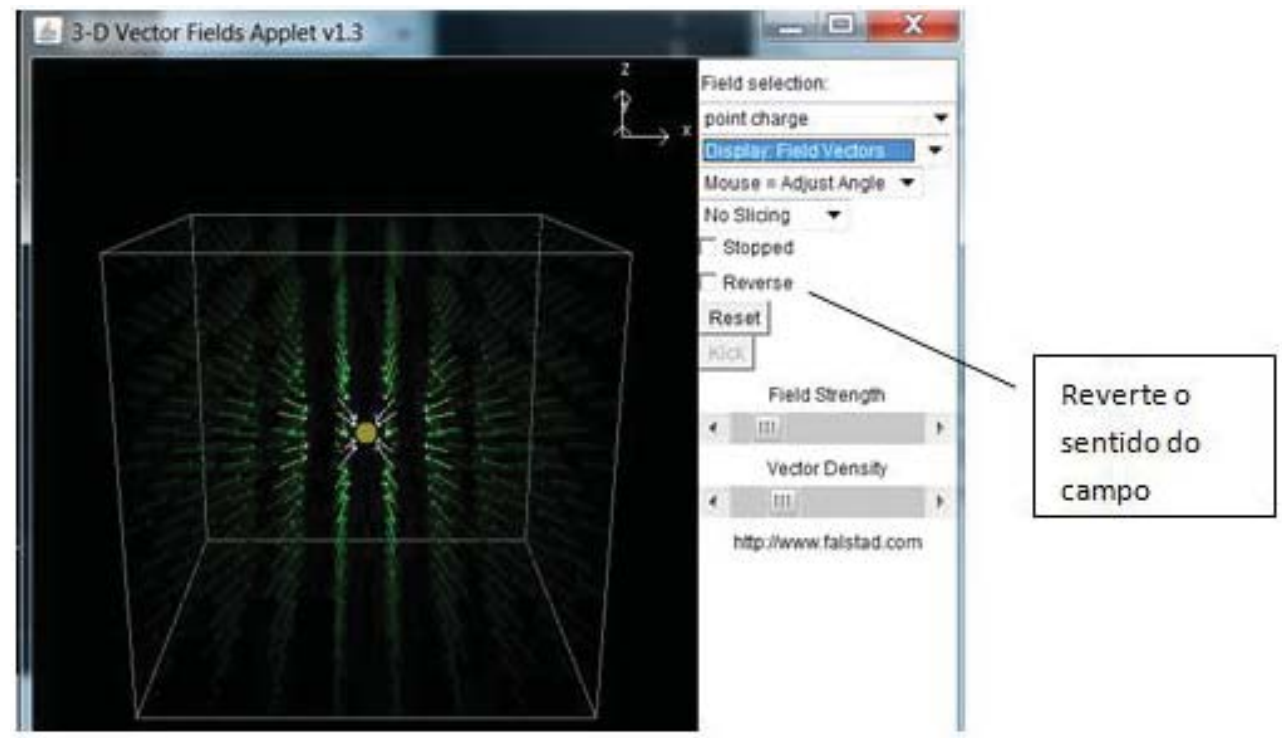

Disponível em <http://www.falstad.com/emstatic/>

Q1. Que figura você espera obter se selecionar: quadrupole charge.

Q2 . Que figura você espera obter se selecionar: charge + plane.

4. Explore esse excelente applet do Professor Falstad, acessando o link: $<$ http://www.falstad.com/emstatic/>.

Note que você pode arrastar a caixa para visualizar o campo de várias posições. 


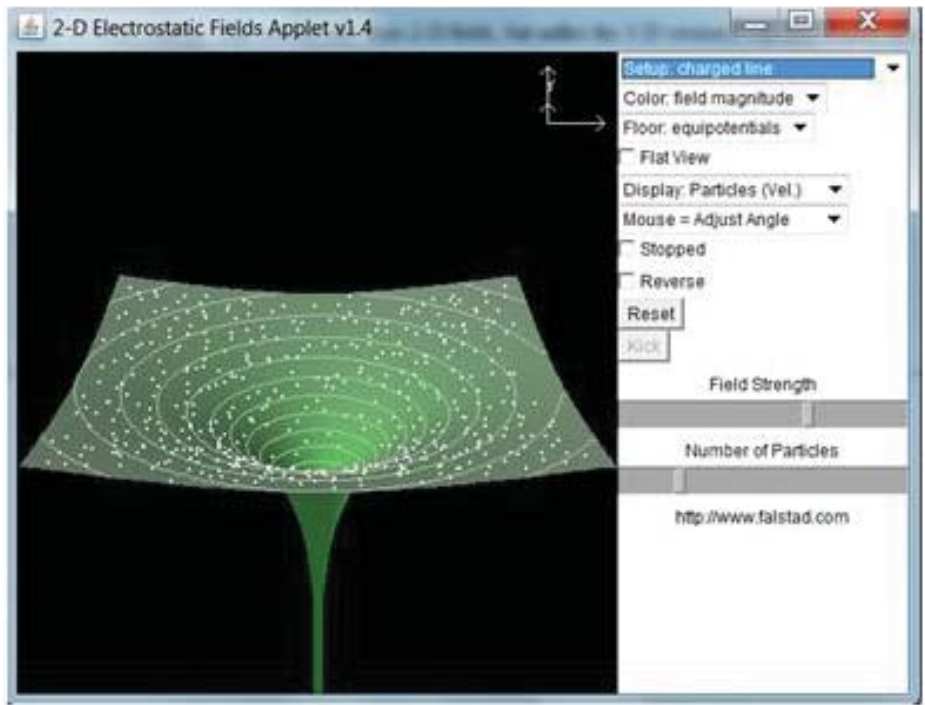

Disponível em <http://www.falstad.com/emstatic/>

Q1. Que figura você espera obter se selecionar: quadrupole.

Q2 . Que figura você espera obter se selecionar: dipole.

5. Explore esse excelente applet do site lecture on line. Neste applet você pode mover as duas cargas, arrastando-os com o mouse. Você também pode alterar suas magnitudes (e sinais), clicando sobre as caixas. Link: http:// lectureonline.cl.msu.edu/ mmp/kap18/RR447app.htm.

\section{Field Lines}

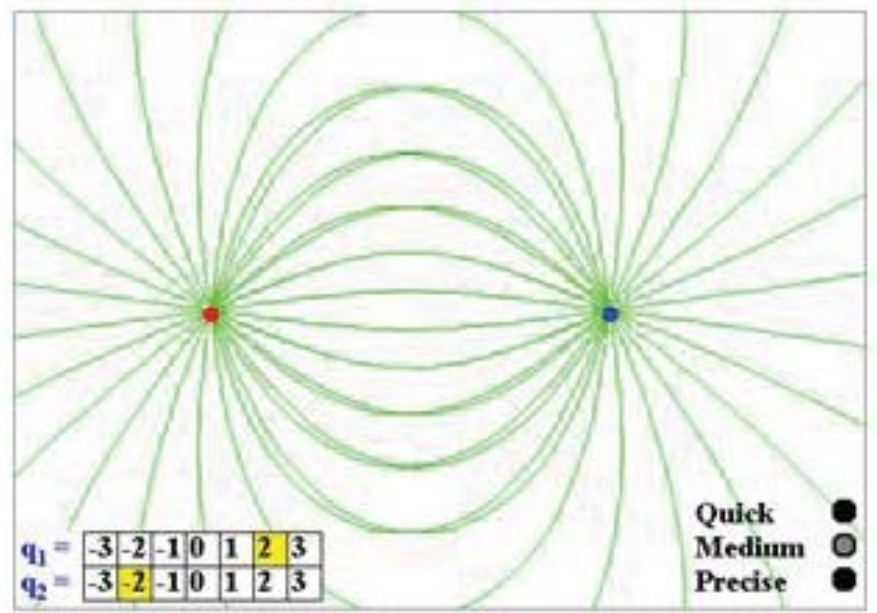

Disponível em http://lectureonline.cl.msu.edu/ mmp/kap18/ RR447app.htm.

\section{VIDEOS AULAS}

1. Acesse o video que explica o conceito de campo elétrico, através do link: $<$ http:/ / www.youtube.com/watch?gl=BR\&feature $=$ related $\& h l=p t \& v=6$ UKxj7cba68>. 
2. Acesse o vídeo que define campo a partir do conceito de força elétrica, através do link: <http://www.youtube.com/watch?v=hInQeiyv5 o\&feature $=$ related $>$.

3. Acesse o vídeo sobre linha de campo de um dipolo, através do link: $<$ http:/ $/$ www.youtube.com/watch?v $=U v$ fa7sN_SCY\&feature= related $>$.

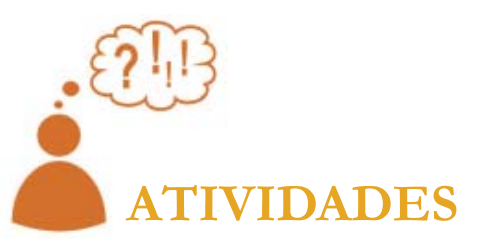

1. Qual dos dois textos, Portal São Francisco ou do projeto Educar, você usaria como referência para ministrar uma aula sobre campo elétrico? Por quê?

2. Você concorda com as resoluções do PNLEM que "obrigam" (sinalizam) aos novos livros didáticos, dentre outras coisas, a mostrar que a ciência é um produto histórico e social e que não é um produto acabado (pronto) devido ao trabalho de sociedades privilegiadas? Comente?

3. Do seu ponto de vista, qual é o conceito mais intuitivo para os estudantes do $2^{\circ}$ grau: Força ou campo?

4. Como você ilustraria o conceito de campo elétrico para seus (futuros) alunos?

5. O que você acha do texto tirado do LADIF? Você acha factível a experiência com fubá?

6. Devido ao alto grau de abstração muitos físicos e grupos de ensino estão fazendo animações gráficas e applets que demonstram virtualmente as linhas de campo. Colocamos alguns links acima para você poder explorar alguns deles. Faça um comentário a respeito deles.

7. Com o advento da televisão alguns grupos de ensino e ou instituições estão fazendo vídeos aulas sobre temas interessantes e complexos de física. Colocamos alguns links acima para você explorá-los. Faça um comentário a respeito deles.

8. Colocamos acima alguns exemplos e/ou links de experimentos de baixo custo para você analisar a possibilidade de usá-los em sala de aula. Comente se você os usaria ou não como recurso didático em sala de aula? Comente. 


\section{CONCLUSÃO}

$\mathrm{Na}$ aula anterior mostramos um texto didático que apresenta a Física como sendo um conjunto de leis e que deixa a impressão ao estudante do ensino médio de que a Física é uma matéria muito matematizada, abstrata e de difícil entendimento. Através da análise da biografia de Michael Faraday o futuro professor deve ter ficado se perguntando se ela deve sempre ser apresentada assim.

O estudante deve ter ficado ciente de que a dificuldade de se ter a disposição experimentos de baixo custo sobre campo elétrico, fez com que muitos físicos e grupos de ensino desenvolvem-se vários e excelentes applets e simuladores de campo elétrico, e que estes podem ser usados como ótimos recursos de apoio didático.

Com a análise dos experimentos de baixo custo e dos recursos de multimídias que colocamos no final da aula o futuro professor deve ter ficado com algumas boas idéias de como este pode enriquecer uma aula sobre o tema Lei de Coulomb.

\section{COMENTÁRIOS SOBRE AS ATIVIDADES}

O aluno deve começar a se ver como futuro professor. Isto é, ele deve começar a ver a física não como matéria ser aprendida e sim como a ser ensinada. Aqui ele deve começar a enxergar as diversas possibilidades que o mundo moderno lhe oferece como educador.

Como o conceito de Campo é muito abstrato, focamos essa aula nas atividades experimentais, applets e nas vídeos aulas.

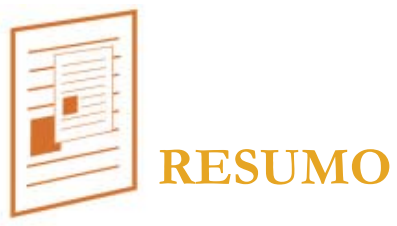

Nesta aula apresentamos a história de um cientista, Faraday, que apesar de seus parcos (muito pouco) conhecimentos e domínio de matemática se tornou um dos mais importantes e celebres cientistas modernos. Através dessa biografia discutimos se a matemática possui tanta importância assim para a Física do ensino médio. Discutimos o problema de se ensinar o conceito de campo em vez de força.

Em seguida apresentamos vários experimentos de baixo custo para que o aluno explore as possibilidades que estes oferecem para se ministrar um curso usando mais ferramentas fenomenológicas e menos formais. Devido a grande dificuldade que os estudantes tem de visualizar o campo resultante de várias cargas, colocamos vários e excelentes applets de ensino 
como recurso de simulação de fenômeno físico para ser explorado pelo futuro professor.

Como há ótimos vídeos de ensino colocamos alguns deles como referência, e deixamos sua exploração como atividade para os estudantes. Neste curso de instrumentação I não usamos os vídeos didáticos como ferramenta didática principal.

\section{RESPOSTA DAS ATIVIDADES}

1 - Resposta pessoal

2 - Sim, pois a educação deve mostrar que o conhecimento e sua produção depende de condições sociais e da capacidade humana 3 - Força

4 - Espero que com experimentos applets e vídeos.

5 - É possível de ser realizado, mas dá muito trabalho.

6 - São muito bons. Resposta pessoal

7 - São muito bons. Resposta pessoal

8 - São muito bons. Resposta pessoal

\section{REFERÊNCIAS}

ALMEIDA, M. A. Projeto Ladif. Disponível em <http://omnis. if.ufrj.br/ ladif/tea/fenel/eletro-capitulo2.pdf $>$ p. 22 e 23. Acesso em 15/10/2011.

APPLETS-ELETROMAGNETISMO. Universidade do Colorado. Disponível em: < https://sites.google.com/site/professorpifer/Home/fisicamix/eletromagnetismo>. Acesso em 15/10/2011.

EXPLICATORIUM. Disponível em: <http://www.explicatorium.com/ Michael-Faraday.php $>$. Acesso em 15/10/2011.

PORTAL SÃO FRANCISCO. Disponível em: < http://www.portalsaofrancisco.com.br/alfa/fisica/campo-eletrico-1.php>. Acesso em 15/10/2011. PROGRAMA EDUCAR. CDCC- São Carlos - USP. Disponível em < www. educar.sc.usp.br>. Acesso em 15/10/2011.

YOUTUBE. Campo Elétrico. Disponível em: <http://www.youtube. $\mathrm{com} /$ watch $? \mathrm{gl}=\mathrm{BR} \&$ feature $=$ related $\& \mathrm{hl}=\mathrm{pt} \& \mathrm{v}=6 \mathrm{UKxj} 7 \mathrm{cba} 68>$. Acesso em 15/10/2011.

- Campo Elétrico. Disponível em: <http://www.youtube.com/ watch?v $=$ hInQeiyv-5o\&feature $=$ related $>$. Acesso em 15/10/2011.

Lineas de campo. Disponível em: <http://www.youtube.com/ watch?v=Uvfa7sN_SCY\&feature $=$ related $>$. Acesso em 15/10/2011. WIKIPÉDIA, A enciclopédia livre. Disponível em: < http://pt.wikipedia. org/wiki/Michael_Faraday>. Acesso em 15/10/2011. 



\section{Aula 4}

\section{POTENCIAL ELÉTRICO}

META

Fazer com que o estudante comece a pensar no ensino de ciências como algo "orgânico"

que está em profunda transformação;

Fazer com que os alunos percebam, através de um texto básico complementado com atividades lúdicas, applets de ensino, vídeos, e com materiais de baixo custo, que o conceito de potencial elétrico pode ser apreendido de forma simples e divertida;

Analisar o problema da transposição didática;

Fazer com que o futuro professor perceba que ele pode começar um curso ensinando a

Física das coisas.

OBJETIVOS

Ao final desta aula, o aluno deverá: estar cientes das novas possibilidades, dos desafios que envolvem o ensino de ciências em geral e das dificuldades de se ministrar um curso de eletricidade e magnetismo; Discutir a possibilidade de se ensinar o conceito de potencial elétrico de uma forma mais intuitiva, a partir da Física dos objetos do cotidiano.

Ter compreendido que as ciências naturais estão baseadas na experimentação e que esta é feita de ensaios, experiências e medidas e que estas levam à compreensão e a matematização dos conceitos físicos (naturais em geral); Trazer a discussão sobre o papel que a Matemática tem na formação e no ensino de Física;

PRÉ-REQUISITOS Os alunos deverão ter cursado as disciplinas Psicologia da Educação, Física A, Física B e Instrumentação I. 


\section{INTRODUÇÃO}

Vamos a seguir apresentar três textos sobre a definição de potencial elétrico.

O primeiro texto foi extraído do curso de EAD da Universidade de Brasília do prof. Kleber Mundim, em que o conceito de potencial elétrico é apresentado em nível da Física básica do curso universitário. O professor Mundim começa revisando o teorema da conservação da energia e em seguida introduz o conceito de potencial, definindo o trabalho para se transportar uma carga elétrica de um ponto a outro em certa região do espaço. Como, alias, é feito na maioria dos livros textos.

Se pegarmos o capítulo da maioria dos livros textos do ensino médio, veremos que eles seguem a mesma estrutura acima. No livro do Ramalho, $\sigma^{a}$ edição, o capítulo que trata do assunto é denominado "Trabalho e Potencial Elétrico". Nele inicia-se definindo o trabalho que é realizado sobre uma carga elétrica em um campo elétrico uniforme e na seção seguinte, em um campo qualquer. A partir de então, apresenta a definição do conceito de potencial elétrico.

No segundo texto selecionado, observamos a mesma transposição didática do ensino superior para o ensino médio.

Como terceiro texto, tomamos emprestado a aula do projeto GREF, onde se introduz o conceito de potencial elétrico, através da ddp das tomadas das residências e dos valores nominais dos eletrodomésticos.

$1^{\circ}$ texto - disponível em: <http://vsites.unb.br/iq/kleber/EaD/Eletromagnetismo/PotencialEletrico/PotencialEletrico.html>

\section{"POTENCIAL E ENERGIA ELÉTRICA}

O conceito de energia, em mecânica, mostrou-se ser de suma importância no estudo de problemas nesta área da Física, principalmente naqueles casos onde os cálculos envolvendo as leis de Newton têm solução complexa.

No caso da eletrostática o conceito de energia é também especialmente valioso. Ele não somente estende a lei de conservação, mas também permite nos ver o fenômeno eletrostático de outro ponto de vista, fornecendo assim, uma ferramenta poderosa na solução de problemas. Em muitos problemas eletrostáticos, a solução fica mais simples quando usamos relações envolvendo a energia, do que aplicando as leis envolvendo a força e o campo elétrico.

Para aplicar a conservação da energia, necessitamos definir o conceito de energia potencial elétrica, como tem sido feito para o caso de outras energias potenciais, por exemplo, a gravitacional. Isto pode ser feito analisando o trabalho realizado para mover uma carga de prova $\mathrm{q}_{0}$ na presença de um campo elétrico externo. 
Ao abandonar-se, em repouso, uma carga elétrica q, puntiforme, numa região onde existe um campo elétrico isolado, ela fica sujeita a uma força elétrica resultante $\mathrm{F}$ e desloca-se espontaneamente na direção e sentido desta força. Nestas condições, o trabalho realizado por F é sempre positivo.

Com relação à forma da trajetória descrita pela carga $\mathrm{q}_{\mathrm{o}}$ nada se pode prever, pois a direção da força $F$ é variável (tangente a uma linha de força ou linha de campo em cada ponto). Não se deve afirmar que a trajetória da partícula coincide com uma linha de força, a menos que esta seja retilínea. O movimento da partícula se dará sempre no sentido da força $\mathrm{F}$.

Durante o movimento espontâneo da partícula q verificam-se algumas propriedades que se seguem:

Em todo movimento espontâneo de carga elétrica, na presença de campo elétrico, a energia potencial elétrica da mesma diminui.

Cargas elétricas positivas, abandonadas em repouso na presença de campo elétrico e sujeitas apenas à ação da força elétrica, deslocam espontaneamente para ponto de menor potencial elétrico. Se a carga for negativa o deslocamento se dará no sentido de maior potencial elétrico.

O trabalho ( $\Delta \mathrm{W}$ ) realizado, sobre uma partícula de prova $\mathrm{q}_{\mathrm{o}}$, para provocar um pequeno deslocamento $\Delta \mathrm{r}$ é definido pelo produto escalar entre o vetor força $\mathrm{F}$ e o vetor deslocamento, como a seguir:

$$
\Delta \mathrm{W}=-\overrightarrow{\mathrm{F}} \cdot \Delta \overrightarrow{\mathrm{r}}=-\left(\mathrm{F}_{\mathrm{x}} \Delta \mathrm{x}+\mathrm{F}_{\mathrm{y}} \Delta \mathrm{y}+\mathrm{F}_{\mathrm{z}} \Delta \mathrm{z}\right)
$$

Disponível em: <http://vsites.unb.br/iq/kleber/EaD/Eletromagnetismo/PotencialEletrico/PotencialEletrico.html>

Neste caso o trabalho é igual à diferença de energia gasta para mover a carga de prova $\mathrm{q}_{\mathrm{o}}$ de um certo ponto a outro. Supomos agora, que a partícula $\mathrm{q}_{\mathrm{o}}$ é forçada a deslocar de um ponto A a um outro ponto $\mathrm{B}$, na presença de um campo elétrico, não necessariamente uniforme. Veja Fig.1 


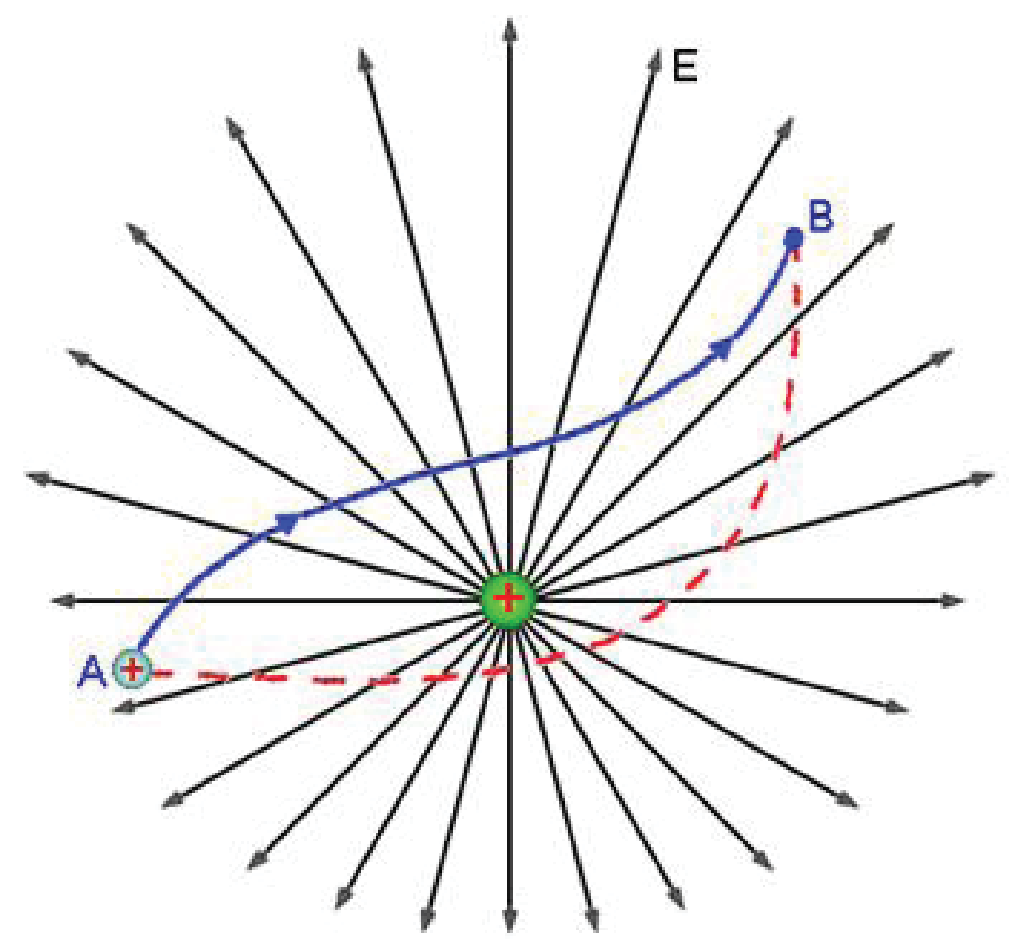

Figura 1 - Movimento de uma partícula na presença de campo elétrico Disponível em: <http://vsites.unb.br/iq/kleber/EaD/Eletromagnetismo/ PotencialEletrico/PotencialEletrico.html>

Pela a lei de Coulomb podemos escrever a força sobre a partícula em termos do campo elétrico, isto é,

$$
\overrightarrow{\mathrm{F}}=\mathrm{q}_{0} \overrightarrow{\mathrm{E}}
$$

Disponível em: <http://vsites.unb.br/iq/kleber/EaD/Eletromagnetismo/PotencialEletrico/PotencialEletrico.html>

podemos ainda escrever esta relação explicitando as componentes vetoriais da força em termos do campo elétrico, então,

$$
\mathrm{F}_{\mathrm{x}}=\mathrm{q}_{\circ} \mathrm{E}_{\mathrm{x}}, \quad \mathrm{F}_{\mathrm{y}}=\mathrm{q}_{\circ} \mathrm{E}_{\mathrm{y}} \quad, \quad \mathrm{F}_{\mathrm{z}}=\mathrm{q}_{\circ} \mathrm{E}_{\mathrm{z}}
$$

Disponível em: <http://vsites.unb.br/iq/kleber/EaD/Eletromagnetismo/ PotencialEletrico/PotencialEletrico.html>

Substituindo a equação (2) em (1), obtemos o trabalho realizado em função do campo elétrico $\overrightarrow{\mathrm{E}}$, isto é;

$$
\mathrm{dW}_{\mathrm{BA}}=-\mathrm{q}_{0} \overrightarrow{\mathrm{E}} \cdot \mathrm{d} \overrightarrow{\mathrm{r}} \quad \text { ou } \quad \frac{\mathrm{dW}_{\mathrm{BA}}}{\mathrm{q}_{0}}=-\overrightarrow{\mathrm{E}} \cdot \mathrm{d} \overrightarrow{\mathrm{r}}
$$

Disponível em: < http://vsites.unb.br/iq/kleber/EaD/Eletromagnetismo/PotencialEletrico/ PotencialEletrico.html> 


$$
\Delta \mathrm{W}_{\mathrm{BA}}=-\mathrm{q}_{\mathrm{o}} \overrightarrow{\mathrm{E}} \cdot \Delta \overrightarrow{\mathrm{r}}=-\mathrm{q}_{\mathrm{o}}\left(\mathrm{E}_{\mathrm{x}} \Delta \mathrm{x}+\mathrm{E}_{\mathrm{y}} \Delta \mathrm{y}+\mathrm{E}_{\mathrm{z}} \Delta \mathrm{z}\right)
$$

Disponível em: <http://vsites.unb.br/iq/kleber/EaD/Eletromagnetismo/ PotencialEletrico/PotencialEletrico.html>

No capítulo anterior, definimos o conceito de campo elétrico como sendo igual à força por unidade de carga, no sentido de torná-lo uma grandeza independente da carga de prova $\mathrm{q}_{\mathrm{o}}$, ou melhor falando, ser dependente apenas da distribuição de cargas elétricas que está criando o campo E. De forma semelhante, vamos introduzir o conceito de potencial elétrico como sendo uma grandeza independente de qo, como mostra a segunda equação em (5). Isto é;

$$
\mathrm{dV}_{\mathrm{BA}}=\frac{\mathrm{dW}_{\mathrm{BA}}}{\mathrm{q}_{0}}=-\overrightarrow{\mathrm{E}} \cdot \mathrm{d} \overrightarrow{\mathrm{r}}
$$

Disponível em: < http://vsites.unb.br/iq/kleber/EaD/Eletromagnetismo/PotencialEletrico/PotencialEletrico.html>

ou na forma diferencial

$$
\Delta \mathrm{V}_{\mathrm{x}}=-\mathrm{E}_{\mathrm{x}} \Delta \mathrm{x} \quad, \quad \Delta \mathrm{V}_{\mathrm{y}}=-\mathrm{E}_{\mathrm{y}} \Delta \mathrm{y} \quad, \quad \Delta \mathrm{V}_{\mathrm{z}}=-\mathrm{E}_{\mathrm{z}} \Delta \mathrm{z}
$$

Disponível em: <http://vsites.unb.br/iq/kleber/EaD/Eletromagnetismo/PotencialEletrico/ PotencialEletrico.html $>$

Onde $\Delta \mathrm{V}_{\mathrm{x}}=-\mathrm{E}_{\mathrm{x}} \Delta \mathrm{x}$ é diferença de potencial elétrico entre dois pontos, no eixo x, em uma região do espaço contendo um campo elétrico. Ë importante notar que as grandezas $\Delta \mathrm{V}_{\mathrm{x}}, \Delta \mathrm{V}_{\mathrm{y}}$ e $\Delta \mathrm{V}_{\mathrm{z}}$ não são componentes de um vetor, pois o potencial elétrico, de acordo com a definição dada na eq.(5) é uma grandeza escalar e não vetorial.

Integrando ambos lados da eq.(5), temos que:

$$
\mathrm{V}_{\mathrm{BA}}=\mathrm{V}_{\mathrm{B}}-\mathrm{V}_{\mathrm{A}}=\int_{A_{A}}^{\mathrm{B}} \mathrm{d} \mathrm{V}_{\mathrm{AB}}=-\int_{\mathrm{A}_{\mathrm{A}}}^{\mathrm{B}} \overrightarrow{\mathrm{E}} \cdot \mathrm{dr}
$$

Disponível em: <http://vsites.unb.br/iq/kleber/EaD/Eletromagnetismo/ PotencialEletrico/PotencialEletrico.html>

O potencial elétrico é definido crescente no sentido da lçinha de força ou linha de campo

Vimos que o campo elétrico foi introduzido aqui com o propósito de discutir a energia de uma carga elementar (carga muito pequena) ao deslocar- 
se de um ponto a outro no espaço contendo um campo elétrico. $\mathrm{O}$ caso mais simples deste tipo interação é o de uma carga elementar $\mathrm{q}_{1}$ se movendo na presença de uma outra carga $\mathrm{q}_{2}$. Esta questão foi indiretamente tratada quando falamos sobre a lei de Coulomb. Um outro ponto importante a destacar é que as interações eletrostáticas guardam um certa semelhança com as gravitacionais. A tabela abaixo mostra algumas das relações equivalentes.

\begin{tabular}{|c|c|c|c|c|}
\hline Interação & Campos & Forças & Energias & Potencial \\
\hline Graciitbserarare qu & $\mathrm{E}_{\mathrm{g}}=-\mathrm{G} \frac{\mathrm{m}_{1}}{\mathrm{r}^{2}}$ & $F_{g}=-G \frac{m_{1} m_{2}}{r^{2}}$ & $\mathrm{U}_{\mathrm{g}}=-\mathrm{G} \frac{\mathrm{m}_{1} \mathrm{~m}_{2}}{\mathrm{r}}$ & $\mathrm{V}_{\mathrm{g}}=-\mathrm{G} \frac{\mathrm{m}_{1}}{\mathrm{r}}$ \\
\hline Elétrica & $\mathrm{E}_{\mathrm{e}}=\mathrm{k} \frac{\mathrm{q}_{\mathrm{l}}}{\mathrm{r}^{2}}$ & $\mathrm{~F}_{\mathrm{e}}=\mathrm{k} \frac{\mathrm{q}_{1} \mathrm{q}_{2}}{\mathrm{r}^{2}}$ & $\mathrm{U}_{\mathrm{e}}=\mathrm{k} \frac{\mathrm{q}_{1} \mathrm{q}_{2}}{\mathrm{r}}$ & $\mathrm{V}_{\mathrm{e}}=\mathrm{k} \frac{\mathrm{q}_{\mathrm{l}}}{\mathrm{r}}$ \\
\hline
\end{tabular}

Disponível em: <http://vsites.unb.br/iq/kleber/EaD/Eletromagnetismo/PotencialEletrico/ PotencialEletrico.html>

sinal negativo como na gravitacional. Isto significa que se as cargas $\mathrm{q}_{1} \mathrm{e}$ $\mathrm{q}_{2}$ são ambas positivas ou negativas a interação entre elas será repulsiva, enquanto que se as cargas têm sinais opostos então a interação será atrativa. Isto não ocorre como caso gravitacional, onde as interações entre dois corpos massivos são sempre atrativas, por isto aparece o sinal negativo nas expressões.

De acordo com a definição de diferença de potencial elétrico dado na Eq. (5), $V_{\text {BA }}$ depende apenas do campo elétrico na região e conseqüentemente da distribuição de cargas. Devemos lembrar que, mesmo tendo introduzido o conceito de potencial, elétrico ou gravitacional, apenas as diferenças de energias potenciais podem ser medidas experimentalmente."

$2^{\circ}$ texto - disponível em <http://www.portalsaofrancisco.com.br/alfa/ potencial-eletrico/potencial-eletrico.php $>$

\section{"ENERGIA POTENCIAL ELÉTRICA}

Imagine dois chietns eletrizados rom raroas de mesmo sinal, ini-

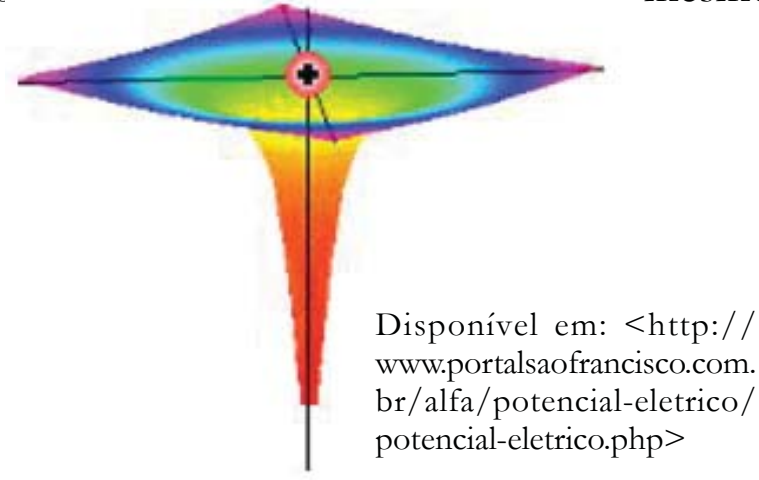


cialmente afastados. Para aproximá-los, é necessária a ação de uma força externa, capaz de vencer a repulsão elétrica entre eles. O trabalho realizado por esta força externa mede a energia transferida ao sistema, na forma de energia potencial de interação elétrica. Eliminada a força externa, os objetos afastam-se novamente, transformando a energia potencial de interação elétrica em energia cinética à medida que aumentam de velocidade. $\mathrm{O}$ aumento da energia cinética corresponde exatamente à diminuição da energia potencial de interação elétrica.

\section{POTENCIAL ELÉTRICO}

Com relação a um campo elétrico, interessa-nos a capacidade de realizar

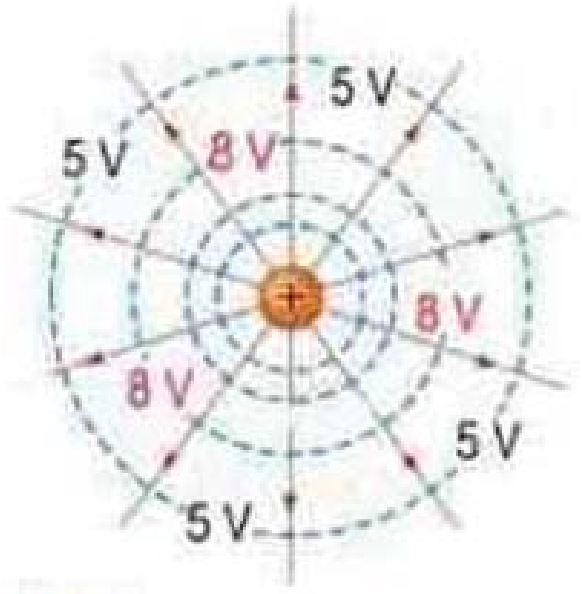

Disponível em: <http://www.portalsaofrancisco.com. $\mathrm{br} / \mathrm{alfa} /$ potencial-eletrico/potencial-eletrico.php>

trabalho, associada ao campo em si, independentemente do valor da carga q colocada num ponto desse campo. Para medir essa capacidade, utiliza-se a grandeza potencial elétrico.

Para obter o potencial elétrico de um ponto, coloca-se nele uma carga de prova q e mede-se a energia potencial adquirida por ela. Essa energia potencial é proporcional ao valor de q. Portanto, o quociente entre a energia potencial e a carga é constante. Esse quociente chama-se potencial elétrico do ponto.

Diferença de potencial 


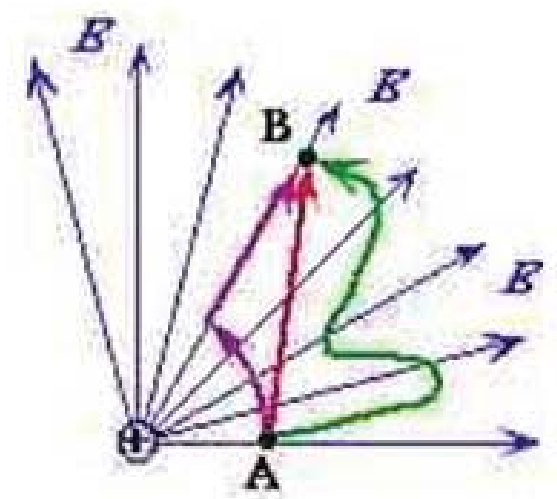

Disponível em: <http://www.portalsaofrancisco.com.br/alfa/potencial-eletrico/potencialeletrico.php>

A diferença de potencial entre dois pontos, em uma região sujeita a um campo elétrico, depende apenas da posição dos pontos. Assim, podemos atribuir a cada ponto um potencial elétrico, de tal maneira que a diferença de potencial entre eles corresponda exatamente à diferença entre seus potenciais, como o próprio nome indica.

Fisicamente, é a diferença de potencial que interessa, pois corresponde ao trabalho da força elétrica por unidade de carga.

Fonte: geocities.yahoo.com.br

\section{POTENCIAL ELÉTRICO}

Com relação a um campo elétrico interessa-nos a capacidade de realizar trabalho, associada ao campo em si, independentemente do valor da carga q colocada num ponto desse campo. Para medir essa capacidade, utiliza-se a grandeza potencial elétrico.

Para obter o potencial elétrico de um ponto, coloca-se nele uma carga de prova q e mede-se a energia potencial adquirida por ela. Essa energia potencial é proporcional ao valor de q. Portanto, o quociente entre a energia potencial e a carga é constante. Esse quociente chama-se potencial elétrico do ponto. Ele pode ser calculado pela expressão:

$$
V=\frac{E p}{q}
$$

onde $\mathrm{V}$ é o potencial elétrico, Ep a energia potencial e q a carga. A unidade no S.I. é J/C = V (volt). Portanto, quando se fala que o potencial elétrico de um ponto $\mathrm{L}$ é $\mathrm{VL}=10 \mathrm{~V}$, entende-se que este ponto consegue dotar de 10J de energia cada unidade de carga da 1C. Se a carga elétrica for 3C por exemplo, ela será dotada de uma energia de 30J, obedecendo 
à proporção. Vale lembrar que é preciso adotar um referncial para tal potencial elétrico. Ele é uma região que se encontra muito distante da carga, localizado no infinito.

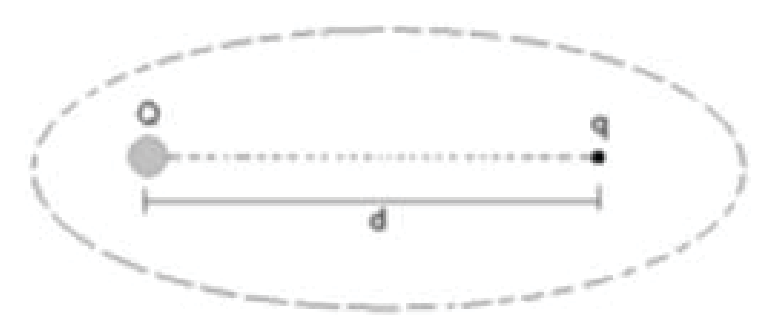

Disponível em: <http://www.portalsaofrancisco.com.br/ alfa/potencial-eletrico/potencial-eletrico.php $>$

Para calcular o potencial elétrico devido a uma carga puntiforme usase a fórmula:

$$
V=\frac{K \cdot Q}{d}
$$

No S.I. , d em metros , K é a constante dielétrica do meio, e Q a carga geradora.

Como o potencial é uma quantidade linear, o potencial gerado por várias cargas é a soma algébrica (usa-se o sinal) dos potenciais gerados por cada uma delas como se estivessem sozinhas:

$$
V L=\frac{K \cdot Q 1}{d 1}+\frac{K \cdot Q 2}{d 2}+\frac{K \cdot Q 3}{d 3}+\frac{K \cdot Q 4}{d 4}+\frac{K \cdot Q 5}{d 5}
$$

\section{SUPERFÍCIE EQUIPOTENCIAL}
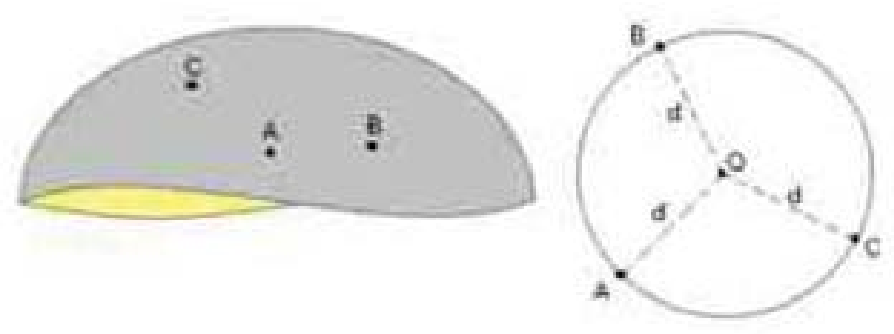

Disponível em: <http://www.portalsaofrancisco.com.br/alfa/ potencial-eletrico/potencial-eletrico.php> 
Superfície equipotencial quando uma carga puntiforme está isolada no espaço, ela gera um campo elétrico em sua volta. Qualquer ponto que estiver a uma mesma distância dessa carga possuirá o mesmo potencial elétrico. Portanto, aparece ai uma superfície equipotencial esférica. Podemos também encontrar superfícies equipotenciais no campo elétrico uniforme, onde as linhas de força são paralelas e eqüidistantes. Nesse caso, as superfícies equipotenciais localizam-se perpendicularmente às linhas de força (mesma distância do referencial). O potencial elétrico e distância são inversamente proporcionais, portanto o gráfico cartesiano $\mathrm{V}$ x d é uma assíntota.

Nota-se que, percorrendo uma linha de força no seu sentido, encontramos potenciais elétricos cada vez menores.

Vale ainda lembrar que o vetor campo elétrico é sempre perpendicular à superfície equipotencial, e conseqüentemente a linha de força que o tangencia também.$$
\mathrm{V}_{\mathrm{A}}=\mathrm{V}_{\mathrm{B}}=\mathrm{V}_{\mathrm{C}}=\mathrm{V}
$$$$
\text { POTENCIAL ELÉTRICO NO }
$$$$
\text { ELETROMAGNETISMO }
$$

No eletromagnetismo, potencial elétrico ou potencial eletrostático é um campo equivalente à energia potencial associada a um campo elétrico estático dividida pela carga elétrica de uma partícula-teste. A unidade de medida do SI para o potencial é o volt. Como um bom potencial, apenas diferenças de potencial elétrico possuem significado físico.

O potencial elétrico gerado por uma carga pontual q a uma distância r é, a menos de uma constante arbitrária, dado por:

$$
\phi_{\mathbf{E}}=\frac{q}{4 \pi \epsilon_{o} r}
$$

Disponível em: < http://vsites.unb.br/iq/kleber/EaD/Eletromagnetismo/PotencialEletrico/PotencialEletrico.html>

$3^{\circ}$ texto - Extraído do projeto GREF

\section{CUIDADO! É 110 OU 220?}

Com o levantamento das informações você deve ter percebido que elas podem aparecer de diferentes maneiras: existem números, letras, palavras e sinais. O importante é saber que muitas vezes, apesar de parecer de forma diferente, trata-se da mesma informação. Por exemplo: em alguns aparelhos vem escrito 110V; em outros vem escrito voltagem 110V; já em outros essa mesma informação aparece como tensão elétrica 110 volts. 
Aparelho

Aspirador de pó

Máquina de lavar roupatensão elétrica

Lâmpada
Informações do fabricante

110 volts

$110 \mathrm{~V}$

$110 \mathrm{~V}$

Veja que por simples comparação você pode saber que se trata de várias informações a respeito de uma mesma grandeza elétrica, que no caso é a tensão, o seu valor numérico, que é 110; a sua unidade de medida, que é volt e o símbolo de sua unidade, que é $\mathrm{V}$.

Se você observar o conjunto das informações que aparecem nos aparelhos, perceberá que existem outras grandezas elétricas, com outros calores, unidades de medida e símbolos diferentes.

Que outras grandezas elétricas você identificou nas informações dos fabricantes?

Para organizar as suas respostas você pode construir uma tabela como a ilustrada a seguir:

\begin{tabular}{|c|c|c|}
\hline nome da grandeza & o valor e sua unidade & o símbolo \\
\hline 1. Tensão elétrica & $110 / 220$ volts & $\mathrm{V}$ \\
\hline$\ldots$ & $\ldots$ & $\ldots$ \\
\hline$\ldots$ & $\ldots$ & $\ldots$ \\
\hline
\end{tabular}

Disponível em: < http://www.if.usp.br/gref/eletro/eletro1.pdf>)

Pelo levantamento das informações fornecidas pelos fabricantes de aparelhos elétricos e sua organização em tabelas de acordo com o que você acabou de fazer, foram identificadas algumas das principais grandezas elétricas. Comentaremos algo sobre elas a partir de agora.

\section{T'ENSÃO ELÉTRICA OU VOLTAGEM (U)}

Os aparelhos elétricos que são ligados na tomada ou à rede elétrica da residência trazem escrito os valores de $110 \mathrm{~V}$ ou 220V. Alguns aparelhos, como rádios, por exemplo, permitem que se ajuste o aparelho à tensão da rede elétrica da residência da cidade onde você mora e que pode ser $110 \mathrm{~V}$ ou $220 \mathrm{~V}$.

Outros aparelhos, como a geladeira, a máquina de lavar roupas, o ferro de passar, o liquidificador, não têm tal botão que permite o ajuste da tensão. Eles funcionam ou na tensão $110 \mathrm{~V}$ ou na $220 \mathrm{~V}$.

No caso de um desses aparelhos ser ligado numa tensão maior que a especificada pelo fabricante, ele queima quase imediatamente. Se ele for ligado a uma tensão menor que a especificada, ou o aparelho não funciona ou funciona precariamente. 


\section{POTÊNCIA (P)}

A potência é a grandeza elétrica que indica o consumo de energia do aparelho em cada unidade de tempo de seu funcionamento. Por exemplo, se uma lâmpada tem potência de 100 watts, significa que em cada segundo de funcionamento ela consome 100 joules de energia elétrica.

A maioria dos aparelhos elétricos tem apenas um valor de potência, mas existem alguns que trazem escrito mais de um valor, como por exemplo o chuveiro elétrico. Nesse caso, ele tem geralmente um valor para a posição verão e outro para o inverno. Na verão, em que a água é menos aquecida, o valor é menor. $\mathrm{Na}$ inverno, em que a água é mais aquecida, o valor da potência é maior e, conseqüentemente, o consumo de energia elétrica é também maior.

\section{CORRENTE ELÉTRICA (I)}

A maioria dos aparelhos elétricos não traz essa informação especificada. Ela, entretanto, está presente em todos os aparelhos elétricos quando eles estão em funcionamento.

A corrente elétrica é uma grandeza cujo valor depende da potência do aparelho e também da tensão em que ele é colocado para funcionar. Por exemplo, uma lâmpada de 100 watts feita para funcionar na tensão 110 volts, quando ligada requer maior corrente elétrica que uma de potência de 60 watts e de mesma tensão. É por essa razão que a lâmpada de 100 watts apresenta luminosidade maior que a de 60 watts.

Existem dois tipos de corrente elétrica: a corrente contínua, que é fornecida por pilhas e baterias, e a corrente alternada, que é aquela fornecida pelas usinas para casas, indústrias etc.

A corrente contínua tem valor que não se altera para um mesmo aparelho e tem como símbolo nos folhetos ou mesmo nas chapinhas dos aparelhos as letras "CC" ou "DC".

A corrente alternada tem um valor que varia dentro de um intervalo durante o funcionamento de um mesmo aparelho elétrico. Ela tem como símbolos as letras "CA" ou "AC" ou mesmo o sinal .

\section{FREQÜÊNCIA (F)}

Embora a freqüência seja uma grandeza presente na maioria dos aparelhos elétricos nos valores / e na unidade herts $(\mathrm{Hz})$, ela não é usada somente na eletricidade. Nesse caso, ela se refere a uma característica da corrente elétrica alternada obtida com as usinas geradoras de eletricidade. No Brasil, a freqüência da corrente alternada é de hertz, ou seja, ciclos por segundo. Há países, como Portugal e o Paraguai, em que a freqüência é de hert:. 
nomes de nomes

esclarecendo....

Antes que você pense que isso é tudo convém esclarecer que a voltagem, a potência, a corrente e a freqüência não são as únicas grandezas elétricas que existem. Mas elas são as que mais aparecem quando investigamos as informações fornecidas pelos fabricantes de aparelhos elétricos.

Saiba que elas constituem um conjunto mínimo de informações necessárias para a utilização adequada dos aparelhos. Por isso é sempre recomendável ler as instruções antes de ligar o aparelho que se acabou de comprar.

Você pode estar se perguntando por que as unidades de medida dessas grandezas têm nomes tão diferentes das que você estudou até hoje: volt, watt, ampère e hertz:

Essas palavras são sobrenomes de cientistas que tiveram uma contribuição importante no conhecimento dos fenômenos da eletricidade. Veja na tabela a seguir algumas informações sobre de onde elas surgiram:

\begin{tabular}{|l|l|l|l|l|}
\hline \multicolumn{1}{|c|}{ unidade } & \multicolumn{1}{c|}{ grandeza } & \multicolumn{1}{c|}{ homenageado } & Nacionalidade & Época em que viveu \\
\hline volt & Tensão elétrica & Alessandro Volta & Italiano & $1745-1827$ \\
\hline watt & Potência & James P. Watt & Inglês & $1818-1889$ \\
\hline ampère & Corrente elétrica & André M. Ampère & Francês & $1775-1836$ \\
\hline hertz & frequencia & Heinrich R. Hertz & alemão & $1857-1894$ \\
\hline
\end{tabular}

Disponível em: <http://www.if.usp.br/gref/eletro/eletro1.pdf>)

\section{Responda rápido:}

\section{No folheto de uma secadora encontram-se as \\ seguintes informaçōes:}

\section{enfitita secadora}

Modelo : 040/AT Plus

Voltagem: $120 / 220 \mathrm{~V}-60 \mathrm{~Hz}$

Potência : (M) $90 \mathrm{~W}$

பாட1200W

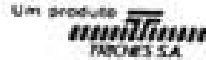

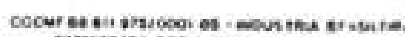

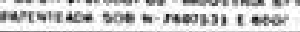

a) quais as grandezas que aparecem?

b) quals seus valores e unidades?

(GREF. p. 14, 15 e 16. Disponível em: <http://

www.if.usp.br/gref/eletro/eletro1.pdf $>$ ) 


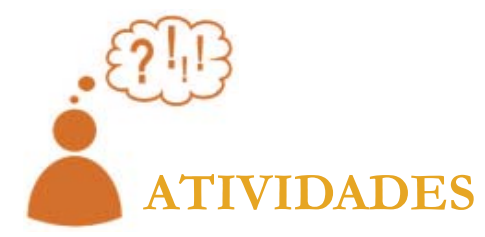

1. Os livros textos são realmente uma simples simplificação dos textos universitários?

2. A falta de conexão com o cotidiano do aluno é realmente desmotivante? 3. Você ainda acha que apesar de muito criticado um texto do tipo do Ramalho é mais prático de ser usado em sala de aula do que um do tipo do GREF?

4. Qual dos dois textos, Ramalho ou do projeto GREF, você usaria como referência para ministrar uma aula sobre campo elétrico? Por quê?

5. Você acha que para você, licenciando, o texto do GREF é útil para complementar os seus conhecimentos antes de ministrar uma aula?

6. Você acha que os físicos formados na década de 70 e 80 e que escreveram os nossos livros didáticos foram influenciados por estes projetos de ensino de Física?

7. Você acha que podemos ensinar Física sem usar tantas definições e fórmulas? Comente.

8. Devido ao alto grau de abstração dos conceitos de Física muitos físicos e grupos de ensino estão fazendo animações gráficas e applets que demonstram virtualmente o conceito de potencial elétrico. Colocamos alguns links para você acima para você poder explorar alguns deles. Faça um comentário a respeito deles.

9. Com o advento da televisão alguns grupos de ensino e ou instituições estão fazendo vídeos aulas sobre temas interessantes e complexos de física. Colocamos alguns links para você acima para você poder explorar alguns deles. Faça um comentário a respeito deles.

10. Colocamos acima alguns exemplos e/ou links de experimentos de baixo custo para você analisar a possibilidade de usá-los em sala de aula. Comente se você os usaria ou não como recurso didático em sala de aula? Comente.

\section{APPLETS DE ENSINO}

1 - Explore esse excelente applet do Professor Falstad, acessando o link: $<$ http://www.falstad.com/emstatic/>.

Note que você pode arrastar as cargas e escolher vários tipos de arranjos de carga. 


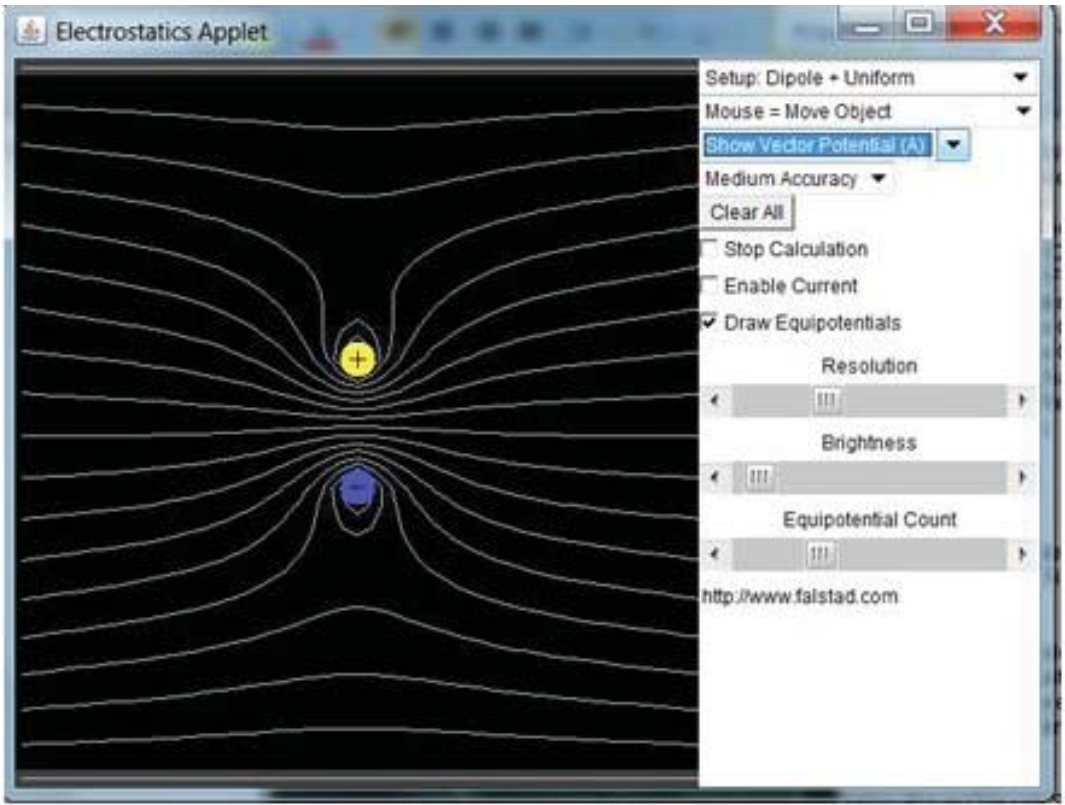

Disponível em: <http://www.falstad.com/emstatic/>

Q1. Que figura você espera obter se selecionar: quadrupole charge.

Q2. Que figura você espera obter se selecionar: charge + plane.

2 - Explore esse excelente applet do Professor Falstad, acessando o link: $<$ http://www.falstad.com/emstatic/>.

Note que você pode arrastar a caixa para visualizar as linhas de eqüipotenciais de várias posições.

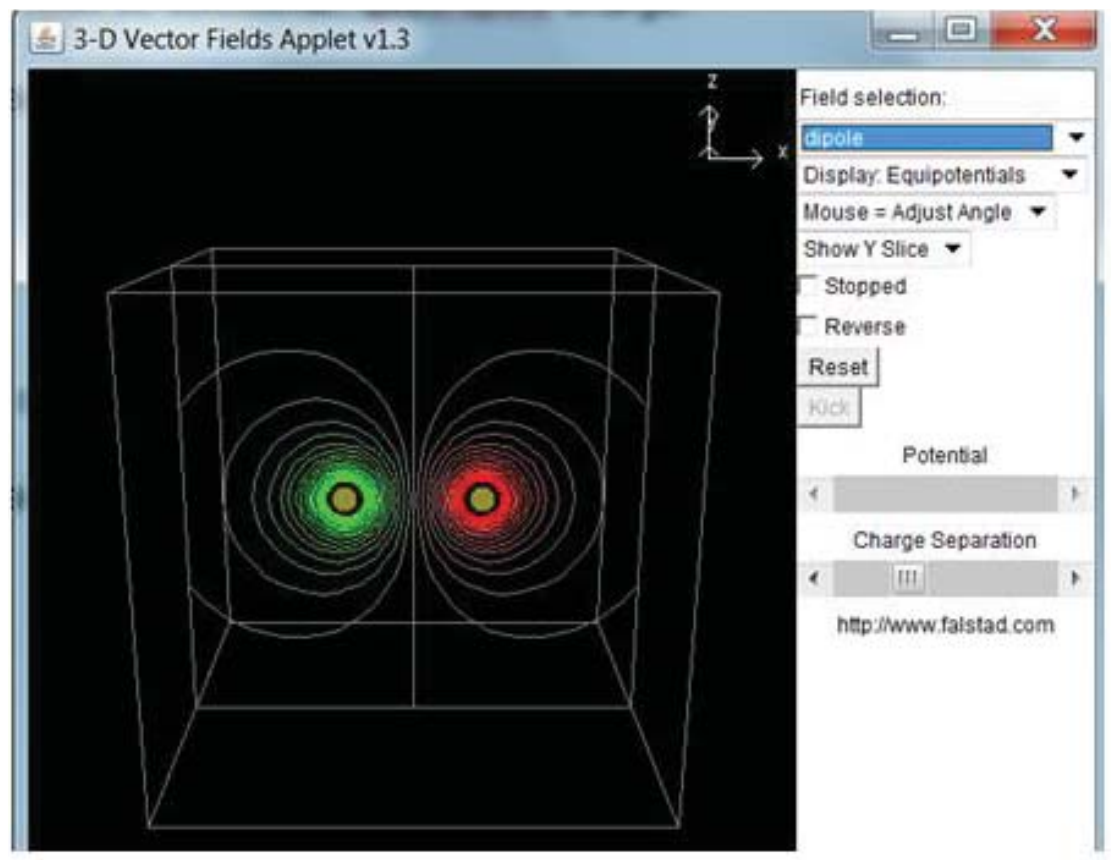

Disponível em: <http://www.falstad.com/emstatic/> 
Q1. Que figura você espera obter se selecionar: quadrupole charge.

Q2 . Que figura você espera obter se selecionar: charge + plane.

3 - Explore esse excelente applet do Professor Falstad, acessando o link: $<$ http://www.falstad.com/emstatic/>.

Note que você pode arrastar a caixa para visualizar as linhas de eqüipotenciais de várias posições.

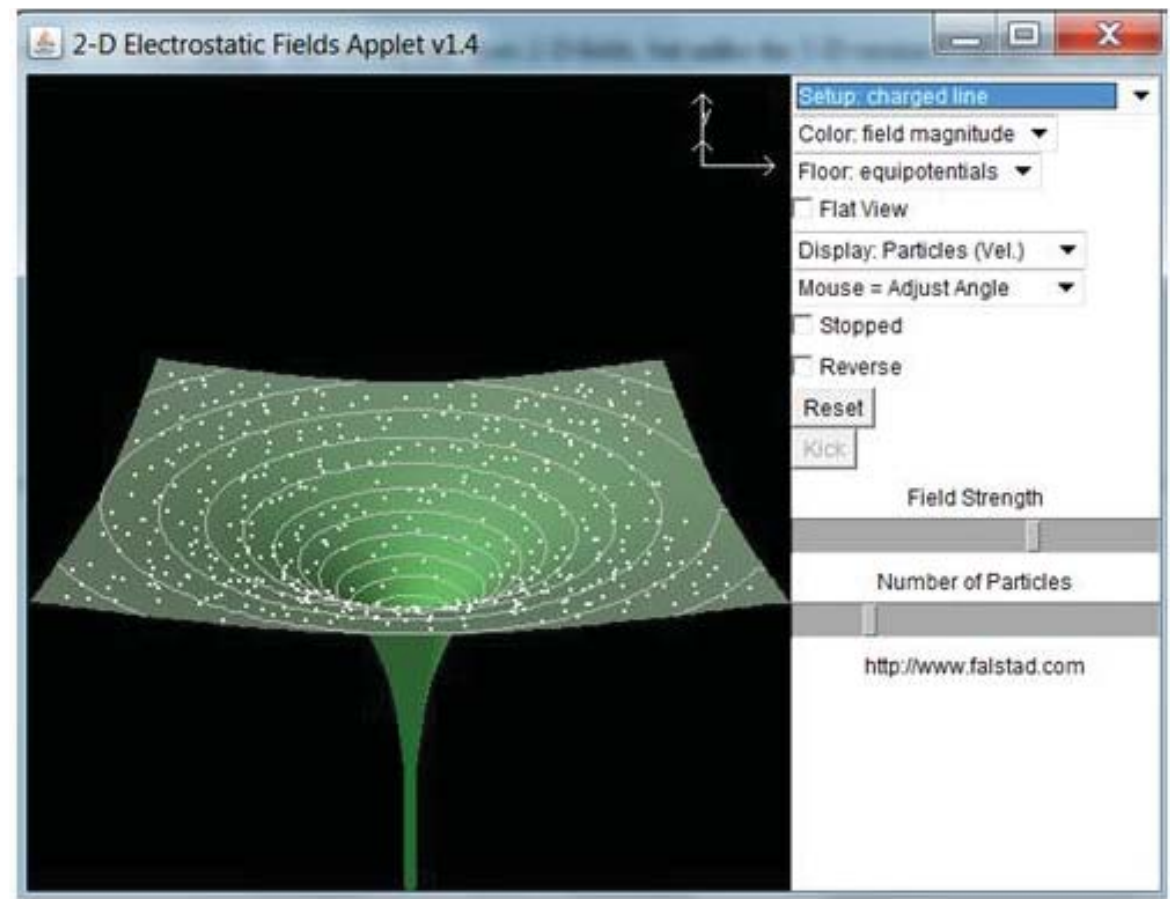

Disponível em: <http://www.falstad.com/emstatic/>

Q1. Que figura você espera obter se selecionar: quadrupole.

Q2 . Que figura você espera obter se selecionar: dipole lines.

\section{VÍDEOS DE ENSINO}

1 - Vídeo sobre potencial elétrico da série "O Universo Mecânico". Pode ser visto no link: < http://www.youtube.com/watch?v=WdtTaojzapg\&fe ature $=$ related $2>$

2 - Vídeo sobre eletricidade estática da série “O Universo Mecânico”. Pode ser visto no link: <http:/ / www.youtube.com/watch?v=8W8F2hgEFY4\& feature $=$ related $>$

3 - Vídeo do Prof. Vitor. - Física 51 - Potencial elétrico - trabalho no campo elétrico Parte 1. Link: < http://www.youtube.com/watch?v= vsinF76S63o > 4 - Vídeo do Prof. Vitor. Física 51 -- Potencial elétrico -- trabalho no campo elétrico Parte 2. Link: <http://www.youtube.com/watch?v=LE5eu3kOb2M> 


\section{CONCLUSÃO}

Vimos nessa aula como é feita em geral a transposição didática do livro universitário para o livro do Ensino Médio. O estudante deve ter percebido através do texto feito por um professor do ensino médio que a maioria dos textos didáticos é uma cópia simplificada dos textos universitários. Neles não aparecem as fórmulas com integrais e diferenciais e alguns conceitos são simplificados ou omitidos.

Com a apresentação do material do GREF para o mesmo assunto podemos ver que, como já está ocorrendo com vários textos atuais, que essa receita de transposição não precisa ser feita e que existe outras formas de se ensinar para o ensino médio. Além disso, esta forma de apresentação do conteúdo deixa o curso de Física entediante e sem propósito para o aluno do ensino médio

Com a análise dos experimentos de baixo custo e dos recursos de multimídias que colocamos no final da aula o futuro professor deve ter ficado com algumas boas ideias de como este pode enriquecer uma aula sobre o tema Lei de Coulomb.

\section{COMENTÁRIOS SOBRE AS ATTIVIDADES}

Em geral os alunos que fazem o curso de licenciatura em Física têm um curso muito superficial ou não tiveram nenhuma aula de Física. Se têm, usam algum livro texto tradicional, onde a Física é apresentada como uma coleção de definições e fórmulas para ser aplicada em problemas e exercícios. Assim, a maioria deles só possui o conhecimento de Física dado na universidade. Com a discussão que trouxemos procuramos mostrar que a maioria dos textos didáticos são uma simplificação dos textos universitários.

Os futuros professores devem ter compreendido o papel central que eles têm na escolha do conteúdo, da técnica e da didática a ser utilizada em sala de aula. Este deve ter adquirido uma ideia de como se deve preparar um curso ou apenas uma aula. Eles devem compreender que uma aula é um processo dinâmico e orgânico. 


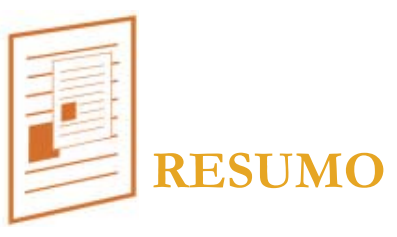

Apresentamos aqui três textos sobre o tema "Potencial Elétrico". O primeiro texto, preparado para o curso de EAD da UnB pelo professor Mundin, temos o assunto apresentado na forma em que é lecionado nos cursos básicos de exatas. No segundo texto vimos como em geral os textos didáticos para o ensino médio fazem a transposição didática a partir dos textos universitários. No último texto apresentamos uma forma nada convencional de se fazer a transposição didática para o curso de Física.

Em seguida apresentamos vários experimentos de baixo custo para que o aluno explore as possibilidades que estes oferecem para se ministrar um curso usando mais ferramentas fenomenológicas e menos formais. Devido a grande dificuldade que os estudantes tem de visualizar o potencial resultante de várias cargas, colocamos vários excelentes applets de ensino como recurso de simulação do fenômeno físico para ser explorado pelo futuro professor.

Como há ótimos vídeos de ensino colocamos alguns deles como referência, e deixamos sua exploração como atividade para os estudantes, uma vez que, no curso de Instrumentação I não usamos os vídeos didáticos como ferramenta didática principal.

1- Na maioria das vezes sim.

\section{RESPOSTA ÀS A'TIVIDADES}

2-Sim.

3- Resposta pessoal.

4- Os dois.

5- Sim.

6- Resposta pessoal.

7- Resposta pessoal.

8- São muito bons. Resposta pessoal.

9- São muito bons. Resposta pessoal.

10- São muito bons. Resposta pessoal. 


\section{REFERÊNCIAS}

DUFFY, Andrew; CHRISTIAN, Wolfgang. Davidson College Physlet Archive. Disponível em: <http://webphysics.davidson.edu/Applets/Applets.html $>$. Applet em Java autorizado pelos autores para uso educacional. Configurações do script original adaptadas para o português por V. E. Barlette. Disponível em: <http://sites.unifra.br/Portals/13/CD_Recursos2009/carlos/simulacao_X.html.> Acesso em 15/10/2011>. Acesso em 15/10/2011.

GREF - Grupo de Reelaboração do Ensino de Física, Instituto de Física da USP - Leituras de física - Gref - Eletromagnetismo para ler, fazer e pensar - versão preliminar. Disponível em: <http://www.if.usp.br/gref/ eletro/eletro1.pdf>. Acesso em 15/10/2011.

Kleber Mundin; Curso de EAD Universidade de Brasilia. - Potencial e Energia Elétrica. Disponível em: <http://vsites.unb.br/iq/kleber/EaD/ Eletromagnetismo/PotencialEletrico/PotencialEletrico.html>. Acesso em 15/10/2011.

PORTAL SÃO FRANCISCO, Potencial Elétrico - Fonte: geocities.yahoo. com.br . Disponível em: <http://www.portalsaofrancisco.com.br/alfa/ potencial-eletrico/potencial-eletrico.php. Acesso em 15/10/2011> YOUTUBE. 30 - O Universo Mecânico - Capacitância e Potencial (Wide). Disponível em: <http://www.youtube.com/watch?v=8W8F2hgEFY4\&fe ature $=$ related $>$. Acesso em 15/10/2011.

31 - O Universo Mecânico. Voltagem Energia e Força (Wide). Disponível em: <http://www.youtube.com/watch?v=WdtTaojzapg\&feature $=$ related $2>$. Acesso em 15/10/2011.

Física 51 - Potencial elétrico - trabalho no campo elétrico Parte 1.

Link: $<$ http: $/ /$ www.youtube.com/watch? $\mathrm{v}=$ vsinF76S63o $>$

Física 51 - Potencial elétrico -- trabalho no campo elétrico Parte 2.

Link: <http://www.youtube.com/watch?v=LE5eu3kOb2M> 



\section{Aula 5}

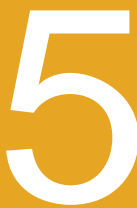

\section{CORRENTE E RESISTÊNCIA ELÉTRICA}

META

Fazer com que o estudante comece a pensar no ensino de ciências como algo "orgânico"

que está em profunda transformação.

Fazer com que os alunos percebam, através de um texto básico complementado com atividades lúdicas, applets de ensino, vídeos, que o conceito de associação de resistores

pode ser apreendido de forma simples e divertida.

Fazer uma análise comparativa entre o texto produzido para o ensino profissionalizante do SENAI e o do projeto GREF, sobre o tema força elétrica de modo que o aluno condições de analisar duas formas de se apresentar este conceito.

\section{OBJETIVOS}

Ao final desta aula, o aluno deverá: estar ciente das novas possibilidades e dos desafios que envolvem o ensino de ciências em geral e das dificuldades de se ministrar um curso de eletricidade e magnetismo; Ter compreendido que as ciências naturais estão baseadas na experimentação e que esta é feita de ensaios, experiências e medidas e que estas levam à compreensão e matematização dos conceitos físicos (naturais em geral).

ficar cientes das vantagens e desvantagens de se apresentar um conteúdo de forma resumida e técnica (SENAI) e de uma forma que parta do cotidiano dos alunos (GREF).

PRÉ-REQUISITOS

Os alunos deverão ter cursado as disciplinas Psicologia da Educação, Física A, Física B e Instrumentação I. 


\section{INTRODUÇÃO}

Vamos começar analisando o curso "Eletrotécnica Básica - Instrumentaşão" preparado pelo professor Jader de Oliveira para o SENAI/CST (Companhia Siderúrgica de Tubarão). Esse era um curso preparatório para trabalhadores, mas no nível do ensino médio, como veremos abaixo. Escolhemos esse curso, pois a Eletricidade é uma disciplina que está envolvida em quase todas as coisas do nosso cotidiano (exemplo: eletrodomésticos, lâmpadas, motores elétricos, rede elétrica, e assim por diante). Assim, surge a questão pedagógica: por que não ensiná-la como estivéssemos preparando nossos alunos para a atividade profissional e não para passar de ano?

Como vimos nas aulas anteriores, todos os projetos de ensino visavam algum tipo de objetivo nacional. Em geral, estavam envolvidos com o desenvolvimento tecnológico do país ou com a industrialização. Então, qual seria o melhor tipo de ensino? Será que no nosso mundo globalizado os nossos alunos não prefeririam um curso mais prático? Assim, vamos começar mostrando mais um tipo de abordagem ao curso de eletromagnetismo.

\section{ASSOCIAÇÃO DE RESISTORES E DIVISORES DE TENSÃO E CORRENTE}

\section{ASSOCIAÇÃO DE RESISTORES}

Duas ou mais resistências podem ser associadas de três maneiras:

a) Associação em série

b) Associação em paralelo

c) Associação mista

\section{CONSIDERAÇÕES}

- Resistores podem ser ligados de diversas maneiras de modo que seus efeitos sejam combinados;

- Qualquer que seja a maneira como ligamos os resistores, o efeito obtido ainda será o de uma resistência;

- Essa resistência poderá ser maior ou menor que os resistores associados, mas ainda assim o conjunto seguirá a lei de $O \mathrm{hm}$.

- O resultado de uma associação de resistores depende não só dos valores dos resistores associados como também da forma como são ligados. 


\section{ASSOCIAÇÃO EM SÉRIE}

Quando os resistores estão ligados um em seguida ao outro. $\mathrm{Na}$ figura abaixo, mostramos “"n”, resistores ligados em série. Nesse tipo de associação, a corrente I passa por um dos resistores, é a mesma que passa por todos os outros. Aplicando a lei de $\mathrm{Ohm}$ ao $1^{\circ}, 2^{\circ}, \ldots$, enésimo resistor, temos:

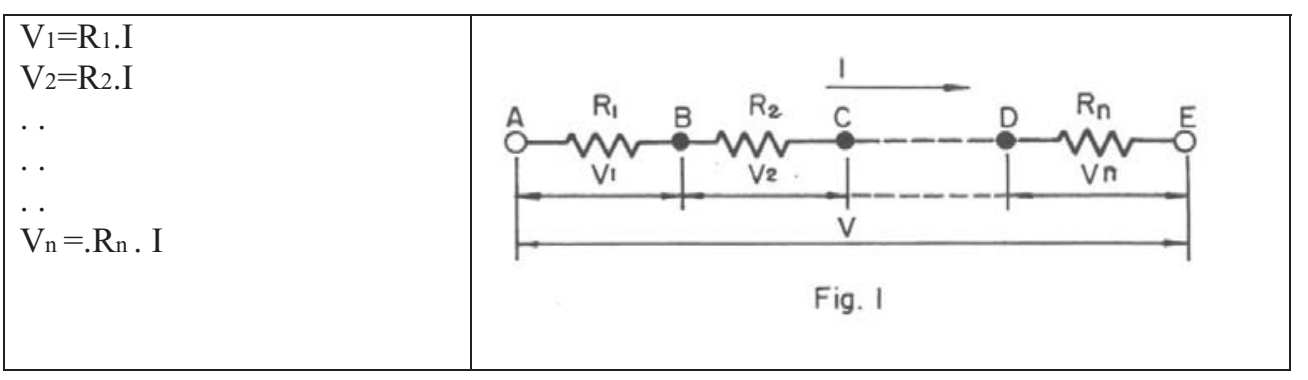

A tensão $\mathrm{V}$, fornecida, é igual à soma das quedas de tensão em cada resistor.

$$
\begin{aligned}
& \mathrm{V}=\mathrm{V} 1+\mathrm{V} 2+\ldots+\mathrm{Vn}=\mathrm{R} 1 . \mathrm{I}+\mathrm{R} 2 . \mathrm{I}+\ldots+\mathrm{Rn} . \mathrm{I}=(\mathrm{R} 1+\mathrm{R} 2+\ldots+\mathrm{Rn}) . \mathrm{I} \\
& \mathrm{V}=(\mathrm{R} 1+\mathrm{R} 2+\ldots+\mathrm{Rn}) . \mathrm{I}=\mathrm{RT}
\end{aligned}
$$

onde:

$$
\mathrm{RT}=\mathrm{R} 1+\mathrm{R} 2+\ldots+\mathrm{Rn}
$$

\section{CONCLUSÃO}

A resistência total (ou equivalente) de uma associação de resistores em série é igual à soma dos resistores da série.

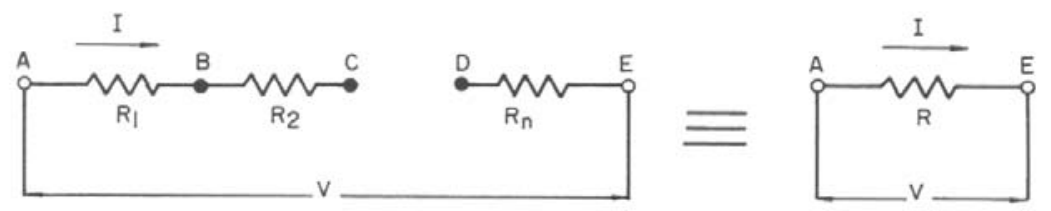

\section{CASO PARTICULAR}

Quando os resistores tiverem resistências iguais, isto é, $\mathrm{R} 1=\mathrm{R} 2=\ldots$ $=\mathrm{Rn}$, é fácil provar que neste caso resulta também $\mathrm{V} 1=\mathrm{V} 2=\ldots=\mathrm{Vn}$.

Chamamos respectivamente R1 e V1 a resistência e a diferença de potencial entre os extremos de cada resistor, temos: 


$$
\begin{aligned}
& \mathrm{RT}=\mathrm{nRi} \\
& \mathrm{V}=\mathrm{nV} 1
\end{aligned}
$$

Na figura 3, temos exemplos de associação de 3 resistores em série.
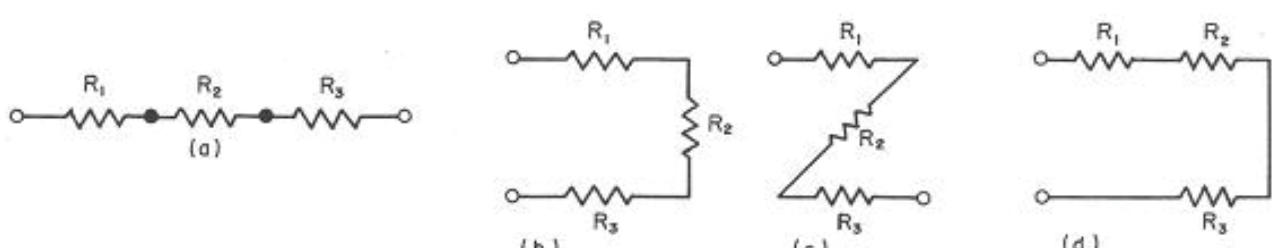

(b)

(c)

(d)

Sendo R1, R2 e R3 os mesmos, as associações (a), (b), (c) e (d) são iguais.

Exemplo 1 :

Determinar a resistência total em um circuito série, onde se têm R1 = $22 \Omega, \mathrm{R} 2=33 \Omega$ e R3 $=10 \Omega$.

Solução:

$$
\begin{aligned}
& \mathrm{RT}=\mathrm{R} 1+\mathrm{R} 2+\mathrm{R} 3 \\
& \mathrm{RT}=22+33+10=65 \\
& \mathrm{RT}=65[\Omega]
\end{aligned}
$$

\section{ASSOCIAÇÃO EM PARALELO}

Quando os resistores estão ligados aos mesmos pontos, e portanto submetidos à mesma d.d.p., dizemos que estão associados em paralelo. $\mathrm{Na}$ figura abaixo mostramos $\mathrm{n}$ resistores ligados em paralelo.

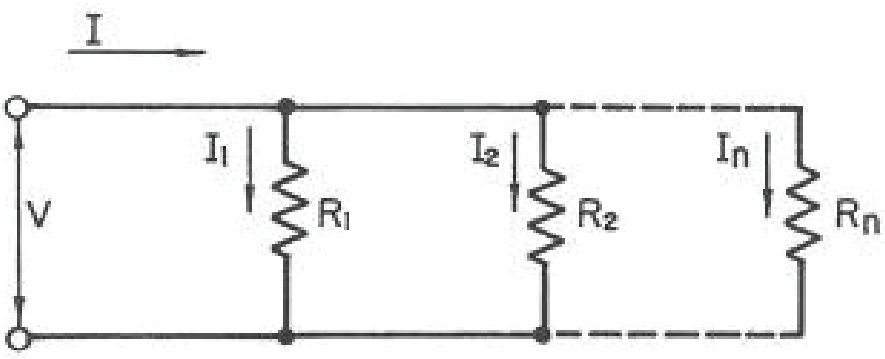

Nesse tipo de associação, todos os resistores estão submetidos a mesma tensão V. Aplicando a lei de $O h m$ aos n resistores, temos: 


$$
\frac{\mathrm{I} 1}{R_{1}}=V, \frac{\mathrm{I} 2}{R_{2}}=V, \frac{\mathrm{I} 3}{R_{3}}=V, \ldots . ., \frac{\mathrm{In}}{R_{n}}=V,
$$

A corrente I é igual à soma das correntes em cada resistor.

$$
\begin{aligned}
& I=I_{1}+I_{2}+\ldots+I_{n}=\frac{V}{R_{1}}+\frac{V}{R_{2}}+\ldots+\frac{V}{R_{n}}=\frac{1}{R_{1}}+\frac{1}{R_{2}}+\ldots+\frac{1}{R_{n}} \cdot V \\
& I==\frac{1}{R_{1}}+\frac{1}{R_{2}}+\ldots+\frac{1}{R_{n}} \cdot V=\frac{V}{R_{T}}
\end{aligned}
$$

onde:

$$
\begin{aligned}
& \frac{1}{\mathrm{R}_{\mathrm{T}}}=\frac{1}{\mathrm{R}_{1}}+\frac{1}{\mathrm{R}_{2}}+\ldots+\frac{1}{\mathrm{R}_{\mathrm{n}}} \\
& \mathrm{Ou} \\
& \mathrm{R}_{\mathrm{T}}=\frac{1}{\frac{1}{\mathrm{R}_{1}}+\frac{1}{\mathrm{R}_{2}}+\ldots+\frac{1}{\mathrm{R}_{\mathrm{n}}}}
\end{aligned}
$$

\section{CONCLUSÃO}

A resistência total (equivalente) de uma associação em paralelo é igual ao inverso da soma dos inversos das resistências componentes.

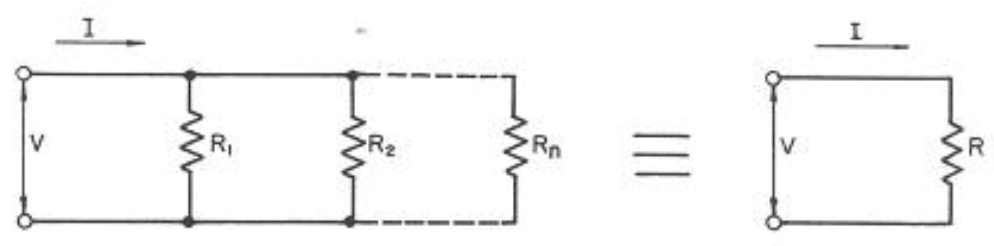

onde

$$
\mathrm{R}_{\mathrm{T}}=\frac{1}{\frac{1}{\mathrm{R}_{1}}+\frac{1}{\mathrm{R}_{2}}+\ldots+\frac{1}{\mathrm{R}_{\mathrm{n}}}}
$$

\section{CASO PARTICULAR (1 )}

No caso de um grupo formado por apenas dois resistores diferentes R1 e R2, a resistência total pode ser determinada da seguinte maneira: 


$$
\begin{aligned}
& \mathrm{R}_{\mathrm{T}}=\frac{1}{\frac{1}{\mathrm{R}_{1}}+\frac{1}{\mathrm{R}_{2}}}=\frac{\mathrm{R}_{1} \times \mathrm{R}_{2}}{\mathrm{R}_{1}+\mathrm{R}_{2}} \\
& \therefore \mathrm{R}_{\mathrm{T}}=\frac{\mathrm{R}_{1} \times \mathrm{R}_{2}}{\mathrm{R}_{1}+\mathrm{R}_{2}}
\end{aligned}
$$

\section{CASO PARTICULAR (2)}

Os resistores têm resistências iguais, isto é, $\mathrm{R} 1=\mathrm{R} 2 .=\mathrm{Rn}$. Neste caso as intensidades de corrente nas derivações também são iguais:

$$
\begin{aligned}
& \mathrm{I} 1+\mathrm{I} 2=\ldots=\mathrm{In} \\
& \text { Logo: } \quad \mathrm{I}=\mathrm{n} . \mathrm{I} 1 \\
& \text { Logo: } \frac{1}{R_{T}}=\frac{n}{R_{1}} \\
& \qquad \mathrm{R}_{\mathrm{T}}=\frac{\mathrm{R}}{\mathrm{n}}=\frac{1}{\mathrm{n}} \cdot \mathrm{R}_{1}
\end{aligned}
$$

Neste caso particular, a resistência da associação é igual a $1 / \mathrm{n}$ da resistência de cada resistor e a intensidade da corrente é n vezes maior que a corrente que circula em cada resistor: $\mathrm{Na}$ figura abaixo, temos três exemplos de resistores associados em paralelo.

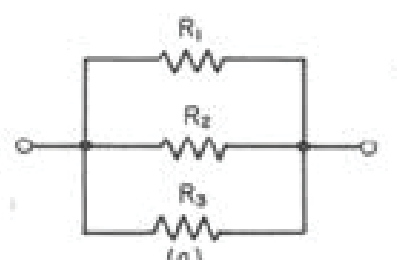

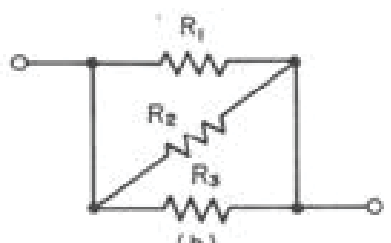

(b)

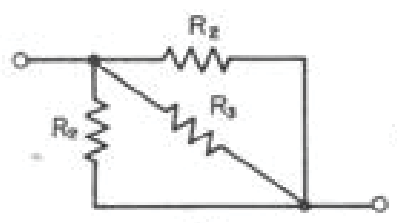

(c)

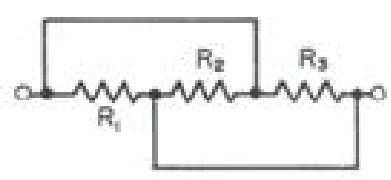

(d)

Sendo R1, R2 e R3 os mesmos, as associações (a), (b), (c) e (d) são iguais.

Na seqüência é apresentado um conjunto de exemplos de exercícios exemplos mais ou menos simples, porém não constam exercícios preparatórios para o vestibular. 
A seguir colocamos o texto do GREF para você possa fazer uma análise comparativa entre os textos.

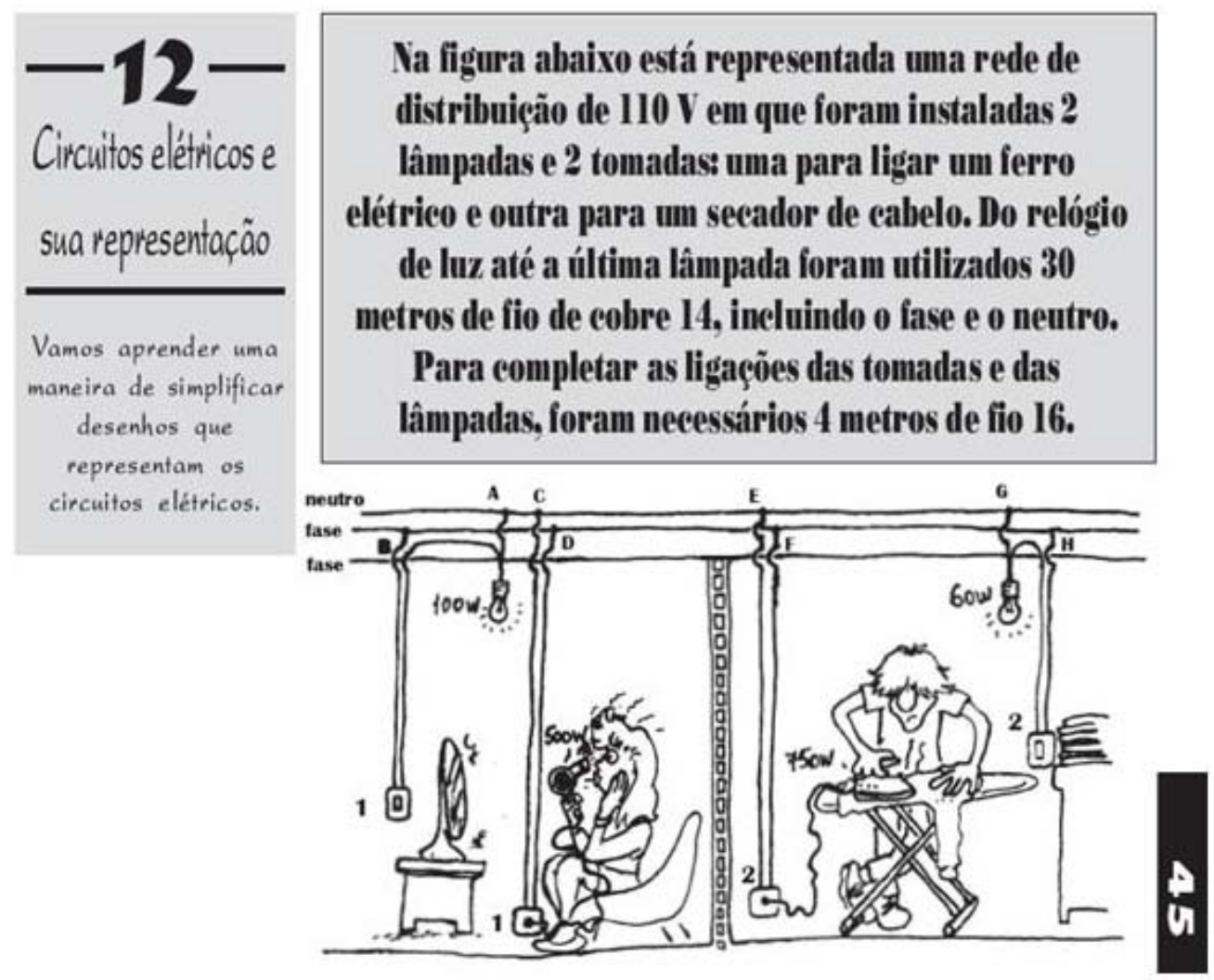

GREF. P. 45. Disponível em: <http://www.if.usp.br/gref/eletro/eletro2.pdf >

\section{CIRCUITOS ELÉTRICOS E SUA REPRESENTAÇÃO}

1. Com base nos dados indicados na figura da página anterior, vamos discutir as questões:

a) Identifique se as ligações dos aparelhos foram feitas em série ou em paralelo.

b) Qual o fusível adequado para proteger essa instalação, sabendo-se que a corrente máxima admissível para o fio 14 é 20A?

c) Discuta por que é possível substituir por um fio mais fino (16) as ligações das lâmpadas e tomadas.

d) Represente esquematicamente esse circuito, calculando os valores das resistências em cada trecho.

a) Para identificar se as ligações foram feitas em série ou em paralelo vamos observar onde os fios da tomada e das lâmpadas foram conectados. Nesse caso foram conectados nos fios fase e neutro, que fornecem uma tensão de 110V. Portanto, a ligação foi feita em paralelo. 
Nesse tipo de ligação, o funcionamento desses aparelhos não é interrompido quando um deles é ligado, desligado ou está "queimado".

b) Para sabermos qual o fusível adequado para uma instalação, devemos levar em conta que todos os aparelhos estejam ligados, fazer a soma total da potência consumida de cada aparelho e desprezar a potência dissipada na fiação.

$\mathrm{P}_{\text {total }}=500+100+60+750=1410 \mathrm{~W}$

Usando a equação: $\mathrm{P}=\mathrm{Ui}$, obtemos: $\mathrm{i}=\frac{P}{U}=\frac{1410 \mathrm{~W}}{110 \mathrm{~V}} \cong 12,8 \mathrm{~A}$, que é a corrente que passa pela chave na caixa de luz. O fusível adequado para proteger a instalação elétrica é de $15 \mathrm{~A}$, pois é compatível com a corrente máxima admitida pelo fio de cobre 14 e está acima do valor da corrente requerida por todos os aparelhos funcionando ao mesmo tempo.

c) Suponhamos que apenas a lâmpada do interruptor 1 esteja ligada. A corrente exigida para seu funcionamento será:

$$
\mathrm{i} 1=\frac{1410 \mathrm{~W}}{110 \mathrm{~V}} \cong 0,91 \mathrm{~A} \text {, }
$$

se ligarmos também o ferro elétrico na tomada 2, a corrente exigida para seu funcionamento será: i2.

$$
\mathrm{i} 2=\frac{750 \mathrm{~W}}{110 \mathrm{~V}} \cong 6,81 \mathrm{~A}
$$

De modo que a corrente entre o relógio entre o relógio de luz e os pontos E e F será:

$$
\mathrm{i}=\mathrm{i}_{1}+\mathrm{i}_{2}=0,91+6,81=7,72 \mathrm{~A}
$$

Se todos os aparelhos estiverem funcionando, cada um exigirá uma determinada corrente que pode ser calculada pela equação $\mathrm{P}=\mathrm{U} . \mathrm{i}$, e a corrente total, que é a soma de todas essas correntes, corresponderá apenas ao trecho entre o relógio de luz e os pontos A e B.

d) O cálculo das resistências podem ser feitos usando-se as equações: $\mathrm{P}=\mathrm{U}$.i e $\mathrm{R}=\mathrm{U} / \mathrm{i}$. Usando o símbolo:

\section{$-1+4$}

(GREF. p. 46. Disponível em: <http://www.if.usp.br/gref/eletro/eletro2.pdf>)

para os resistores, temos: 


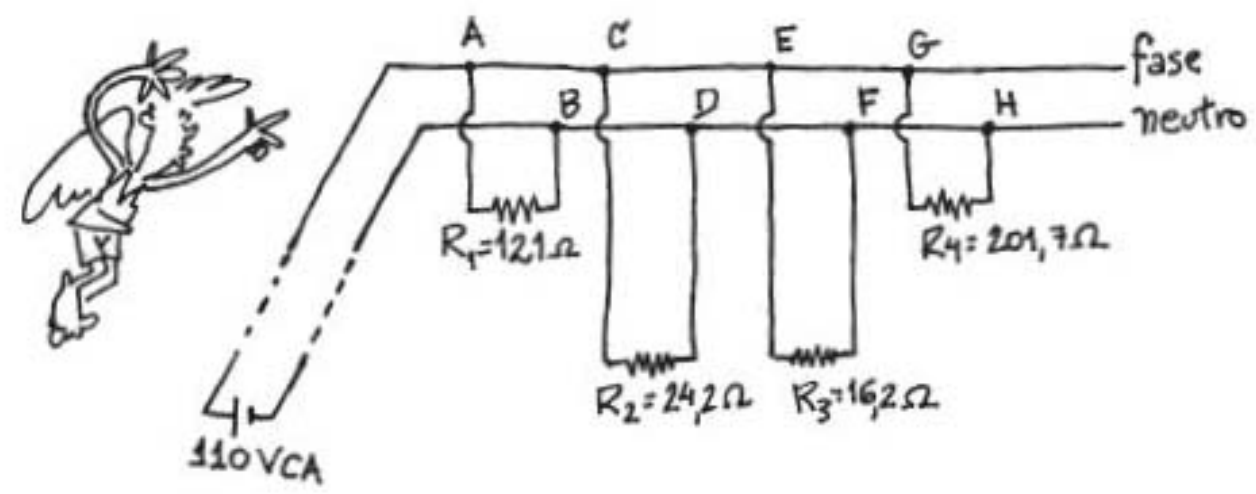

(GREF. p. 46. Disponível em: <http://www.if.usp.br/gref/eletro/eletro2.pdf>)

Admitindo-se que a escolha dos fios foi adequada, tanto os fios da rede principal quanto os fios que se ligam aos aparelhos, possuem resistência elétrica desprezível. Assim, podemos simplificar um pouco mais o circuito e representá-lo da maneira ilustrada

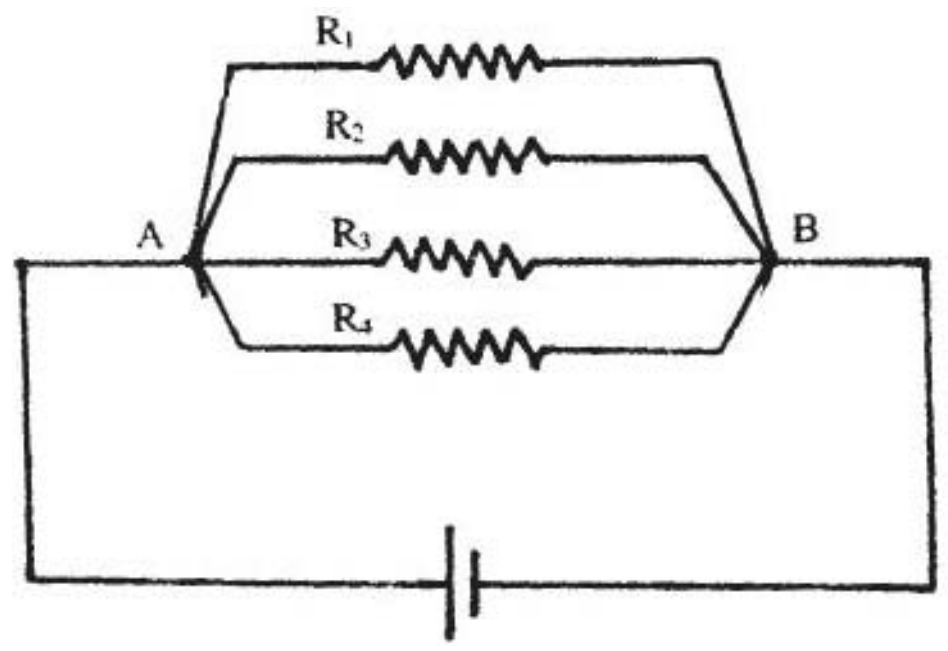

(GREF. p. 46. Disponível em: <http://www.if.usp.br/gref/eletro/eletro2.pdf>)

2. Vamos verificar de que modo podemos ligar três lâmpadas L1, L2 e L3 de mesma tensão em um circuito.

Existem quatro formas diferentes: todas em série, todas em paralelo, duas em série e em paralelo com a terceira ou duas em paralelo e em série com a terceira.

As vantagens e as desvantagens de cada tipo de associação, serão discutidas a seguir:

1. Ligação em série: neste tipo de ligação a mesma corrente se estabelece nas três lâmpadas do circuito. Vejamos a figura. 


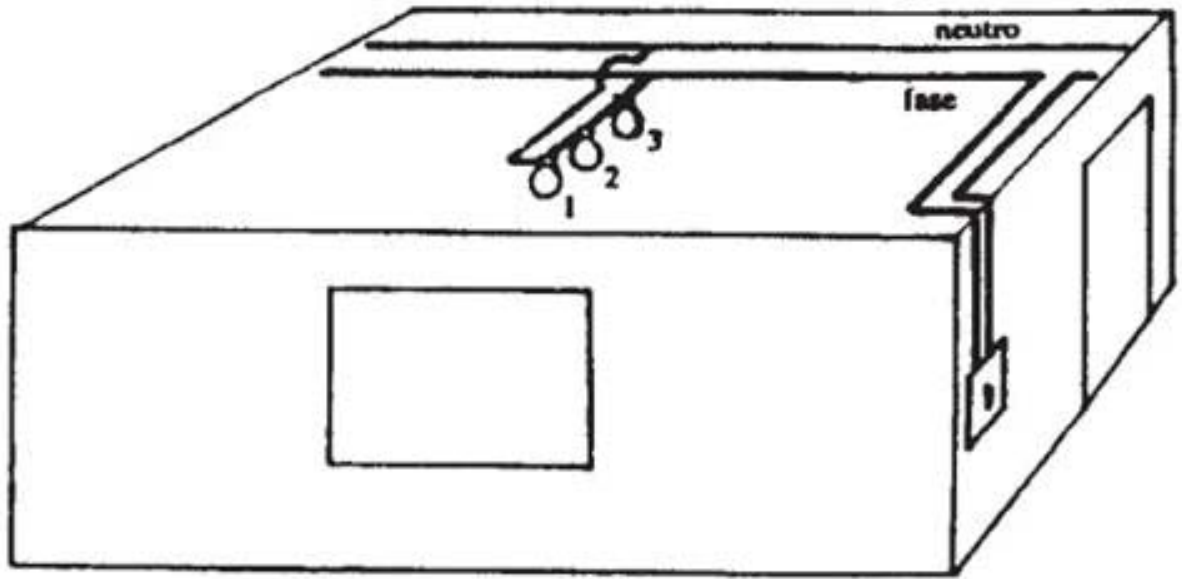

(GREF. p. 47. Disponível em: <http://www.if.usp.br/gref/eletro/eletro2.pdf>)

De um modo mais simplificado, temos:
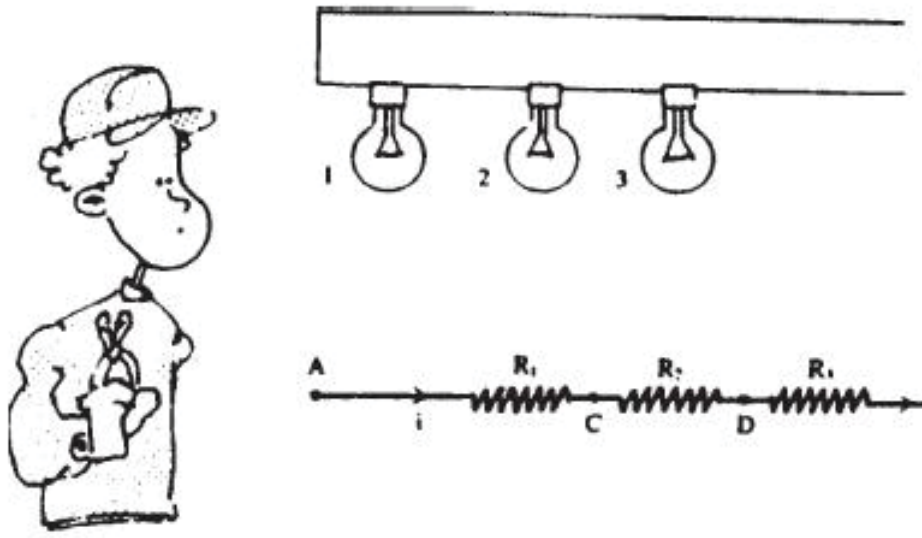

$110 \mathrm{~V}$

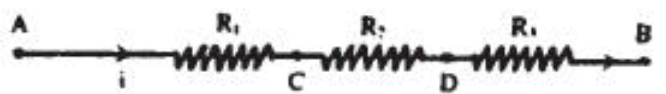

(GREF. p. 47. Disponível em: <http://www.if.usp.br/gref/eletro/eletro2.pdf>)

Na associação em série, cada lâmpada do circuito está submetida a uma tensão cuja soma equivale à tensão total entre os extremos A e B do circuito (uma vez que as perdas na fiação podem ser consideradas desprezíveis).

A tensão total aplicada às três lâmpadas pode ser escrita como:

$$
\mathrm{U}_{\mathrm{AB}}=\mathrm{U}_{\mathrm{AC}}+\mathrm{U}_{\mathrm{AD}}+\mathrm{U}_{\mathrm{DB}}
$$

Como: $\mathrm{U}_{\mathrm{AC}}=\mathrm{R}_{1} \cdot \mathrm{i}, \mathrm{U}_{\mathrm{CD}}=\mathrm{R}_{2} \cdot \mathrm{i}$ e $\mathrm{U}_{\mathrm{DB}}=\mathrm{R}_{3} \cdot \mathrm{i}$

então: $\mathrm{U}_{\mathrm{AB}}=\mathrm{R}_{1} \cdot \mathrm{i}+\mathrm{R}_{2} \cdot \mathrm{i}+\mathrm{R}_{3} \cdot \mathrm{i}$

Para calcularmos a resistência equivalente da associação usaremos a relação: $\mathrm{U}_{\mathrm{AB}}=\mathrm{R}_{\mathrm{eq}} \cdot \mathrm{i}$, portanto: $\mathrm{R}_{\mathrm{eq}} \cdot \mathrm{i}=\left(\mathrm{R}_{1}+\mathrm{R}_{2}+\mathrm{R}_{3}\right) \cdot \mathrm{i}$

$\mathrm{R}_{\mathrm{eq}}=\mathrm{R}_{1}+\mathrm{R}_{2}+\mathrm{R}_{3}$ 
A potência dissipada na associação em série é calculada pela relação:

$$
\begin{aligned}
& \mathrm{P}=\mathrm{R} \cdot \mathrm{i}^{2}=\mathrm{R}_{\text {eq }} \cdot \mathrm{i}^{2}=\left(\mathrm{R}_{1}+\mathrm{R}_{2}+\mathrm{R}_{3}\right) \cdot \mathrm{i}^{2}=\mathrm{R}_{1} \cdot \mathrm{i}^{2}+\mathrm{R}_{2} \cdot \mathrm{i}^{2}+\mathrm{R}_{3} \cdot \mathrm{i}^{2} \\
& \text { ou seja, } \\
& \mathrm{P}=\mathrm{P}_{1}+\mathrm{P}_{2}+\mathrm{P}_{3}
\end{aligned}
$$

Como a tensão em cada lâmpada é sempre menor que a tensão aplicada nos terminais da associação, a potência dissipada em cada uma delas na ligação em série é sempre menor do que a indicada pelo fabricante. Nessas condições ela terá um brilho bem menor que o esperado. Além disso, se uma lâmpada queimar, interrompe o circuito e conseqüentemente as outras apagam. Por isso esse tipo de ligação não é usado nas instalações residenciais, mas pode ser achada nos cordões de luzes de árvore de natal; se desligarmos apenas uma delas, apagará toda a seqüência de lâmpadas em série.

2. Ligação em paralelo: este tipo de ligação se caracteriza pelo fato de todas as lâmpadas estarem submetidas a uma mesma tensão, desprezando-se a resistência elétrica dos fios da instalação.

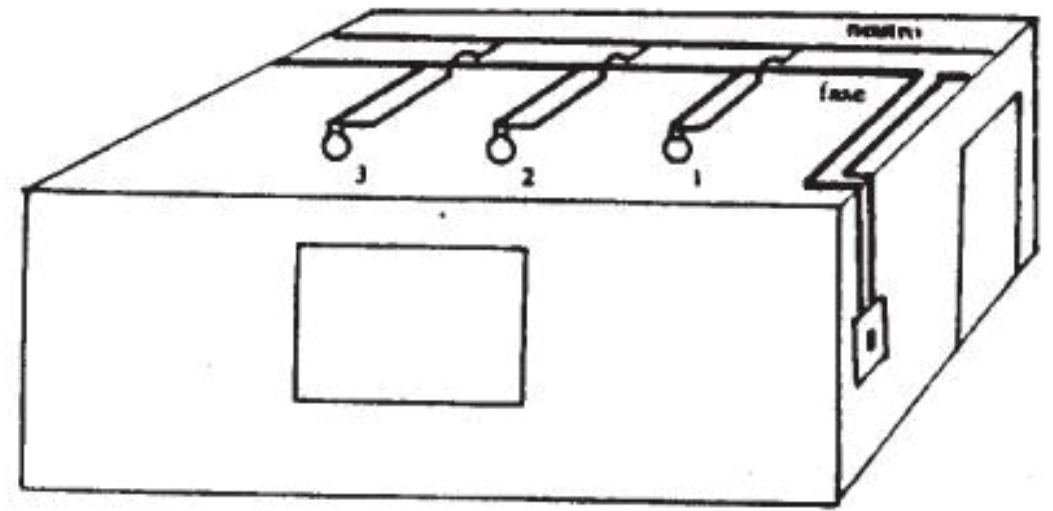

(GREF. p. 48. Disponível em: < http://www.if.usp.br/gref/eletro/eletro2.pdf>)

Podemos ainda representar esquematicamente a mesma ligação da seguinte forma:

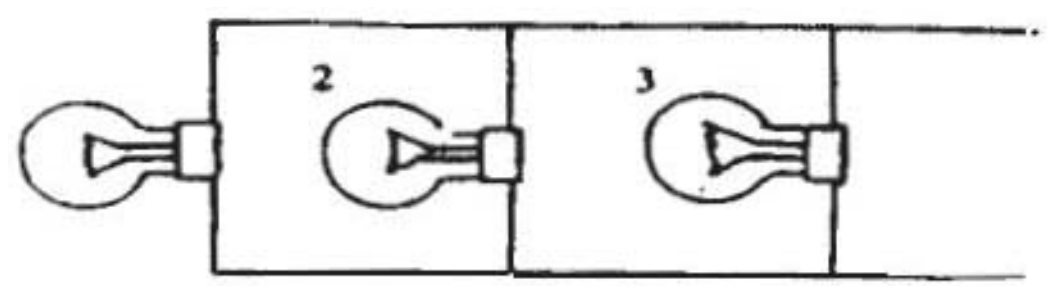

$110 \mathrm{~V}$

(GREF. p. 48. Disponível em: <http://www.if.usp.br/gref/eletro/eletro2.pdf>) 
A tensão $\mathrm{AB}$ é igual às tensões $\mathrm{CD}, \mathrm{EF}$ e $\mathrm{GH}$, pois estamos desprezando a resistência dos fios. Desse modo podemos reduzir ainda mais o esquema:

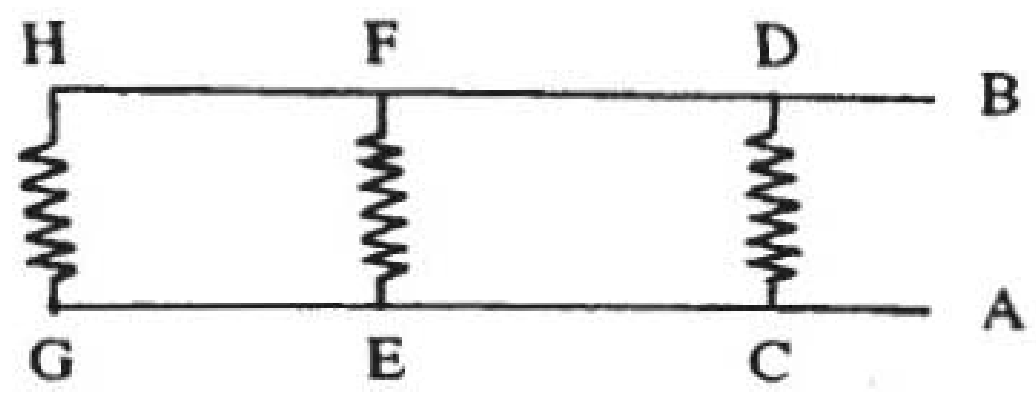

(GREF. p. 48. Disponível em: < http://www.if.usp.br/gref/eletro/eletro2.pdf>)

As correntes estabelecidas em cada uma delas será $i=i_{1}+i_{2}+i_{3}$. Assim, se a tensão é a mesma, pela lei de $O h m$, temos:

$\mathrm{i}=\mathrm{U} / \mathrm{R}_{\mathrm{eq}}$, onde $\mathrm{R}_{\mathrm{eq}}$ é a resistência equivalente da associação.

Sendo $i_{1}=U / R_{1}, i_{2}=U / R_{2}$ e $i_{3}=U / R_{3}$

Substituindo na equação $\mathrm{i}=\mathrm{i}_{1}+\mathrm{i}_{2}+\mathrm{i}_{3}$, teremos: $\mathrm{U} / \mathrm{R}_{\text {eq }}=\mathrm{U} / \mathrm{R}_{1}+\mathrm{U} /$ $\mathrm{R}_{2}+\mathrm{U} / \mathrm{R}_{3}$ ou

$$
1 / R_{\text {eq }}=1 / R_{1}+1 / R_{2}+1 / R_{3}
$$

$\mathrm{Na}$ associação em paralelo, a tensão em cada lâmpada é a mesma, e a potência dissipada em cada lâmpada independe do número de lâmpadas agrupadas, e, consequentemente, o brilho da lâmpada também. O brilho é igual ao que teria se ela estivesse sozinha. Além disso, se uma das lâmpadas queimar, as demais não sofrem alteração. É por isso que essa ligação é utilizada nas instalações elétricas residenciais.

3. Ligação mista: ocorre quando combinamos os dois tipos de ligação conforme mostra a figura:
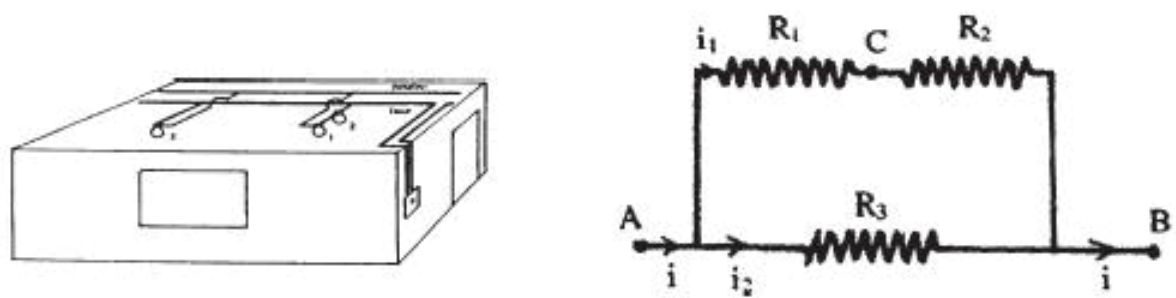

(GREF. p. 48. Disponível em: <http://www.if.usp.br/gref/eletro/eletro2.pdf>) 
Nessa situação, a tensão U se aplica nos terminais da série R1 + R2 e em R3. Assim, L3 terá brilho maior que L1 e L2; Em função dessa característica, esse tipo de circuito também não é empregado nas instalações elétricas residenciais, mas é muito utilizado nos circuitos internos dos aparelhos eletrônicos, como rádio, TV, computadores etc.

\section{APPLETS DE ENSINO}

Como nas outras Instrumentações, sugerimos alguns sites de ensino com material de multimídia para análise. Segue abaixo um guia de applets com dicas.

\section{SIMULADORES DE CIRCUITOS ELÉTRICOS}

Existe na literatura e nos sites de algumas empresas de eletrônica e de ensino simuladores de circuitos elétricos. Dentre eles cabe citar:

\section{LOGIC CIRCUIT DESIGNER 1.5}

Esse é um software educacional desenvolvido como uma ferramenta tecnológica para a compreensão de funcionamento de circuitos lógicos. Usando um software como um designer interativo, temos como principal vantagem a oportunidade de eliminar todos os erros de projeto possível, mesmo antes de prosseguir para a compra de componentes e da montagem. Do ponto de vista educacional, o aplicativo, Designer Logic Circuit, destina-se a ajudar tanto os estudantes e usuários, estudando arquitetura de computadores ou, mais especificamente, circuitos de lógica digital. Este programa é um simulador de circuitos lógicos, permitindo ao aluno visualizar melhor e entender como funciona um circuito lógico, que lhe permite construir qualquer circuito lógico que quiser, e visualmente simular o seu funcionamento.

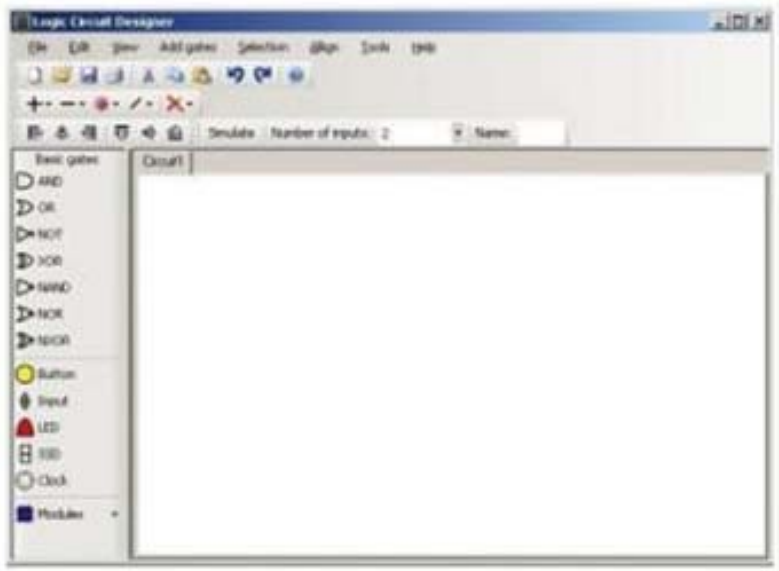


Baseado em uma interface amigável, o aluno pode interagir com seu circuito lógico, alterar os dados de entrada, e observar as mudanças de saída de dados para os modelos sequenciais. Essa ferramenta será de grande ajuda para qualquer aluno que tenha interesse nesta área, e permitir-lhe compreender melhor a lógica do processo de desenho de circuitos.

\section{ELETROCALC}

Programa para criar esquemas e simulação. Este é um ótimo programa de manipulação de projetos de circuitos eletrônicos, além de possuir uma imensa biblioteca compatível com o padrão Spice disponíveis em diversos fabricantes de componentes, este simulador de circuito tem suporte para desenho e roteamento de circuitos eletrônicos, além de dispor de simulação de inúmeros equipamentos de bancada como multímetro, osciloscópio, gerador de funções, analisador de rede, analisador de Spectro, Gráfico de Bode e outros, além de permitir analise de Fourier de circuitos eletrônicos e permitir com facilidade resolver mapas de Karnout de até 8 bits. Faça o download de demonstração deste software no site do fabricante (Versão demonstrativa com algumas restrições).

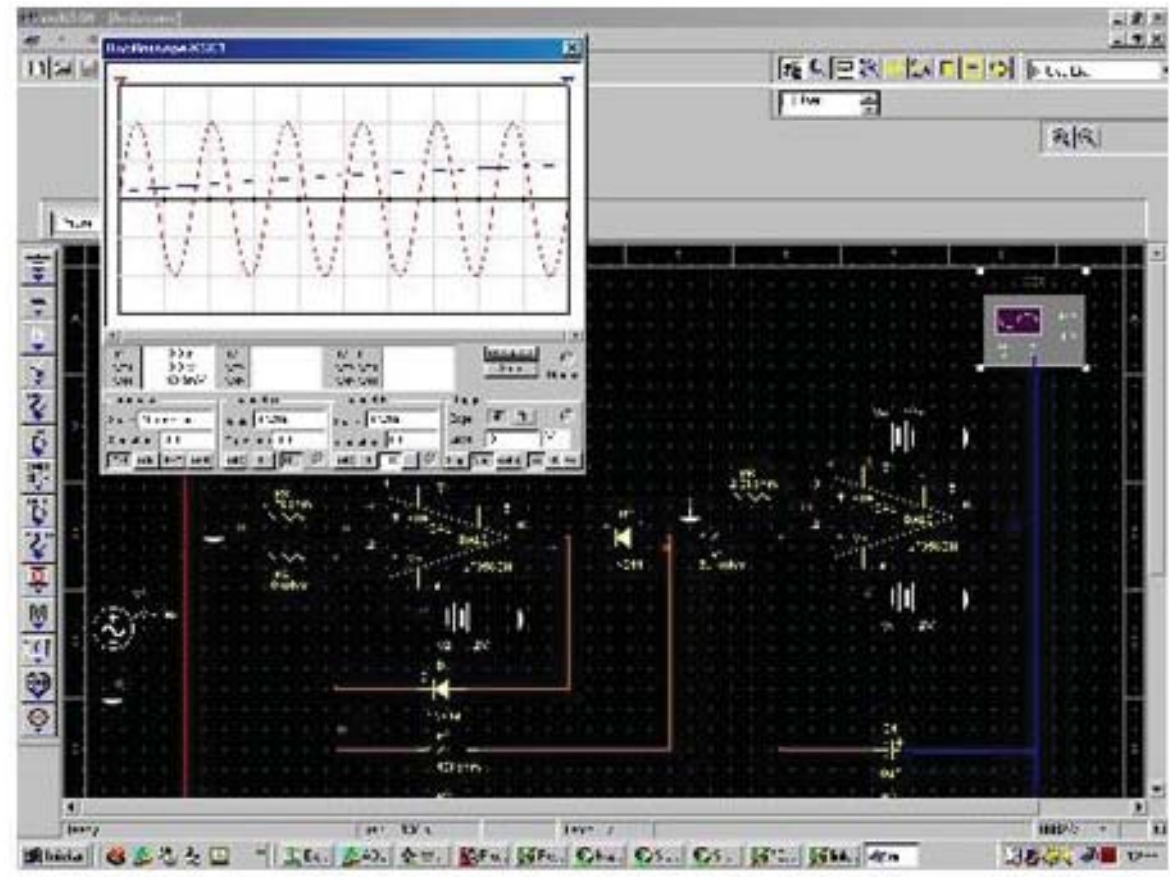

$<$ http://www.eletrocalc.tirech.com.br/eletrocalc/index.php?option=com_content\&v iew $=$ article $\&$ id $=8 \&$ Itemid $=9>$ ) 


\section{WINDRAFT}

É um bom programa para esquemas.

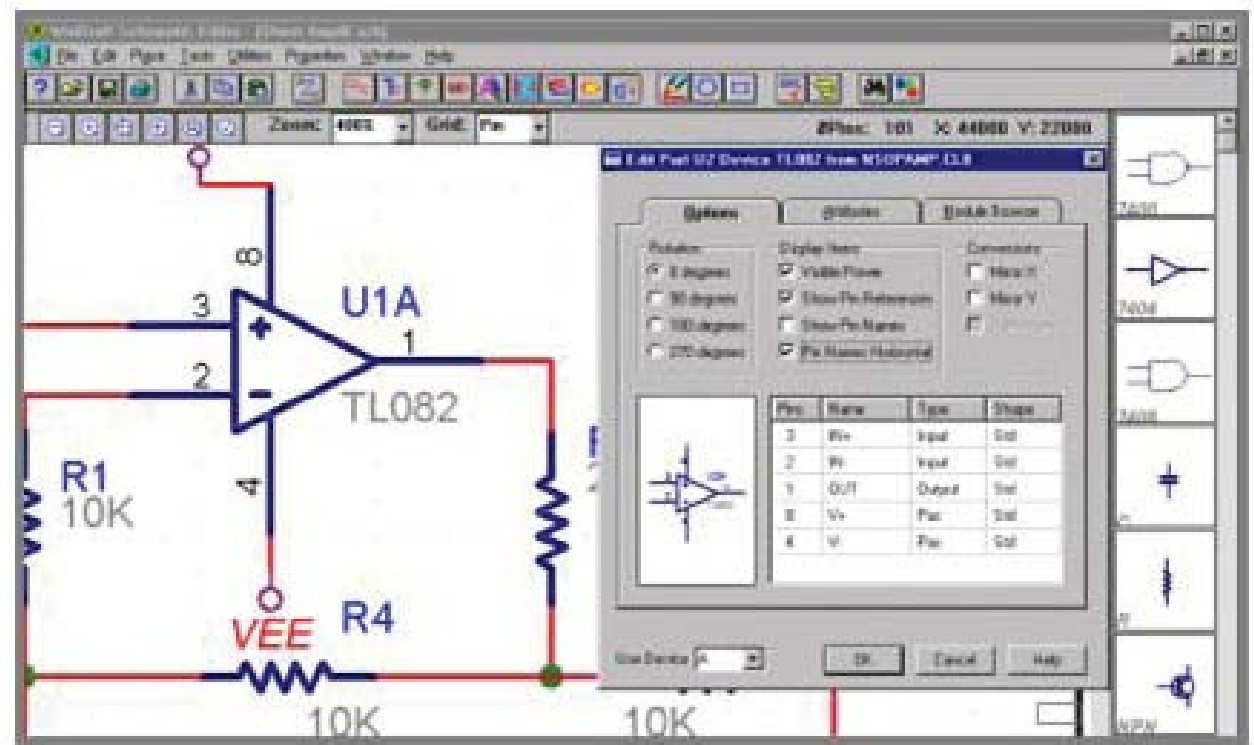

(Disponível em: <http://www.eletrocalc.tirech.com.br/eletrocalc/index. php?option $=$ com_content\&view $=$ article\&id $=8 \&$ Itemid=9>)

\section{CROCODILE PHYSICS}

Crocodile Physics contém uma ampla gama de componentes elétricos e eletrônicos. De baterias, lâmpadas e chaves até portas lógicas, circuitos integrados e semi-condutores. Uma vasta biblioteca de componentes permite ao usuário investigar e experimentar sistemas com vários graus de complexidade.

A criação de circuitos é muito simples. Basta arrastar os componentes para a área de trabalho e ligá-los desenhando fios entre os seus terminais.

A simulação é matematicamente precisa, permitindo que você teste os sistemas e explore as leis físicas por trás dos sistemas.

Você pode usar o Crocodile Physics para simulações e experimentos em Mecânica. Por exemplo, realizar um experimento para estudo da conservação de energia em uma colisão é muito simples: apenas arraste os "carrinhos" da barra de ferramentas, coloque sobre eles sensores e ajuste-os para que eles se movimentem em sentidos opostos. Gráficos de velocidade e energia poderão ser visualizados durante a simulação.

Crocodile Physics combina simulações em circuitos elétricos/eletrônicos com a simulação de elementos mecânicos, além de permitir experiências com ondas e som. Com ele você tem acesso a um laboratório virtual e total controle das simulações. 
1. Applet de ensino do site do Prof. Falstad. Você pode escolher vários tipos de circuitos. Experimente!

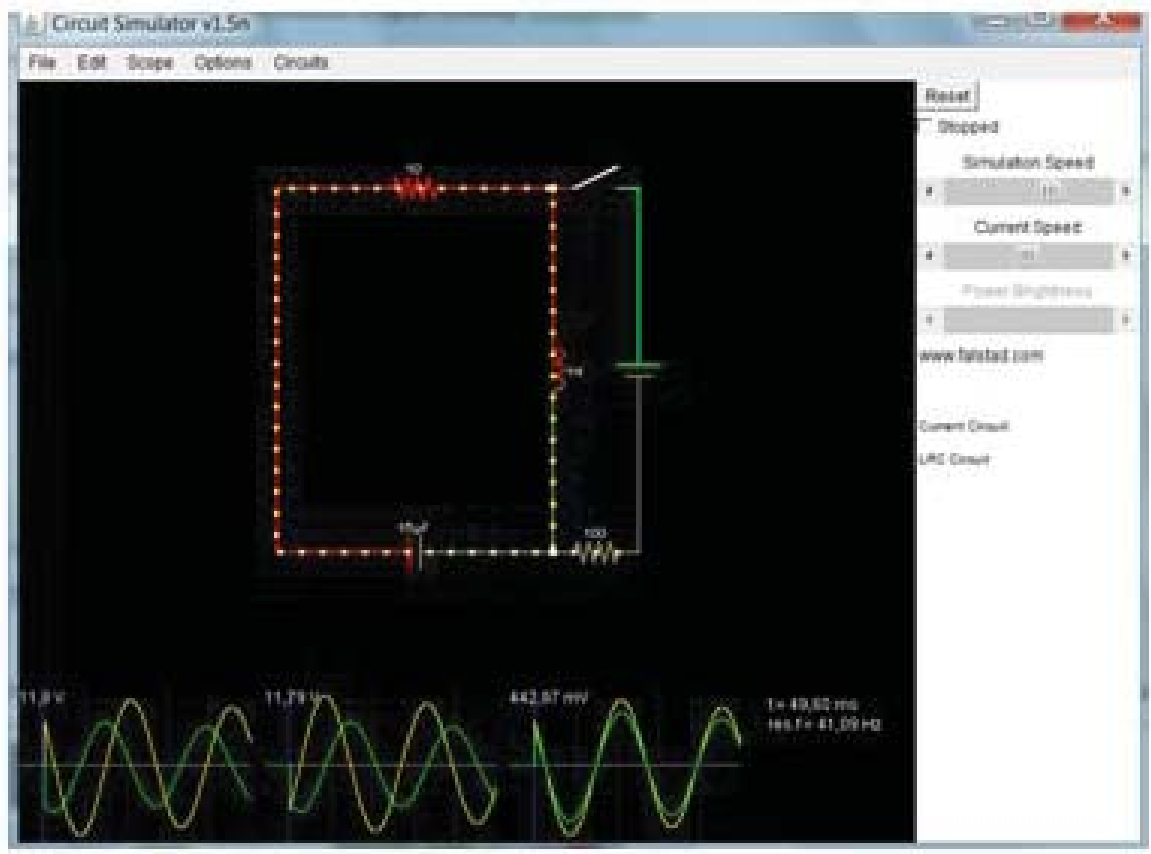

2. Monte o seu circuito elétrico usando o applet do curso da Universidade do Colorado através do link: <https:// sites.google.com/site/professorpifer/ Home/fisica-mix/eletromagnetismo $>$.

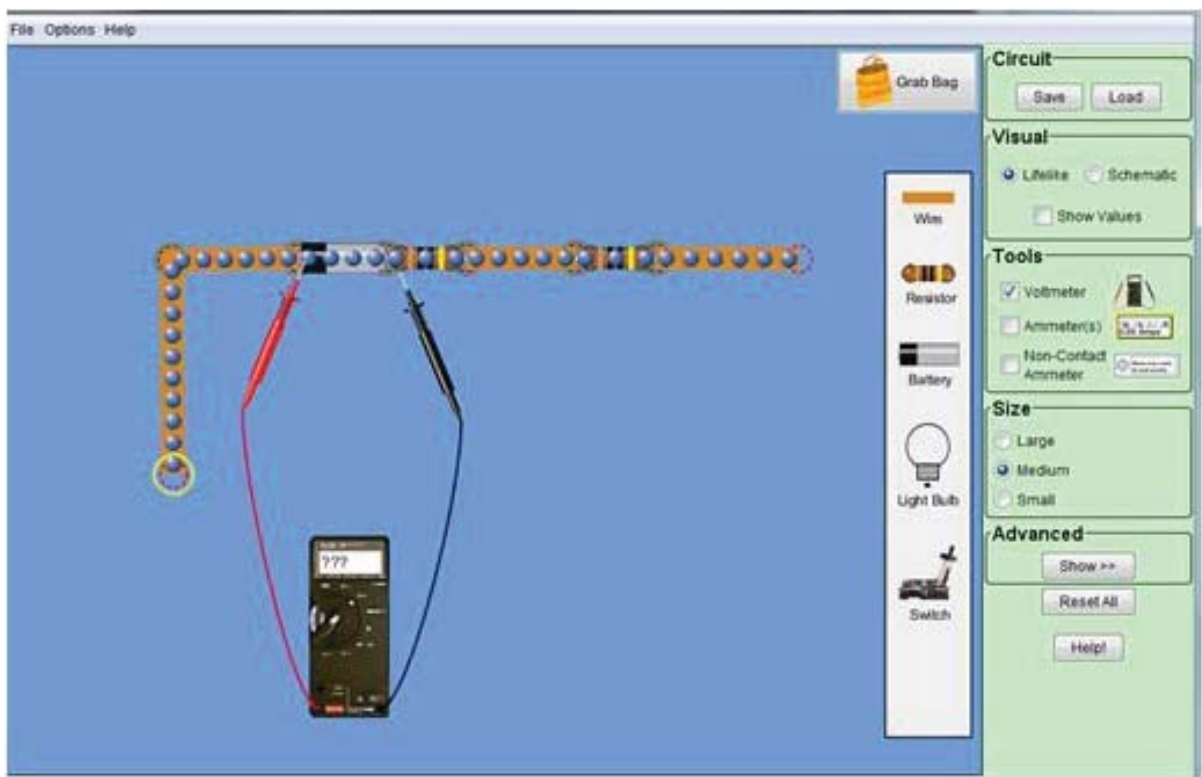


Arraste os componentes para a tela e monte o circuito. Depois selecione um medidor na janela "Tools" e irá aparecerá na tela. Arraste seus terminais para o dispositivo o qual você deseja saber seu valor nominal. Divirta-se.

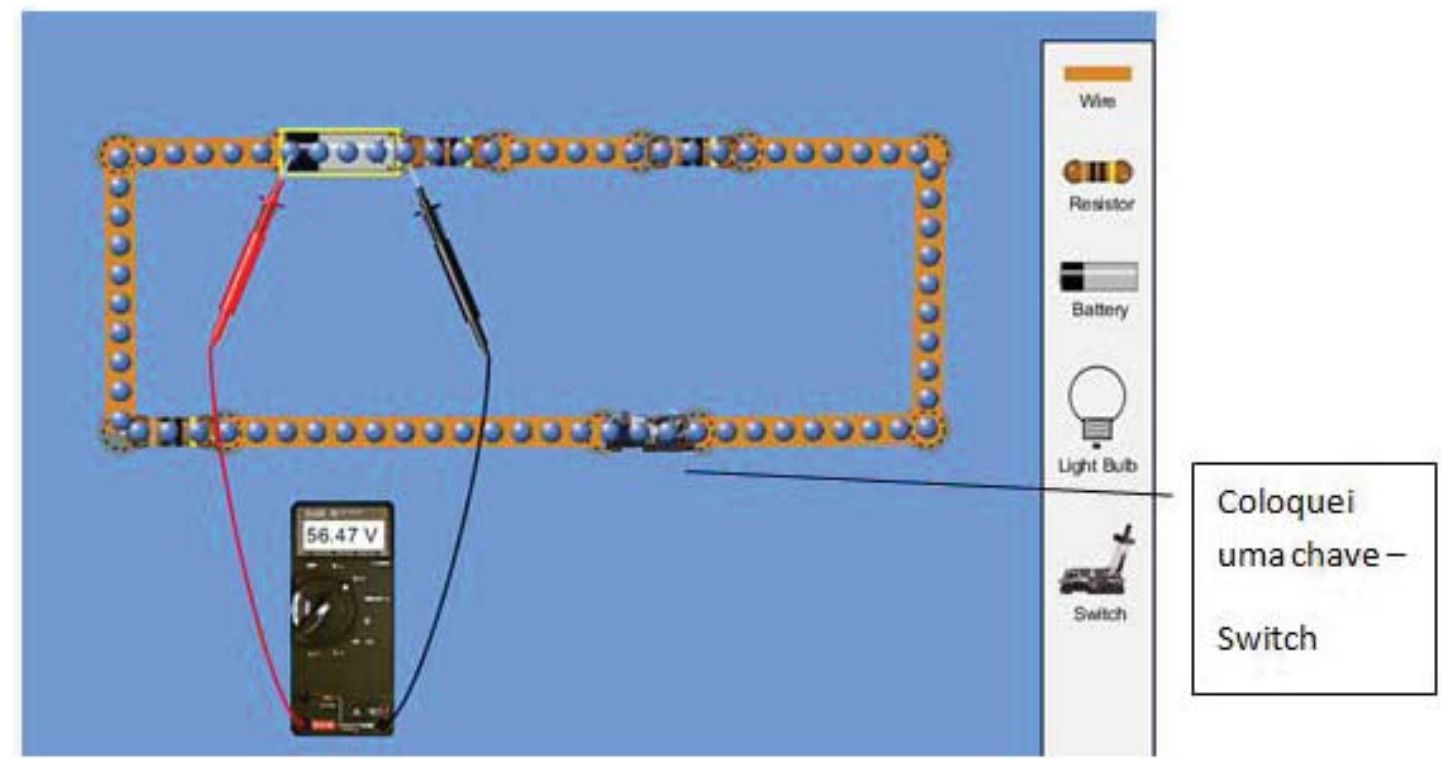

3. Applet sobre associação de resistores do prof. Walter-Fendt. Este applet permite associar até três resistências em série e em paralelo, podendo cada utilizador definir o valor de cada resistência e da tensão nas caixas de texto, não esquecendo de validar cada dado com a tecla "Enter".

Os resultados da associação surgem na parte inferior esquerda da zona amarela, podendo ser colocados no circuito, marcando os botões respectivos na zona verde. Um aparelho de medida de tensão e/ou um de intensidade. Note que esses aparelhos são colocados nos terminais das associações que forem definidas pelo utilizador, bastando para isso, ativar com o rato as zonas de inserção dos diferentes componentes na zona amarela. Os componentes que ficam enquadrados por uma cor amarelo torrado são aqueles que constituem a parte do circuito à qual são aplicados os aparelhos de medida, tal como pode constatar ao inserí-los.

Faça a Atividade de Laboratório de Informática:

O simulador disponível em <http:/ / www.walter-fendt.de/ph14e/combrlc.htm $>$ possibilita a associação de componentes eletrônicos em série ou em paralelo, bem como a determinação da corrente e/ou da diferença de potencial gerada pela presença de cada um dos componentes eletrônicos. Para este plano de aula será encaminhado apenas a associação em série e paralelo de resistores.

Antes de disponibilizar o simulador, você deverá retomar a $1^{\text {a }}$ lei de Ohm e também explicar a $1^{\text {a }}$ lei de Kirchhoff. Vale a pena lembrar que ao explanar sobre a lei de Kirchhoffé importante citar que ela também é conhecida como lei dos nós ou lei das correntes. Você pode obter mais informações 
em < http://dee.feg.unesp.br:8080/Disciplinas/SEL4001/Capitulo_2.pdf ou em $<$ http://www.portalimpacto.com.br/docs/00000DantasVestAula1 1LeisdeKIRCHHOFF.pdf $>$.

Agora, em duplas, disponibilize o recurso 1. Digitem no campo "Resistance" o número 10.0 e clique em "add (in series)". Irá aparecer um resistor em série com o já existente com o valor de $10.0 \mathrm{ohm}$. Com as setas do teclado, volte para o resistor que já existia, com o valor de $100 \mathrm{obm}$, e clique em "Remove". Assim, ele deverá ser removido.

Com o valor da resistência, os alunos deverão calcular matematicamente o valor da corrente que passa sobre este resistor $(i=U / R)$ e depois, com este valor, eles também poderão calcular a diferença de potencial sobre o resistor. Para verificar se os valores previstos estão coerentes com os reais apresentados pela ferramenta, basta clicar em "Amperage" para verificar a corrente sobre o resistor e "Voltage" para verificar a tensão sobre o resistor. É importante lembrar que esta ferramenta só possibilita o cálculo da corrente e da d.d.p. gerada sobre um resistor de cada vez.

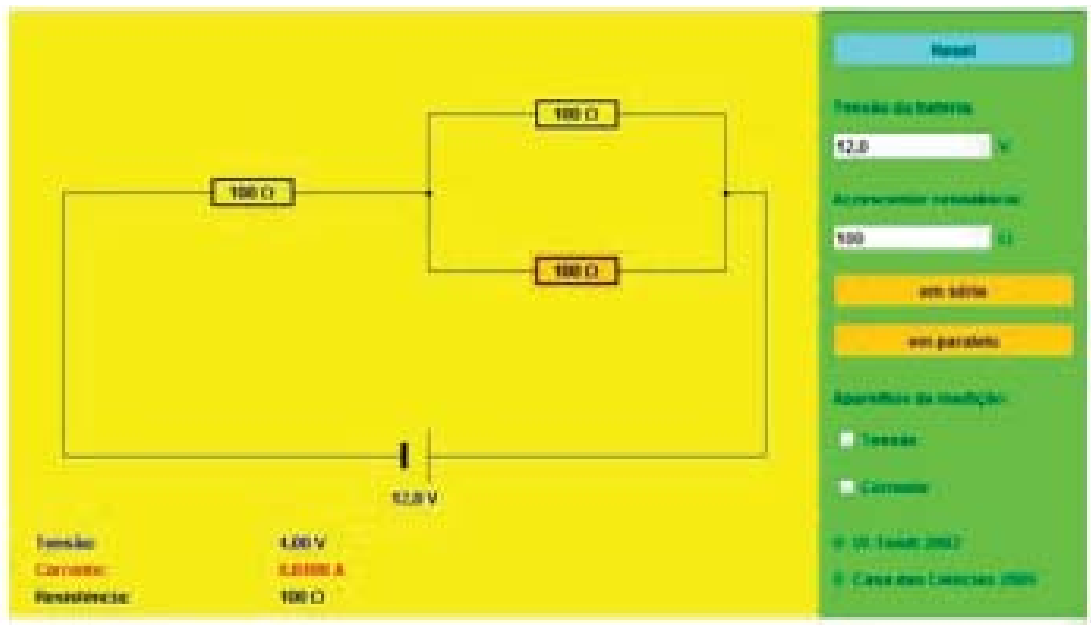

Associação de resistores

(Disponível em: <http://portaldoprofessor.mec.gov.br/fichaTecnicaAula.html?aula=25010>)

\section{ASSOCIAÇÃO DE RESISTORES EM SÉRIE}

Depois que os alunos tenham adquirido certa familiaridade com a ferramenta, peça para que eles insiram outro resistor de $10.0 \mathrm{ohm}$ em série com o primeiro. Para isso, basta clicar novamente em "add (in series)". Peça para que calculem o valor da resistência equivalente, da corrente sobre cada resistor e da d.d.p. gerada pela presença de cada um dos resistores e, com os valores anotados, verifiquem se os dados estão compatíveis com os apresentados pela ferramenta. Eles deverão utilizar estes dados para preencherem a tabela.

Agora, encaminhe o trabalho para a construção de outros dois circuitos com resistores associados apenas em série com os valores que eles tiverem 
interesse. Para cada um dos novos circuitos, eles deverão preencher a tabela calculando os valores da resistência equivalente, da corrente elétrica e da d.d.p. gerada pela presença de cada resistor.

Tabela: Associação de resistores em série em circuitos elétricos

\begin{tabular}{|l|l|l|l|}
\hline $\begin{array}{c}\text { Valor dos resistores } \\
\text { (em ohms) }\end{array}$ & $\begin{array}{c}\text { Resistência } \\
\text { equivalente (em } \\
\text { ohms) }\end{array}$ & $\begin{array}{c}\text { Corrente sobre } \\
\text { cada resistor (em A) }\end{array}$ & $\begin{array}{c}\text { d.d.p. gerada por } \\
\text { cada resistor (em V) }\end{array}$ \\
\hline $\mathrm{R}_{1}=10,0$ & & & \\
\hline $\mathrm{R}_{2}=10,0$ & & & \\
\hline $\mathrm{R}_{1}=$ & & & \\
\hline $\mathrm{R}_{2}=$ & & & \\
\hline $\mathrm{R}_{1}=$ & & & \\
\hline $\mathrm{R}_{2}=$ & & & \\
\hline $\mathrm{R}_{3}=$ & & & \\
\hline
\end{tabular}

Tabela 1 - Associação de resistores em série em circuitos elétricos

\section{ASSOCIAÇÃO DE RESISTORES EM PARALELO}

Peça para que os alunos deixem apenas um resistor de $10 \mathrm{ohm}$ e adicionem outro de $10 \mathrm{obm}$ em paralelo. Para isso, eles deveram clicar em "add (in parallel)" e repetir os procedimentos de cálculo da associação em série para completar a tabela.

Tabela: Associação de resistores em paralelo em circuitos elétricos

\begin{tabular}{|c|c|c|c|}
\hline $\begin{array}{c}\text { Valor dos resistores } \\
\text { (em ohms) }\end{array}$ & $\begin{array}{c}\text { Resistência } \\
\text { equivalente (em } \\
\text { ohms) }\end{array}$ & $\begin{array}{l}\text { Corrente sobre cada } \\
\text { resistor (em A) }\end{array}$ & $\begin{array}{l}\text { d.d.p. gerada por } \\
\text { cada resistor (em V) }\end{array}$ \\
\hline$R_{1}=10,0$ & & & \\
\hline $\mathrm{R}_{2}=10,0$ & & & \\
\hline $\mathrm{R}_{1}=$ & & & \\
\hline $\mathrm{R}_{2}=$ & & & \\
\hline $\mathrm{R}_{1}=$ & & & \\
\hline$R_{2}=$ & & & \\
\hline$R_{3}=$ & & & \\
\hline
\end{tabular}

Tabela 2 - Associação de resistores em paralelo em circuitos elétricos 


\section{VIDEOS AULAS}

1. Outro material bastante explicativo, ilustrativo e com linguagem acessível sobre do funcionamento dos circuitos elétricos pode ser acessado através do link: $<$ http://www.youtube.com/watch?v $=3 \mathrm{TfPjNx} 8 j u M \&$ feature $=$ re lated $>$.

Adiante o vídeo para o tempo de 4 minutos.

2. Física Animada. Associação de resistores com lâmpadas. Acesse através do link: <http://www.youtube.com/watch?v= nj8nQcyuoQ\&feature $=$ related $>$.

4. Física Animada. Associação de resistores. Acesse através do link: $<$ http:// www.youtube.com/watch?v $=$ he0dBNQjZ9U\&feature $=$ related $>$.

5. Assista o vídeo do Prof. Fábio Teixeira através do link: <http://www. youtube.com/watch? $=$ _mMbrQUxJsg $>$.

\section{EXPERIMENTOS DE BAIXO CUSTO}

1. Analise a aula proposta no site do portal do professor abaixo

ASSOCIAÇÃO DE RESISTORES EM CIRCUITOS ELÉTRICO <http://portaldoprofessor.mec.gov.br/fichaTecnicaAula. html?aula $=25010>$

Dados da Aula

- O que poderá aprender com esta aula:

- A determinar a resistência equivalente na associação de resistores;

- Aplicações da $1^{a}$ Lei de Kirchboff;

- Cálculos sobre a diferença de potencial sobre resistores elétricos.

Consideração inicial:

No início desta aula será realizado um experimento que tem como objetivo a compreensão do cálculo da resistência equivalente na associação de resistores. Depois, serão determinadas a diferença de potencial (d.d.p.) gerada e a corrente em um circuito elétrico, com uso da lei de Kirchboff.

Materiais:

- Kit contendo: três resistores de valores iguais e dois resistores com outros valores;

- Ponta de prova;

- Multímetro.

Introdução à aula:

Inicie a aula perguntando aos alunos "de que maneira é possível associar resistores?" e "o que ocorre com a resistência em cada uma das associações?”. 


\section{LABORATÓRIO EXPERIMENTAL}

Após as considerações realizadas pelos alunos, separe-os em grupos de até quatro indivíduos e entregue o kit e um multímetro por grupo. Caso o colégio possua poucos multímetros ou resistores, você poderá realizar os procedimentos demonstrando aos alunos e pedir para que anotem os resultados.

Peça para que cada grupo anote na tabela a sequência de cores presentes nos próprios resistores.

Tabela: Determinando o valor dos resistores

\begin{tabular}{|l|l|}
\hline Sequência de cores & Valor do resistor em Ohms \\
\hline \hline & \\
\hline & \\
\hline & \\
\hline & \\
\hline & \\
\hline & \\
\hline
\end{tabular}

Com o multímetro na função ohmímetro (figura 24) eles deverão medir os valores de cada um dos resistores anotando na coluna "Valor do resistor em ohms". Para realizar a medida da resistência elétrica do componente eletrônico, é importante que o circuito elétrico em que ele está inserido, esteja desligado para não danificar o multímetro. Depois disto ser verificado, peça para que os alunos liguem o ohmímetro, através das pontas de prova, ao elemento que se quer verificar o valor da resistência de modo que o ohmímetro e o componente eletrônico fiquem em paralelo (figura 25). 


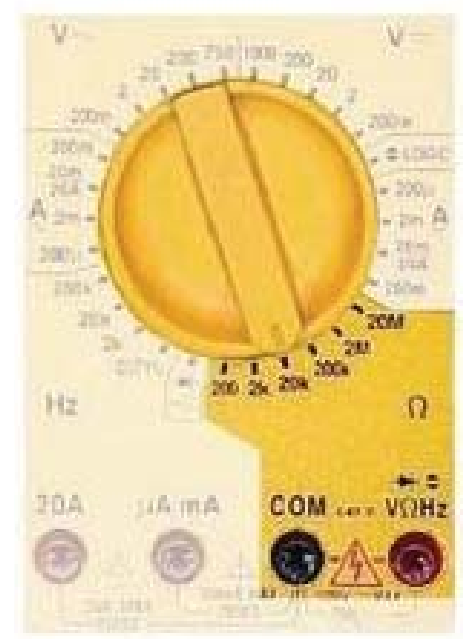

Multímetro na função ohmímetro

(Disponível em: <http://portaldoprofessor.mec.gov.br/fichaTecnicaAula.html?aula=25010>)

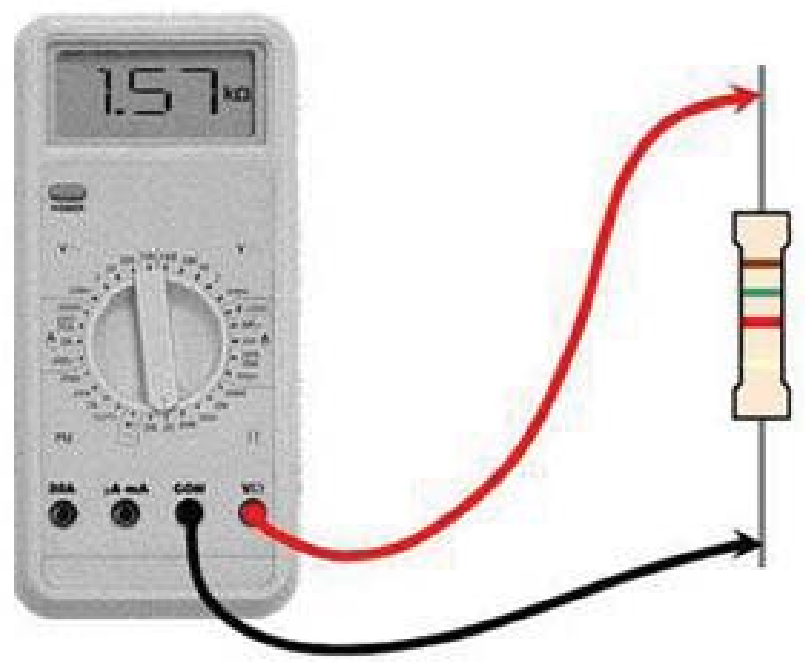

Simulação da medida da resistência de um resistor

(Disponível em: <http://portaldoprofessor.mec.gov.br/ficha'TecnicaAula.html?aula=25010>)

Depois de determinar o valor de cada resistor, você poderá sugerir para que os alunos montem as associações em série e em paralelo utilizando:

$1^{\circ}$. Dois resistores de mesmo valor;

$2^{\circ}$. Três resistores de valores iguais;

$3^{\circ}$. Dois resistores de valores diferentes;

$4^{\mathrm{o}}$. Três resistores de valores diferentes. 

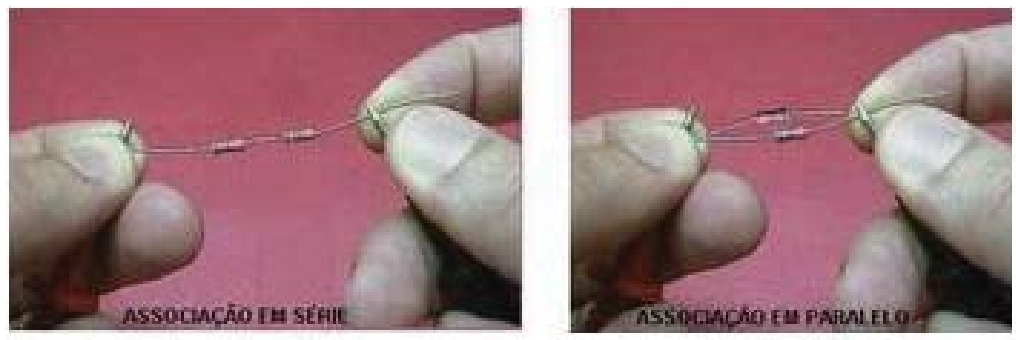

Representação de resistores associados em série e em paralelo em contato com as pontas de prova (Disponível em: <http://portaldoprofessor.mec.gov.br/fichaTecnicaAula.html?aula=25010>)

Peça para que eles anotem os valores na tabela. É importante lembrar que na terceira coluna os alunos deveram anotar o inverso do valor medido.

Tabela: Associação de resistores

\begin{tabular}{|c|c|c|}
\hline $\begin{array}{c}\text { Valor dos resistores utilizados } \\
\text { (em Ohm) }\end{array}$ & $\begin{array}{c}R_{e q} \text { da associação em série } \\
(\text { em Ohm) }\end{array}$ & $\begin{array}{c}\text { 1/R } \mathrm{R}_{\mathrm{eq}} \text { da associação em } \\
\text { paralelo (em Ohm) }\end{array}$ \\
\hline $\begin{array}{l}\mathrm{R}_{1}= \\
\mathrm{R}_{2}=\end{array}$ & & \\
\hline $\begin{array}{l}\mathrm{R}_{1}= \\
\mathrm{R}_{2}= \\
\mathrm{R}_{3}=\end{array}$ & & \\
\hline $\begin{array}{l}\mathrm{R}_{1}= \\
\mathrm{R}_{2}=\end{array}$ & & \\
\hline $\begin{array}{l}\mathrm{R}_{1}= \\
\mathrm{R}_{2}=\ldots \\
\mathrm{R}_{3}=\end{array}$ & & \\
\hline
\end{tabular}

Para realizar a análise dos dados obtidos, você poderá entregar o questionário a seguir:

1. Quando a sequência de cores era igual entre dois resistores, o que ocorria com o valor da resistência medida? Compare os valores utilizando o arredondamento na casa das unidades.

2. Ao somar o valor das resistências utilizadas em cada associação, a resistência equivalente tem seu valor mais próximo da associação em série ou da associação em paralelo?

3. Ao somar o inverso do valor das resistências utilizadas em cada associação, a resistência equivalente tem seu valor mais próximo da associação em série ou da associação em paralelo?

4. Construa uma equação que seja possível calcular a resistência equivalente para associações em série e outra para associações em paralelo e depois verifique no link: <http://www.efeitojoule.com/2008/07/associacao-deresistores.html> como elas são apresentadas. 
Disponibilize o recurso 1 que possibilita a montagem de dois circuitos, um envolvendo resistores em série e outro resistores em paralelo. O circuito é formado por uma pilha e dois resistores. Um amperímetro é usado para determinar a corrente elétrica que circula no circuito. Com este recurso os alunos terão a possibilidade de montar um circuito que contenha uma fonte geradora e dois resistores.
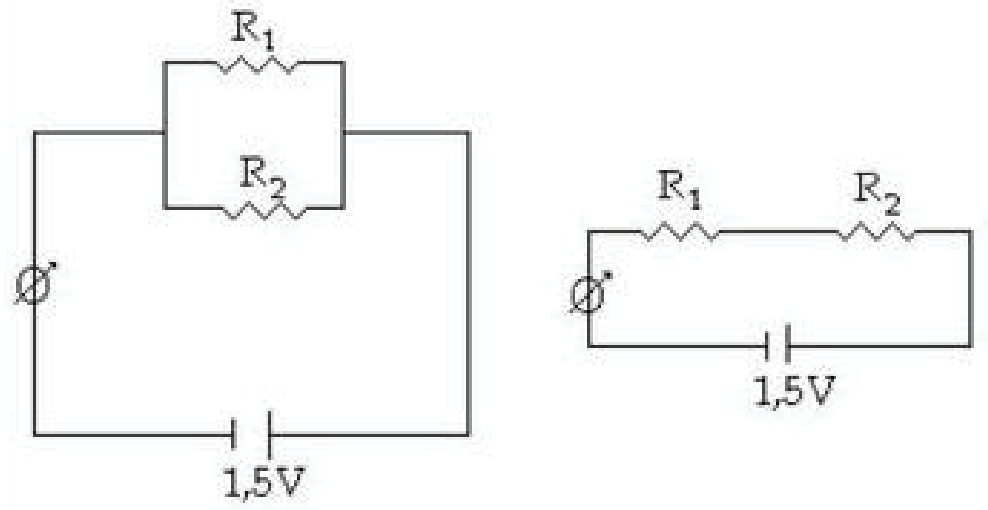

(Disponível em: < http://portaldoprofessor.mec.gov.br/fichaTecnicaAula.html?aula=25010>)

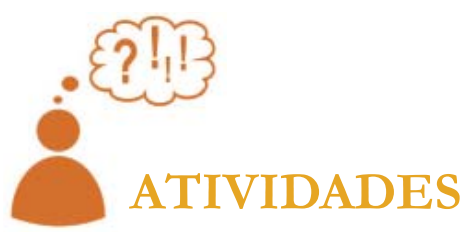

1. Qual dos dois textos, apostila do SENAI ou do projeto GREF, você usaria como referência para ministrar uma aula sobre campo elétrico? Por quê? 2. Você concorda que circuitos elétricos deveriam ser dados como já estivéssemos preparando os nossos alunos para o mercado de trabalho e não para o vestibular? Comente?

3. Tente acessar algum dos simuladores de circuitos elétricos acima e discuta a sua utilidade no ensino?

4. Simuladores de circuitos elétricos ou outros softwares semi profissionais ajudam ou atrapalham o ensino? Comente?

5. Devido ao fato de que muitas escolas não possuem laboratórios muitos físicos e grupos de ensino estão fazendo animações gráficas e applets que demonstram virtualmente experiências de Física. Colocamos alguns links para você acima para você poder explorar alguns deles. Faça um comentário a respeito deles.

6. Com o advento da televisão alguns grupos de ensino e ou instituições estão fazendo vídeos aulas sobre temas interessantes e complexos de Física. Colocamos alguns links para você acima para você poder explorar alguns deles. Faça um comentário a respeito deles.

7. Colocamos acima alguns exemplos e/ou links de experimentos de baixo custo para você analisar a possibilidade de usá-los em sala de aula. Comente se você os usaria ou não como recurso didático em sala de aula? Comente. 


\section{CONCLUSÃO}

O futuro professor deve ter se questionado sobre as novas possibilidades de se ensinar eletricidade e magnetismo. Este deve estar se perguntando por que não se ensinar como estivéssemos preparando o aluno para o mercado de trabalho, e não como a Física fosse uma disciplina abstrata e sem conexão com o cotidiano.

Com a análise dos experimentos de baixo custo e dos recursos de multimídias que colocamos no final da aula o futuro professor deve ter ficado com algumas boas ideias de como este pode enriquecer uma aula sobre associação de resistores.

\section{COMENTÁRIOS SOBRE AS ATIVIDADES}

Em geral os alunos que fazem o curso de licenciatura em Física têm um curso muito superficial ou não têm nenhuma aula de Física. Se têm, usam algum livro texto tradicional, onde a Física é apresentada como uma coleção de definições e fórmulas para ser aplicada em problemas e exercícios. Assim, a maioria deles só possui o conhecimento de física dado na universidade. O estudante de licenciatura deve ficar ciente, depois dessa aula, que é possível se ensinar eletricidade como estivéssemos preparando o aluno para a vida profissional.

Os futuros professores devem ter compreendido o papel central que eles têm na escolha do conteúdo, da técnica e da didática ser utilizada em sala de aula. Este deve ter adquirido uma ideia de como se deve preparar um curso ou apenas uma aula. Eles devem compreender que uma aula é um processo dinâmico e orgânico.

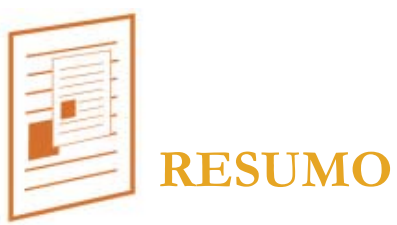

Como o tema dessa aula foi: qual a possibilidade de se usar material didático confeccionado para curso profissionalizante?, tomamos o texto confeccionado para o curso do SENAI (Tubarão) e analisamos a possibilidade de usá-lo em curso regular do Ensino Médio. Para motivar mais ainda o futuro professor a usar formas alternativas de se ensinar, colocamos novamente o texto do GREF para este assunto.

Encerramos a aula com a apresentação e discussão sobre a possibilidade de se usar softwares de simulação e designer de circuitos no ensino de circuitos elétricos.

Em seguida apresentamos vários experimentos de baixo custo para que 
o aluno explore as possibilidades que estes oferecem para se ministrar um curso usando mais ferramentas fenomenológicas e menos formais. Colocamos dois excelentes applets de ensino como recurso de simulação de fenômeno físico para ser explorado. Não colocamos mais, pois a maioria deles serve mais para explicar a lei de Coulomb do que o fenômeno da eletrização.

Como há ótimos vídeos de ensino colocamos alguns deles como referência, e deixamos sua exploração como atividade para os estudantes, pois no curso de Instrumentação I não usamos os vídeos didáticos como ferramenta didática principal.

\section{RESPOSTA ÀS ATIVIDADES}

1) As duas

2) Sim, pois seria mais prático e motivante.

3) Espero que achem legal e útil.

4) Ajudam. Tornam a matéria mais real.

5) São muito bons. Resposta pessoal

6) São muito bons. Resposta pessoal.

7) São muito bons. Resposta pessoal.

\section{REFERÊNCIAS}

APPLETS-ELETROMAGNETISMO. Universidade do Colorado. Disponível em: <https:// sites.google.com/site/professorpifer/Home/fisicamix/eletromagnetismo>. Acesso em 15/10/2011.

ESTEVÃO, Vanks. Efeito Joule. Disponível em: < http://www.efeitojoule. com/2008/07/associacao-de-resistores.html>. Acesso em 15/10/2011. FENDT, W. Combinations of Resistors, Inductors and Capacitors. Disponívem em: <http://www.walter-fendt.de/ph14e/combrlc.htm>. Acesso em 15/10/2011.

GREF - Grupo de Reelaboração do Ensino de Física, Instituto de Física da USP - Leituras de física - Gref - Eletromagnetismo para ler, fazer e pensar - versão preliminar. Disponível em: <http://www.if.usp.br/gref/ eletro/eletro2.pdf > . Acesso em 15/10/2011.

OLIVEIRA, J. Eletrotécnica Básica - Instrumentação. SENAI/CST (Companhia Siderúrgica de Tubarão). Disponível em: http://www.joinville. ifsc.edu.br/ jlcurzel/Eletronica_Digital_I/Mais\%20apostilas/apostila_de_ eletronica_digital\%28CST\%29.pdf. Acesso 10/10/2010.

SIMULADORES DE CIRCUITOS ELETRÔNICOS. Disponível em http://www.eletrocalc.tirech.com.br/eletrocalc/index.php?option=com_co ntent\&view $=$ article\&id $=8 \&$ Itemid $=9$. Acesso em 15/10/2011. 
VASCONCELOS, Laércio. Eletrônica básica - parte 1/4. Disponível em: $<$ http://www.laercio.com.br/artigos/hardware/hard-052/hard-052.htm>. Acesso em 15/10/2011.

YOUTUBE. O Mundo de Beakman eletricidade beakmania lâmpada 1992 (01). Disponível em: <http://www.youtube.com/watch?v=3TfPjNx 8juM\&feature $=$ related $>$. Acesso 15/10/2011.

Física Animada. Associação de resistores (lâmpadas). Disponívelem: $<$ http://www.youtube.com/watch?v=_nj8nQcyuoQ\&feature=related $>$. Acesso em 15/10/2011.

Física Animada. Associação de resistores. Disponível em: $<$ http:/ / www.youtube.com $/$ watch?v $=$ he0dBNQjZ9U\&feature=related $>$. Acesso em 15/10/2011.

Associação de resistores. Disponível em: < http://www.youtube. $\mathrm{com} /$ watch?v=_mMbrQUxJsg $>$. Acesso em 15/10/2011. 


\section{Aula 6}

\section{O PROJETO PEF E O EFEITO JOULE}

META

Fazer com que o estudante comece a pensar no ensino de ciências como algo "orgânico"

que está em profunda transformação.

Fazer com que os alunos percebam através de um texto básico complementado com atividades lúdicas, applets de ensino, vídeos, e com materiais de baixo custo que o conceito da conservação da energia e o efeito Joule, em particular, podem ser apreendidos de forma simples e divertida.

Analisar dois textos sobre o tema "efeito Joule" de modo que o aluno possa analisar como

o projeto PEF (Projeto de Ensino de Física) apresentava este conceito e como um livro didático apresenta este tema.

OBJETIVOS

Ao final desta aula, o aluno deverá: estar ciente das novas possibilidades e dos desafios que envolvem o ensino de ciências em

geral.

Ter compreendido que as ciências naturais estão baseadas na experimentação e que esta é feita de ensaios, experiências e medidas levando a compreensão e matematização dos conceitos físicos (naturais em geral).

PRÉ-REQUISITOS Os alunos deverão ter cursado as disciplinas Psicologia da Educação, Física A e B. 


\section{INTRODUÇÃO}

Na disciplina de Instrumentação I fizemos uma apresentação resumida dos projetos de ensino de Física, porém, não analisamos nenhum texto em particular. Neste curso de Instrumentação III, vamos comparar um tópico do curso do eletromagnetismo tirado de um livro texto, no nosso caso do Ramalho $6^{a}$ edição, e vamos comparar com o mesmo tópico de um projeto de ensino em particular. Nesse aula, iniciaremos com a apresentação o capítulo do efeito Joule do projeto PEF.

\section{HISTÓRIA DO PROJETO DE ENSINO DE FÍSICA}

O PEF teve seu início com a necessidade de readaptação do ensino devido a Lei 5692/1971 (que reestruturou o ensino de $1^{\circ}$ e $2^{\circ}$ graus). Por conta dessa lei foi lançado o Projeto Nacional para a Melhoria do Ensino de Ciências.

Durante a realização do primeiro SNEF (Simpósio Nacional de Ensino de Física), muitos professores e pesquisadores na área do ensino de Física demonstraram insatisfação com a utilização do material do PSSC.

Com isso, eles iniciaram o processo de criação de um material para o ensino de Física nacional. Após algumas tentativas desastradas, obtiveram verbas do Instituto de Física da Universidade de São Paulo, e foi criado o PEF.

O que estava ocorrendo? Na década de 60 e 70, ainda havia uma disputa entre os EUA e a antiga União Soviética para saber qual era o melhor sistema de governo. Os dois países se digladiavam em uma corrida armamentista e aero espacial. Nesse contexto histórico, ilustrado pelo texto abaixo, surgiram os grandes projetos de ensino. O PEF surgiu na década de 70 no Brasil embalado por estas grandes reformas.

Referindo-se ao período, escreve Jenkins: "a Segunda Guerra Mundial foi para o ensino de Ciências, assim como para o resto, um divisor de águas".

Um marco invocado para datar o início do processo foi o progresso científico soviético, evidenciado pelo lançamento do Sputnik, em 1957.

Durante essa fase, chamada por Hurd de "período de crise no ensino de Ciências", surgiram os embriões dos grandes projetos curriculares. Estes alteraram os programas das disciplinas científicas nos Estados Unidos e, posteriormente, tais unificações ocorreram também em países europeus, bem como em outras regiões influenciadas por essas tradicionais metrópoles culturais. (E.W.Jenkins, From Armstrong to Nuffield. Londres, John Murray, 1979, p. 97) 
Fruto destas disputas, no Brasil, por ele estar aliado aos países do eixo capitalista, o Estados Unidos da América concretizou sua intervenção externa através do MEC-USAID (Ministério da Educação e United States Agency for International Development) em 1964, que foi na realidade, um grupo de acordos entre o governo americano e o governo brasileiro, no âmbito educacional, em síntese, este acordo fez uma espécie de importação dos projetos educacionais elaborados por pesquisadores americanos, não por imposição, mas também por vontades de professores brasileiros que interessaram-se por alguns projetos que estavam sendo desenvolvidos nos Estados Unidos.

\section{SITUAÇÃO SÓCIO-POLÍTICA}

Pós-Guerra: O mundo estava vivendo ainda um clima de Pós-Guerra. A pesar da Segunda Guerra Mundial ter terminado em 1945, os EUA e a União Soviética continuavam sustentando pequenas guerras ao redor do mundo. A principal era a do Vietnam. Nessa época os EUA e a União Soviética estavam disputando quem fazia o maior número de mísseis e armas nucleares.

Luta Contra Ditaduras: Estávamos vivendo o problema da expansão do comunismo pelo mundo e a manutenção dos regimes ditatoriais pelo EUA. Os regimes ditatoriais eram eminentemente militares e no Brasil começou um grande programa de desenvolvimento. Nessa época houve um grande desenvolvimento da indústria militar brasileira: Embraer, ITA, Engesa, e a criação do Instituto de Pesquisa de Energia Nuclear (IPEN). A marinha brasileira começou a fazer pesquisa sobre reatores nucleares para equipar navios de guerra, propulsão nuclear, e se diz que o Brasil estava desenvolvendo um projeto de bomba nuclear.

Industrialização: $\mathrm{Na}$ década de 60 o presidente Juscelino Kubistchek (JK) começou a instalação do parque industrial das montadoras de automóvel no Brasil. Criou a Indústria Nacional de Motores (FNM) e começou um programa de criação de autoestrada pelo Brasil. Na década de 70 vivíamos um período conhecido como o "milagre brasileiro" onde foi criada a Petrobrás e outras grandes empresas. Nessa época, para sustentar o crescimento nacional, foram criadas várias usinas hidroelétricas e portos pelo Brasil.

Curso Ginasial Propedêutico: nessa época os cursos ginasiais (fundamental) e do antigo colegial (ensino médio) eram, como denominados atualmente "verbalistas", carregados com muita literatura e o ensino de latim era mais importante que o de ciências. Como podemos ver no texto abaixo: Uma das mudanças pretendidas era substituir os chamados métodos tradicionais por uma metodologia ativa. Aqueles configuravam o ensino verbalista, centrado no uso de livros-texto e na palavra do professor, cuja principal função era a transmissão de informações 
que deveriam ser memorizadas e repetidas. Já nessa época, um dos grandes objetivos visados foi o de proporcionar maior liberdade e autonomia ao aluno para participar ativamente do processo de aquisição de conhecimentos.

O ensino de Ciências era, como hoje, teórico, livresco, memorístico, estimulando a passividade. As modificações reclamadas centravam-se em alguns pontos básicos:

A expansão do conhecimento científico, ocorrida durante a guerra, não tinha sido incorporada pelos currículos escolares. Grandes descobertas nas áreas de Física, Química e Biologia permaneciam distantes dos alunos das escolas primária e média que, nas classes, aprendiam muitas informações já obsoletas. A inclusão, no currículo, do que havia de mais moderno na Ciência, para melhorar a qualidade do ensino ministrado a estudantes que ingressariam nas Universidades, tornara-se urgente, pois possibilitaria a formação de profissionais capazes de contribuir para o desenvolvimento industrial científico e tecnológico. A finalidade básica da renovação era, portanto, formar uma elite que deveria ser melhor instruída a partir dos primeiros passos de sua escolarização. (Notas para a História da Educação - Manifesto dos Pioneiros da Educação". Revista Brasileira de Estudos Pedagógicos, INEP, 108(34), junho-setembro/1960)

Nessa época tínhamos um grande impasse. Formar grandes intelectuais com grande cabedal de informações e literatura ou formar profissionais para a indústria. Isto é, devemos ter cursos extensos e com muita literatura ou devemos ter cursos mais enxutos com somente o necessário para o cidadão exercer suas atividades profissionais.

Baseado nesse impasse, o regime militar decretou a Lei 5.692/71, que visava entre outras coisas introduzir o ensino profissionalizante.

Nessa época se instaurou o ensino profissionalizante com o único intuito de formar o trabalhador para a industrialização do país. Esses métodos de ensino estavam baseados na filosofia beheaviorista e o estudo dirigido foi introduzido no Brasil.

Nessa época começou a degradação da escola pública que culminou com a rebelião das escolas particulares. Com a instalação do parque industrial brasileiro, surgiram as grandes escolas de engenharia (FEI e Mauá), e começamos a ver o aparecimento dos cursinhos pré-vestibulares.

Que tipo de formação? Nessa época começou a formação de professores e trabalhadores a partir do estudo dirigido. Isto é, os livros textos traziam um resumo da teoria e a avaliação (treinamento) era feita através de testes. Tínhamos o estudo dirigido. Atrás dessa filosofia de ensino estava a concepção de que trabalhador é a mesma coisa que a massificação do ensino. Daí resultou em uma má formação dos professores e consequentemente da população em geral.

Mas, fazer ciências ou formar cientistas requer capacidade de pensar 
critica e logicamente. Daí surgiu uma rebelião da comunidade científica que resultou no PREMEN (Programa de Expansão e Melhoria do Ensino - 1972).

\section{SURGIMENTO E CARACTERÍSTICAS DO PEF}

Depois de decretada a lei 5692/71, a qual implantou o ensino primário e secundário criando bases e diretrizes para o mesmo programa, foram sendo criados com a intenção de readequar a antiga grade curricular com as novas diretrizes impostas pela lei 5692/71. Um desses programas criados foi o Programa Nacional para a Melhoria do Ensino de Ciências, o qual foi responsável por fomentar ideias de novos projetos que já estariam sendo desenvolvidas muito antes da implantação da nova lei, tendo em vista o grande descontentamento de educadores para com os projetos implantados pelos convênios gerados pelo MEC-USAID. Isto ficou claro durante a realização do $1^{\circ}$ Simpósio Nacional de Ensino de Física (ISNEF) da SBF (Sociedade Brasileira de Física), realizado em 1970 em São Paulo, que teve, dentre as diversas moções aprovadas, uma que solicitava que fossem concedidas verbas para a implantação de projetos brasileiros de elaboração de textos e material de ensino de Física.

Já, em 1969 um grupo de professores coordenados pelos professores Ernest W. Hambúrguer e Giorgio Moscati, do Instituto de Física da Universidade de São Paulo, estavam se reunindo para discutir e planejar o desenvolvimento de textos e materiais de ensino de Física para o segundo grau, tendo elaborado um "Projeto Inicial" que após algumas tentativas fracassadas, obteve recursos do Instituto de Física da USP para o seu desenvolvimento dando origem ao PEF. De acordo com relatos de professores que participaram do PEF, o projeto ganhou apoio e credibilidade, graças ao prestígio de seu idealizador o Professor Ernest W. Hambúrguer, o qual era pesquisador da área de Física nuclear e possuia um grande renome entre a comunidade cientifica.

\section{PROJETO DE ENSINO DE FÍSICA (PEF)}

Tal projeto tinha dentre alguns de seus objetivos principais proporcionar aos alunos e professores materiais didáticos de qualidade e adequados à realidade brasileira, assim como, preparar os professores para o exercício de suas funções na perspectiva da legislação vigente criando condições para a elaboração de material por professores e universidades brasileiras.

De acordo com os dados constantes no Guia do Professor (1980), na sua versão final, o PEF constituiu-se de quatro conjuntos de textos e materiais experimentais (Mecânica 1 e 2, Eletricidade e Eletromagnetismo) e de um Guia do Professor, destinados ao ensino do segundo grau 
(denominação da época para o Ensino Médio), tendo sido elaborado no Instituto de Física da Universidade de São Paulo (IFUSP) mediante convênios com a FENAME (Fundação Nacional de Material Escolar) e o PREMEN, tendo como coordenadores os profs. Ernest W. Hamburger e Giorgio Moscati e envolvendo uma equipe de cerca de trinta pessoas, que incluiu professores universitários e secundários de Física, pesquisadores em Física, programadores visuais, redatores, fotógrafos, entre outros. $\mathrm{Na}$ sua apresentação, o Guia do Professor esclarecia que os direitos autorais do PEF tinham sido cedidos à FENAME, do Ministério da Educação e Cultura (MEC), que ficou responsável pela publicação e distribuição dos fascículos e do Guia do Professor, bem como pela produção e distribuição dos conjuntos experimentais.

Os textos foram publicados em fascículos, cada um deles correspondendo a um capítulo e que eram compostos, em geral, por um texto principal, por exercícios de aplicação, por um texto optativo e por uma leitura suplementar, estes últimos previstos para aquelas classes que dispusessem de um número maior de aulas semanais ou para atender a alunos mais interessados.

- Esse material didático estaria baseado em:

- História da Ciência

- Experimentação

- Construção do conhecimento

- Questões de reforço para cada tópico

- Exercícios complementares

Segundo os próprios autores:

Este é um curso no qual você terá participação ativa. Isto porque ele não é um texto pronto, que você só precisa ler e aceitar o que está escrito; muito ao contrário, para seguir o curso você deverá completar o texto, escrevendo as respostas às questões e resultados de experiências.

Entretanto, o curso se inicia com uma apresentação do modelo atômico da matéria, modelo este que não admite comprovação experimental direta em classe. Você deverá se familiarizar com esse modelo, cuja utilidade só se tornará mais evidente à medida em que você avançar no curso.

Dessa maneira, a parte experimental dos dois primeiros capítulos é muito reduzida, mas seu conteúdo é extremamente importante para a compreensão dos assuntos abordados nos capítulos seguintes; a partir do Capítulo 3, a situação se inverte: a quantidade de informações se torna pequena em comparação com o número de experiências que se deve realizar. (Projeto de Ensino de Física, Cargas e Estrutura da Matéria, vol. Eletricidade, fascículo 1, p. 1-1) 
O PEF apesar de se auto intitular como sendo um material para alunos que não mais utilizariam a Física em sua vida acadêmica ou profissional, preocupou-se em inserir no aprendizado do aluno do segundo grau conceitos de Física moderna como a relatividade e também assuntos, como astronomia, que poderiam motivar o aluno a interessar-se sobre a Física, assim como outras abordagens práticas-científicas que eram explanados em partes suplementares ao texto principal.

\section{DIDÁTICA DO PEF}

O PEF utilizou-se de técnicas pedagógicas modernas, onde o aluno participava ativamente no aprendizado, deixando para trás as aulas totalmente expositivas.

Com relação aos textos podemos dizer que eles eram apresentados de forma auto-explicativa e a maior parte deles expunham os conceitos da Física de forma conceitual sem muitas fórmulas, porém bem exemplificados por fotos comuns e estroboscópicas, ou seja, havia um bom uso de recursos gráficos para melhor entendimento por parte dos alunos.

O leitor era convidado a raciocinar usando as concepções obtidas através de questões, as quais eram intercaladas com o texto conceitual. Havia uma preocupação com que o aluno não absorvesse tacitamente o assunto, a qual ficava claro na parte de apresentação dos volumes onde foi dedicado um texto ao estudante, fornecendo uma metodologia para o melhor aproveitamento do curso.

No que se refere aos experimentos, eles também apareciam durante o decorrer dos textos. Com uma simples leitura e com o material do experimento em mãos o aluno era capaz de fazê-lo sem maiores dificuldades. As questões referentes ao experimento induziam o aluno a realizar uma observação detalhada.

Como o projeto foi realizado para que o aluno interagisse em sala de aula ele exigia um certo esforço deste, pois sem a leitura de todo o texto seria impossível de realizar os experimentos. O próprio Guia do Professor expõe que ler o texto, responder as questões, resolver exercícios, realizar experimentos, efetuar discussões com colegas e professor são atividades principais que o aluno exerce durante a aula.

Em contra partida ao esforço do aluno entrava o papel do professor, que segundo afirmam os autores do projeto deveria ser de forma ativa, auxiliando, coordenando, estimulando o raciocínio para que os alunos se auto-esclarecessem suas dúvidas e finalmente complementando a aula com exemplos diferentes e melhores do apresentado no texto. De acordo com o Guia do Professor, haveria de existir um sobre esforço inicial do professor, pois ele poderia se deparar com certa resistência dos alunos, os quais estariam acostumados e acomodados com as aulas simplesmente exposi- 
tivas. É nesse ponto que o papel do professor seria crucial para o sucesso do curso, pois inicialmente ele catalisaria a fase de aceitação do curso por parte dos alunos.

\section{CONSIDERAÇÕES}

No sentido de preparo de pessoal levando a discussões sobre o ensino de Física no Brasil, qual o melhor método a ser aplicado no ensino etc. Porém foi um fracasso devido à dificuldade de aplicação; treinamento dos professores, escassez de material. O MEC deveria fornecer os materiais às escolas juntamente com os kits experimentais e abastecer com regularidade os pontos de distribuição, e isto não aconteceu, ficando assim este fato como um dos principais motivadores do insucesso do Projeto de Ensino de Física.

Para termos uma melhor visão do projeto PEF, segue abaixo, o texto didático confeccionado para se ensinar o Efeito Joule.

\section{SUMÁRIO}

\section{CAPÍTULO 8 - Efeito Joule}

1. Transformações de energia ................................................. 8 - 3

2. Dissipação de energia dos elétrons num metal ................ 8 - 3

3. Cálculo da energia térmica produzida ............................... 8 - 9

4. Potência elétrica .............................................................. 8 - 10

5. Efeito Joule ……................................................................. 8 - 12

6. Exercícios de aplicação ....................................................... 8 - 20

Leitura Suplementar

Supercondutividade ................................................... $8-26$

Muitas vezes uma descoberta importante é feita com aparelhamento muito simples. O que importa é a habilidade do experimentador em formular experiências significativas, levando em conta somente os efeitos importantes. A figura é copiada do artigo que Joule publicou na revista científica Philosophical Magażine, em 1841, e mostra o aparelho que levou a concluir, nas palavras de Joule, que: "quando uma corrente de eletricidade voltaica é propagada por um condutor metálico, o calor produzido em dado tempo é proporcional ao produto da resistência do condutor pelo quadrado da intensidade elétrica”. 


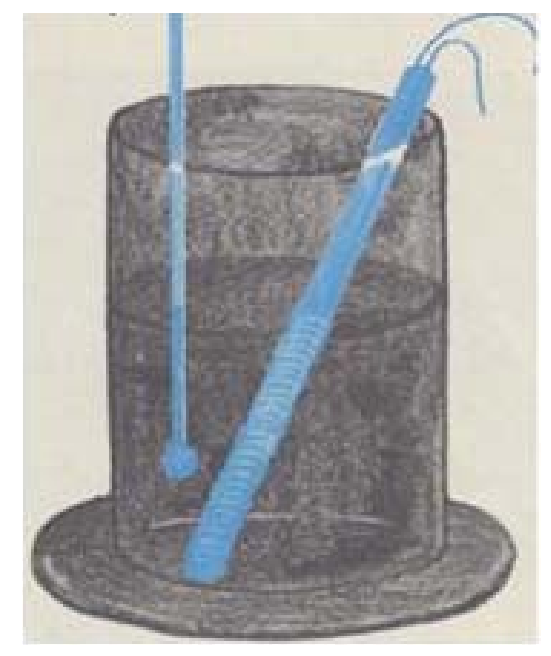

PEF - Efeito Joule, vol. Eletricidade, fasc. 08, p. 8-1. Disponível em <http:// www.cienciamao.usp.br/tudo/exibir. php? midia $=$ pef\&cod=_eletricidadeefeitojoulec $>$

\section{EFEITO JOULE}

Enquanto uma corrente elétrica flui em um circuito, está havendo transformação de energia. Assim, por exemplo, a energia química de uma pilha ligada a um circuito transforma-se em energia elétrica, térmica, além de outras formas de energia: luminosa, magnética, etc.

A produção de energia térmica pela corrente elétrica, que é uma transformação de energia elétrica em energia térmica, chama-se efeito Joule e é o assunto deste capítulo.

James Prescott Joule viveu na Inglaterra, de 1818 a 1889. Nessa época realizavam-se grandes esforços para aumentar o rendimento das máquinas a vapor utilizadas nas indústrias e ferrovias. Joule iniciou seus trabalhos com a finalidade de desenvolver máquinas mais eficientes para a fábrica de cerveja de seu pai.

Até então não se havia chegado a conclusões claras sobre o calor. Alguns acreditavam na teoria do calórico, segundo a qual o calor seria uma substância chamada calórico, que podia realizar trabalho, quando passava de um corpo em temperatura alta para um corpo em temperatura baixa. Outros, porém, e entre eles Joule, defendia a idéia, hoje aceita, de que o calor é uma forma de energia e quando passa de um corpo a outro não abriga à passagem de matéria.

Muitas experiências foram realizadas e Joule conseguiu demonstrar que a quantidade de calor produzido a partir de energia mecânica é sempre igual ao trabalho realizado. Um dos aparelhos utilizados por Joule em suas experiências está ilustrado na página 1 do capítulo 11, de Mecânica 2, do PEF. Outro, você pode ver acima. 
Por causa dessas experiências, o nome de Joule é lembrado na unidade de energia $(1 \mathrm{~J}=1 \mathrm{~N}$ X $1 \mathrm{~m})$ e no efeito de aquecimento dos fios pela corrente elétrica: efeito Joule.

Os conceitos de trabalho, energia potencial e princípio de conservação de energia são importantes neste capítulo. Há uma discussão detalhada desses conceitos no volume Mecânica 2, do PEF, capítulos 10 e11; consulteos se tiver dúvidas. A energia potencial elétrica, por sua vez, está discutida no capítulo 3 deste volume.

(PEF - Efeito Joule, vol. Eletricidade, fasc. 08, p. 8-1)

\section{TRANSFORMAÇÕES DE ENERGIA}

Com um simples toque de botão obtemos energia luminosa. Parece elementar, não? No entanto, essa energia, obtida de modo aparentemente simples, passou por uma série de transformações. A energia potencial de uma certa quantidade de água, numa elevação, foi transformada em energia cinética ao descer da elevação. Essa energia cinética da água foi transferida para rodas (turbinas), ligadas a dispositivos (dínamos)* que, ao girarem, provocaram o aparecimento de uma corrente elétrica. Levada por fios condutores, essa corrente elétrica chegou ao local em que estamos e, ao passar pela lâmpada, foi transformada em energia térmica (se a lâmpada for do tipo incandescente) e, finalmente em energia luminosa.

A energia luminosa emitida pela lâmpada é, então, resultante de transformações sucessivas da energia potencial da água na elevação. Essa energia, por sua vez, é devida à energia solar, responsável pela evaporação da água e formação da chuva.

Neste caso, o importante para obter a energia na forma elétrica é conseguir fazer girar a turbina presa ao dínamo. A energia que, no nosso exemplo, proveio da energia potencial da água na elevação poderia ser obtida da energia química contida em combustíveis como carvão, madeira, gasolina, etc., que também é, na origem, proveniente do Sol. Neste caso, a energia é liberada na queima dos combustíveis, em motores que fazem girar o dínamo. Poder-se-ia também aproveitar a energia nuclear, armazenada nos núcleos atômicos. A energia nuclear já está sendo utilizada em pequena escala e até o fim do século espera-se que seja ela a responsável pela produção de grande parte da energia elétrica a ser consumida. 


\section{DISSIPAÇÃO DE ENERGIA DOS ELÉTRONS NUM METAL}

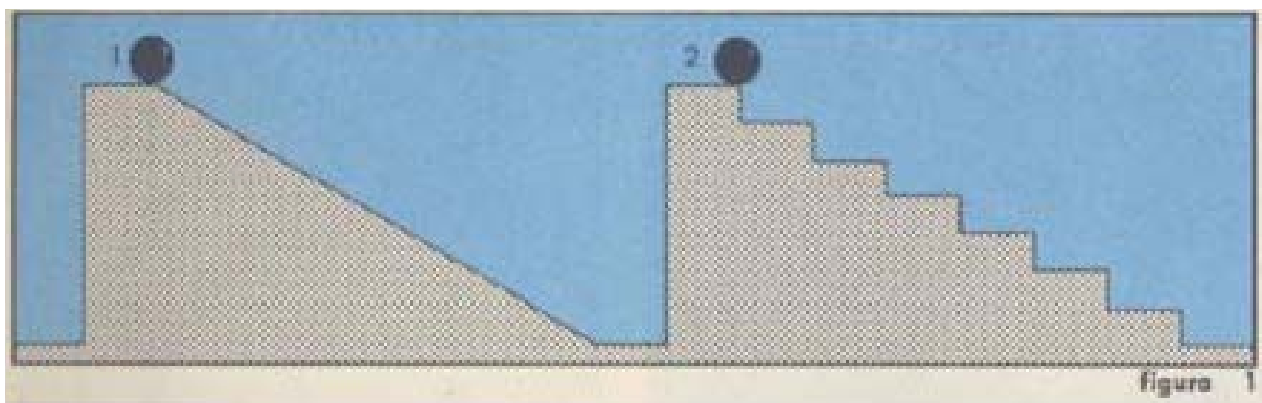

os caminhos que cada uma das bolinhas deve percorrer na descida

PEF - Efeito Joule, vol. Eletricidade, fasc. 08, p. 8-3. Disponível em < http://www.cienciamao.usp. br/tudo/exibir.php?midia=pef\&cod=_eletricidadeefeitojoulec $>$

Quando se aplica uma diferença de potencial entre as extremidades de um fio, ligando-as, por exemplo, a uma pilha, aparece dentro dele um campo elétrico. Nesse campo, os elétrons ficam sujeitos a forças que tendem a deslocá-las no sentido do pólo positivo.

Vamos comparar o movimento dos elétrons livres no interior de um condutor, sob ação do campo elétrico, com o movimento de bolinhas de aço no campo gravitacional.

Duas bolinhas foram levantadas até uma altura h, acima do chão. A figura 1 mostra os caminhos que cada uma das bolinhas deve percorrer na descida. A primeira desce uma rampa lisa, a segunda desce uma escada; nos choques com os degraus a bolinha 2 perde uma parte considerável de sua energia, que se transforma em energia térmica.

(PEF - Efeito Joule, vol. Eletricidade, fasc. 08, p. 8-3)

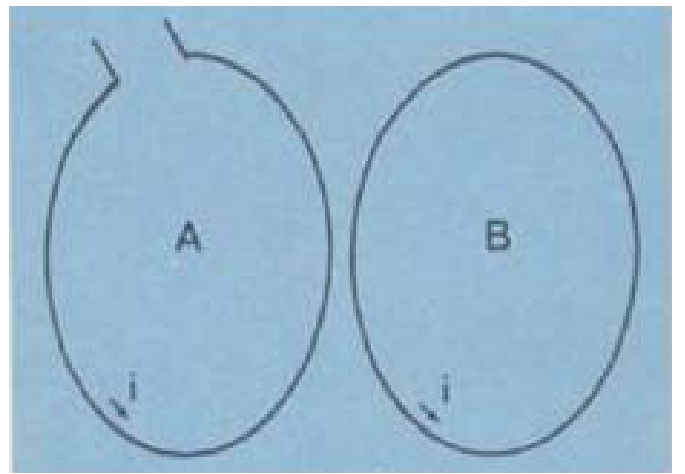

Alguns materiais apresentam o fenômeno da supercondutividade e isto ocorre a temperaturas muito baixas, próximas do zero absoluto $\left(-273^{\circ} \mathrm{C}\right)$. No final deste capítulo há um texto suplementar que trata de materiais supercondutores em detalhe. Se o fio supercondutor formar um anel fechado, então, uma vez produzida uma corrente elétrica no anel, ela continuará a fluir durante anos, sem que seja necessário fornecer energia aos elétrons! A corrente poder ser produzida no anel, fazendoo atravessar por um campo magnético variável. No fio em condições normais, a corrente cessaria rapidamente por causa da perda de energia cinética dos elétrons, nos choques com os átomos do fio. PEF - Efeito Joule, vol. Eletricidade, fasc. 08, p. 8-4. Disponível em <http://www.cienciamao.usp. $\mathrm{br} /$ tudo/exibir.php?midia=pef\&cod=_eletricidadeefeitojoulec $>$ 
Q1 - Na situação da figura 1, ou seja, antes das bolinhas começarem a descer, a energia potencial das bolinhas é a mesma?

Q2 - Ao chegar ao chão, qual das bolinhas tem maior energia cinética?

No início, ambas tinham a mesma energia potencial gravitacional, mas a bolinha 1 chegou com maior velocidade ao chão, ou seja, com mais energia cinética que a bolinha 2 .

Q3 - O que ocorreu com a energia que a bolinha 2 perdeu?

Vimos anteriormente que, aplicando uma tensão a um fio metálico, aparecem forças que tenderão a empurrar os elétrons livres através do fio.

Consideremos agora dois fios metálicos A e B. O fio B encontram-se em um estado tal, que se comporta como um supercondutor, ou seja, não oferece nenhuma oposição ao movimento dos elétrons que constituem a corrente elétrica. O fio A encontra-se em condições normais.

Q4 - Em qual dos fios o movimento dos elétrons é semelhante à bolinha 1 e qual corresponde à bolinha 2 (figura 1)? Por quê?

Q5 - Qual a resistência elétrica do fio supercondutor?

Q6 - A resistência do fio em condições normais é nula?

No fio condutor comum, os elétrons livres perdem energia ao chocar-se com os átomos do fio. Para onde vai essa energia perdida?

A colisão dos elétrons aumenta a vibração dos átomos dentro da rede cristalina. Os átomos do metal têm sempre um movimento vibratório em torno de suas posições de equilíbrio. Em temperaturas baixas, esses movimentos têm pequena amplitude. A temperaturas altas a amplitude aumenta e a energia cinética média de vibração dos átomos também aumenta. Esse é o motivo pelo qual a resistência elétrica de um metal aumenta a temperaturas altas, pois, havendo maior vibração dos átomos, cresce a probabilidade de colisão dos elétrons da corrente com os átomos de metal.

Agora vamos discutir a relação inversa: será que as colisões dos elétrons com os átomos afetam a temperatura?

Q7 - Como você responderia a pergunta acima?

Quando um elétron colide com um átomo do metal, desloca-o ligeiramente de sua posição de equilíbrio. Mas os átomos vizinhos exercem, sobre aquele átomo, forças que o fazem voltar à posição de equilíbrio. $\mathrm{O}$ átomo passa, então, a oscilar em torno de sua posição de equilíbrio. A situação é semelhante à de um peso pendurado de uma mola, como na figura a seguir. 


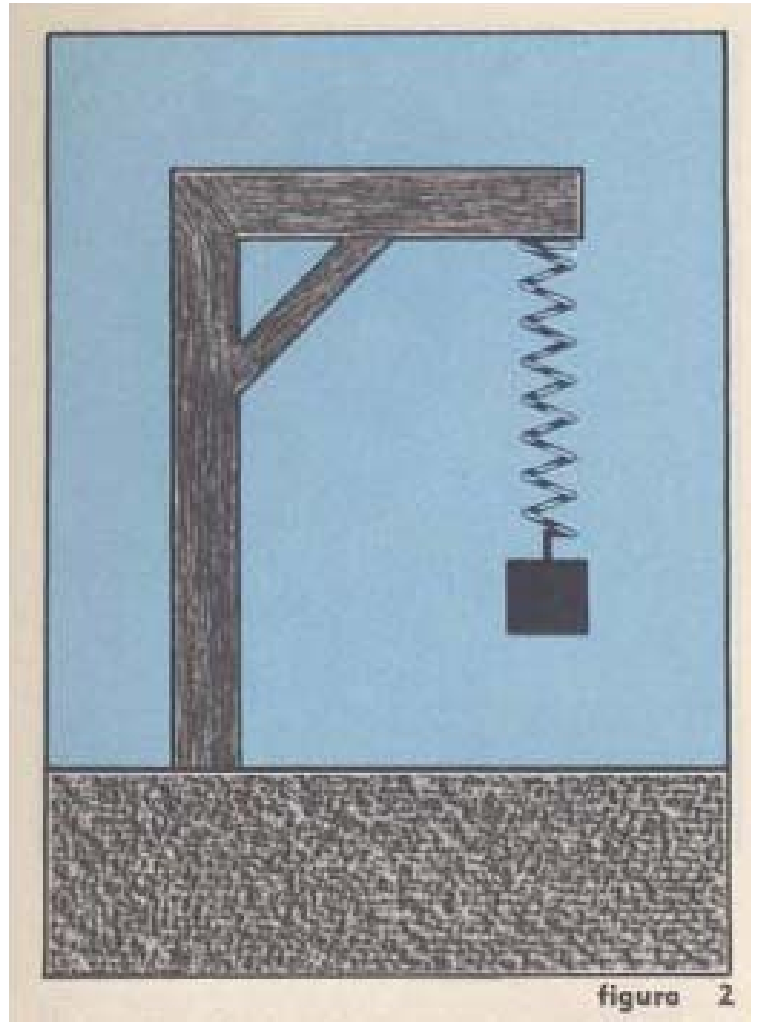

peso pendurado de uma mola

PEF - Efeito Joule, vol. Eletricidade, fasc. 08, p. 8-5.

Disponível em <http://www.cienciamao.usp.br/tudo/

exibir.php?midia=pef\&cod=_eletricidadeefeitojoulec $>$

Q8 - Se você der um puxão vertical no peso (figura a cima) e depois soltá-lo, como será o movimento subseqüente do peso?

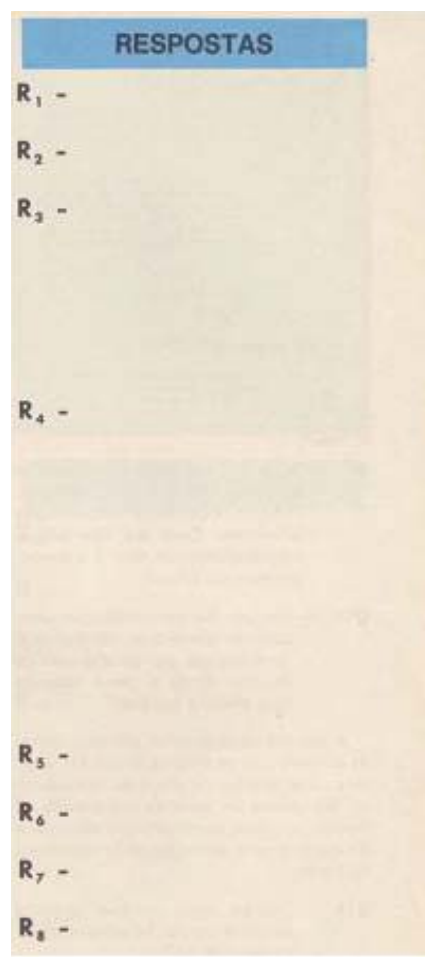

Espaço para os alunos preencherem as respostas dos exercícios em boxes PEF - Efeito Joule, vol. Eletricidade, fasc. 08, p. 8-5. Disponível em <http:// www.cienciamao.usp.br/tudo/exibir. php?midia $=$ pef\&cod=_eletricidadeefeitojoulec $>$ 
$\mathrm{R} 1-\mathrm{Sim}$.

R2 - A bolinha 1.

R3 - Foi transformada em energia térmica nos choques com a escada (há uma pequena elevação da temperatura da bola e da escada).

$\mathrm{R} 4$ - O fio A corresponde à bolinha 2, porque a bolinha 2 perde energia cinética nas colisões com os degraus, assim como os elétrons perdem energia cinética nas colisões com os átomos do fio. $\mathrm{O}$ fio $\mathrm{B}$, em que os elétrons não sofrem colisões corresponde à bolinha 1 .

R5 - Zero.

R6 - Não.

R7 - Veja texto após a questão.

R8 - O peso oscilará verticalmente em torno de sua posição de equilíbrio, com amplitude que depende do puxão inicial.

Q9 - A figura abaixo representa um átomo de cobre em três fios deste metal (I, II e III), mantidos a temperaturas diferentes. Qual dos fios está à temperatura mais alta? E à temperatura mais baixa?

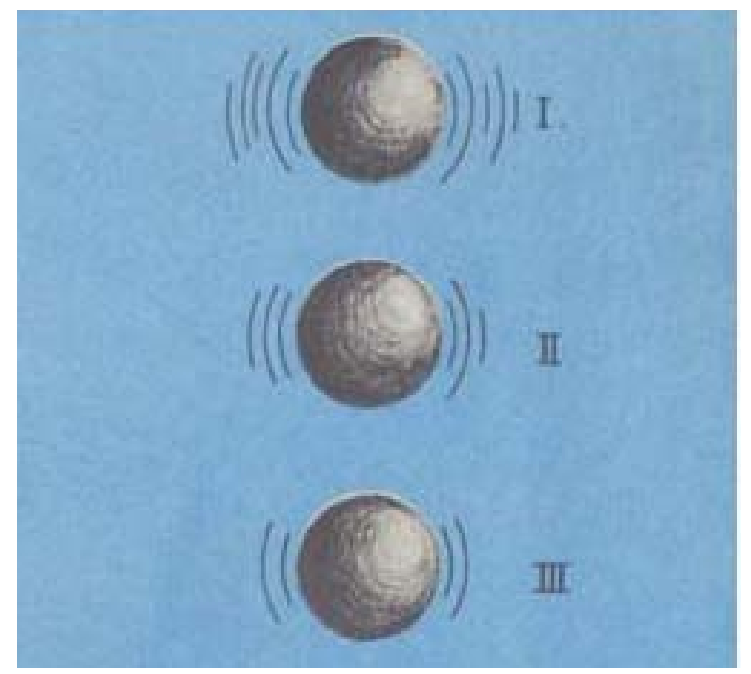

Representação esquemática da vibração de um átomo de cobre em torno de sua posição de equilíbrio em fios a três temperaturas diferentes (a vibração de átomos tem dimensão menor do que o diâmetro do átomo).

(PEF - Efeito Joule, vol. Eletricidade, fasc. 08, p. 8-4, 5 e 6 ) 
A seguir são apresentados vários questionários que caracterizam um estudo dirigido, tanto teórico como experimental. Para que o projeto fosse realizável, foi criado o FUNBEC (Fundação Brasileira para o Desenvolvimento do Ensino de Ciências) que possuía uma oficina em um galpão na Cidade Universitária da USP, onde era produzido e distribuído material para a realização de experimentos de baixo custo.

Q10 - Em um fio percorrido por uma corrente elétrica, os elétrons perdem energia por colisão com os átomos. Onde e como aparece essa energia perdida?

A energia perdida pelos elétrons, quando colidem com os átomos de um fio, aparece como energia de vibração desordenada dos átomos em torno de sua posição de equilíbrio, isto é, como energia térmica, e dá lugar a uma elevação de temperatura do metal.

Q11 - Quando uma corrente elétrica percorre um fio, há sempre aquecimento do fio?

Q12 - Quando uma corrente elétrica percorre um fio supercondutor, há aquecimento do fio?

Você fará, agora, uma verificação dos efeitos da agitação térmica.

Providencie uma vela ou uma chama de gás e aqueça a ponta de um fio de cobre, sem esmalte, por uns 5 segundos (figura abaixo). Observe o efeito no fio.

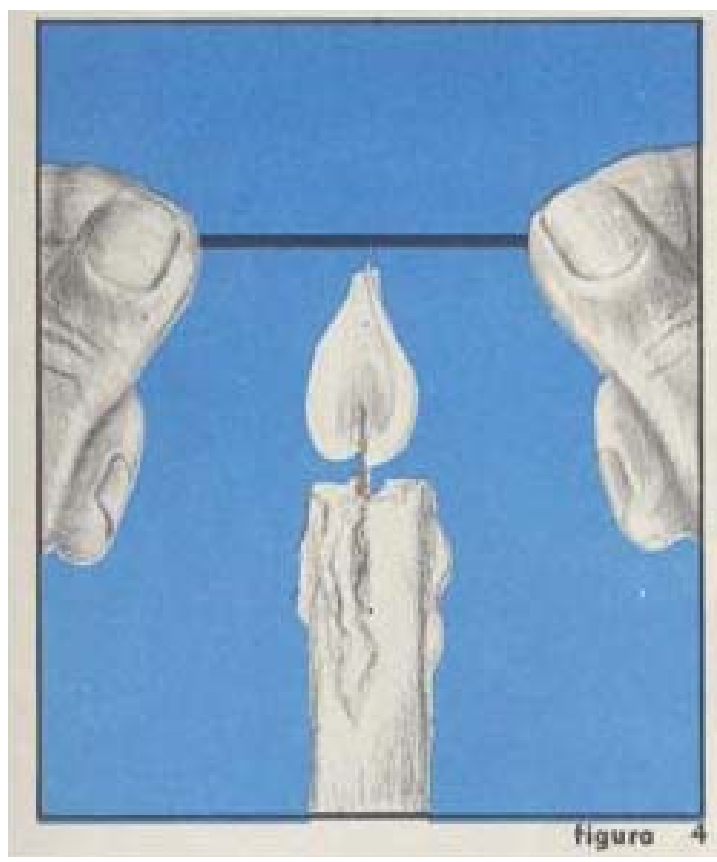

Efeito Joule, vol. Eletricidade, fasc. 08, p. 8-7. Disponível em < http://www.cienciamao.usp.br/tudo/exibir. php?midia=pef\&cod=_eletricidadeefeitojoulec $>$ 


\section{Q13 - O fio ficou rubro?}

Ligue o fio de $\mathrm{Ni}-\mathrm{Cr} \mathrm{n}^{\circ} 36$, em série, a quatro pilhas de $1,5 \mathrm{~V}$ cada uma (figura abaixo). Vá aproximando, nesse fio, um dos terminais do fio de ligação até a distância de uns 3 ou $4 \mathrm{~cm}$ da outra extremidade e observe o efeito no Ni-Cr (tome cuidado para não se queimar). Desligue logo a seguir, para não descarregar as pilhas.

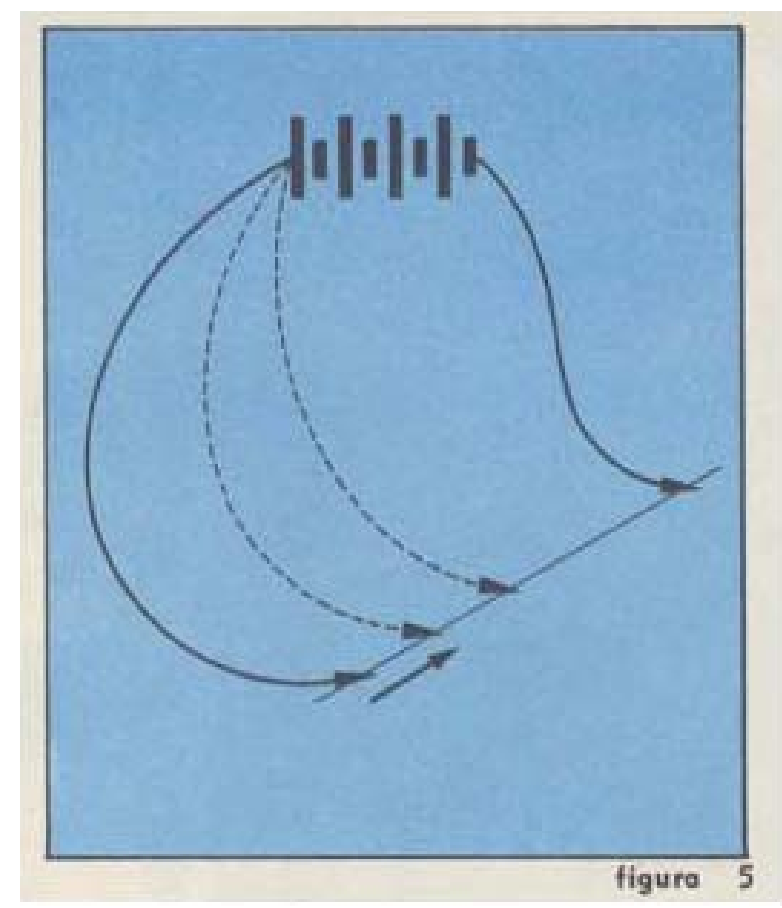

PEF - Efeito Joule, vol. Eletricidade, fasc. 08, p. 8-7. Disponível em <http://www.cienciamao.usp. br/tudo/exibir.php?midia=pef\&cod=_eletricidadeefeitojoulec $>$

Q14 - Descreva o que você observou.

Q15 - Você pode concluir, das duas experiências, que no interior do fio ocorreram fenômenos semelhantes?

Quando você forneceu calor ao fio, com a vela, a amplitude de vibração dos átomos aumentou, ou seja, aumentou a agitação térmica e, com isso, a temperatura do fio.

No segundo caso, quando você ligou as pilhas ao fio, a corrente que passou provocou maior amplitude de vibração dos átomos. Isso por causa dos choques dos elétrons, que constituem a corrente com os átomos do fio. Aumentando a agitação térmica, a temperatura tornou-se maior. (PEF - Efeito Joule, vol. Eletricidade, fasc. 08, p. 8-6) 


\section{CÁLCULO DA ENERGIA TÉRMICA PRODUZIDA}

Quando uma carga é deslocada de um a outro ponto, numa região onde existe um campo elétrico, uma força elétrica realiza um trabalho.

Esse trabalho corresponde a uma variação da energia potencial da carga no campo e é igual à energia térmica liberada, quando se trata de uma corrente em um condutor.

Vamos chamar o trabalho de r; como vimos no capítulo 3:

$$
{ }_{T}=\Delta \mathrm{EP}=\mathrm{q} \cdot \mathrm{V},
$$

PEF - Efeito Joule, vol. Eletricidade, fasc. 08, p. 8-10. Disponível em <http://www.cienciamao.usp.br/tudo/exibir.php?midia=pef\&cod=_eletricidadeefeitojoulec $>$

ou seja, r é igual a variação da energia potencial EP, e igual, também, ao produto da carga $\mathrm{q}$ deslocada pela diferença de potencial $\mathrm{V}$.

Considere, agora, um condutor linear (fio metálico) de resistência $\mathrm{R}$, submetido à diferença de potencial constante V. Pelo condutor irá fluir uma corrente elétrica de intensidade i também constante. Se durante um tempo t passa uma quantidade de carga q, temos:

$$
\mathrm{i}=\frac{\mathrm{q}}{\mathrm{t}} \rightarrow \mathrm{q}=\mathrm{i} . \mathrm{t}
$$

PEF - Efeito Joule, vol. Eletricidade, fasc. 08, p. 8-10. Disponível em < http://www.cienciamao.usp.br/tudo/exibir.php?midia=pef\&cod=_eletricidadeefeitojoulec $>$

Q19 - Qual é a expressão do trabalho r em função da corrente i e da diferença de potencial V? Utilize as equações (1) e (2).

Esse trabalho representa a energia potencial elétrica consumida no transporte da carga q, entre as extremidades do fio. Vamos representá-la por .

$$
=\text {. Assim, }
$$

$$
\dot{\varepsilon}=\text { V.i.t. }
$$

PEF - Efeito Joule, vol. Eletricidade, fasc. 08, p. 8-10. Disponível em <http://www.cienciamao. usp.br/tudo/exibir.php?midia=pef\&cod=_eletricidadeefeitojoulec $>$

Q20 - Escreva a expressão da energia dissipada, , em função somente de R, i e t. Utilize a Lei de Ohm e a equação (3).

(PEF - Efeito Joule, vol. Eletricidade, fasc. 08, p. 8 - 9) 
Vemos acima que havia no livro texto espaço para os alunos preencherem as respostas dos exercícios em boxes (figura 9). Apesar disso, o texto era longo e todo baseado em evidências experimentais. Só no momento de se resolver os exercícios havia uma preocupação maior com a formulação matemática da teoria.

\section{POTÊNCIA ELÉTRICA}

Muitas vezes a grandeza mais importante não é a energia total dissipada por um resistor, mas a taxa de dissipação de energia por unidade de tempo, que se chama potência dissipada:

$$
\mathrm{P}=\frac{\varepsilon}{\mathrm{t}}
$$

PEF - Efeito Joule, vol. Eletricidade, fasc. 08, p. 8-11. Disponível em <http://www.cienciamao.usp. br/tudo/exibir.php?midia=pef\&cod=_eletricidadeefeitojoulec $>$

Como vimos, $=\mathrm{R} \cdot \mathrm{i} 2 \cdot \mathrm{t}$, então:

$$
\mathrm{P}=\frac{\mathrm{R} \cdot \mathrm{i}^{2} \cdot \mathrm{t}}{\mathrm{t}} \therefore \mathrm{P}=\mathrm{R} \mathrm{i}^{2}
$$

PEF - Efeito Joule, vol. Eletricidade, fasc. 08, p. 8-11. Disponível em <http:/ /www.cienciamao.usp.br/tudo/exibir.php?midia=pef\&cod=_eletricidadeefeitojoulec $>$

A unidade de potência é o watt, representada por W, que vale um joule por segundo.

De $\frac{\varepsilon \text { (jouls) }}{t(s)}=P$ (watt) , dizemos que $1 \mathrm{~W}=1 \mathrm{~J} / 1 \mathrm{~s}$.

Convém exprimir a potência dissipada em função de $\mathrm{R}$ e $\mathrm{V}$ e em função de i e V.

Q27 - Deduza uma expressão de P em função somente de R e de V, utilizando a equação (6) e a Lei de Ohm.

(PEF - Efeito Joule, vol. Eletricidade, fasc. 08, p. 8-10 e 11)

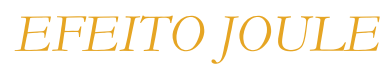

Num circuito composto apenas de fios condutores e resistores, a energia elétrica absorvida é transformada em energia térmica (calor). Diz-se, neste caso, que o circuito é resistivo. Se, por outro lado, o circuito contém condensadores ou indutores, ou, ainda, motores, geradores, parte da energia da corrente elétrica é transformada em energia do campo eletromagnético e o circuito diz-se reativo. 
Vamos considerar, aqui, somente circuitos que possam ser considerados, com boa aproximação, resistivos. Neste caso, a energia potencial elétrica da fonte de corrente é transformada em energia térmica (calor). Do ponto de vista da fonte de corrente, o circuito consumiu energia elétrica, produzindo energia térmica. É o efeito Joule.

Vamos verificar se, num circuito em que não há outros elementos além dos condutores e resistores, a quantidade de energia transformada em calor é igual à energia elétrica despendida.

Inicialmente, vamos fazer algumas considerações e, a seguir, você poderá fazer uma experiência para calcular as energias elétrica e térmica e comparar os valores obtidos. Para fazer essa comparação, precisará medir a energia térmica liberada por um resistor durante certo tempo. Para isso você medirá a elevação de temperatura de certa quantidade de água, na qual estará colocado o resistor.

Todos sabemos que as mãos esquentam, quando esfregamos uma contra a outra.

Sempre que duas superfícies, entre as quais há atrito, deslizam uma sobre a outra há aquecimento. Quando um sólido se desloca dentro de um líquido, por exemplo, um remo ou a pá de uma hélice de barco a motor na água, também há atrito e aquecimento.

Considere um aparelho semelhante ao de Joule (figura 6), em que um recipiente termicamente isolado, com dez litros de água, contém pás gigantes, que agitam a água. Suponha que foram realizadas duas medidas. $\mathrm{Na}$ primeira, o trabalho realizado pelas pás, na água, foi de $1,2 \times 10^{5} \mathrm{~J} \mathrm{e}$ observou-se uma elevação de temperatura de $20^{\circ} \mathrm{C}$ para $23^{\circ} \mathrm{C}$, isto é, $\Delta T$ $=3^{\circ} \mathrm{C}$. Na segunda experiência, o trabalho realizado pelas pás foi o dobro: $2,4 \times 10^{5} \mathrm{~J}$.

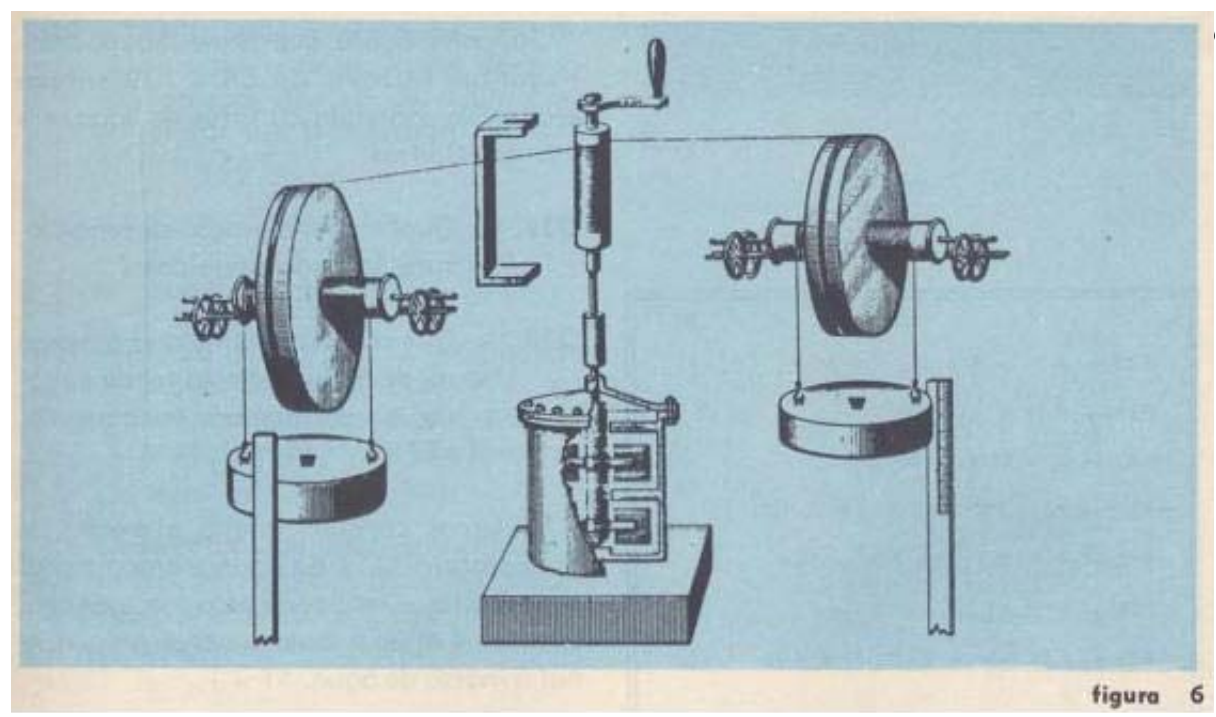

PEF - Efeito Joule, vol. Eletricidade, fasc. 08, p. 8-13. Disponível em <http://www.cienciamao. usp.br/tudo/exibir.php?midia=pef\&cod=_eletricidadeefeitojoulec $>$ 
Q36 - É correto afirmar que Joule verificou que, em todos os casos, a elevação de temperatura é proporcional ao trabalho realizado pela força de atrito?

As experiências de Joule e todas as experiências realizadas posteriormente mostraram que a elevação de temperatura da água é proporcional ao trabalho realizado pela força de atrito (pás gigantes), contanto que o recipiente esteja termicamente isolado, isto é, que não haja transmissão de energia térmica para o ambiente.

Suponha, agora, que as mesmas pás realizam um trabalho de $2,4 \times 10^{5} \mathrm{~J}$ em um recipiente contendo 20 litros de água, em vez de 10 litros.

Q37 - Qual será a elevação de temperatura da água neste caso?

Q38 - Que relação existe entre a massa $\mathrm{m}$, de água que está sendo agitada, e a elevação de temperatura $\Delta T$ ?

Podemos concluir que a elevação de temperatura $(\Delta T)$ da água é proporcional ao trabalho $\mathrm{r}$ realizado pela força de atrito sobre a água e inversamente proporcional à massa de água $\Delta T \alpha \mathrm{r}$ :

$\Delta T \propto \frac{1}{m}$, então, $\Delta T$ é proporcional ao produto $\mathrm{r} \cdot \frac{1}{m}$.

Portanto:

$\Delta T \alpha \frac{r}{m}$ ou $\mathrm{r} \alpha_{\mathrm{m}} \Delta T$, ou, ainda,

onde c é uma constante.

$$
{ }_{T}=\operatorname{C} \cdot \mathrm{m} \Delta \mathrm{T}
$$

PEF - Efeito Joule, vol. Eletricidade, fasc. 08, p. 8-14. Disponível em < http:/ /www. cienciamao.usp.br/tudo/exibir.php?midia=pef\&cod=_eletricidadeefeitojoulec $>$

Muitas medidas comprovaram que c, dado por $\mathrm{c}=\frac{r}{m \Delta T}$, é realmente constante.

Medidas quantitativas mostram que, se $\Delta T$ for medido em celsius $\left({ }^{\circ} \mathrm{C}\right)$, m em kg e r em joules (J), então,

$$
\mathrm{C}=4180 \frac{\mathrm{J}}{\mathrm{kg}^{\circ} \mathrm{C}}
$$

(Esse é o valor de c para a água pura; para outras substâncias, o quociente $\frac{r}{m \Delta T}=\mathrm{c}$ também é constante, mas de calor diferente.)

(PEF - Efeito Joule, vol. Eletricidade, fasc. 08, p. 8-12 a 14)

Para a experiência a seguir você precisará de um ebulidor, de uma 
quantidade de água de massa conhecida e de um termômetro com escala até $100^{\circ} \mathrm{C}$ (figura abaixo).

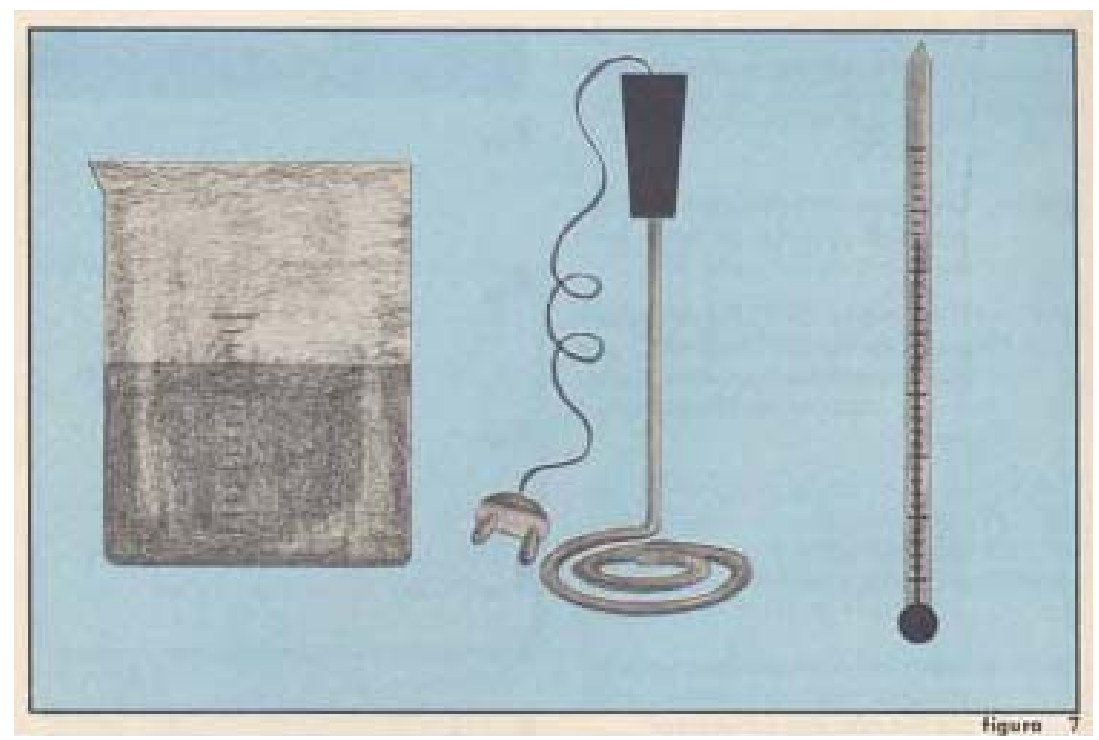

PEF - Efeito Joule, vol. Eletricidade, fasc. 08, p. 8-16. Disponível em <http://www. cienciamao.usp.br/tudo/exibir.php?midia=pef\&cod=_eletricidadeefeitojoulec $>$

Se não houver possibilidade de realizar esta experiência, acompanhe seu desenvolvimento, utilizando os resultados que obtivemos, que se encontram nas respostas às questões.

Observação: A resistência elétrica dos metais aumenta com a temperatura. Os ebulidores são feitos, em geral, com fios de Ni-Cr, que, no entanto, dentro do intervalo de $0^{\circ} \mathrm{C}$ a $100^{\circ} \mathrm{C}$, têm uma variação de resistência muito pequena e não significativa para esta experiência.

Q44 - Meça a resistência elétrica do ebulidor. Escreva o valor encontrado.

Q45 - Conhecendo a resistência $\mathrm{R}$ do ebulidor e a tensão $\mathrm{V}$ aplicada durante t segundos, como você calcula a energia consumida?

(PEF - Efeito Joule, vol. Eletricidade, fasc. 08, p. 8-16)

Podemos ver acima que os estudantes faziam as experiências ao mesmo tempo em que resolviam os exercícios e aprendiam a teoria. Apesar de ser um estudo dirigido, o material didático exigia uma grande dose de leitura e atividade participativa dos alunos.

$\mathrm{Na}$ sequência forneciam uma série de exercícios de aplicação e em seguida várias aplicações do conteúdo estudado. No final do capítulo havia uma leitura complementar. Nesse caso era sobre a supercondutividade. 


\section{APPLETS DE ENSINO}

Como nas outras Instrumentações, sugerimos alguns sites de ensino com material de multimídia. Segue abaixo um guia de applets com dicas para você analisar.

1.1 - Explique o princípio de funcionamento do applet abaixo do curso da Universidade do Colorado. < https://sites.google.com/site/professorpifer/ Home/fisica-mix/eletromagnetismo $>$

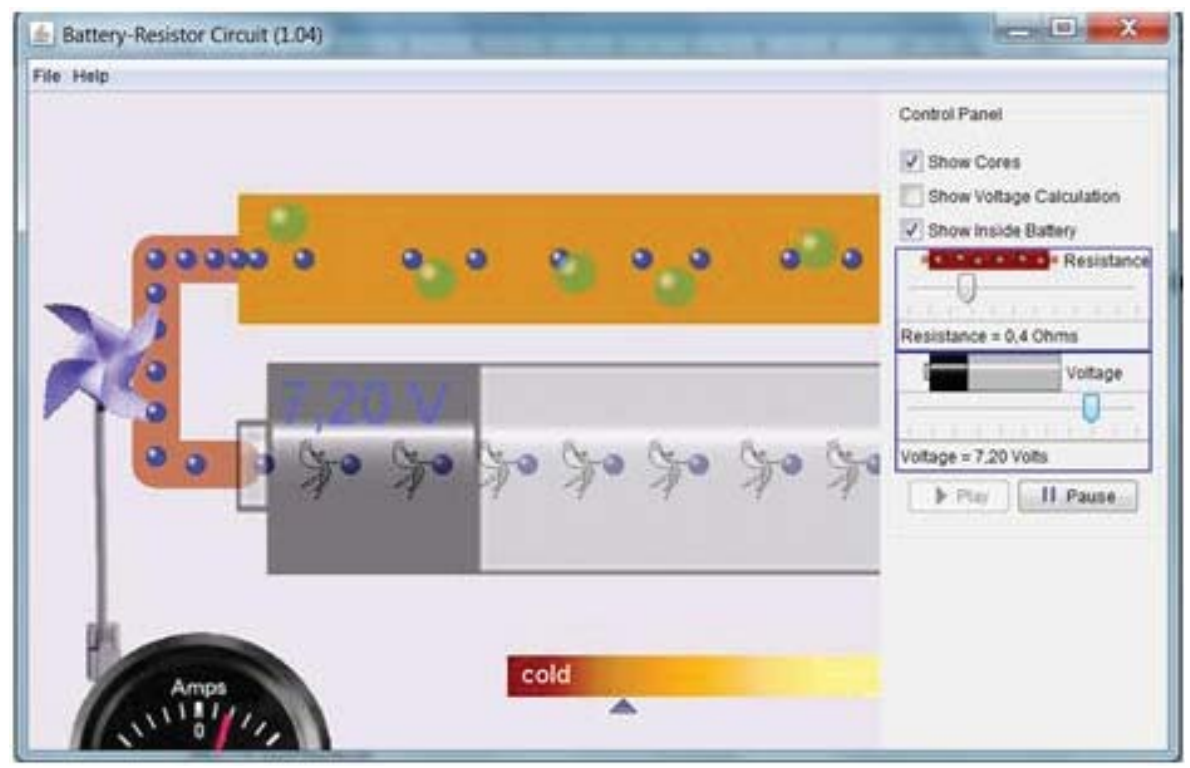

Disponível em <https://sites.google.com/site/professorpifer/Home/fisica-mix/eletromagnetismo $>$

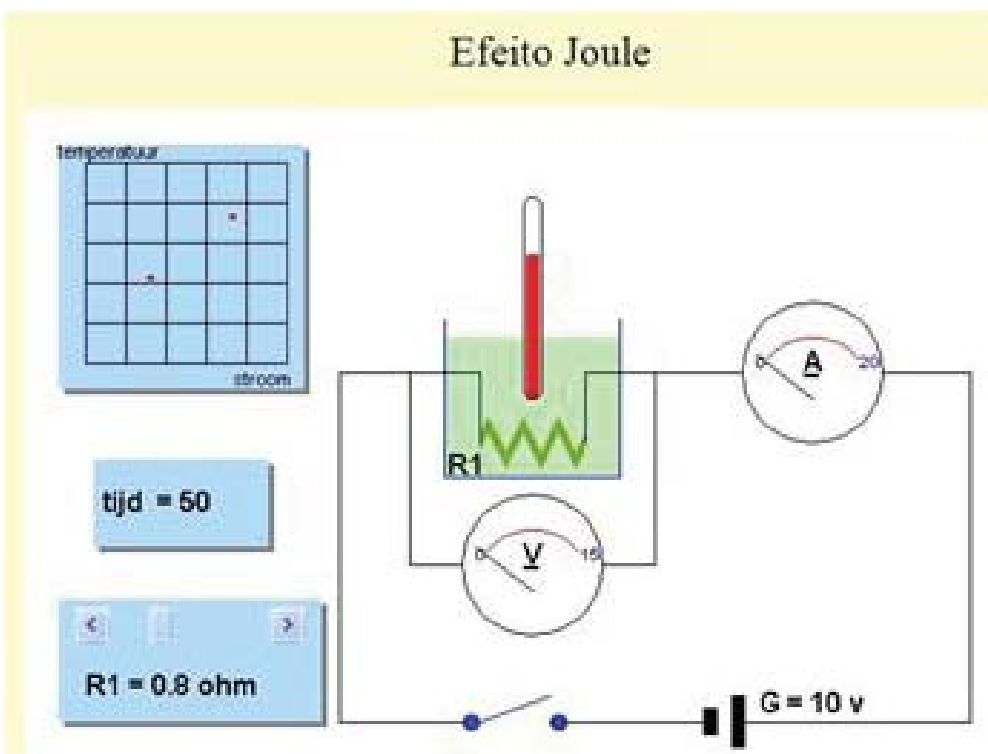

Disponível em <https://sites.google.com/site/professorpifer/Home/ fisica-mix/eletromagnetismo $>$. 


\section{VÍDEOS DE ENSINO}

2. Assista a boas aulas nos links que se seguem:

Física 54 - Efeito joule - Potência elétrica Parte 1.

Link: <http://www.youtube.com/watch?v=EBTxO2goEBg>

Física 54 - Efeito joule -- potência elétrica Parte 2

Link: <http://www.youtube.com/watch?v $=$ HlyXh3F9u0M\&feature $=$ re lated $>$

Física 54 - Efeito joule -- potência elétrica Parte 3

Link: $<$ http: $/ /$ www.youtube.com $/$ watch?v $=2 U f a N V C P L M 8 \&$ feature $=$ related $>$

\section{EXPERIMENTOS DE BAIXO CUSTO}

3.1 - Por que os eletrodomésticos esquentam? Verifique pondo a mão atrás de uma: televisão; geladeira; freezer.

3.2 - Explique o princípio de funcionamento de um: a) aquecedor de cabelo; b) chuveiro elétrico.

3.3 - Qual é a diferença entre uma lâmpada fria e uma quente? Explique por que a lâmpada incandescente esquenta.

3.4 - Tome um liquidificador e ponha $1 \mathrm{~L}$ de água em seu interior. Meça sua temperatura inicial. Bata a água por uns 5 minutos. Meça sua temperatura final. Calcule seu rendimento.

Dica: Leia no seu verso a sua potência elétrica.

3.5 - Na experiência abaixo poderá ser visto o efeito Joule usando o tato. Desta forma, ligaremos as duas extremidades de uma fita de papel alumínio nos pólos da pilha, estabelecendo-se uma corrente elétrica. Depois de certo tempo a fita irá se aquecer devido à passagem da corrente elétrica. Este aquecimento é pequeno e somente será percebido pelo sentido do tato, numa região do corpo sensível a pequenas temperaturas. Como por exemplo, as costas da mão, o punho, etc.

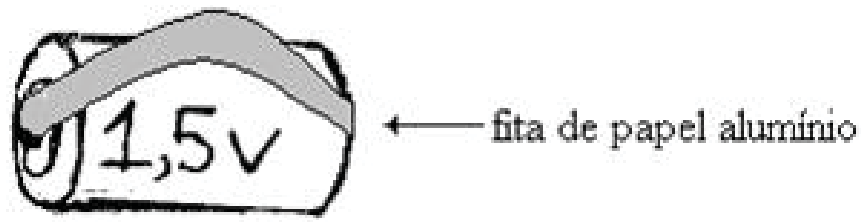

Fita de alumínio ligada nos pólos de uma pilha 
3.6 - Na experiência da figura abaixo será visualizada o efeito Joule na queima de uma palha de aço por causa da corrente elétrica de uma pilha. Quando a corrente elétrica que sai da pilha chega à palha de aço pelos fios, ela aquece uma pequena região da palha onde os fios estão ligados, mas a palha não é queima totalmente no início. Como a palha de aço é um emaranhado de filamentos, um queima o outro sucessivamente até que todo o pedaço de palha esteja queimado.

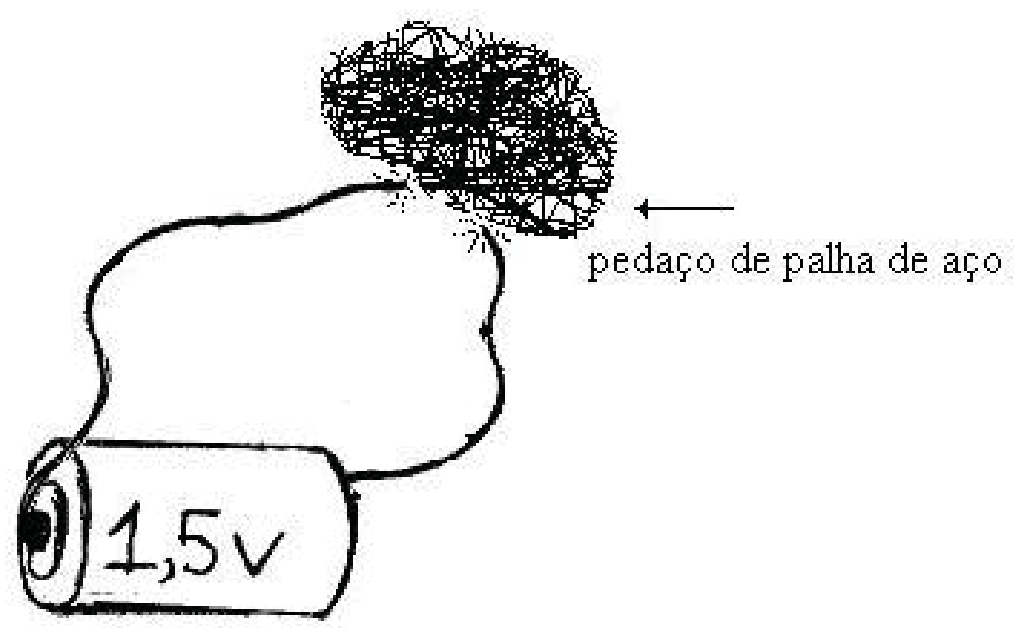

Pedaço de palha de aço ligada nos pólos de uma pilha

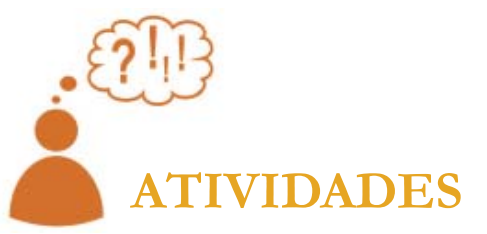

4.1 - Qual dos dois textos, o livro didático padrão ou do projeto PEF você usaria como referência para ministrar uma aula? Por quê?

4.2 - Você concorda que as resoluções do PNLEM é uma volta ao que havia de melhor nos projetos de ensino de Física? Comente?

4.3 - Como você ilustraria o efeito Joule para seus (futuros) alunos?

$4.4-$ O que você acha do texto tirado do PEF? Você acha factível (realizável) a sua aplicação em sala de aula?

4.5 - Você acha que o governo federal deveria retornar com o FUNBEC? 


\section{COMENTÁRIOS SOBRE AS ATIVIDADES}

Em geral os alunos que fazem o curso de licenciatura em Física têm um curso muito superficial ou não têm nenhuma aula de Física. Se têm, usam algum livro texto tradicional, onde a Física é apresentada como uma coleção de definições e fórmulas para ser aplicada em problemas e exercícios. Assim, a maioria deles só possui o conhecimento de física dado na universidade. A apresentação do projeto PEF deve ter dado uma visão geral de toda a complexidade de se montar um curso de Física e como esse pode se tornar mais atraente.

Os futuros professores devem ter compreendido o papel central que eles têm na escolha do conteúdo, da técnica e da didática ser utilizada em sala de aula. Este deve ter adquirido uma ideia de como se deve preparar um curso ou apenas uma aula. Eles devem compreender que uma aula é um processo dinâmico e orgânico.

\section{CONCLUSÃO}

Ao final desta aula o futuro professor deve ter compreendido a profunda relação entre os projetos de ensino realizados no Brasil e os feito no exterior, principalmente nos EUA. Deve ter Ficado ciente da importância do PEF na formação dos primeiros professores de física no Brasil e sua influência sobre o papel do livro didático nacional.

Com a análise dos experimentos de baixo custo e dos recursos de multimídias que colocamos no final da aula o futuro professor deve ter ficado com algumas boas ideias de como este pode enriquecer uma aula sobre o tema Lei de Joule.

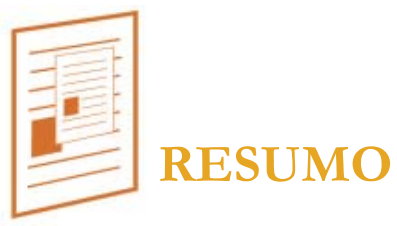

Apresentamos um resumo da história do projeto PEF e o seu material sobre o tema efeito Joule. Analisamos a sua relação com os outros projetos e sua influência sobre a história do livro didático.

Em seguida apresentamos vários experimentos de baixo custo para que explore as possibilidades que estes oferecem para se ministrar um curso usando mais ferramentas fenomenológicas e menos formais. Colocamos vários e excelentes applets de ensino como recurso de simulação de fenômeno físico para ser explorado pelo futuro professor. Colocamos várias experiências de baixo custo sobre o tema e demos varias dicas de como podemos fazer outras que não estão disponíveis na internet. 
Como há ótimos vídeos de ensino colocamos alguns deles como referência, e deixamos sua exploração como atividade, pois no curso de Instrumentação I não usamos os vídeos didáticos como ferramenta didática principal.

\section{RESPOSTA ÀS A'TIVIDADES}

1 - Eles têm que assistir e fazer uma resenha.

2 - Eles têm que assistir e fazer uma resenha.

3 - Eles têm que assistir e fazer uma resenha.

4.1 - Espero que responda PEF.

4.2 - Sim. É um resgate de uma boa leitura com vários experimentos lúdicos

4.3 - Resposta pessoal

4.4 - $\mathrm{Na}$ integra não, mas é um bom texto de referência.

4.5 - Espero que responda sim.

\section{SIGLAS}

PEF - Projeto de Ensino de Física

PSSC - Physical Science Study Committee

MEC-USAID - Ministério da Educação e United States Agency for International

Development

PREMEN - Programa de Expansão e Melhoria do Ensino

\section{REFERÊNCIAS}

\section{GARCIA, N. M. D. ENSINANDO A ENSINAR FÍSICA: UM PRO-} JETO DESENVOLVIDO NO BRASIL NOS ANOS 1970. Disponível em: <http://www.sbhe.org.br/novo/congressos/cbhe4/individuaiscoautorais/eixo02/Nilson\%20Marcos\%20Dias\%20Garcia.pdf>. Acesso em 16/10/2011.

GUIA DO PROFESSOR. Projeto de Ensino de Física. Rio de Janeiro, Fename, 1980.

PROJETO DE ENSINO DE FÍSICA. IFUSP - Instituto de Física da Universidade de São Paulo MEC/FENAME/PREMEN. Cargas e Estrutura da Matéria, vol. Eletricidade, fasc. 01. Disponível em: < http://www. cienciamao.usp.br/tudo/exibir.php?midia=pef\&cod=_eletricidadecargaseestru>. Acesso em: 16/10/2011.

. IFUSP - Instituto de Física da Universidade de São Paulo MEC/FENAME/PREMEN. Efeito Joule, vol. Eletricidade, fasc. 08. Disponível em: <http://www.cienciamao.usp.br/tudo/exibir.php?midia=pef\&cod=_eletricidadeefeitojoulec $>$. Acesso em: 16/10/2011. 
YOUTUBE. Física 54 - Efeito joule - Potência elétrica Parte 1. Disponível em: <http://www.youtube.com/watch?v=EBTxO2goEBg>. Acesso em: 16/10/2011.

Física 54 - Efeito joule - potência elétrica Parte 2. Disponível em: $<$ http:/ / www.youtube.com $/$ watch?v $=$ HlyXh3F9u0M\&feature $=$ related $>$. Acesso em: 15/10/2011.

Física 54 - Efeito joule - potência elétrica Parte 3. Disponível em:

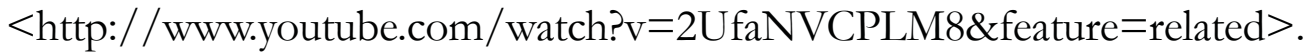
Acesso em 15/10/2011.

WIKIPÉDIA, A enciclopédia livre. Disponível em: < http://pt.wikipedia. org/wiki/Guerra_Fria>. Acesso em: 16/10/2011. 



\section{Aula 7}

\section{CAMPO E FORÇA MAGNÉTICA}

META

Fazer com que o estudante comece a pensar no ensino de ciências como algo "orgânico"

que está em profunda transformação.

Fazer com que os alunos percebam, através de um texto básico complementado com atividades lúdicas, applets de ensino, vídeos, que o conceito de campo e força magnética pode ser compreendido de forma simples e divertida.

Analisar como os livros textos relatam a história da ciência e fazer com que o estudante reflita sobre o que é fazer e ensinar Física.

Introduzir o problema de como se ensinar o conceito de campo magnético. Introduzir a questão: "o que é ensinar Física?".

\section{OBJETIVOS}

Ao final desta aula, o aluno deverá: estar ciente das novas possibilidades e dos desafios que envolvem o ensino de ciências em geral e das dificuldades de se ministrar um curso de eletricidade e magnetismo. Ter compreendido que as ciências naturais estão baseadas na experimentação e que esta é feita de ensaios, experiências e medidas e que estas levam a compreensão e matematização dos conceitos físicos (naturais em geral). Através do tema "campo e força magnética" discutir as dificuldades inerentes de se ensinar física, que vão além das teorias pedagógicas e de ensino usuais. Vamos discutir a papel da história da ciência como complemento pedagógico ao ensino de física.

\section{PRÉ-REQUISITOS}

Os alunos deverão ter cursado as disciplinas Psicologia da Educação, Física A, Física B e Instrumentação I. 


\section{INTRODUÇÃO}

Nessa aula e na próxima, vamos abordar novamente o problema da transposição científica, só que agora analisando o problema de se introduzir um pouco de história da ciência nos livros didáticos em geral. Vamos refletir se há necessidade no Ensino Médio e Fundamental, de se carregar os livros textos com nomes e datas.

Vamos nesta aula analisar o material de ensino do projeto GREF, onde eles ensinam o conceito de campo e força magnética a partir de experimentos simples tirado de objetos do nosso cotidiano. Na próxima aula analisaremos o material de ensino do livro aprovado pelo PNLEM "Física Ensino Médio” dos autores Beatriz Alvarenga e Antônio Máximo.

Para embasar melhor nossa discussão vamos colocar aqui um resumo das deliberações tomadas pelo PNLEM (Programa Nacional do Livro Didático do Ensino Médio)

\section{O PAPEL DO LIVRO DIDÁTICO - PNLD 2007}

Quando abrimos o caderno do PNLD (Programa Nacional do Livro Didático) - Guia do livro didático, nos deparamos com o seguinte conselho: É necessário perguntar, ser curioso, investigar, descobrir, criar..., é necessário transformar o mundo! Ciência é realidade, imaginação, perseverança, trabalho, criatividade. Ciência é ação. Os interesses dos alunos estão centrados na ação, no diálogo, na confrontação de idéias, no trabalho em equipe, na experimentação, na reflexão conjunta, na busca de novos questionamentos. Portanto, as aulas de Ciências devem transmitir o caráter de empresa vital, humana, fascinante, indagadora, aberta, útil e criativa que tem a atividade científica. E o livro didático deve contribuir para isso e não ser utilizado para tornar o ensino de Ciências em simples literatura.

O livro didático é um suporte de conhecimentos e de métodos para o ensino, e serve como orientação para as atividades de produção e reprodução de conhecimento. Mas, não podemos nos transformar em reféns do livro, imaginando encontrar alí todo o saber verdadeiro e a narrativa ideal. Sim, pois o livro é também instrumento de transmissão de valores ideológicos e culturais, que pretende garantir o discurso dos autores. Em um processo pouco dinâmico como o que se estabelece no sistema tradicional de ensino de Ciências, cria-se um círculo vicioso: o professor torna-se um reprodutor desses mitos e imagens errôneas e passa, ele também, a acreditar neles. O resultado é que, para os alunos, a Ciência ensinada na escola acaba sendo chata, pouco útil e muito difícil.

Para construir uma opinião própria e independente é importante a leitura de textos complementares, revistas especializadas e livros disponíveis na biblioteca da escola, da cidade, dos alunos, dos amigos etc. Todos os 
livros apresentam problemas e o professor deve estar sempre atento para trabalhar eventuais incorreções. Neste Guia indicamos, em linhas gerais, os pontos positivos e os problemas identificados em cada coleção.

Também é preciso perceber que o livro é uma mercadoria do mundo editorial, sujeito a influências sociais, econômicas, técnicas, políticas e culturais como qualquer outra mercadoria que percorre os caminhos da produção, distribuição e consumo. Portanto, muito cuidado! É fundamental preservar sua independência, ter clareza do que é Ciência e de como ensinar Ciências para que se possa fazer uma boa escolha do livro que será utilizado em suas aulas.

Apresentamos, a seguir, os critérios utilizados pela equipe de avaliação da área de Ciências, divididos em critérios eliminatórios e critérios de classificação.

\section{Critérios de avaliação}

Critérios eliminatórios

\section{Aspectos teórico-metodológicos}

- estar em consonância com conceitos atuais da teoria pedagógica e do conhecimento científico, veiculando informação correta, precisa, adequada e atualizada;

- ser coerente com a proposta pedagógica expressa no manual do professor;

- garantir o acesso a conceitos fundamentais para cada etapa de escolaridade, respeitando-se o princípio da progressão;

- considerar, na seleção de conceitos, textos e atividades, que o desenvolvimento cognitivo dos alunos se caracteriza por estruturas diferenciadas de pensamento;

- contemplar a iniciação às diferentes áreas do conhecimento científico, buscando um equilíbrio com a seleção de aspectos centrais em Física, Astronomia, Química, Geologia, Ecologia e Biologia (incluindo Zoologia, Botânica, saúde, higiene, Fisiologia e corpo humano);

- integrar o tratamento de fatos, conceitos, valores e procedimentos por meio de uma coerência de princípios, evitando-se a segmentação entre os volumes da coleção;

- considerar que ensinar Ciência é estimular o fazer Ciência, utilizando o método científico como procedimento para a construção do conhecimento;

- assegurar que os experimentos descritos são factíveis, com resultados confiáveis e interpretação teórica correta;

- privilegiar a apresentação da terminologia científica, fazendo uso, quando necessário, de aproximações adequadas sem, no entanto, ferir o princípio da correção conceitual; 
- explicitar termos que têm diferentes significados e contextos, tomando o cuidado de evitar confusões terminológicas;

- veicular ilustrações adequadas, que induzam à construção de conceitos corretos;

- trazer, nas ilustrações (fotos, esquemas e desenhos), citação de fontes, locais, datas e outras informações necessárias ao crédito;

- zelar pela integridade física de alunos, professores, funcionários, familiares e população em geral. A seleção dos experimentos e atividades de investigação científica deverá partir de uma distinção não ambígua entre riscos aceitáveis e não-aceitáveis. Assim, considerando que a teoria do risco zero é superada, a coleção deverá alertar sobre os riscos e recomendar claramente os cuidados para prevenção de acidentes na realização das atividades propostas.

Critérios de qualificação

Espera-se que o livro didático de Ciências observe, ainda, os seguintes aspectos:

1. Aspectos teórico-metodológicos

- valorizar a manifestação pelo aluno e a identificação pelo professor do conhecimento que o aluno detém sobre o que se vai ensinar;

- favorecer o reconhecimento, pelo aluno, de que a construção do conhecimento é um empreendimento laborioso e que envolve diferentes pessoas e instituições às quais se deve dar o devido crédito; - relacionar o conhecimento construído com o historicamente acumulado, considerando que a descoberta tem um ou mais autores e um contexto histórico que deve ser enfatizado e trabalhado;

- propiciar situações, tanto coletivas como individuais, para observações, questionamentos, formulação de hipóteses, experimentação e elaboração de teorias e leis pelo aluno, submetendoas à validação no processo de troca professor-classe;

- buscar a sistematização de conhecimentos por meio de textos, desenhos, figuras, tabelas e outros registros característicos das áreas de Ciências;

- estimular o emprego (construção e análise) de recursos de comunicação comumente utilizados em Ciências, como tabelas, diagramas e gráficos;

- utilizar recursos (cores, escalas etc.) que assegurem a formação correta do conceito na apresentação das ilustrações;

Comecemos com o material do GREF. Escolhemos novamente este, pois é uma proposta radicalmente diferente das demais e assim fica mais fácil de vermos os padrões e mesmice que todo livro didático incorre. 
Nota: O material do GREF só é recomendado para professores experientes ou que estejam engajados em algum tipo de projeto de ensino.

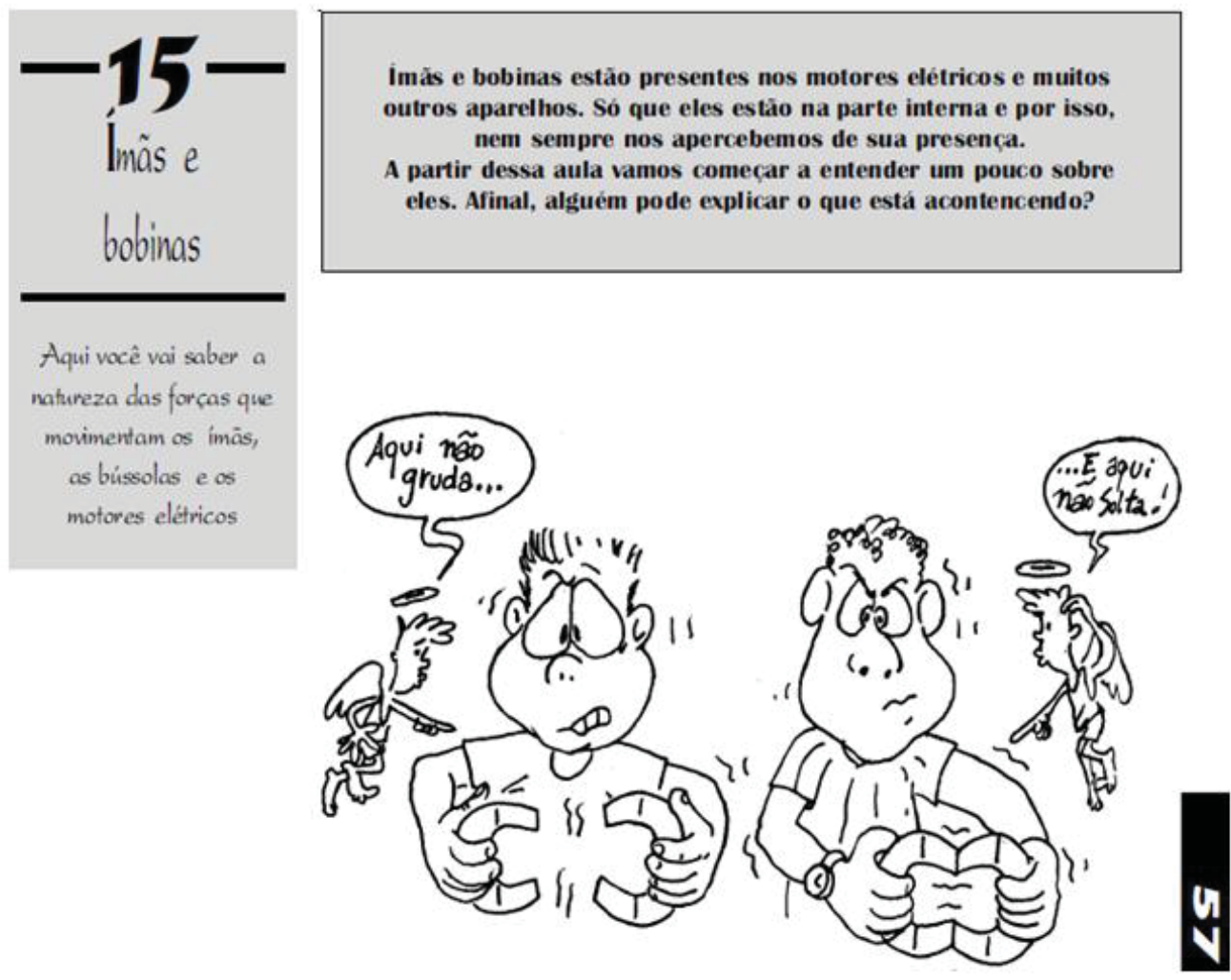

(GREF- Eletromagnetismo, cap. 14 a 19, p. 57)

Note que o livro do GREF já começa com uma ilustração do porque os imãs nos fascinam. Ele já começa com a indagação: por que os imãs possuem dois pólos?

Note, pelo texto a seguir, que eles começam introduzindo a teoria eletromagnética explicando como funciona o motor elétrico, onde se utiliza os imãs permanentes, só depois eles se preocupam em explicar o fenômeno do magnetismo.

\section{5 ÍMÃS E BOBINAS}

No estudo dos motores elétricos pudemos verificar que eles são feitos de duas partes: uma é o eixo, onde se encontram vários circuitos elétricos, e a outra é fixa. Nesta, podemos encontrar tanto um par de ímãs como um par de bobinas. Em ambos os tipos de motor, o princípio de funcionamento é o mesmo, e o giro do eixo é obtido quando uma corrente elétrica passa a existir nos seus circuitos. Nesta aula vamos entender melhor a natureza da força que faz mover os motores elétricos, iniciando com uma experiência envolvendo ímãs e bobinas. 


\section{INVESTIGAÇÃO COM ÍMAS, BÚSSOLAS E BOBINAS}

Para realizar esta investigação serão necessários uma bússola, dois ímãs, quatro pilhas comuns, uma bobina (que é fio de cobre esmaltado enrolado) e limalha de ferro.

\section{ROTEIRO}

1. Aproxime um ímã do outro e observe o que acontece.

2. Aproxime um ímã de uma bússola e descubra os seus pólos norte e sul. Lembre que a agulha da bússola é também um ímã e que o seu pólo norte é aquele que aponta para a região norte.

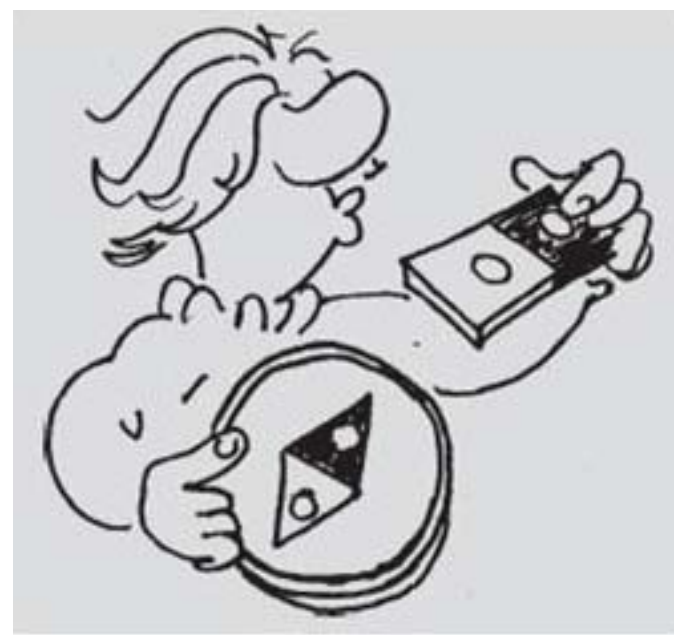

(GREF- Eletromagnetismo, cap. 14 a 19, p. 58)

3. Coloque o ímã sobre uma folha de papel e aproxime a bússola até que sua ação se faça sentir. Anote o posicionamento da agulha, desenhando sobre o papel no local da bússola. Repita para várias posições.

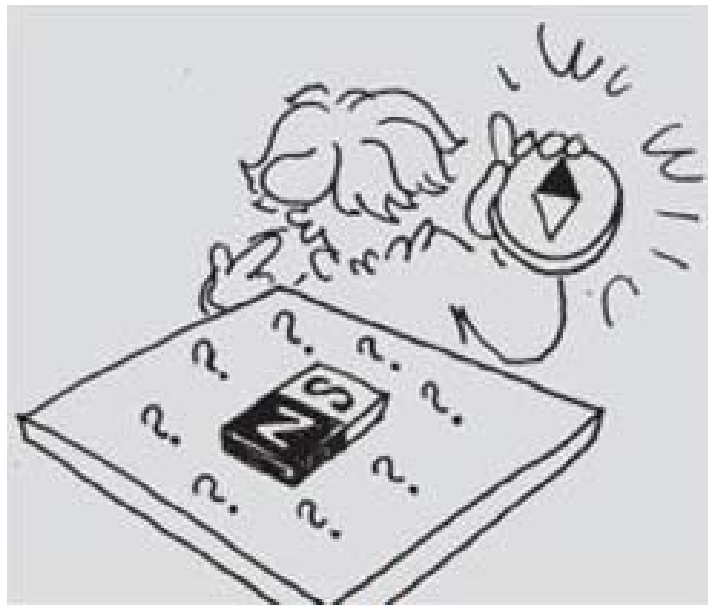

(GREF- Eletromagnetismo, cap. 14 a 19, p. 58) 
4. Coloque sobre o ímã essa folha de papel na mesma posição anterior e espalhe sobre ela limalha de ferro. Observe a organização das limalhas e compare com os desenhos que indicavam o posicionamento da agulha.

5. Ligue a bobina à pilha utilizando fios de ligação. Aproxime um ímã e observe o que ocorre.

6. No mesmo circuito anterior, aproxime uma folha de papel ou de cartolina contendo limalha de ferro e verifique o que ocorre com a limalha.

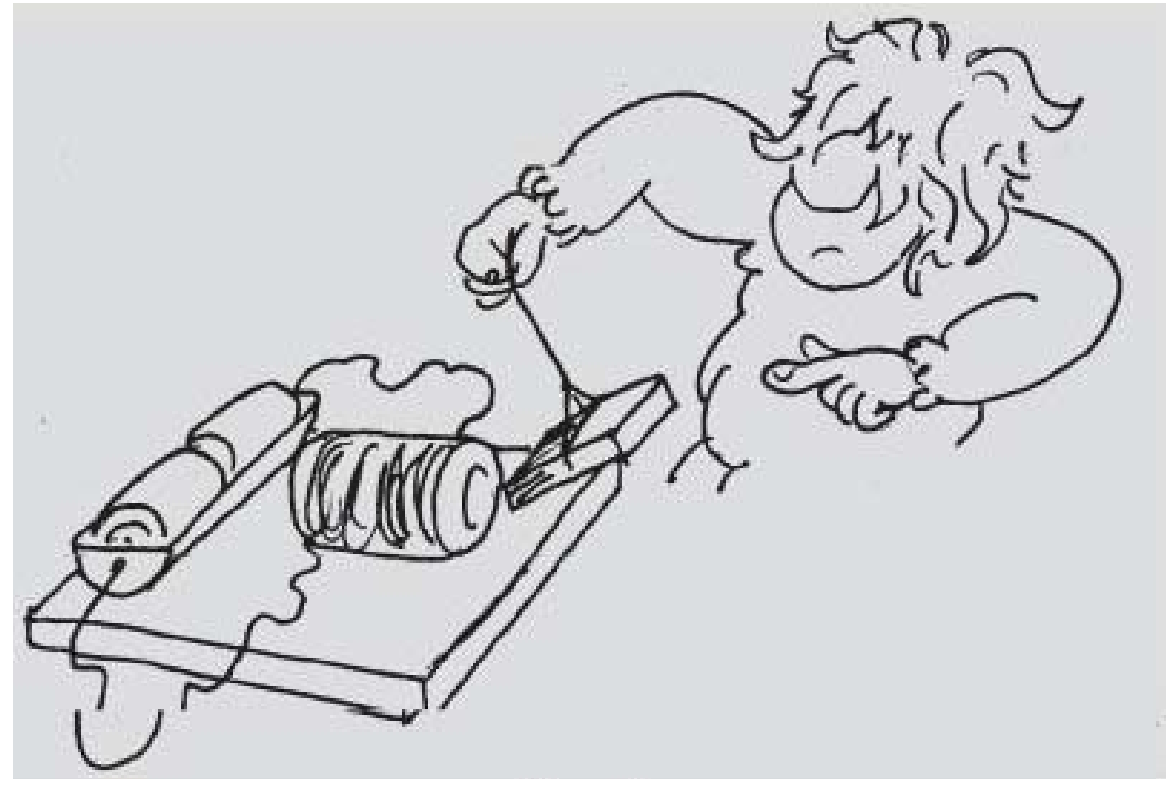

(GREF- Eletromagnetismo, cap. 14 a 19, p. 58)

Veja que eles aproveitam do fato de termos imãs a nossa disposição. Antes de começar contar qualquer fato histórico, teoria, fórmulas e leis, eles instigam aos alunos a explorarem ao máximo os fenômenos magnéticos, incitando assim a curiosidade do aluno.

Nota: Observe que na época em que este material foi escrito não estava na moda os imãs de geladeira. Vá até sua geladeira e pegue vários imãs. Qual a diferença entre os imãs de enfeite (aqueles feitos com pequenas barras de imã e algum enfeite de porcelana) e as propagandas (de gás, pizza,...). Note que os imãs de propaganda são feitos de um material mole, parecendo uma borracha. Eles têm pólos?

Veja que só na página seguinte eles explicam de uma forma nada formal o fenômeno do magnetismo. Note que eles misturam imãs permanentes com bobinas. Para eles o importante é a propriedade de atração e da existência de dois pólos.

Independentemente da forma, quando se aproxima um ímã de outro, eles podem tanto se atrair como se repelir. Esse comportamento é devido ao efeito magnético que apresentam, sendo mais intenso nas proximidades das extremidades, razão pela qual elas são denominadas de pólos magnéticos. 
A possibilidade de atração ou de repulsão entre dois pólos indica a existência de dois tipos diferentes de pólo magnético, denominados de pólo norte e pólo sul. A atração entre os ímãs ocorre quando se aproximam dois pólos diferentes e a repulsão ocorre na aproximação de dois pólos iguais.

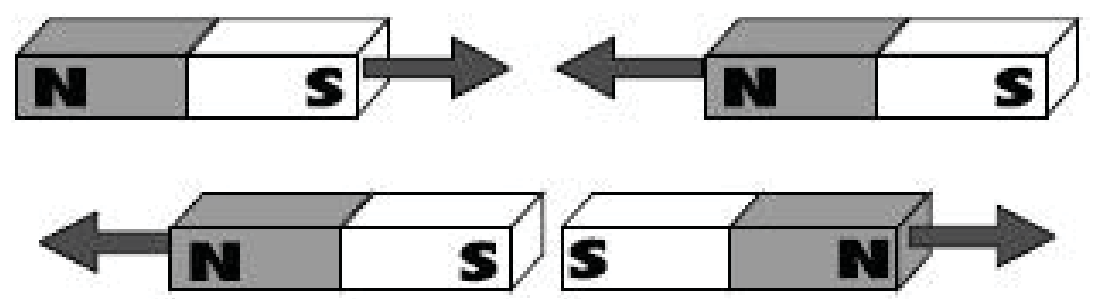

(GREF- Eletromagnetismo, cap. 14 a 19, p. 59)

A atração ou a repulsão entre ímãs é resultado da ação de uma força de natureza magnética e ocorre independentemente do contato entre eles, isto é, ocorre a distância. O mesmo se pode observar na aproximação do ímã com a bússola. Isso evidencia a existência de um campo magnético em torno do ímã, criado por ele. A agulha de uma bússola, que é imantada, tem sensibilidade de detectar campos magnéticos criados por ímãs e, por isso, alteram sua posição inicial para se alinhar ao campo magnético detectado.

Ela é usada para orientação justamente pelo fato de que sua agulha fica alinhada ao campo magnético terrestre, que apresenta praticamente a direção norte-sul geográfica.

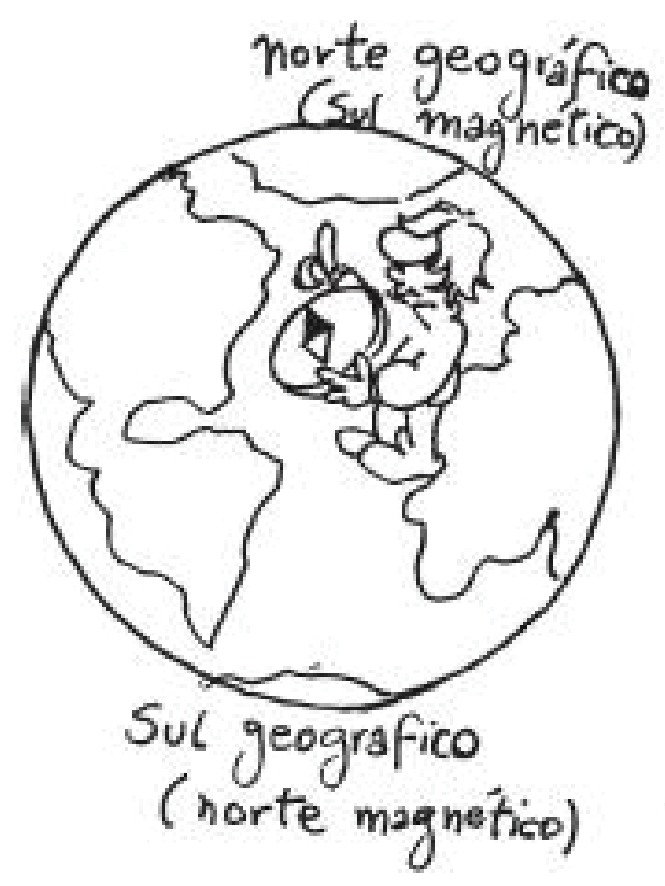

(GREF- Eletromagnetismo, cap. 14 a 19, p. 59) 
O mapeamento do campo magnético produzido por um ímã nas suas proximidades pode ser feito com o auxílio de uma bússola. Esse mapa nos permite "visualizar" o campo magnético.

Não são apenas os ímãs que criam campo magnético. $\mathrm{O}$ fio metálico com corrente elétrica também cria ao seu redor um campo magnético. Quando o fio é enrolado e forma uma bobina, existindo corrente elétrica, o campo magnético tem um mapeamento semelhante ao de um ímã em barra.

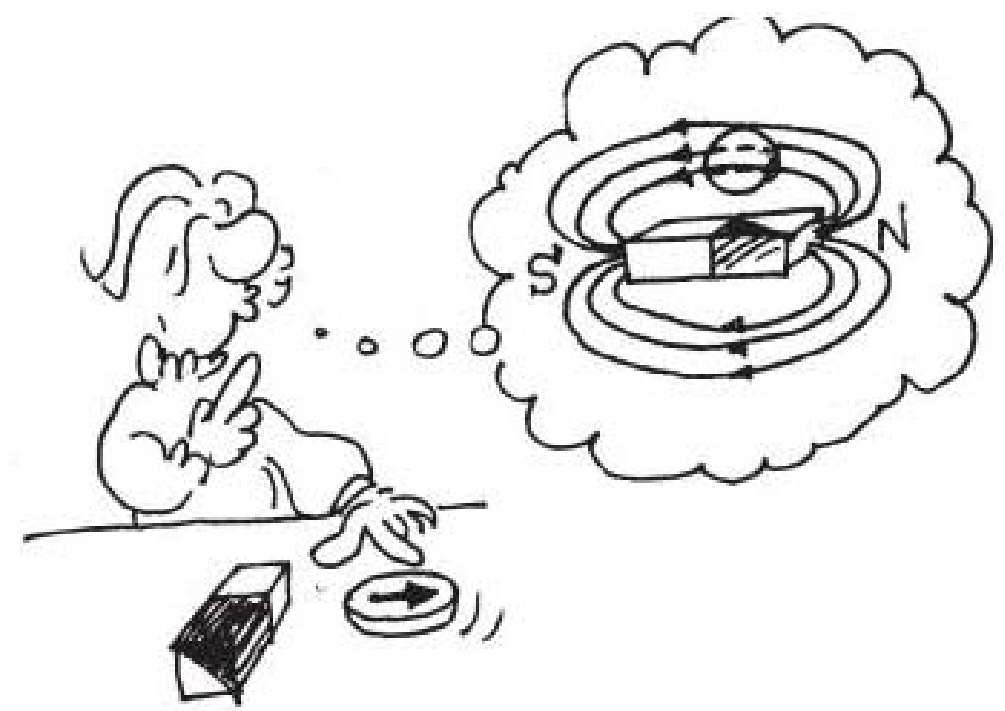

(GREF- Eletromagnetismo, cap. 14 a 19, p. 59)

Isso nos permite entender por que a limalha de ferro fica com um aspecto muito parecido em duas situações: quando é colocada nas proximidades de um pólo de um ímã e quando é colocada nas proximidades de uma bobina.

Podemos agora entender fisicamente a origem do movimento nos motores elétricos. Ele é entendido da mesma maneira que se compreende a repulsão ou a atração entre dois ímãs, entre um ímã e uma bússola, entre um ímã e uma bobina com corrente ou entre duas bobinas com corrente. Esses movimentos acontecem devido a uma ação a distância entre eles. Da mesma forma que a agulha da bússola se move quando "sente" o campo magnético de um ímã, o eixo do motor também se move quando um dos seus circuitos que está com corrente "sente" o campo magnético criado pela parte fixa do motor. Esse campo tanto pode ser criado por um par de ímãs (motor do carrinho do autorama) como por um par de bobinas com corrente elétrica (motor de um liquidificador). 


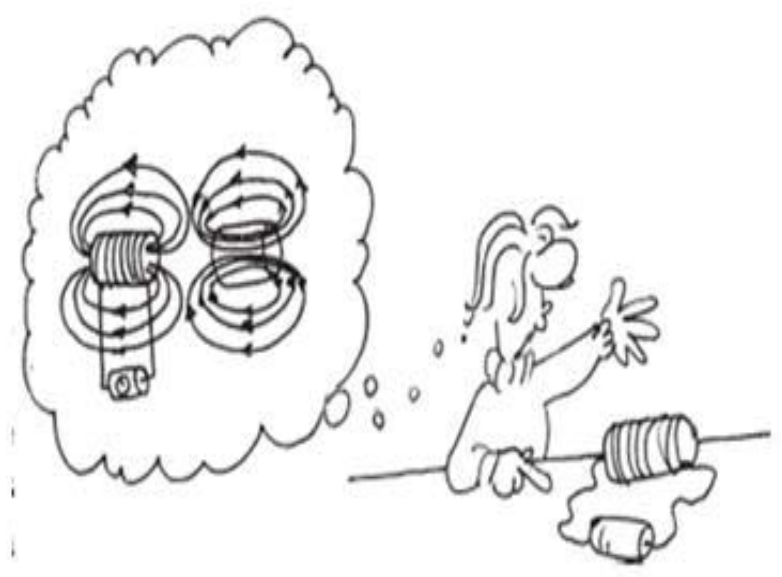

A diferença em relação ao ímã é que no flo o campo magnético delxa de existir quando a corrente elétrica cessa.

(GREF- Eletromagnetismo, cap. 14 a 19, p. 59)

\section{EXPERIMENTOS DE BAIXO CUSTO}

\section{FORÇAS MAGNÉTICAS}

Acesso: <http://www.seara.ufc.br/sugestoes/fisica/sugestoesfisica. htm\#elet>

Objetivo:

- Ilustrar a ação de forças magnéticas.

Descrição:

Ponha uma esfera de aço sobre um ímã cilíndrico. Encoste um clipe de prender papel, preso a um fio, na esfera de aço. Pergunte aos espectadores:

- Se eu puxar o fio, quem se separa: o clipe da esfera ou a esfera do ímã? Puxe o fio. A esfera sobe, presa ao clipe.

Como é possível que a força magnética entre o clipe e a esfera seja maior que entre a esfera e o ímã, que é a origem da força magnética na experiência?

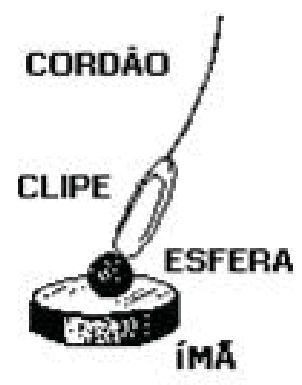

Forças Magnéticas

Disponível em <http://www.seara.ufc.br/sugestoes/

fisica/sugestoesfisica.htm\#elet $>$ 
Análise:

A força depende da intensidade de magnetização na superfície de contato e é tanto maior quanto menor for a área de contato. Como a área de contato entre o clipe e a esfera é pequena a intensidade nesse ponto é grande.

Mostre que depois de separados, o clipe e a esfera só se atraem se você aproximar o clipe exatamente do ponto onde antes eles se tocavam. É que esse ponto ficou fortemente magnetizado.

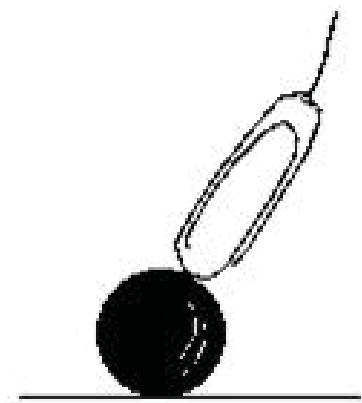

Disponível em <http://www.seara.ufc.br/sugestoes/fisica/sugestoesfisica.htm\#elet> Forças Magnéticas

Material:

Uma esfera de aço, dessas usadas em rolamentos.

Um ímã cilíndrico. Esse tipo de ímã pode ser retirado de um velho alto-falante queimado. Arranje um em uma oficina eletrônica.

Um clipe de papel - metálico, é claro.

Um pedaço de cordão.

Dicas:

Essa experiência pode fazer parte de um conjunto sobre forças magnéticas. Com seu ímã você pode fazer um monte de truques interessantes.

\section{ALGUMAS EXPERIÊNCIAS COM UM ÍMÃ}

Objetivo:

Realizar experiências simples com um ímã permanente. 


\section{Descrição:}

O principal ítem dessas experiências é um ímã permanente. Um daqueles pequenos ímãs usados para pregar coisas na porta da geladeira pode servir. Você pode também conseguir um excelente ímã retirando-o de um alto-falante queimado. O dono de uma oficina eletrônica pode até lhe dar um. Pergunte se ele tem também um aparelho de CD-ROM danificado. Dentro dele existe um ímã fortíssimo que você pode aproveitar. Se ele tiver e concordar em lhe presentear, peça, como mais um favor, que ele retire-o do aparelho. Isso é um tanto difícil, sem as ferramentas certas e muita experiência.

Bem, agora você dispõe de dois ímãs. Dois? Sim, o que ganhou de presente e a Terra, planeta onde mora. Vamos usar os dois nessas demonstrações.

1. Faça uma bússola. É provável que seu ímã seja redondo, que nem uma rosca. Amarre-o com um cordão e pendure-o na borda de uma mesa. Observe que ele gira um pouco e pára em um certa posição. Se você tentar movê-lo um pouco para outra direção, o ímã, teimosamente, volta para a posição que prefere. Essa é a direção Norte-Sul. Você fez uma bússola. Seus dois ímãs estão interagindo, um se alinhando na direção do campo magnético do outro. Como a Terra é um tanto pesada, quem se alinha é seu ímã que, além de leve, está pendurado em um cordão.

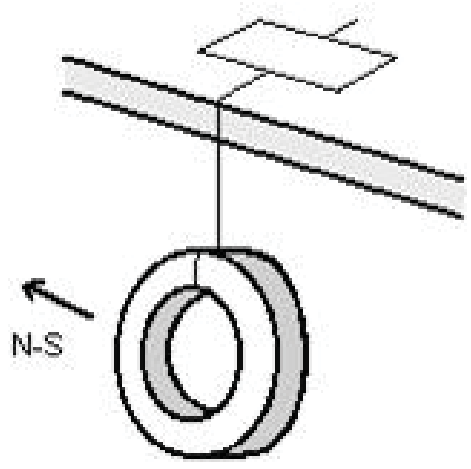

Disponível em < http://www.seara.ufc.br/sugestoes/fisica/sugestoesfisica.htm\#elet> Experiências com um ímã permanente

2. Faça um clipe de metal levitar. Amarre o clipe com um cordão e encosteo ao ímã. Depois, puxe devagar o cordão até descolar o clipe do ímã. $O$ clipe fica levitando. Prenda o cordão com uma fita adesiva e deixe o clipe levitando para sua platéia ver.

Agora, faça alguns testes. Verifique se é possível "cortar" a força magnética inserindo alguma coisa entre o ímã e o clipe. Tente uma folha de papel, uma chapa de metal, de vidro ou de madeira, sua mão, qualquer coisa. 
Alguns desses objetos "blindam” a força magnética, outros não. Anote os resultados: você é o pesquisador.
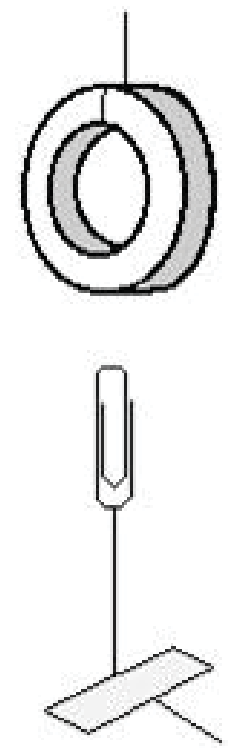

Disponível em <http://www.seara.ufc.br/sugestoes/fisica/sugestoesfisica.htm\#elet $>$ Experiências com um ímã permanente

3. Magnetizando objetos de metal. Pendure, "magneticamente", um clipe ao ímã. Depois, encoste outro clipe no primeiro. Ele também ficará pendurado. Vá acrescentando outros clipes, enquanto conseguir mantê-los pendurados. Seus clipes virarm ímãs. Encostando objetos metálicos no ímã eles podem ficar magnetizados ( ou "imantados"). Magnetize uma colher e atrai alguns clipes com ela. Depois bata com a colher na mesa e tente, de novo, pegar o clipe. Sua colher perdeu a imantação com o choque.

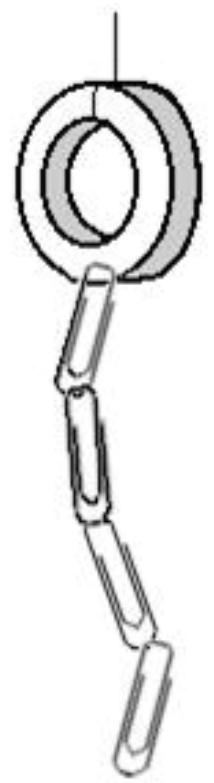

Disponível em < http:/ /www.seara.ufc.br/sugestoes/fisica/sugestoesfisica.htm\#elet> Experiências com um ímã permanente 
4. Reproduzindo a experiência de Oersted. Em 1818, Hans Oersted fez uma experiência que se tornou clássica: mostrou que uma corrente elétrica cria um campo magnético, como um ímã. Corte uma rodela de isopor do tamanho de uma moeda. Magnetize uma agulha com o ímã, ponha-a sobre a rodela e faça o conjunto flutuar sobre a água em um copo de vidro. Pegue um pedaço de fio condutor e descasque as pontas. Estique o fio sobre o copo, paralelo à agulha imantada. Encoste as pontas do fio nos pólos de uma pilha e observe o que acontece com a agulha. Você reproduziu a experiência de Oersted.

Deixe uma das pontas ligada e vá encostando e desencostando a outra ponta do outro pólo da pilha. Com jeito, você conseguirá fazer a agulha girar em círculos. Você construiu um motor, primitivo mas bem ilustrativo.

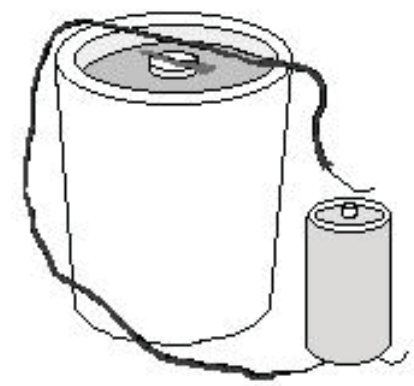

Disponível em <http:/ /www.seara.ufc.br/sugestoes/fisica/sugestoesfisica.htm\#elet> Experiências com um ímã permanente

Análise:

Alguns materiais podem ser imantados. Esses materiais já possuem, naturalmente, pequeníssimos ímãs, ou "dipólos" magnéticos, de dimensões atômicas. O nome "dipolo" já indica que esses ímãs microscópicos possuem dois pólos, como todo ímã que se preza. É o caso de vários metais, como o ferro ou o níquel. Na temperatura ambiente, os dipólos desses metais estão, em geral, desalinhados, isto é, apontam em todas as direções (A). Colocando o metal na região de um forte campo magnético, esses dipólos se alinham, pelo menos parcialmente (B). No caso da colher, ou dos clipes, esse alinhamento é fraco e pode ser desfeito apenas com um golpe sobre o objeto.

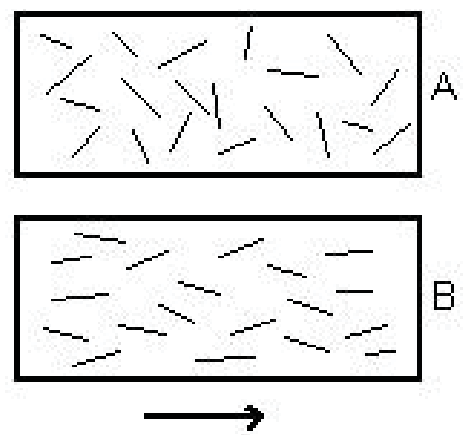

Disponível em < http://www.seara.ufc.br/sugestoes/fisica/sugestoesfisica.htm\#elet> Experiências com um ímã permanente 
E quem alinhou os dipólos de seu ímã de alto falante? Foi o fabricante do ímã. O material desses ímãs é especial, em geral uma liga, onde os dipólos são intensos, numerosos e capazes de um um forte alinhamento. Esses ímãs são magnetizados na presença de fortíssimos campos magnéticos artificiais e, no processo, são aquecidos para facilitar o alinhamento dos dipólos. Depois de alinhados, a temperatura retorna ao normal e o alinhamento fica permanente. Seu ímã também pode perder sua magnetização se for submetido a fortes choques mecânicos. Como essa magnetização é intensa, você precisaria golpear o ímã muitas vezes, com muita força, para desmagnetizá-lo alguma coisa. Mas, para que você faria isso?

Material:

Um ímã permanente. Esse tipo de ímã pode ser retirado de um velho alto-falante queimado. Arranje um em uma oficina eletrônica.

Clipes, pregos, agulhas, talheres e outros objetos de metal

Um pedaço de fio elétrico com as pontas descascadas.

Uma pilha de lanterna.

Dicas:

Essa experiência pode fazer parte de um conjunto sobre forças magnéticas. Leia mais sobre a experiência de Oersted em um bom livro-texto e faça um cartaz com essas explicações.

\section{A EXPERIÊNCIA CLÁSSICA DE OERSTED}

Objetivo:

Reproduzir a experiência clássica de Hans Christian Oersted e construir um galvanômetro simples e útil.

Descrição:

Em 1822, durante uma aula experimental, o professor de física dinamarquês Hans Christian Oersted descobriu que uma corrente elétrica passando por um fio deslocava a agulha de uma bússola que estava por perto. Essa foi uma das mais importantes descobertas da eletricidade, possibilitando, a seguir, a construção de motores e geradores que fazem parte essencial da vida moderna.

Coloque uma bússola sobre a mesa e deixe a agulha girar livremente até apontar na direção Norte-Sul (A). Enrole cerca de 30 voltas de um fio fino de cobre em torno da bússola, na direção Norte-Sul, deixando duas 
pontas soltas. Encoste uma das pontas no pólo negativo de uma pilha de 1,5 Volts. Depois, encoste a outra ponta no pólo positivo. A agulha deve girar imediatamente para outro ângulo, afastando-se da direção Norte-Sul (B).
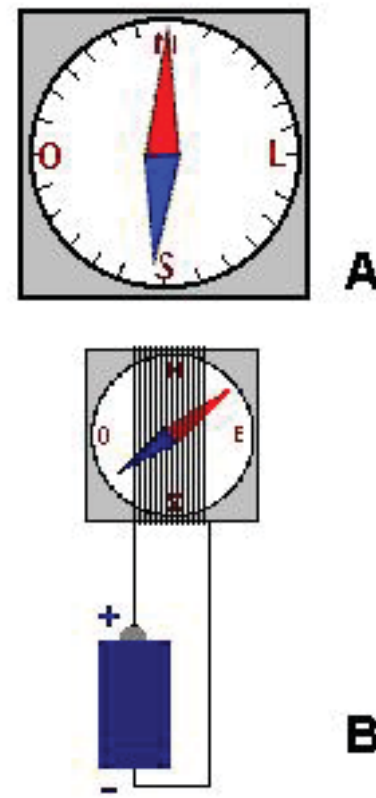

B

Disponível em < http://www.seara.ufc.br/sugestoes/fisica/sugestoesfisica.htm\#elet>

Experiência clássica de Oersted

Essa foi a descoberta acidental de Oersted. Modificando esse arranjo, podemos construir um galvanômetro, isto é, um aparelho para medir correntes ou voltagens elétricas. Use várias pilhas e resistências em série para montar um circuito como esse visto ao lado. Na figura, vemos apenas duas pilhas e duas resistências, mas, você pode usar quantas tiver. O importante é anotar, para cada valor da voltagem total das pilhas e da resistência total, o ângulo de deflexão da agulha da bússola. Faça uma tabela com uma coluna para a voltagem (em Volts), outra para a resistência total (em Ohms) e outra para o ângulo de deflexão da agulha. Com essa tabela, você calibra seu galvanômetro, que poderá ser usado como medidor de corrente ou voltagem em outras experiências.

Veja, na sugestão anterior, uma variação dessa montagem da experiência de Oersted.

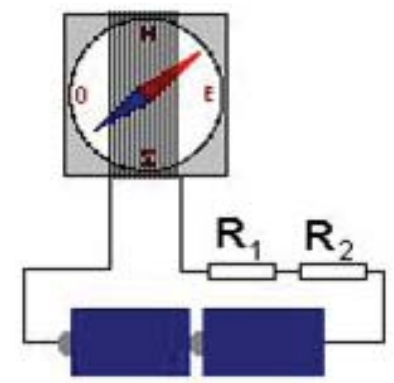

Disponível em <http://www.seara.ufc.br/sugestoes/fisica/sugestoesfisica.htm\#elet> Experiência clássica de Oersted 
Análise:

Quanto maior a corrente elétrica no fio, maior será a deflexão da agulha. A corrente em ampères pode ser calculada usando a lei de Ohm, $\mathrm{i}=\mathrm{V} / \mathrm{R}$, onde $\mathrm{V}$ é a voltagem total das pilhas (em Volts) e $\mathrm{R}$ é a resistência total (em Ohms). Variando V e/ou R, obtemos pares de valores da corrente (ou da voltagem) e do ângulo de deflexão. Com esses valores, você traça um gráfico de calibração de seu galvanômetro. Com ele, basta medir o ângulo para obter o valor de uma corrente desconhecida.

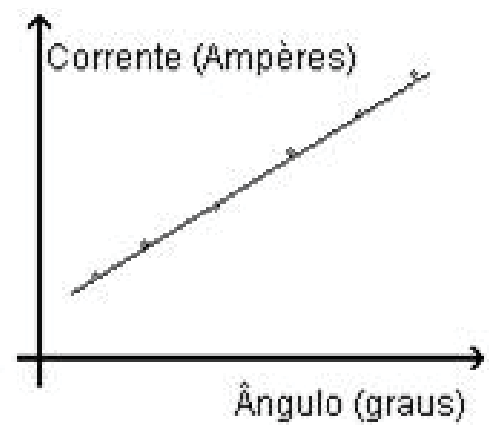

Disponível em < http:/ / www.seara.ufc.br/sugestoes/fisica/sugestoesfisica.htm\#elet> Experiência clássica de Oersted

Material:

Uma bússola simples, que pode ser adquirida em lojas de presentes. Várias pilhas de 1,5 Volts.

Várias resistências, de preferência de $1 \mathrm{Obm}$ cada.

Cerca de dois metros de fio de cobre bem fino.

Suporte para as pilhas e resistências - que você deve construir.

Dicas:

Exerça sua habilidade manual preparando um suporte adequado para as pilhas e resistências. Use, por exemplo, uma pequena prancha de madeira. Para os contatos, use grampos tipo "jacaré". Se souber usar um ferro de soldar, solde as pontas nos terminais e use pedaços soltos de fio para formar as combinações de voltagem e resistência desejadas. Leia mais sobre a experiência de Oersted em um bom livro-texto e faça um cartaz sobre essa experiência histórica. Arranje um amperímetro de verdade para exibir a seu público. 


\section{APPLETS DE ENSINO}

Como nas outras instrumentações, sugerimos alguns sites de ensino com material de multimídia. Segue abaixo um guia de applets com dicas para você analisar.

1 - Applet em Java do Prof. Walter-Fendt, mostra a força de Lorentz exercida sobre um condutor em oscilação colocado no campo magnético de um ímã em ferradura. Pode-se usar o botão superior para Ligar/Desligar a corrente. Os outros dois botões ("Inverter a Polaridade" e "Inverter o ímã") permitem respectivamente mudar a direção da corrente ou do campo magnético. As seleções dos botões seguintes permitem ver a direção convencional da corrente (setas vermelhas), as linhas de campo magnético (azul) e a força de Lorentz (seta preta).

Link: <http://www.walter-fendt.de/ph14pt/lorentzforce_pt.htm>

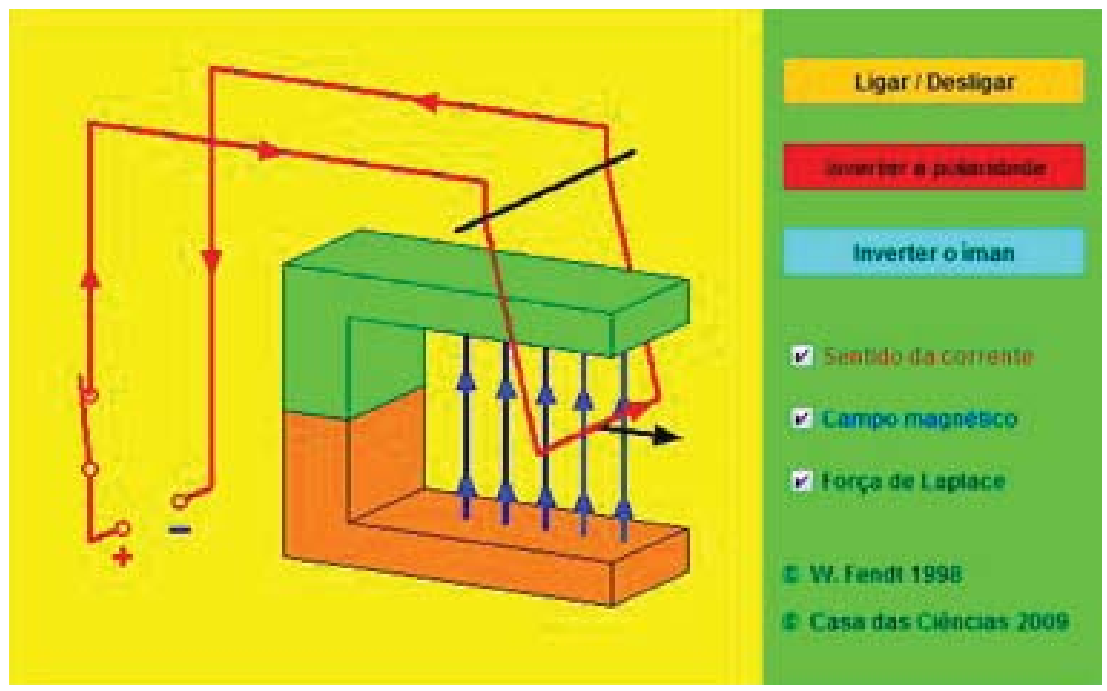

Disponível em <http://www.walter-fendt.de/ph14pt/lorentzforce_pt.htm>

\section{VIDEOS AULAS}

1 - Força Magnética. Prof. Vitor. Física 60 -- Força magnética Parte 1. Link: $<$ http://www.youtube.com/watch?v $=E W t T Z T x w I D k>$ 2 - Força Magnética. Prof. Vitor. Física 60 -- Força magnética Parte 2. Link: $<$ http://www.youtube.com/watch?v $=87$ ir5lIKZP0\&feature=related $>$ 3 - 34. Universo mecânico: Magnetismo $1 / 2$.

Link: <http://www.youtube.com/watch?v=kBTMx3I3384>.

4 - 34. Universo mecânico: Magnetismo $1 / 2$.

Link: <http://www.youtube.com $/$ watch? ${ }_{\mathrm{v}}={ }_{\mathrm{w}} \mathrm{YVqZCv} 4 \mathrm{WuM} \&$ feature $=$ related $>$ 


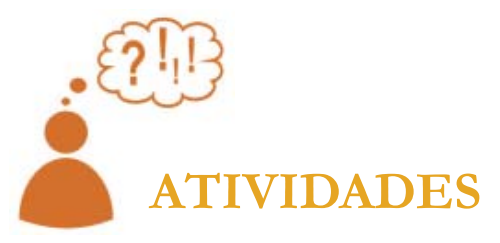

1. Você concorda que o material do GREF é um excelente material de apoio complementar ao livro didático? Por quê?

2. A pesar das resoluções do PNLEM que "obrigam" (sinalizam) aos novos livros didáticos, dentre outras coisas, a mostrar que a ciência é um produto histórico e social e que não é um produto acabado (pronto) devido ao trabalho de sociedades privilegiadas, você concorda que podemos ensinar Física sem citar nomes de cientistas e contar um pouco da história da ciência? Comente?

3. Como você ilustraria o conceito de campo magnético para seus (futuros) alunos?

4. O que você acha do texto tirado da seara da Física? Você acha realizável em sala de aula as experiências indicadas lá (acima)?

5. Colocamos acima alguns exemplos e/ou links de experimentos de baixo custo para você analisar a possibilidade de usá-los em sala de aula. Comente se você os usaria ou não como recurso didático em sala de aula? Comente. 6. Responda e faça as atividades indicadas abaixo, tiradas do projeto GREF.

\section{EXERCITANDO...}

1. Analise se a afirmação abaixo é verdadeira ou falsa e justifique:

"O movimento da agulha de uma bússola diante de um ímã é explicado da mesma forma que o movimento de um ímã diante de um outro ímã." 2. A agulha de uma bússola próxima a um fio que é parte de um circuito elétrico apresenta o comportamento indicado nas três figuras:

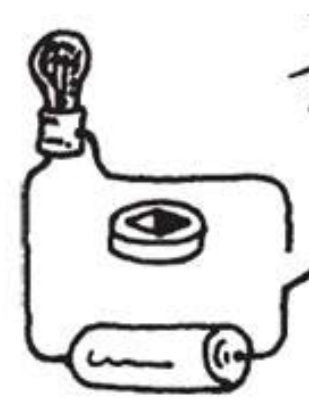

figura 1

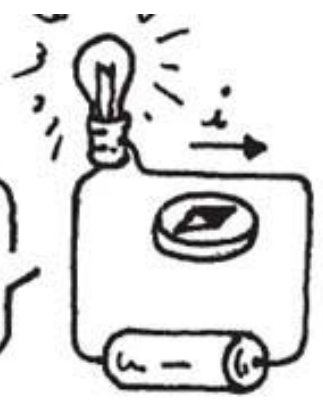

figura 2

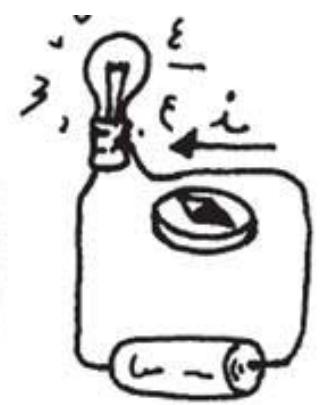

figura 3

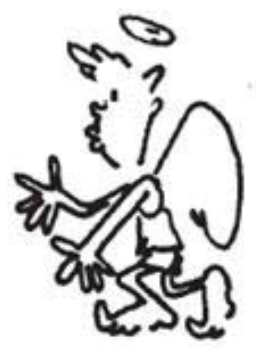

(GREF- Eletromagnetismo, cap. 14 a 19, p. 59) 
a) como se explica o posicionamento da agulha na figura 1?

b) como se explica a alteração da posição da agulha após o circuito ser fechado na figura 2?

c) analisando as figuras 2 e 3 é possível estabelecer uma relação entre o posicionamento da agulha e o sentido da corrente elétrica no fio?

3. Se imaginássemos que o magnetismo terrestre é produzido por um grande ímã cilíndrico, colocado na mesma direção dos pólos geográficos norte-sul, como seriam as linhas do campo magnético? Faça uma figura.

4. Imagine agora que o campo magnético da Terra fosse criado por uma corrente elétrica em uma bobina. Onde ela estaria localizada para que as linhas do campo magnético coincidissem com as do ímã do exercício anterior?

\section{TESTE SEU VESTIBULAR}

1. Uma pequena bússola é colocada próxima de um ímã permanente. Em quais posições assinaladas na figura ao lado a extremidade norte da agulha apontará para o alto da página?

2. Uma agulha magnética tende a:

a) orientar-se segundo a perpendicular às linhas de campo magnético local.

b) orientar-se segundo a direção das linhas do campo magnético local.

c) efetuar uma rotação que tem por efeito o campo magnético local.

d) formar ângulos de 45 graus com a direção do campo magnético local.

e) formar ângulos, não nulos, de inclinação e de declinação como a direção do campo magnético local.

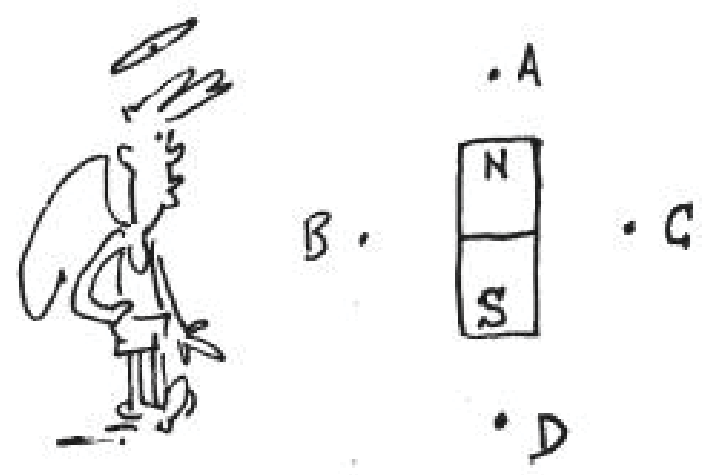

(GREF- Eletromagnetismo, cap. 14 a 19, p. 59)

7 - Discuta a abordagem do GREF de antes de começar a contar qualquer fato histórico, teoria, fórmulas e leis, eles instigam aos alunos a explorarem ao máximo os fenômenos magnéticos, incitando assim a curiosidade do aluno.

8 - Vá até sua geladeira e pegue vários imãs. Qual a diferença entre os imã de enfeite (aqueles feitos com pequenas barras de imã e algum enfeite de porcelana) e as propaganda (de gás, pizza,...). Note que os imã de propaganda 
são feitos de um material mole, parecendo um borracha. Eles têm pólo? 9 - Discuta a abordagem do GREF deles explicarem de uma forma nada formal o fenômeno do magnetismo. Note que eles misturam imãs permanentes com bobinas. Para eles o importante é a propriedade de atração e da existência de dois pólos.

\section{COMENTÁRIOS SOBRE AS ATIVIDADES \\ Em geral os alunos que fazem o curso de licenciatura em Física têm um curso muito superficial ou não têm nenhuma aula de Física. Se têm, usam algum livro texto tradicional, onde a Física é apresentada como uma coleção de definições e fórmulas para ser aplicada em problemas e exercícios. Assim, a maioria só possui o conhecimento de Física dado na universidade. A apresentação do projeto GREF deve ter dado uma visão geral de toda a complexidade de se montar um curso de Física e como esse pode se tornar mais atraente. \\ O aluno deve começar a se ver como futuro professor. Isto é, ele deve estar começando a ver a Física não como matéria ser aprendida e sim como a ser ensinada. Aqui ele deve começar enxergar as diversas possibilidades que o mundo moderno the oferece como educador. Os futuros professores devem ter compreendido o papel central que eles têm na escolha do conteúdo, da técnica e da didática ser utilizada em sala de aula. Este deve ter adquirido uma ideia de como se deve preparar um curso ou apenas uma aula. Eles devem compreender que uma aula é um processo dinâmico e orgânico.}

\section{CONCLUSÃO}

Depois dessa aula o professor deve estar ciente da possibilidade e vantagens de se ensinar alguns conceitos de Física a partir da Física dos objetos do seu cotidiano. Exploramos aqui o fato do magnetismo e suas propriedades atraírem tanto a nossa atenção para mostrar que podemos ensinar Física de uma forma divertida. Aqui no eletromagnetismo dos eletrodomésticos. Este deve estar percebendo, cada vez mais, que a Física pode ser ensinada de forma divertida.

Com a análise dos experimentos de baixo custo e dos recursos de multimídias que colocamos no final da aula o futuro professor deve ter ficado com algumas boas idéias de como este pode enriquecer uma aula sobre o tema Força Magnética. 


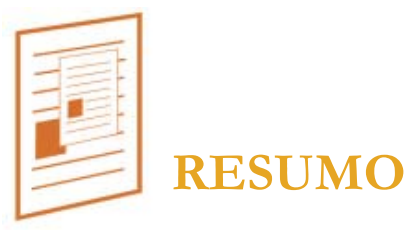

Nessa aula começamos a discutir se devemos ministrar um curso de Física a partir de sua teoria e história ou se devemos ministrar este curso a partir da Física dos objetos de nosso cotidiano. Apresentamos aqui o material do GREF, mais uma vez, e o completamos com muitos experimentos caseiros (baixo custo).

Em seguida apresentamos vários experimentos de baixo custo para que o aluno explore as possibilidades que estes oferecem para se ministrar um curso usando mais ferramentas fenomenológicas e menos formais. Colocamos somente um applets de ensino como recurso de simulação de fenômeno físico para ser explorado pelo futuro professor. Não colocamos mais, pois deixamos isso para a próxima aula.

Como há ótimos vídeos de ensino colocamos alguns deles como referência, e deixamos sua exploração como atividade para os estudantes. Neste curso de Instrumentação I não usamos os vídeos didáticos como ferramenta didática principal.

\section{RESPOSTA ÀS ATIVIDADES}

1 - Sim, porque ele é muito diferente das propostas de aulas normais. Ele deve ser usado com cautela.

2 - Os alunos devem responder em relação ao material do GREF, que não usa a história da ciência.

3 - Resposta pessoal para ser comparada com as que ele deu nos outros capítulos.

4 -Sim, é muito legal. Mas o experimento é elaborado e precisa de cuidados para ser realizado em sala de aula.

5 - Eles têm que assistir e fazer uma resenha.

6 - Eles têm que assistir e fazer uma resenha.

7 - Eles têm que assistir e fazer uma resenha.

8 - Tem que fazer e comentar.

\section{REFERÊNCIAS}

FENDT, Walter. Força de Lorentz. Disponível em: < http://www.walterfendt.de/ph14pt/lorentzforce_pt.htm>. Acesso em 16/10/2011.

GASPAR, A.; Cinquenta anos de Ensino de Física: Muitos equívocos, alguns acertos e a necessidade do resgate do papel do professor; artigo apresentado no XV Encontro de Físicos do Norte e Nordeste; 2002. 
GREF - Grupo de Reelaboração do Ensino de Física, Instituto de Física da USP - Leituras de física - Gref - Eletromagnetismo para ler, fazer e pensar - versão preliminar 14-19, p. 57 a 60.

PNLD. Programa Nacional do Livro Didático. GUIA DE LIVROS DIDÁTICOS. Disponível em: <http://portal.mec.gov.br/index. php?option $=$ com_content $\&$ view $=$ article $\&$ id $=12389 \% 3$ Aguias-do-livrodidatico\&catid $=318 \% 3$ Apnld \&Itemid $=668>$. Acesso em 16/10/2011. SEARA DA CIÊNCIA. Disponível em: < http://www.seara.ufc.br/sugestoes/fisica/sugestoesfisica.htm\#elet>. Acesso em 16/10/2011. YOUTUBE. Física 60 -- Força magnética Parte 1. Disponível em: $<$ http://www.youtube.com/watch?v $=E W t T Z T x w I D k>$. Acesso em $16 / 10 / 2011$

Física 60 -- Força magnética Parte 2. Disponível em: <http:// www.youtube.com $/$ watch? $=87$ ir5lIKZP0\&feature $=$ related $>$. Acesso em $16 / 10 / 2011$.

34. Universo mecânico: Magnetismo 1/2. Disponível em: <http:// www.youtube.com/watch?v=kBTMx3I3384>. Acesso em 16/10/2011

34. Universo mecânico: Magnetismo $1 / 2$. Disponível em:

$<$ http: / $/$ www.youtube.com $/$ watch? ${ }={ }_{\text {wYV }}$ QZCv 4 WuM\&feature $=$ relat ed $>$. Acesso em 16/10/2011. 



\section{Aula 8}

\section{CAMPO MAGNÉTICO}

META

Fazer como que o estudante comece a pensar no ensino de ciências como algo "orgânico"

que está em profunda transformação.

Fazer com que os alunos percebam, através de um texto básico complementado com atividades lúdicas, applets de ensino, vídeos, e com materiais de baixo custo, que o conceito de campo e força magnética podem ser compreendidos de forma simples e

divertida.

Analisar como os livros textos relatam a história da ciência e fazer com que o estudante reflita sobre o que é fazer e ensinar Física. Introduzir o problema de como se ensinar o conceito de campo magnético.

OBJETIVOS

Ao final desta aula, o aluno deverá: estar cientes das novas possibilidades e dos desafios que envolvem o ensino de ciências em geral.

Ter compreendido que as ciências naturais estão baseadas na experimentação e que esta é feita de ensaios, experiências e medidas levando a compreensão e matematização dos conceitos físicos (naturais em geral).

Estar cientes das dificuldades de se ministrar um curso de eletricidade e magnetismo.

Através do tema "campo e força magnética" discutiremos as dificuldades inerentes de se ensinar Física, que vão além das teorias pedagógicas e de ensino usuais. Vamos discutiro a papel da história da ciência como complemento pedagógico ao ensino de Física.

PRÉ-REQUISITOS

Os alunos deverão ter cursado as disciplinas Psicologia da Educação, Física A e Física B e Instrumentação I. 


\section{INTRODUÇÃO}

$\mathrm{Na}$ aula anterior abordamos problema da transposição científica. Nessa aula o faremos novamente abordando a análise do problema de se introduzir um pouco de história da ciência nos livros didáticos em geral. Vamos refletir se há necessidade, no ensino médio e fundamental, de se carregar os livros textos com nomes e datas.

Vamos nesta aula analisar o material de ensino do livro aprovado pelo PNLEM "Física Ensino Médio" dos autores Beatriz Alvarenga e Antônio Máximo. Recorde que na aula anterior analisamos o material de ensino do projeto GREF, onde eles ensinam o conceito de campo e força magnética a partir de experimentos simples tirados de objetos do nosso cotidiano.

Escolhemos o livro da professora Beatriz Alvarenga, pois apesar deste ser um bom livro (considerado ótimo, o que eu concordo), ele contém alguns equívocos inerentes a todo livro. Assim, vou tomar a liberdade de explorá-los para poder ilustrar um ponto muito importante no ensino de ciências: Até que ponto devemos carregar nossos livros didáticos com fatos e histórias? Será que uma abordagem histórica e carregada de leitura está de acordo com o conselho do PNLEM:

É necessário perguntar, ser curioso, investigar, descobrir, criar..., é necessário transformar o mundo! Ciência é realidade, imaginação, perseverança, trabalho, criatividade. Ciência é ação. Os interesses dos alunos estão centrados na ação, no diálogo, na confrontação de idéias, no trabalho em equipe, na experimentação, na reflexão conjunta, na busca de novos questionamentos. Portanto, as aulas de Ciências devem transmitir o caráter de empresa vital, humana, fascinante, indagadora, aberta, útil e criativa que tem a atividade científica.

Na unidade 10 do livro do professor da Beatriz encontramos:

As primeiras observações de fenômenos magnéticos são muito antigas. Acredita-se que estas observações foram realizadas pelos gregos, em uma cidade da Ásia, denominada Magnésia. Eles verificaram que existia, nesta região, um certo tipo de pedra que era capaz de atrair pedaços de ferro. Sabe-se atualmente que estas pedras, denominadas de imãs naturais, são constituídas por um certo óxido de ferro. O termo "magnetismo" foi, então, usado para designar o estudo das propriedades destes imãs, em virtude do nome da cidade onde foram descobertos. 


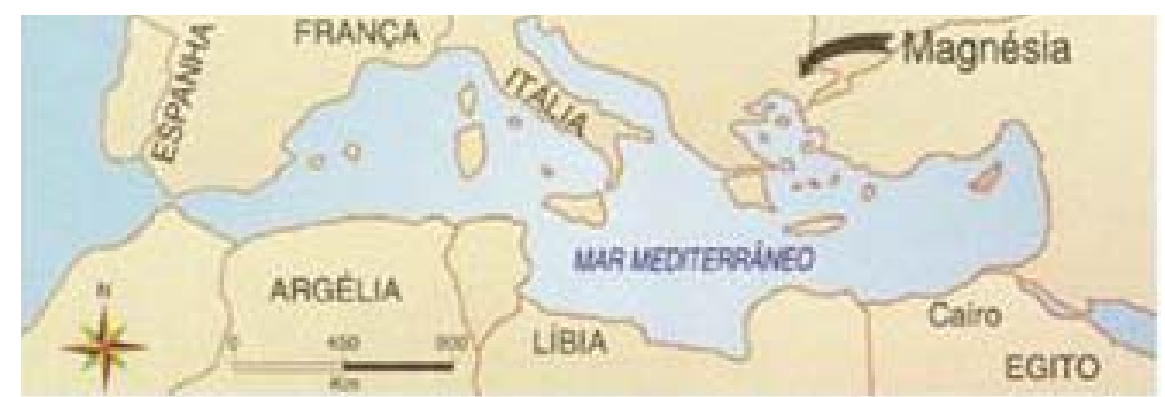

Mapa da região onde supostamente foram observados os primeiros fenômenos magnéticos

Observou-se que um pedaço de ferro, colocado nas proximidades dos imã natural, adquiria as mesmas propriedades do imã natural. Assim, foi possível obter imãs não naturais (artificiais) de várias formas e tamanhos, utilizando pedaços de ferro de várias formas e tamanhos.

Com o decorrer do tempo, várias outras propriedades dos imãs foram sendo descobertas, algumas das quais descreveremos a seguir.

Note-se no texto acima que ele passa várias informações imprecisas ou até errôneas. A primeira informação errônea é que foram os gregos e não os chineses que se depararam com o fenômeno do magnetismo. Outra informação não muito precisa e que pode levar a conclusões errôneas é a de que se aproximarmos um pedaço de metal de um imã ele vai adquirir a propriedade (permanente) deste imã. Isto só vai ocorrer momentaneamente.

\section{PÓLOS DE UM IMÃ}

Verificou-se que pedaços de ferro eram atraídos com maior intensidade por certas partes do imã, as quais foram denominadas pólos do imã. Se tomarmos, por exemplo, um imã em forma de barra e distribuirmos limalha de ferro (pequenos pedaços de ferro) sobre ele, notaremos que a limalha se acumulará nas extremidades da barra (fig. 22-1), isto é, ela é atraída com maior intensidade para estas extremidades. Portanto, um imã em forma de barra possui dois pólos, situados em suas extremidades.

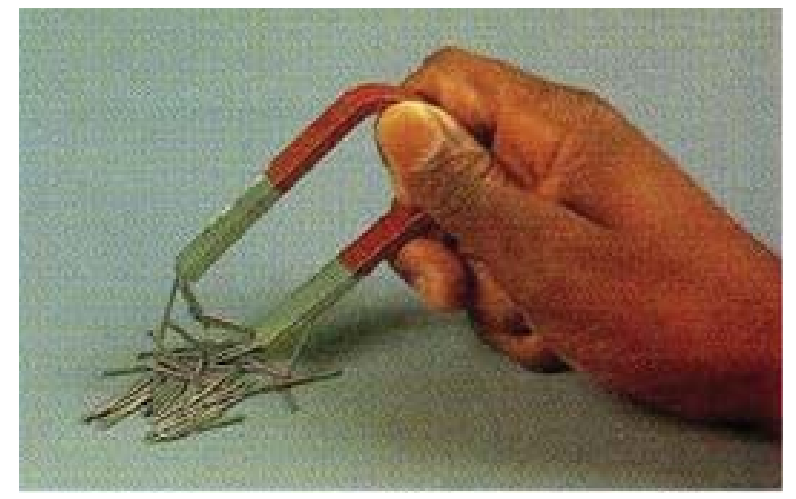

Observe onde estão localizados os pólos desse ímã. 

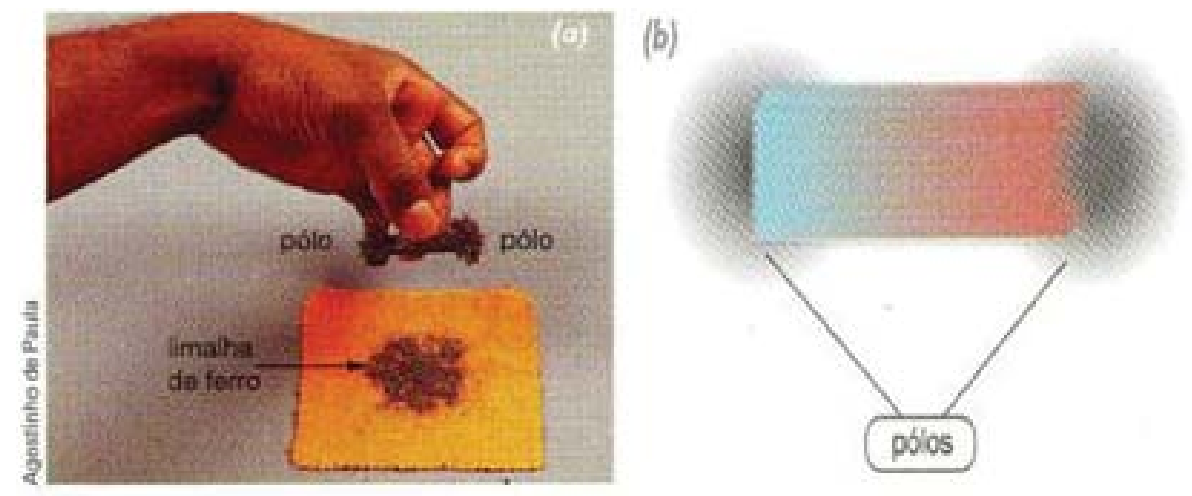

Figura 22-1 Ilustração esquemática. Um imã em forma de barra possui dois pólos, situados em suas extremidades.

Suspendendo-se um imã em forma de barra, de modo que possa girar livremente em torno do seu centro, observa-se que ele se orienta sempre ao longo de uma mesma direção (fig.22-2.a). Tal direção coincide aproximadamente com a direção norte-sul da Terra. Tal propriedade dos imãs foi utilizada na construção das bússolas magnéticas (fig.22-2.a), as quais tornaram possíveis viagens marítimas extensas desde tempos muitos remotos. Como você sabe, estes instrumentos continuam sendo empregados até nossos dias.

(a)

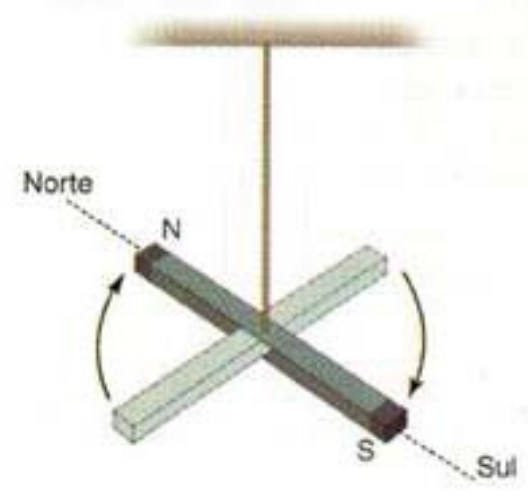

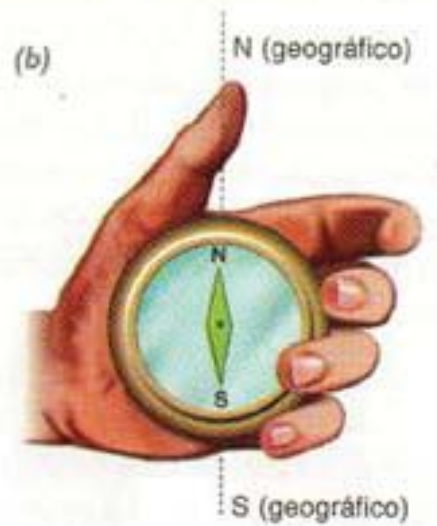

Figura 22-2 Um ímã (ou agulha magnética) suspenso orienta-se na direção norte-sul. Ilustração esquemática.

Os pólos de um imã recebem denominações de "pólo norte magnético" e "pólo sul magnético", de acordo com a seguinte convenção:

Pólo norte de imã é aquela extremidade que, quando o imã pode girar livremente, aponta para o norte geográfico da Terra. A extremidade que aponta para o sul geográfico da Terra é o pólo sul do imã (fig. 22-2) 


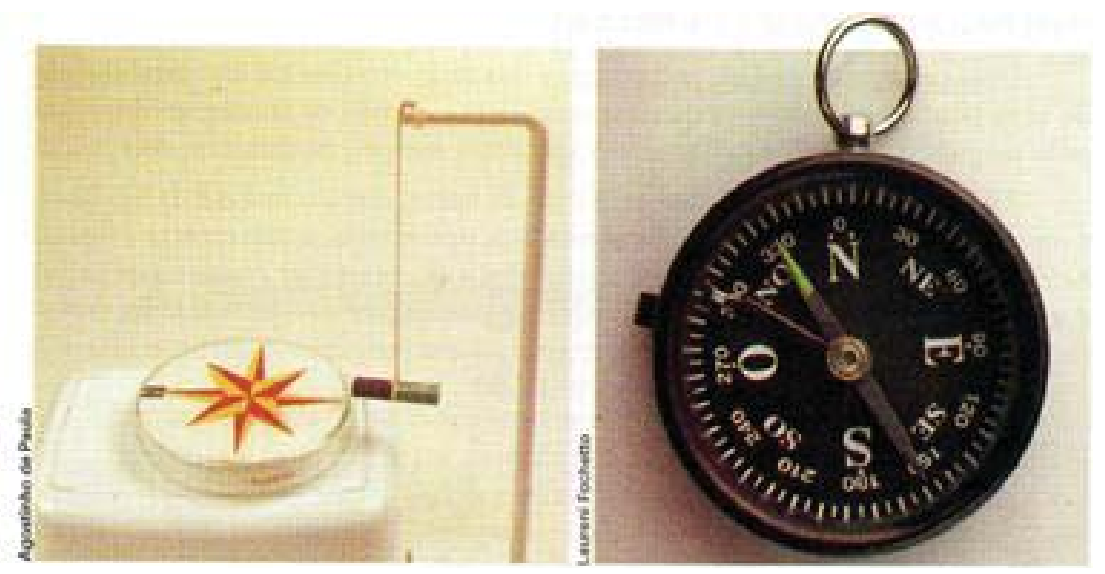

Um imã suspenso livremente é orientado na direção norte-sul pelo campo magnético terrestre.

É possível que você já tenha observado experimentalmente que, ao tentarmos aproximar o pólo norte de um imã do pólo norte de outro imã, notaremos que haverá uma força magnética de repulsão entre estes pólos (fig.22-3-a). do mesmo modo, observaremos que há uma força de repulsão entre os pólos sul de dois imãs (fig.22-3-b), enquanto entre o pólo norte de um imã e o pólo sul de outro imã haverá uma força de atração magnética (fig.22-3-c). Em resumo: pólos magnéticos de mesmo nome se repelem e pólos magnéticos de nomes contrários se atraem.

(a)

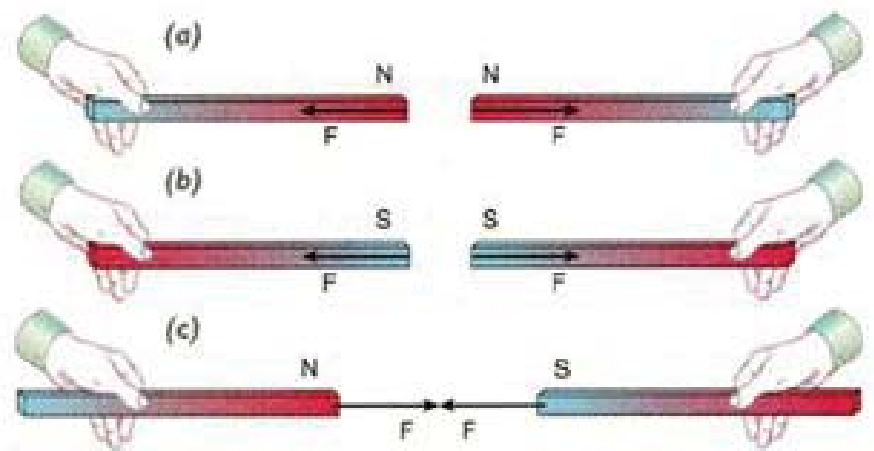

Figura 22-3 - Pólos magnéticos de mesmo nome se repelem e pólos magnéticos de nomes contrários se atraem

No texto acima não cita que os chineses foram os inventores da bússola e de que elas foram usadas pela primeira vez nas grandes navegações na virada do século XIV para o XV. No livro do aluno consta a informação:

- Os fenômenos magnéticos são conhecidos desde a antiguidade. Nessa época, já se utilizava certas pedras - que tinham a propriedade de atrair pedaços de ferro - na rota das grandes viagens.

De novo o texto leva a conclusão falsa de que foram os chineses e os gregos que exploraram o mundo!!!!! 


\section{A TERRA É UM GRANDE IMÃ}

Durante muitos anos, vários filósofos e cientistas tentaram encontrar uma explicação para o fato de um imã (como a agulha de uma bússola) se orientar na direção norte-sul da Terra. Entretanto, a explicação que hoje sabemos ser correta só veio a ser formulada no séc.XVII pelo médico inglês W.Gilbert, cientista cujos trabalhos no campo da Eletricidade já nos referimos no capítulo 17. Em sua obra, denominada De Magnete, publicada em 1600, Gilbert descreve um grande número de propriedades dos imãs, observados experimentalmente por ele, e formula hipóteses procurando explicar estas propriedades.

Uma das principais ideias que ele apresenta em sua obra é a de que a orientação de uma agulha magnética se deve ao fato de a Terra se comportar como um grande imã. Segundo Gilbert, o pólo norte geográfico da Terra seria também um pólo magnético que atraí a extremidade norte da agulha magnética. De modo semelhante, o pólo sul geográfico da Terra se comporta como um pólo magnético que atrai o pólo sul da agulha magnética. Em virtude destas forças de atração, a agulha magnética (ou qualquer outro imã em forma de barra) tende a se orientar ao longo da direção norte-sul.

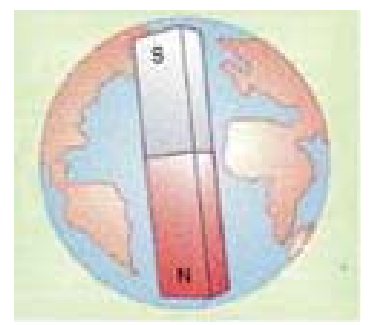

Figura 22-4 - O norte geográfico da Terra é um pólo sul magnético e o sul geográfico é um pólo norte magnético.

É fácil perceber, de acordo com esta explicação, que o pólo norte geográfico da Terra é um pólo sul magnético (pois ele atrai o pólo norte da agulha) e o pólo sul geográfico é um pólo norte magnético. Então, para efeitos magnéticos, podemos imaginar a Terra representada por um grande imã, como se procura ilustrar na fig. 22-4.

\section{INSEPARABILIDADE DOS PÓLOS}

Uma outra propriedade interessante dos imãs consiste na inseparabilidade de seus pólos; verificou-se experimentalmente que não se consegue obter um pólo magnético isolado. Qualquer imã apresenta sempre, no mínimo, dois pólos.

Assim, se tomarmos imã em forma de barra, como imã AB da Fig. 22-5, 
e o partirmos em dois pedaços, obteremos dois novos imãs, como mostra a figura. Observe que as extremidades A e B continuam a se comportar como um pólo sul e um pólo norte, respectivamente. Entretanto, na região em que o imã foi cortado, aparecerão dois pólos: em $\mathrm{C}$ um pólo norte (originando um novo imã $\mathrm{AC}$ ) e em $\mathrm{D}$ um pólo sul (originando outro imã DB).
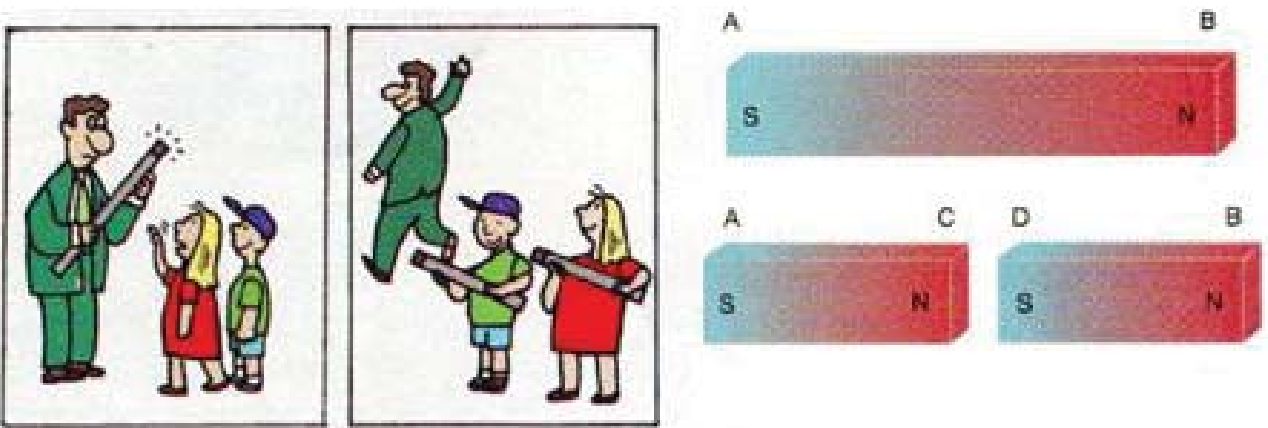

Figura 22-5 - É impossível obter um pólo magnético isolado.

Note-se que semelhantemente ao GREF o livro traz muitas ilustrações e que elas complementam e ilustram o conceito abordado no texto. $\mathrm{Na}$ sequência ele traz vários exercícios de fixação e continua com a teoria.

\subsection{ELETROMAGNE'TISMO}

O magnetismo foi desenvolvendo com o estudo das propriedades dos imãs, algumas das quais foram descritas na seção anterior. Não se suspeitava, então, que pudesse existir qualquer relação entre os fenômenos magnéticos e os fenômenos elétricos. Em outras palavras, o magnetismo e a eletricidade eram consideradas dois ramos da Física totalmente independente e distintos um do outro.

Entretanto, no início do século XIX, um fato notável determinou uma mudança radical nesse ponto de vista. Este fato, observado pelo professor dinamarquês H.C. Oersted, veio mostrar que há uma intima relação entre a eletricidade e o magnetismo, ao contrário do que se pensava até então.

\footnotetext{
Hans Christian Oersted (1777-1851).

Fisico dinamarquess que em 1806 se tornou professor da Universidade de Copenhague, onde desenvolveu várias pesquisas no campo da Fisica e da Quimica. Em um ensaio publicado em 1813, previu que deveria existir uma llgaç̇o entre a Eletricidade e o Magnetismo. Em 1820, durante uma aula. descobriu que uma agulha magnetica 6 desviada quando colocada nas proximidades de um condutor que conduz urna corrente eletrica, assim confirmando experimentalmente sua previsão. Oersted fol professor e conferenclista conceituado, dedicando-se ainda a escrever alguns artigos sobre filosofia. Em 1824, fundou uma sociedade para divulgar os conhecimentos cientiffcos entre o pova.
}

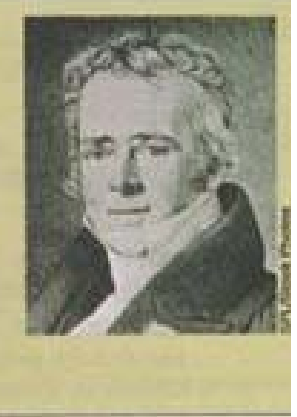




\section{A EXPERIÊNCIA DE OERSTED}

Em 1820, trabalhando em seu laboratório, Oersted montou um circuito elétrico, tendo nas proximidades uma agulha magnética. Não havendo corrente no circuito (circuito aberto), a agulha magnética se orientava na direção norte-sul, como já sabemos. A montagem feita na figura 22-6-a é semelhante aquela feita por Oersted. Observe que um dos ramos do circuito (o fio $\mathrm{AB}$ ) deve ser colocado paralelamente à agulha, isto é, deve ser orientado na direção norte-sul.

Ao estabelecer uma corrente no circuito, Oersted observou que a agulha se desviava da direção norte-sul, tendendo a se orientar na direção perpendicular ao fio $\mathrm{AB}$ (fig. 22-6-b). Interrompendo-se a corrente à agulha voltava a sua posição inicial, ao longo da direção norte-sul. Estas observações realizadas por Oersted mostravam que uma corrente elétrica podia atuar como se fosse um imã, provocando desvios em uma agulha magnética. Verificava-se, assim, pela primeira vez, que existe uma relação entre a eletricidade e o magnetismo: uma corrente elétrica é capaz de produzir efeitos magnéticos.
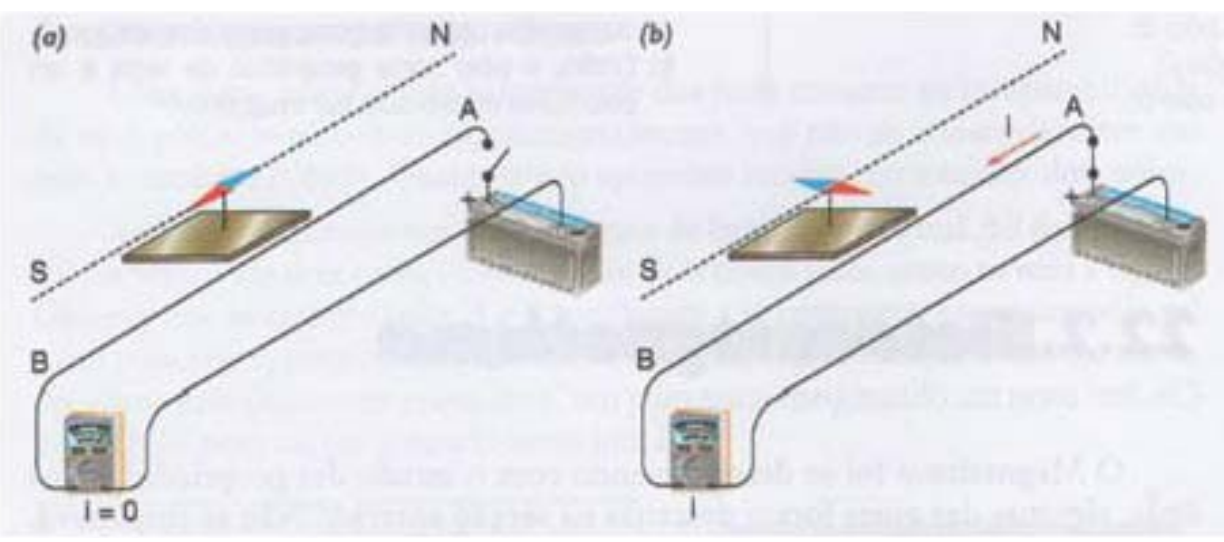

Figura 22-6 - Uma agulha magnética colocada nas proximidades de um fio que conduz uma corrente elétrica tende a se posicionar perpendicularmente ao fio. Ilustração esquemática.

Percebendo a importância de sua descoberta, Oersted divulgou o resultado de suas observações, que imediatamente atraiu a atenção de grandes cientistas da época. Alguns deles passaram a desenvolver pesquisas relacionadas com o fenômeno, destacando-se o trabalho de Àmpere. Em pouco tempo, graças a estas pesquisas, verificou-se que qualquer fenômeno magnético era provocado por correntes elétricas, isto é, conseguia-se de modo definitivo a unificação do magnetismo e da eletricidade, originando o ramo da Física atualmente denominado de Eletromagnetismo.

Analisando com cuidado esta seção 22.2 vemos que o texto induz o estudante a acreditar que a descoberta científica foi proposital e não acidental, como de fato ocorreu. No box em cor mostarda diz que Oersted previu que deveria existir uma relação entre a eletricidade e o magnetismo. Abaixo, no 
texto "Experiência de Oersted" eles dizem que o fato se deu no laboratório e que a montagem do experimento foi com o propósito de verificar o fenômeno físico. Sabemos que o fato se deu de forma acidental em uma palestra, aula de demonstração e nem está claro se foi ele que observou o fato na aula ou se alguém chamou atenção para o fato. Em seguida eles definem:

\section{O FATO BÁSICO DO ELETROMAGNETISMO}

Como resultado dos estudos que acabamos de citar, foi possível estabelecer o princípio básico de todos os fenômenos magnéticos: quando duas cargas elétricas estão em movimento, aparece entre elas uma força que é denominada de força magnética.

Já sabemos que quando duas cargas elétricas estão em repouso, existe entre elas uma força, denominada de força eletrostática, que foi estudada no capítulo 17 (Lei de Coulomb). Quando as duas cargas estão se movendo, além das forças eletrostática, aparece entre elas uma nova força, que é a força magnética. Por exemplo na figura 22-7-a, a carga Q em movimento exerce sobre a carga q também em movimento, além da força eletrostática, uma força magnética , como está indicado na figura.

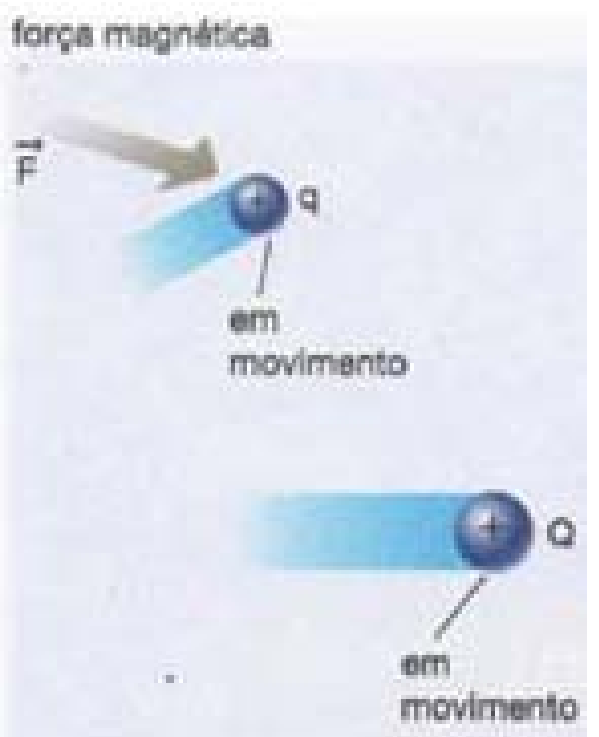

Figura 22-7 - Ilustração esquemática. Quando duas cargas elétricas estão em movimento, manifesta-se entre elas, além da força elétrica, uma força magnética.

Todas as manifestações de fenômenos magnéticos são explicados através desta força entre cargas em movimento. Assim, o desvio da agulha na experiência de Oersted é devido à existência desta força; é também ela a responsável pela orientação da agulha magnética na direção norte-sul: a atração e repulsão entre os pólos de imãs é ainda uma consequência desta 
força magnética. Conforme veremos no capítulo seguinte, existem cargas em movimento na estrutura atômica de um imã que são responsáveis pelas propriedades magnéticas que ele apresenta.

Podemos, então, salientar o seguinte fato básico, que é o fundamento dos fenômenos magnéticos:

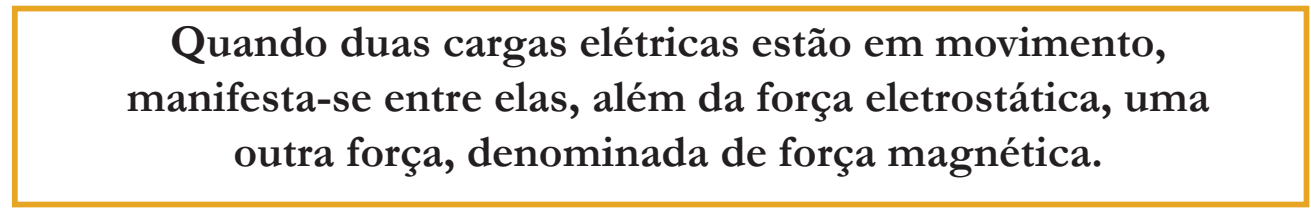

Vemos acima que como no caso da eletrostática (aula1) Beatriz e Máximo lançam mão do conceito moderno da estrutura da matéria para explicar a produção do campo magnético por cargas em movimento. Descoberta que se daria um século depois. De novo temos o problema da transposição didática e a questão: precisamos do conceito de cargas elétricas para ensinarmos magnetismo? Eles seguem definindo:

\section{CAMPO MAGNÉTICO}

\section{O QUE SE ENTENDE POR CAMPO MAGNÉTICO}

Vimos, na secção anterior, que uma carga elétrica em movimento exerce uma força magnética sobre outra carga que também esteja se movendo (fig. 22-7). Podemos descrever este fato de uma outra maneira, dizendo que uma carga em movimento cria no espaço em torno dela um campo magnético, o qual atua sobre a outra carga também em movimento. Como você deve estar lembrando, um procedimento semelhante foi usado no capítulo 18, quando estudamos o campo elétrico. Dizíamos, naquele capítulo, ao analisarmos a interação eletrostática entre duas cargas Q e q, que a carga Q cria um campo elétrico, o qual exerce uma força eletrostática sobre q.

Assim, na fig. 22-7, podemos dizer que a carga Q, em movimento, cria um campo magnético no espaço em torno dela e este campo atua sobre a carga q, também em movimento. Portanto, dentro deste ponto de vista, a força magnética em q é devida à existência do campo magnético criado por Q.

Podemos, pois, destacar:

Uma carga em movimento cria, no espaço em torno dela, um campo magnético que atuará sobre outra carga, também em movimento, exercendo sobre ela uma força magnética. 
Deve-se observar que, se existir uma corrente elétrica passando por um fio, haverá um campo magnético no espaço em torno deste fio, pois uma corrente elétrica, como sabemos, é constituída por cargas elétricas em movimento. Da mesma forma, no espaço em torno de um ímã também existe um campo magnético, pois, como já dissemos, no interior do ímã temos cargas elétricas em movimento que estabelecem este campo.

\section{O VETOR CAMPO MAGNÉTICO}

Consideremos uma região do espaço onde existe um campo magnético. Este campo pode ter sido criado tanto por uma corrente em um fio quanto por um ímã.

De modo semelhante ao que foi feito para o campo elétrico, vamos definir um vetor, representado por $\bar{B}$ e denominado vetor campo magnético (ou vetor indução magnética), que será usado para caracterizar o campo magnético em cada ponto do espaço.

1. Direção e sentido de $\bar{B}$ - O ímã cujo pólo norte está mostrado na fig. 22-8 cria um campo magnético no espaço em torno dele. Colocando-se no ponto $\mathrm{P} 1$, uma pequena agulha magnética, o campo magnético aí existente atuará sobre as cargas móveis desta agulha, fazendo com que ela tome uma certa orientação. A direção do vetor campo magnético $\bar{B}_{1}$ neste ponto é, por definição, a direção na qual a agulha se orienta e o seu sentido é o sentido para o qual aponta o pólo norte da agulha.

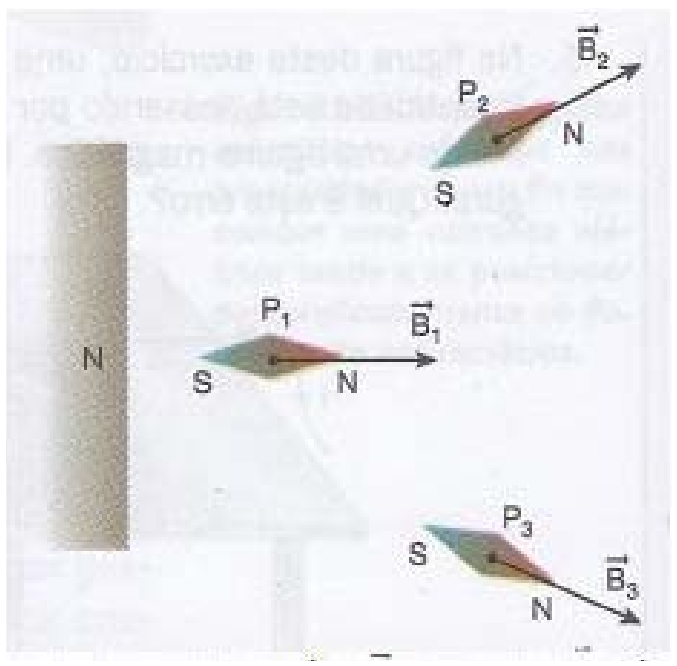

Figura 22-8 - O campo magnético $\bar{B}$ em um ponto está orientado na direção e sentido sul-norte de uma agulha magnética colocada neste ponto. 
E o livro continua com a definição de força magnética entre dois fios, sua equações e regra da mão direita. Apesar de bem escrito, no meu ver, eles continuam seguindo uma linha de apresentação muito próxima dos livros textos universitários. E aí segue a questão posta pelo PNLEM abaixo:

O livro didático é um suporte de conhecimentos e de métodos para o ensino, e serve como orientação para as atividades de produção e reprodução de conhecimento. Mas não podemos nos transformar em reféns do livro, imaginando encontrar ali todo o saber verdadeiro e a narrativa ideal. Sim, pois o livro é também instrumento de transmissão de valores ideológicos e culturais, que pretende garantir o discurso dos autores. Em um processo pouco dinâmico como o que se estabelece no sistema tradicional de ensino de Ciências, cria-se um círculo vicioso: o professor torna-se um reprodutor desses mitos e imagens errôneas e passa, ele também, a acreditar neles. O resultado é que, para os alunos, a ciência ensinada na escola acaba sendo chata, pouco útil e muito difícil.

Na sequência eles não fazem nenhuma abordagem da importância que o eletromagnetismo teve na sociedade moderna. Eles confundem magnetização com material magnético.

- Denominamos substâncias magnéticas àquelas que permitem a orientação dos seus imãs elementares!!!!!

- Denominamos campo magnético a região ao redor de um imã na qual ocorre um efeito magnético!!!!!!

- Magnetização induzida e não indução magnética. Pág. 233

\section{APPLETS DE ENSINO}

1. Explique o princípio de funcionamento do applet abaixo do curso da Universidade do Colorado. < https://sites.google.com/site/professorpifer/ Home/fisica-mix/eletromagnetismo $>$. Você pode mudar o imã de posição (arraste-o com o mouse) e pode mudar a polaridade dele (botão: flip polarity). Você também pode mudar a posição da bússola.

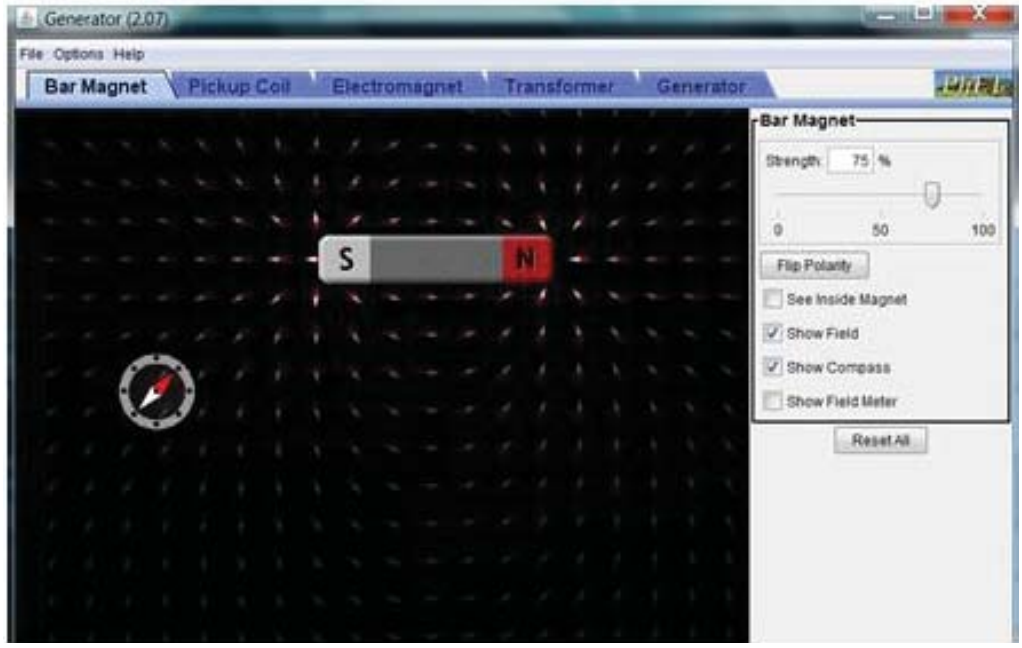


2. Explique o princípio de funcionamento do applet abaixo do curso da Universidade do Colorado.

$<$ https://sites.google.com/site/professorpifer/Home/fisica-mix/eletromagnetismo>. Note que o applet é o mesmo; só foi trocado de gerador para transformador

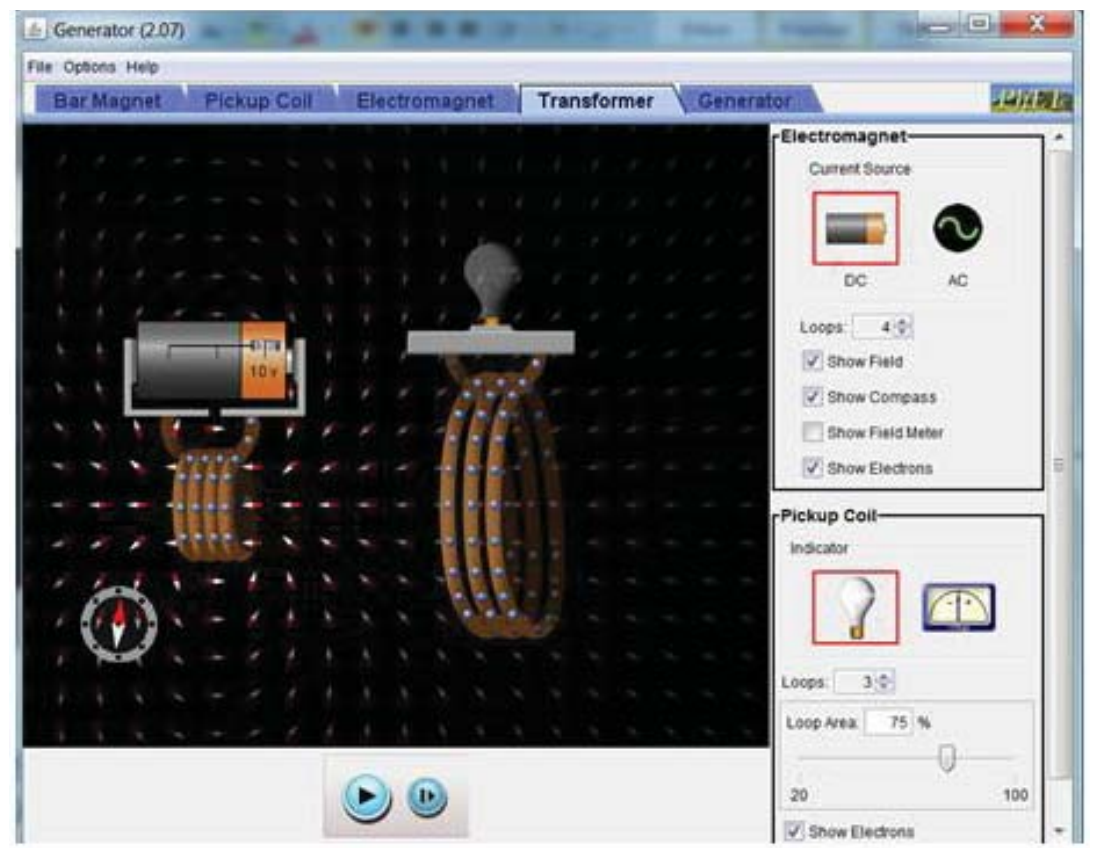

3. Explore esse excelente applet do Professor Falstad acessando o link: http://www.falstad.com/emstatic/.

Note que você pode arrastar a caixa para visualizar a força de várias posições. Observe que nas duas figuras escolhemos campo uniforme. $\mathrm{Na}$ da direita selecionamos mostrar linhas de campo.

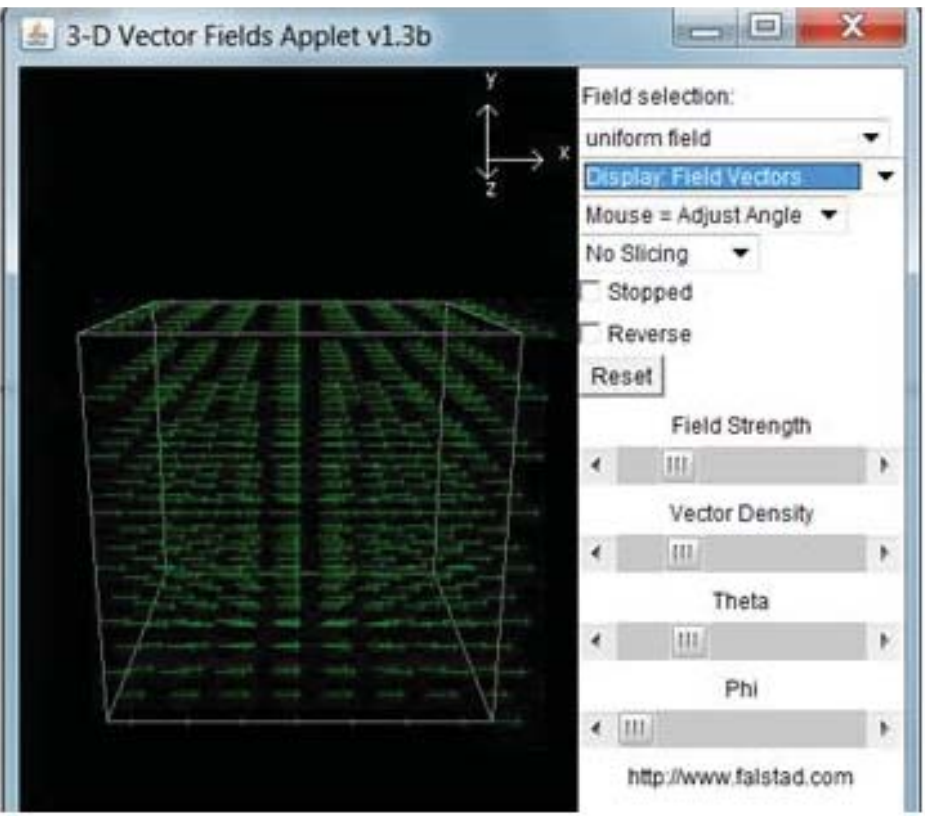


4. Applet do Prof. Walter-Fendt. Este applet simula uma experiência relativa ao campo magnético gerado por uma corrente elétrica num condutor retilíneo. Sabendo que, uma corrente elétrica produz um campo magnético, faz-se passar uma corrente de grande intensidade através de um fio vertical. O utilizador pode inverter o sentido da corrente, utilizando o botão vermelho. Os sinais nas extremidades do fio simbolizam os pólos do gerador a que este se liga. A direção convencional da corrente é dada pela seta vermelha. Note que o movimento dos elétrons (pontos verdes) é o oposto do sentido convencional!

A agulha de uma bússola pode ser colocada (arrastando-a com o botão do rato pressionado) em qualquer posição da superfície. Pode ser observado o campo magnético (azul) em cada posição. Os pólos norte e sul da agulha da bússola estão pintados de vermelho e verde, respectivamente. A influência do campo magnético da Terra é considerada negligenciável nesta simulação.

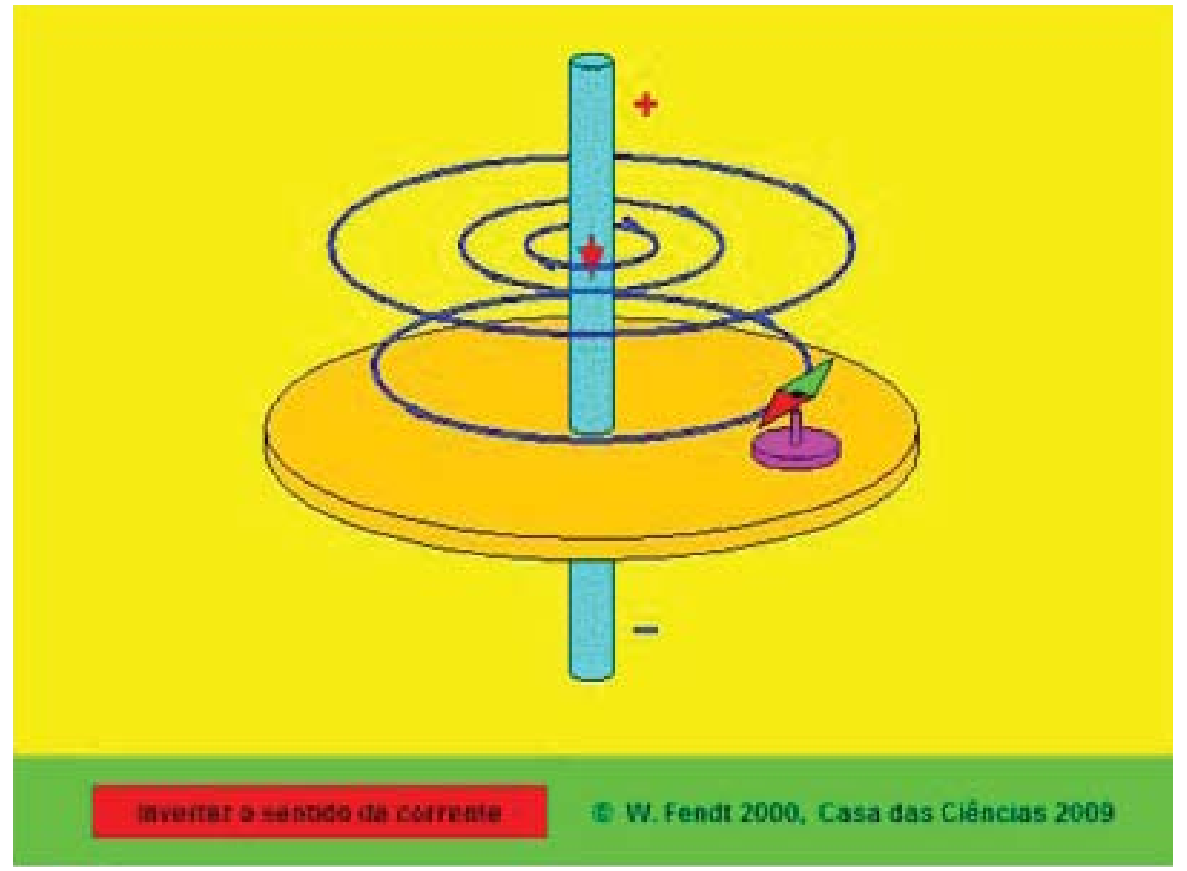

\section{EXPERIMENTOS DE BAIXO CUSTO}

\section{ALGUMAS EXPERIÊNCIAS SIMPLES PARA VOCÊ FAZER}

Primeira experiência

Você já deve ter aprendido que, para determinar os pontos cardeais, basta se posicionar de tal modo que o seu lado direito esteja voltado para o local onde o Sol nasce, isto é, para o Leste. Nestas condições, o seu lado 
esquerdo indicará o Oeste, a sua frente estará voltada para o norte e o Sul estará às suas costas.

$\left.1^{\circ}\right)$ Seguindo esta orientação, determine o Norte e o Sul do local onde você se encontra.

$2^{\circ}$ ) Tome uma pequena bússola e observe a orientação adquirida pela agulha magnética. Indique, então, qual é a extremidade onde se localiza o pólo norte da agulha.

$3^{\circ}$ ) Se você possuir um ímã cujos pólos são desconhecidos, aproxime dele a agulha da bússola e determine qual dos pólos do ímã é o pólo norte e qual é o pólo sul.

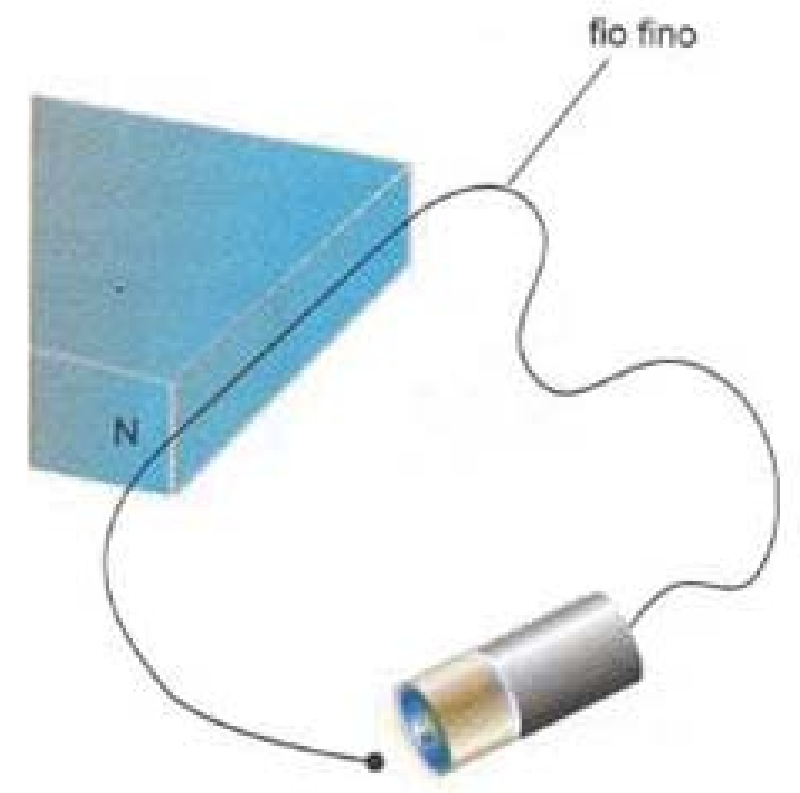

Segunda experiência

A figura desta experiência mostra um pequeno motor de corrente contínua, muito simples, e alguns detalhes que devem ser observados em sua montagem. Orientando-se por esta figura, procure construir um motor semelhante. Para criar o campo magnético, poderão ser empregados ímãs do tipo utilizado para fechar portas de armários. Fornecendo corrente a este moro por meio de uma ou mais pilhas, você verá que ele entrará em rotação muito rápido. 


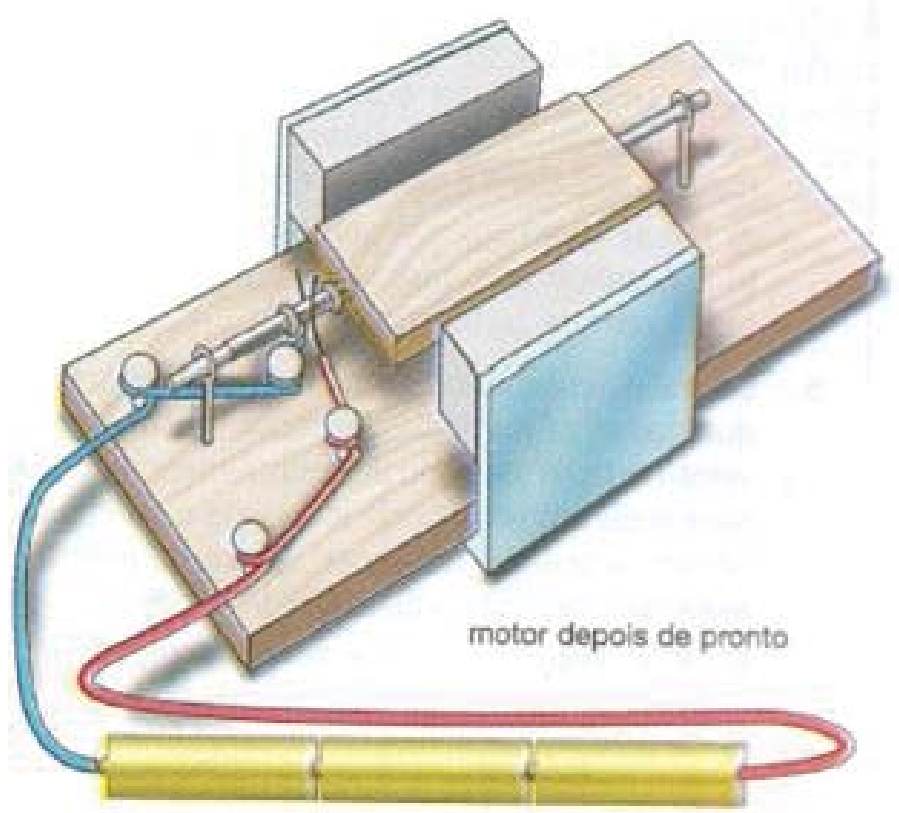

1. A atividade experimental proposta tem a finalidade de comprovar o experimento de Oersted.

Vamos precisar de:

- um pedaço de fio condutor (flexível);

- uma bússola;

- cola pequena;

- uma bateria pequena;

- um pedaço de madeira $(20 \mathrm{~cm} \times 20 \mathrm{~cm})$.

Montagem do aparato experimental

Como mostra a figura acima, fixe com cola a bússola no pedaço de madeira. Em seguida, no lado oposto ao da bússola, cole a bateria. Ligue as extremidades do fio condutor nos pólos da bateria, pólo positivo e pólo negativo. Dobre o fio para que ele fique próximo à superfície de vidro da bússola, a fim de verificar com mais eficiência o deslocamento da sua agulha.

É interessante que o fio fique com uma extremidade livre, servindo de chave aberta ou fechada (em contato com o pólo da bateria).

Conectando o fio ao pólo da bateria, verifique o que acontece com a agulha da bússola, qual direção ela toma. Caso coloque o fio na direção norte-sul, observe que a agulha da bússola ficará paralela ao fio quando o mesmo for percorrido pela corrente elétrica.

Fonte: Por Domiciano Marques. Equipe Brasil Escola. Disponível em: <http://educador.brasilescola.com/estrategias-ensino/construindoexperimento-oersted.htm $>$.

2. Comente o experimento proposto no site: <http://www.enciga.org/ taylor/pr/Oersted.pdf $>$. 
3. Leia o artigo: "Experiência de Oersted em sala de aula" de Chaid e Assis. Você consegue reproduzir o experimento.

\section{VIDEO AULA}

Assista o vídeo: ELETROMAGNETISMO, A EXPERIÊNCIA DE OERSTED, acessando o link: < http://www.youtube.com/ watch?v=piSczdGkpaY>.

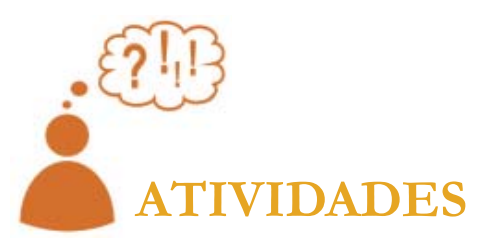

1. Você concorda que o livro da Beatriz Alvarenga, a pesar do capítulo acima em um bom livro didático? Por quê?

2. A pesar das resoluções do PNLEM que “obrigam” (sinalizam) aos novos livros didáticos, dentre outras coisas, a mostrar que a ciência é um produto histórico e social e que não é um produto acabado (pronto) devido ao trabalho de sociedades privilegiadas, você concorda que podemos ensinar Física sem citar nomes de cientistas e contar um pouco da história da ciência? Comente?

3. Você ilustraria a sua aula com história da ciência? Comente.

4. O que você acha dos experimentos tirado do livro da Beatriz Alvarenga? Você acha realizável usá-los em sala de aula as experiências indicadas lá (acima)?

5. Colocamos acima alguns exemplos e/ou links de applets de ensino para você analisar a possibilidade de usá-los em sala de aula. Comente se você os usaria ou não como recurso didático em sala de aula? Comente.

\section{CONCLUSÃO}

Com esta aula e a anterior, o estudante de licenciatura deve ter ficado ciente das dificuldades da transposição didática. Deve ter compreendido que temos várias formas de se ensinar Física. Deve ter compreendido que o livro texto é um livro de apoio, mas que o professor deve estar sempre atento ao modo como seu conteúdo foi elaborado. Deve sempre consultar outras bibliografias para comparar e avaliar o seu conteúdo.

Com a análise dos experimentos de baixo custo e dos recursos de multimídias que colocamos no final da aula o futuro professor deve ter ficado com algumas boas ideias de como este pode enriquecer uma aula sobre o tema Lei de Campo Magnético. 


\section{COMENTÁRIOS SOBRE AS ATTIVIDADES}

Em geral os alunos que fazem o curso de licenciatura em Física têm um curso muito superficial ou não têm nenhuma aula de Física. Se tiverem, usam algum livro texto tradicional, onde a Física é apresentada como uma coleção de definições e fórmulas para ser aplicada em problemas e exercícios. Assim, a maioria deles só possui o conhecimento de Física dado na universidade.

O aluno deve começar a se ver como futuro professor. Isto é, ele deve começar a ver a Física não como matéria ser aprendida e sim como a ser ensinada. Aqui ele deve começar a enxergar as diversas possibilidades que o mundo moderno lhe oferece como educador.

Os futuros professores devem ter compreendido o papel central que eles têm na escolha do conteúdo, da técnica e da didática ser utilizada em sala de aula. Este deve ter adquirido uma ideia de como se deve preparar um curso ou apenas uma aula. Eles devem compreender que uma aula é um processo dinâmico e orgânico.

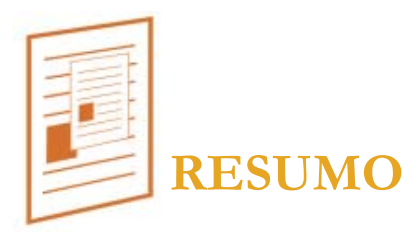

Apresentamos o livro aprovado e muito bom da professora Beatriz Alvarenga. Apesar de ser um livro bom, mostramos que ele contém muitos erros de transposição didática e da história da ciência. Discutimos se há necessidade de se ensinar sempre a física no padrão tradicional dos livros textos e dos perigos da transposição didática.

Em seguida apresentamos vários experimentos de baixo custo para que o aluno explore as possibilidades que estes oferecem para se ministrar um curso usando mais ferramentas fenomenológicas e menos formais. Colocamos vários e excelentes applets de ensino como recurso de simulação de fenômeno físico para ser explorado pelo futuro professor.

Como há ótimos vídeos de ensino colocamos alguns deles como referência, e deixamos sua exploração como atividade para os estudantes, uma vez que, no curso de Instrumentação I não usamos os vídeos didáticos como ferramenta didática principal. 


\section{RESPOSTAS ÀS ATTIVIDADES}

1. Sim, pois a grande maioria de seus capítulos estão bem escritos.

2. Sim. Comentário pessoal.

3. Sim, mas com ressalvas.

4. Ele tem que pesquisar.

5. Fazer a resenha após assistir.

6. Fazer a resenha após assistir.

7. Fazer a resenha após assistir.

\section{REFERÊNCIAS}

APPLETS. Eletromagnetismo. Disponível em: $<$ https://sites.google. $\mathrm{com} / \mathrm{site} /$ professorpifer/Home/fisica-mix/eletromagnetismo>. Acesso em 16/10/2011

Disponível em: <http://www.falstad.com/emstatic/>. Acesso em 16/10/2011

ALVARENGA, B.; MÁXIMO, Antônio. Física - Ensino Médio, v. 3, Unidade 10 - Eletromagnetismo, p. 206 a 212. Ed. Scipione.

Chaid e Assis. Experiência de Oersted em sala de aula. Revista Brasileira de Ensino de Física, v. 29, n. 1, p. 41-51, (2007)

CANAL DO EDUCADOR. Estratégias de Ensino. Física. Construindo o experimento de Oersted. Disponível em: < http://educador.brasilescola. $\mathrm{com} /$ estrategias-ensino/construindo-experimento-oersted.htm>. Acesso em 16/10/2011.

ENCIGA - Associacion dos Ensinantes de Ciencias de Galicia . Prácticas de Física. Electricidad y Magnetismo.Disponível em : <http://www. enciga.org/taylor/pr/Oersted.pdf>. Acesso em 16/10/2011.

GASPAR, Alberto. CINQÜENTA ANOS DE ENSINO DE FÍSICA: MUITOS EQUÍVOCOS, ALGUNS ACERTOS E A NECESSIDADE DO RESGATE DO PAPEL DO PROFESSOR. Departamento de Física e Química - Faculdade de Engenharia. UNESP - Universidade Estadual Paulista - Campus Guaratinguetá. Disponível em: < http://plato.if.usp. br/2-2007/fep0358d/texto_5.pdf>. Acesso em 16/10/2011

PNLD - Programa Nacional do Livro Didático. GUIA DE LIVROS DIDÁTICOS. Disponível em: <http://portal.mec.gov.br/index. php?option $=$ com_content $\& v i e w=$ article $\& i d=12389 \% 3$ Aguias-do-livrodidatico\&catid $=318 \% 3$ Apnld\&Itemid $=668>$. Acesso em 16/10/2011 YOUTUBE. Eletromagnetismo, a experiência de oersted. Disponível em: <http://www.youtube.com/watch?v=piSczdGkpaY>. Acesso em $16 / 10 / 2011$ 



\section{Aula 9}

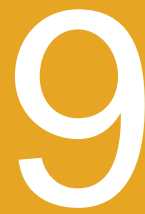

\section{CAMPO MAGNÉTICO PRODUZIDO POR UMA CORRENTE ELÉTRICA}

META

Fazer como que o estudante comece a pensar no ensino de ciências como algo "orgânico"

que está em profunda transformação.

Fazer com que os alunos percebam através de um texto básico complementado com atividades lúdicas, applets de ensino, vídeos, que o fenômeno físico campo magnético produzido por uma corrente elétrica pode ser compreendido de forma simples e divertida. Analisar a biografia de Oersted e Àmpere e fazer com que o estudante reflita sobre o que é

fazer física.

Introduzir o problema de como se ensinar o conceito de campo magnético. Introduzir a questão: "o que é ensinar física".

OBJETIVOS

Ao final desta aula, o aluno deverá: estar ciente das novas possibilidades e dos desafios que envolvem o ensino de ciências em geral e das dificuldades de se ministrar um curso de eletricidade e magnetismo. Ter compreendido que as ciências naturais estão baseadas na experimentação e que esta é feita de ensaios, experiências e medidas e que estas levam a compreensão e matematização dos conceitos físicos (naturais em geral). Trazer a discussão sobre o papel que a Matemática tem na formação e no ensino de Física.

Através do tema "campo magnético produzido por uma corrente elétrica" vamos discutir as dificuldades inerentes de se ensinar física, que vão além das teorias pedagógicas e de

ensino usuais.

\section{PRÉ-REQUISITOS}

Os alunos deverão ter cursado as disciplinas Psicologia da Educação, Física A, Física B e Instrumentação I. 


\section{INTRODUÇÃO}

Vamos nesta aula abordar o famoso experimento de Oersted e da Lei de Àmpere. Escolhemos este tema, pois é um dos temas abordados pelo projeto Harvard (Harvard Project Physics). Não vamos colocar um segundo texto no corpo desta aula, mas vamos pedir que você faça uma análise comparativa no final da aula com os outros textos. Devido ao fato de que há um excelente texto em português contando a história do projeto Harvard e de seu autor, o Prof. Holton, vamos basear nossa análise desse projeto no texto abaixo.

Apesar desse projeto, ter tido vida mais longa e muito mais sucesso que o projeto PSSC, há muito menos material bibliográfico a seu respeito do para o PSSC. Talvez isto se deva ao fato do projeto Harvard ser considerado como um melhoramento deste último, e de que os fatos históricos não terem sido muito modificados dos da época do PSSC.

\section{UMA LEITURA DE: "UMA CONVERSA COM GERALD HOLTON"}

Texto original de Bernardo J. de Oliveira e Olival Freire Jr.

O professor Holton começou sua carreira na área do ensino de Física escrevendo material paradidático para completar sua renda, já que tinha acabado de se casar. Assim, acabou aceitando o convite para escrever um capítulo sobre o som para a enciclopédia "Tesouro da Juventude" ou The book of knowledge. A partir desse artigo ele escreveu o livro de difusão cultural "The story of sound, que continuou sendo publicado por 40 anos. Mais tarde, escreveu o livro "A imaginação científica". Seus livros são "As origens temáticas do pensamento científico" e "Origens Temáticas do Pensamento Científico de Kepler a Einstein". Nesta época, ele era apenas um auxiliar de ensino e não queria que seu nome aparecesse, de modo que suas primeiras publicações foram anônimas.

Foi um dos primeiros cientistas a contribuir a popularização da ciência e é adepto da difusão cultural. É considerado um dos pais da "Abordagem Contextual", que é denominado hoje de "Abordagem conectiva".

Foi ajudado neste desenvolvido pelo fato do Presidente de Harvard, James Conant, desejar que na instituição fosse implantado um curso de introdução geral para as cadeiras de ciências exatas, humanas e sociais, que contemplasse os aspectos históricos como as conexões entre estas ciências. O próprio reitor escrevia esse tipo de texto como lecionava três vezes por semana.

A ideia era ensinar não aquilo que todo estudante de Física tem que aprender leis de Newton, átomos etc., mas algo mais abrangente, que mostrasse os vínculos históricos e técnicos, assim como as conexões com as outras ciências vizinhas. Cada aluno tinha que cursar pelo menos um 
desses cursos, de forma a desenvolver uma visão de mundo científica. Teria tido uma perspectiva ampla e não apenas através das lentes de uma das disciplinas acadêmicas isoladas. Para tais cursos defendia que se retomassem as questões iniciais que os gregos já tinham colocado, sobre o sistema solar, por exemplo, o tamanho da Terra, etc. Indagações que não são novas, mas que revelam de onde a ciência iniciou, que tipo de questões levanta, que tipo de ferramentas teóricas movimenta, como a Matemática e Física valiam para responder tais questões. E fazer isso não somente para Física, mas para Química, Geologia entre outras. Nesse caminho, ir de Galileu até Fermi e a energia nuclear. Este foi um livro muito bem sucedido.

Esse trabalho redundou no livro "Foundations of modern physical science". Na década de 60 a Fundação para a Ciência Nacional o convidou para fazer um material de ensino desse tipo para o Ensino Médio. Esse material recebeu o nome de "Project Physics Course" ou simplesmente de Harvard. É importante frisar que, nos EUA, os cursos de Física são geralmente no final do Ensino Médio, quando os estudantes têm 17 anos, e no ano seguinte estarão nas faculdades como calouros. Portanto, o mesmo livro pode se adequar a esses dois públicos. Assim, o Project Physics, que havia sido idealizado para o Ensino Médio, foi também adotado nas faculdades e foi muito bem até o começo dos anos 70. A cada ano, 200 mil alunos se iniciavam utilizando esse livro, que logo foi traduzido para italiano, chinês, russo, português (traduzido pela Fundação Gulbenkian de Portugal). Ao contrário de outros cursos, foi proibido que esse texto fosse traduzido literalmente, mas, sim, que fosse adaptado para cada pais, cultura. Influência de sua própria formação, pois, este estudou na escola de Viena onde tinha 8 anos de ensino geral. Um outro desdobramento desse trabalho é o livro "Entendo a Física". Um livro que acabou sendo direcionado ao público universitário.

Ao contrário do curso PSSC teve grande aceitação e como prova disso, enquanto que no PSSC havia somente $4 \%$ de adesão dos alunos ao curso de Física, na época do Harvard havia $25 \%$ de adesão dos alunos. Havia treinamento dos professores nas férias (uns 200 mil) e o projeto foi um sucesso enquanto o governo mantinha o financiamento ao treinamento destes, que acabou no governo Nixon. Vale a pena ressaltar que aquele programa só funcionou bem enquanto se podia treinar os professores. É enorme a importância do treinamento dos professores, especialmente para adoção da abordagem conectiva. E naquela época se investiu muito nisso. Treinavam 200 mil professores durante as férias de verão. Em diferentes lugares, professores secundários aprendiam como usar novos materiais e muitos tiveram seu primeiro contato com a História da Ciência, com a Filosofia da Ciência, Ciência Grega e Astronomia.

O projeto contava com o apoio pedagógico de vários filmes de longa metragem produzidos na era PSSC, e contavam com 2 filmes de $50 \mathrm{~min}$ e vários curtas, produzidos no projeto Harvard. O projeto contava com 
inúmeros experimentos, que como dizia o autor, eram fundamentais para a formação e compreensão da Física por parte do aluno.

Veja o que comentava-se sobre estes filmes: "Cada um desses filmes era muito caro. $\mathrm{Na}$ era Sputnik havia dinheiro para isso. O que não há mais hoje em dia. Nós fizemos apenas dois longas-metragens (o PSSC fez muitos), porque a eficácia desses filmes era muito limitada. Em longos períodos no escuro, os estudantes dormiam ou faziam outras coisas, em vez de assistir aos filmes. Por isso, fizemos apenas duas médias metragem (30 ou 40 minutos). Um deles, sobre pesquisa em alta energia, mostrava como um experimento científico é desenhado e realizado. Este levou dois anos e meio para ser feito e tinha uma equipe que incluía até antropólogos. Ele se chamava "Pessoas e partículas", um documentário que ganhou muitos prêmios, inclusive um, por engano, de ficção científica.

\section{UMA LEITURA DOS TEXTOS}

O curso de Física "Harvard" possui uma abordagem humanística e experimental. Seu texto é de fácil leitura contendo muitas informações históricas sobre cada assunto. Ele é composto dos volumes abaixo:

- Física de Partículas

- Luz e Eletromagnetismo

- Mecânica

- Mecânica e Ondulatória

- Movimento nos Céus

Mecânica é um curso que utiliza a história da ciência de forma bem detalhada e dá ênfase na conservação da energia e colisões. Os textos são de fácil leitura e muito interessantes. Os exemplos são acessíveis e ilustrativos. Como todo o projeto, o texto vem acompanhado de questões de fixação de conteúdo, e no final do fascículo apresenta questões e problemas de reforço.

Física de Partículas, com textos envolventes também, é um curso que usa a história da ciência de forma bem detalhada. Traz muitas curiosidades e está de acordo com a realidade da Física da época, onde havia a corrida dos aceleradores de partículas.

Luz e Eletromagnetismo: o texto sobre a luz é de fácil leitura e também é um curso que utiliza a história da ciência de forma bem detalhada. Os exemplos são acessíveis e ilustrativos.

Campo Elétrico é um curso que utiliza a história da ciência, porém não é tão detalhado como os demais. As razões de não se gastar muito tempo com a exposição teórica de campo elétrico era porque se acreditava que o eletromagnetismo é uma ciência eminentemente experimental, como eles mesmo falam no texto abaixo que transcrevemos. Foi introduzido o conceito 
de campo no seu aspecto mais geral, ou seja, definem a palavra campo em seus diversos significados. Inicia com a história da descoberta da magnetita e do âmbar e definem os campos elétricos e magnéticos ao mesmo tempo. Fazem uma introdução histórica baseada nos textos de Gilbert e expõe alguns modelos que foram usados na época e depois rejeitados; como a ideia do fluido elétrico.

\section{CAPÍTULO CATORZE}

\section{CAMPOS ELÉTRICOS E MAGNÉTICOS}

O tema "eletricidade e magnetismo" constitui um grande domínio da Física moderna e tem ligações importantes com quase todas as outras áreas da Física, Química e Engenharia. Seria impossível esgotar completamente este assunto no tempo destinado a um curso geral. Neste curso consideraremos apenas alguns dos tópicos principais que servirão de base aos capítulos posteriores. As principais aplicações dos conhecimentos introduzidos neste capítulo aparecerão mais tarde: o desenvolvimento da tecnologia elétrica (Capítulo 15), o estudo da natureza da luz e das ondas electromagnéticas (Capítulo 16) e o estudo das propriedades das partículas atômicas e sub-atômicas (Unidade 5).

Neste capítulo trataremos em primeiro ligar das cargas eléctricas e das forças que se estabelecem entre elas. Esta análise será breve porque a melhor maneira de aprender este assunto não é lendo mas fazendo experiências no laboratório (ver experiência 4-3 do Manual). Em seguida mostraremos como é que a ideia de um "campo" simplifica a descrição dos efeitos eléctricos e magnéticos. Depois ], consideraremos as correntes eléctricas que são constituídas pro cargas em movimento. Combinando o conceito de campo com a idéia de energia potencial, podemos estabelecer relações quantitativas entre a intensidade de corrente eléctrica, tensão e potência. Essas relações serão necessárias para as aplicações práticas que se analisarão no Capítulo 15.

(Projeto Harvard - Campos Eléctricos e Magnéticos, p. 31 Cap. 14 <http://www.cienciamao.usp.br/ dados/hpp/_camposeletricosemagnetic.arquivopdf.pdf)

No momento em que abordam os conceitos de força elétrica e magnética e de campos elétricos e magnéticos, fazem uso dos textos clássicos e da comparação com o campo gravitacional para obter a Lei de Coulomb, ou seja, da equação da força elétrica. Em seguida, discutem a experiência de Millikan, na qual se determinou o valor da carga elementar. Como todo o projeto, os textos são acompanhados de questões de fixação de conteúdo, e no final do fascículo são apresentados questões e problemas de reforço. 


\section{REQUISITOS BÁSICOS PARA UM PROFESSOR}

\section{USAR ESTE MATERIAL}

- Bom conhecimento da história da ciência e muita leitura;

- Bom domínio da parte experimental envolvida;

- Saber conduzir uma sala de aula com aula expositiva e ao mesmo tempo aberta ao debate.

- Ter em mente que os exercícios são um estudo dirigido complementar ao estudo do texto.

\section{ANÁLISE COMPARATIVA}

Uso da História da Ciência

- O projeto Harvard tem um caráter humanista. Ao ler os seus textos, tem-se a impressão de um diálogo com o autor, como se ele estivesse lhe contando uma história.

- Já o PEF é um material que coloca o aspecto histórico como "texto complementar". Usa a história ou para ilustrar a física ou em leituras suplementares para classes que dispusessem de um número maior de aulas semanais ou para atender aos alunos mais interessados.

- Por exemplo, no Harvard observamos que para problematizar e iniciar os estudos do campo elétrico foi utilizado trechos dos trabalhos do cientista Gilbert enquanto que no PEF observamos somente um box no final do texto contando a história de Alexandro Volta.

- O projeto Harvard mostra como ocorreu todo o desenvolvimento dos pensamentos sobre a eletricidade mostrando no início dos estudos sobre o campo elétrico a dificuldade em se diferenciar um campo elétrico de um campo magnético, o que não é convencional nos livros didáticos atuais, e um refinamento da ideia de campo em outros aspectos que não só físicos, como por exemplo, campo de futebol, campo de batalha, campo político etc.

- Em contrapartida o PEF trata o assunto campo elétrico isoladamente e de forma direta. Através de experimentos que ocorreram ao longo de toda a história da humanidade.

- O Harvard mostra também toda a evolução de um pensamento, incluindo quebra de paradigmas. 


\section{ASPECTOS MATEMÁTICOS}

- Quanto aos aspectos matemáticos, tanto o projeto Harvard quanto o PEF, ao menos na parte de campo elétrico, não há deduções matemáticas complicadas.

- O projeto Harvard talvez por ter um caráter humanístico, constrói as fórmulas a partir da evolução do pensamento dos cientistas, as fórmulas são mostradas, explicadas e dificilmente deduzidas.

- Os exercícios do PEF são mais numéricos e fechados.

- Ao passo que no Harvard temos dois tipos de exercícios: os apresentados ao final de cada texto que são geralmente fáceis; e os apresentados no final de cada capítulo, onde observamos um grau maior de complexidade, que são mais reflexivos.

- O projeto PEF tem um material mais ilustrado, onde não há muita discussão. O material é mais direto em suas relações. Utiliza a experimentação como forma de aprendizado.

\section{ACÇÃO DAS CORRENTES ELÉCTRICAS SOBRE OS ÍMANES}

No princípio do séc. XVIII, começaram a aparecer relatos sobre o facto de as faíscas modificarem a magnetização das agulhas das bússolas e transformarem facas e colheres em imanes. Alguns investigadores acreditavam que tinham magnetizado agulhas de aço, descarregando uma garrafa de Leyden através delas. Estas comunicações sugeriam que a electricidade e o magnetismo estava, de algum modo, intimamente relacionados. Estas observações não foram, no entanto, seguidas por experiências deliberadamente planeadas que podiam ter conduzido a conceitos e teorias úteis.

Nenhum destes primeiros relatos surpreendeu os filósofos naturalistas europeus do séc. XIX. Estes filósofos estavam convencidos de que todos os fenômenos observados na natureza eram apenas efeitos diferentes de uma única "força". A sua crença na unidade das forças físicas levava-os naturalmente a esperar que as forças eléctricas e magnéticas estivessem de algum modo associadas ou relacionadas.

A primeira prova concreta da existência de uma reação entre a electricidade e o magnetismo surgiu em 1820, quando Oersted realizou uma série de experiências extremamente importantes. (Veja as ilustrações da página seguinte). Oersted colocou uma agulha magnética de uma bússola debaixo de um fio condutor comprido e colocado na horizontal. O fio estava alinhado com a direcção N-S magnética da Terra, de modo que a agulha magnética se orientava naturalmente paralelamente ao fio. Quando Oersted ligou o fio aos terminais de uma bateria, a agulha da bússola rodou para uma orientação Leste-Oeste - quase perpendicularmente ao fio! 
As cargas em repouso não afetam um íman, mas as cargas em movimento (uma corrente) exercem força estranha sobre um íman.

Os resultados de Oersted foram os primeiros que se obtiveram em que uma força não actuava paralelamente à linha que unia as origens das forças (como é o caso para as forças existentes entre os planetas ou para as forças que se estabelecem entre cargas eléctricas ou entre pólos magnéticos). A força que se exerce entre um fio onde passa corrente e cada um dos pólos magnéticos da agulha da bússola não actua segundo a linha que liga o fio ao pólo. De facto, para que a agulha se mova como o faz, a força tem que actuar perpendicularmente a esta linha. A agulha magnética não é atraída nem repelida pelo fio, roda sim no plano horizontal, devido às forças que actuam sobre os seus pólos.

Este era um efeito completamente novo e não admira que tenha levado tanto tempo até que alguém descobrisse a relação entre a electricidade e o magnetismo. Uma análise mais aprofundada revelou mais claramente o que acontecia nesta experiência. O fio rectilíneo e comprido por onde passava a corrente cria um campo magnético. Este campo faz girar um íman pequeno de modo que a direcção Norte-Sul do íman fique tangente a um círculo com centro no fio e situado num plano perpendicular a este. Deste modo, a corrente produz um campo magnético circular e não um campo orientado para o centro, como se esperava.

Definimos a direcção e sentido do vector campo magnético em cada ponto como sendo a direcção e sentido da força que se exerce sobre o pólo de uma agulha magnética que aponta para o Norte quando colocado nesse ponto. A força que se exerce sobre o pólo Sul da agulha terá um sentido oposto ao do campo. A agulha de uma bússola reagirá às forças opostas que actuam nos seus pólos rodando até apontar, tão exactamente quanto é possível, no sentido do campo. Podemos visualizar a "forma" do campo magnético à volta de uma corrente, espalhando limalha de ferro numa folha de papel que é atravessado pelo fio onde passa a corrente. A limalha fica magnetizada e comporta-se como um conjunto de pequenas agulhas magnéticas, indicando a direcção e sentido do campo. Os bocadinhos que constituem a limalha de ferro têm também tendência a unir-se pela extremidades e, desse modo, a forma em que se dispõe a limalha de ferro indica as linhas de força que se criam à volta de qualquer fio onde passa corrente ou em redor de uma barra magnética. Estas linhas constituem uma "representação visual" do campo magnético. 

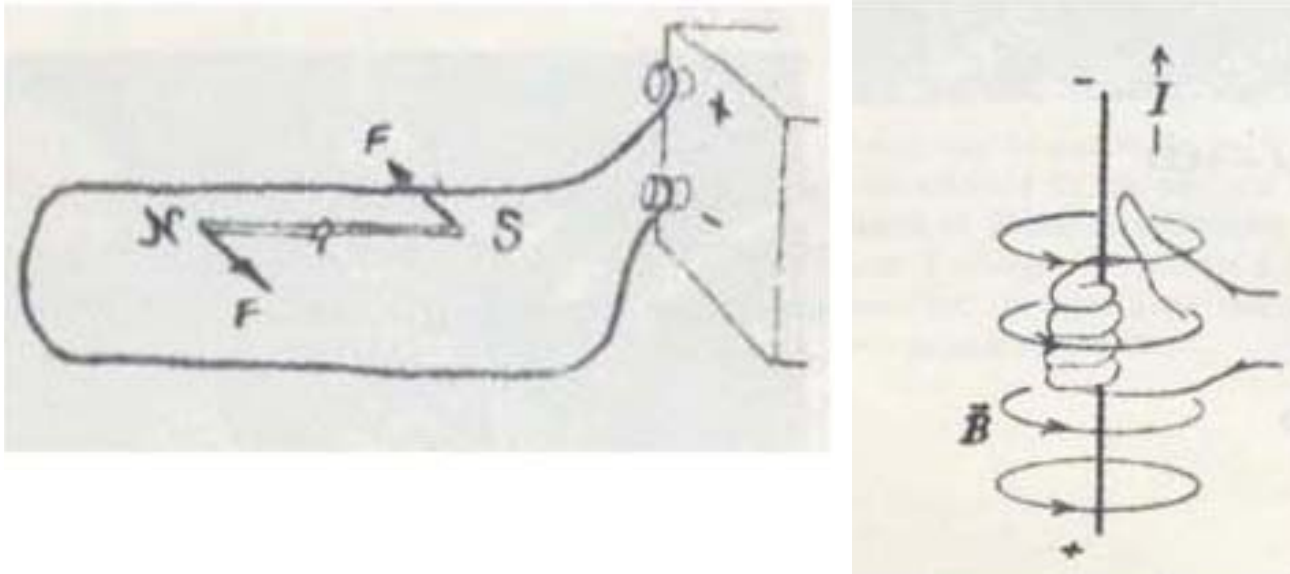

Uma regra útil: se o polegar apontar no sentido do deslocamento da carga, os dedos dobram-se no sentido das linhas de força do campo magnético. Discutir-se-à o módulo de na Secção 14.13. Use a mão direita para o fluxo de cargas positivas, e a mão esquerda para o fluxo de cargas negativas.

Projeto Harvard - Campos Eléctricos e Magnéticos, p. 62 Secção 14.11.

Disponível em: < http://www.cienciamao.usp.br/dados/hpp/_camposeletricosemagnetic.arquivopdf.pdf>

Podemos usar um argumento semelhante para determinar a "forma" do campo magnético produzido pela corrente que passa numa bobina, em vez de passar por um fio rectilíneo. Para isso, enrola-se o fio em espiral, de modo a que as espiras atravessem o papel em dois sítios. Os efeitos magnéticos que a diferentes partes do fio provocam na limalha de ferro produzem uma figura semelhante àquela que é produzida por uma barra magnética.

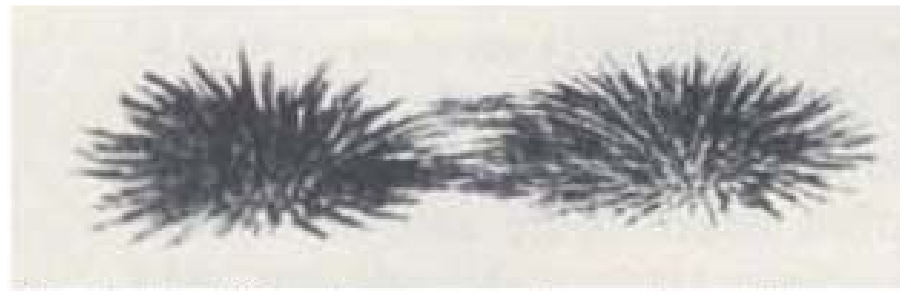

Cristais de óxido de ferro em forma de agulhas num campo magnético criado por uma barra magnética. O íman está colocado debaixo da folha de papel onde se espalhou o óxido de ferro.

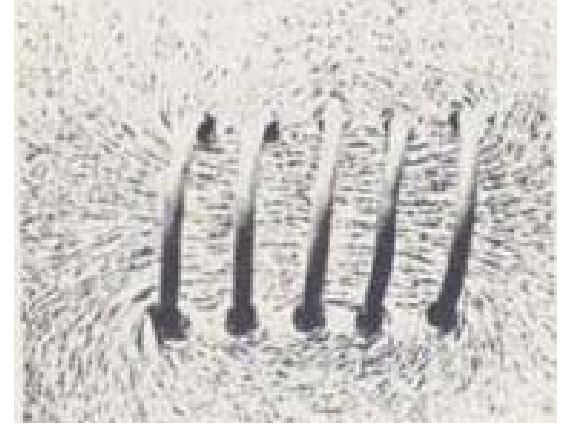

Alinhamento da limalha de ferro produzido pela corrente que passa numa bobina.

Projeto Harvard - Campos Eléctricos e Magnéticos, p. 64 Secção 14.11.

Disponível em: <http://www.cienciamao.usp.br/dados/hpp/_camposeletricosemagnetic.arquivopdf.pdf> 


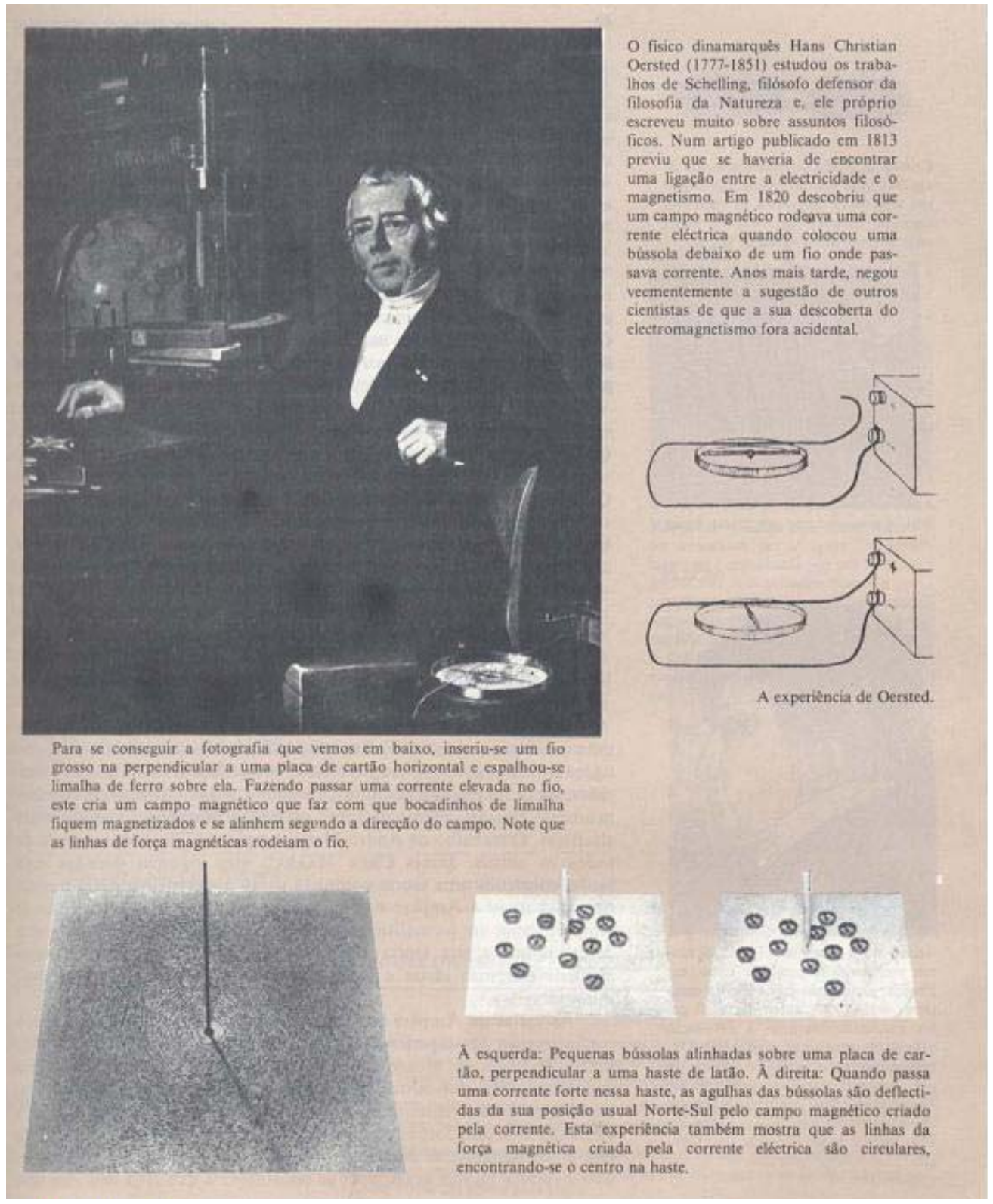

Projeto Harvard - p.63.

Disponível em: < http://www.cienciamao.usp.br/dados/hpp/_camposeletricosemagnetic.arquivopdf.pdf>

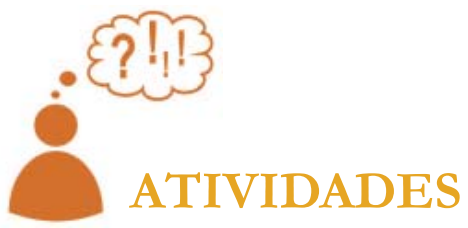

\section{APPLETS DE ENSINO}

Como nas outras Instrumentações, sugerimos alguns sites de ensino com material de multimídia para análise. Segue abaixo, um guia de com dicas para você analisar. 
Explore os applets do projeto webphysics do prof. Davidson acessando o link: <http://webphysics.davidson.edu/physlet_resources/bu_semester2/ menu_semester2.html >

1. Campo produzido por um fio infinito. Link: $<$ http://webphysics.davidson.edu/physlet_resources/bu_semester2/c15_ampere_long.html $>$

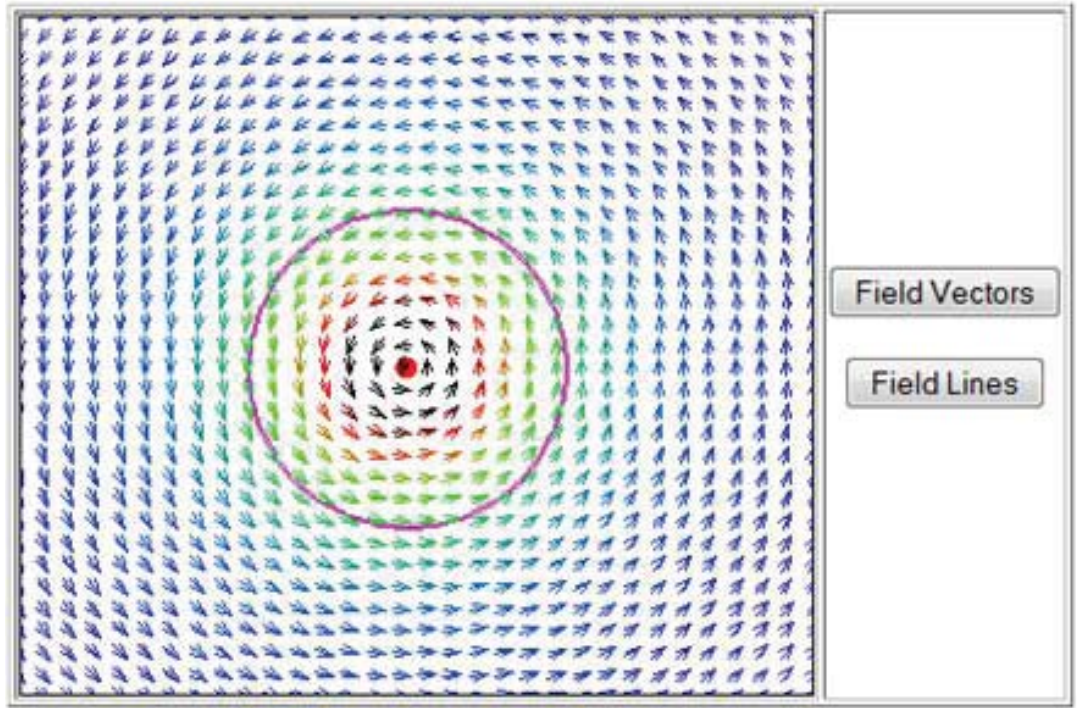

Applets do projeto webphysics.

Disponível em: <http://webphysics.davidson.edu/physlet_resources/

bu_semester2/c15_ampere_long.html $>$

2 - Campo dentro de um solenóide. Link; <http://webphysics.davidson. edu/physlet_resources/bu_semester2/c15_solenoid.html $>$

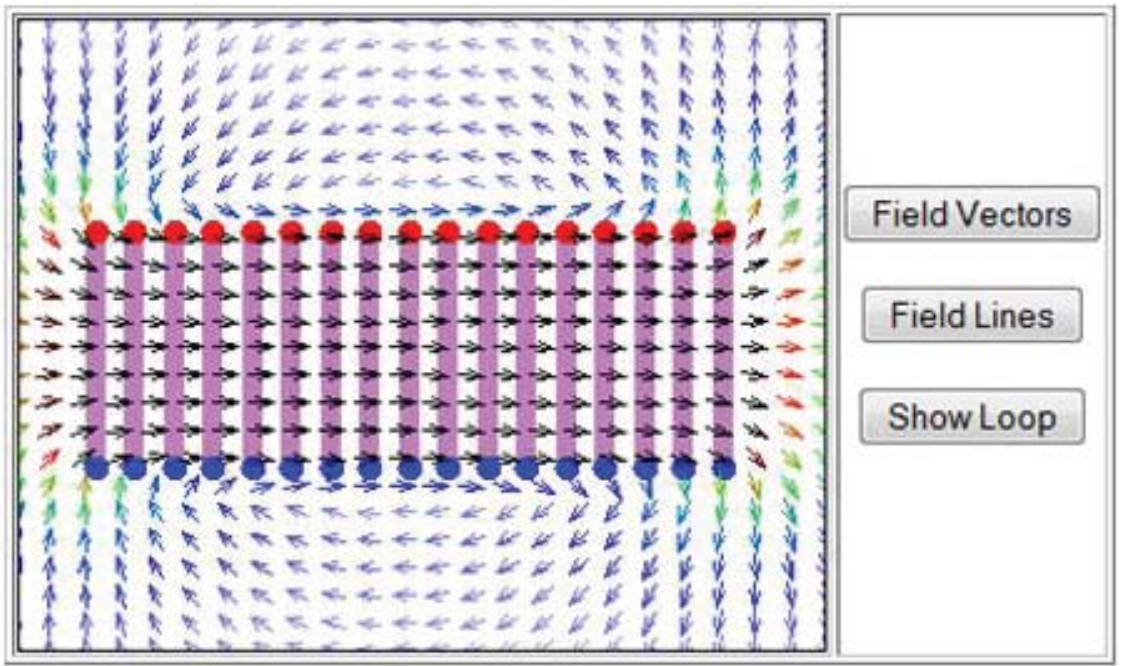

Applets do projeto wehphysics.

Disponível em: < http://webphysics.davidson.edu/physlet_resources/bu_semester2/ c15_solenoid.html> 


\section{VIDEO AULAS}

1. ELETRICIDADE - Campo Magnético Gerado por Corrente Elétrica. Link: <http://www.youtube.com/watch?v=6DjHQmtz2UQ>

2. Física Animada- Interação Entre Campo Magnético e Corrente Elétrica. Link: <http://www.youtube.com/watch?v=p9aciGjJ6nA>

\section{EXPERIMENTOS DE BAIXO CUSTO}

1. Lei de Àmpere. Experimento tirado do Projeto Experimentos de Física com Materiais do Dia-a-Dia - UNESP/Bauru. Link: <http://www2. fc.unesp.br/experimentosdefisica/ele20.htm>

Ideia do Experimento

É possível mostrar de forma simples o experimento feito por Ampère usando apenas fios finos e pilhas comuns. Os fios devem ser finos e leves porque estamos tratando de um experimento simples e com baixas correntes. Isso gera um campo magnético fraco e consequentemente a força magnética de atração associada a ele também será fraca. Se os fios são pesados demais, esta força não será suficiente para movê-los. Então, tomando estes cuidados, veremos que dois fios finos se atraem mutuamente, quando passam por eles correntes elétricas de mesmo sentido. Para isso, basta esticarmos dois pedaços de fios de fone de ouvido (os fios de fone de ouvido retirados de "walkman" são mais indicados por serem finos e leves) sobre uma régua de madeira e conectá-los a algumas pilhas. Nesta conexão, faz-se com que a corrente elétrica fornecida pelas pilhas passe em ambos os fios e com o mesmo sentido. O resultado final, é que estes fios se atraem mutuamente (mais na região central do que nas extremidades). 
Tabela do Material

\begin{tabular}{|l|l|}
\hline \multicolumn{1}{|c|}{ Item } & \multicolumn{1}{c|}{ Observações } \\
\hline $\begin{array}{l}\text { ripa de } \\
\text { madeira }\end{array}$ & $\begin{array}{l}\text { Uma ripa de madeira com aproximadamente } 2 \mathrm{~cm} \text { X60 cm, } \\
\text { que pode ser conseguida em construções ou nos retalhos } \\
\text { de uma marcenaria. Pode ser usado uma régua de } 60 \mathrm{~cm} \\
\text { de madeira que pode ser comprada em papelarias. }\end{array}$ \\
\hline $\begin{array}{l}\text { fio de } \\
\text { "walkman" }\end{array}$ & $\begin{array}{l}\text { Neste experimento usamos o fio de fone de ouvido de } \\
\text { "walkman". Alguns fios de fone de ouvido são bem leves } \\
\text { e maleáveis. Estes são os mais indicados. }\end{array}$ \\
\hline $\begin{array}{l}\text { fio elétrico } \\
\text { para } \\
\text { conexões }\end{array}$ & $\begin{array}{l}\text { Fio elétrico para conexões podem ser encontrados em } \\
\text { casa de materiais elétricos, supermercados ou podem ser } \\
\text { retirados de aparelhos elétricos velhos. }\end{array}$ \\
\hline pilhas & $\begin{array}{l}\text { Podem ser compradas em lojas, papelarias, padarias e } \\
\text { supermercados. Serão necessárias um mínimo de quatro } \\
\text { pilhas comuns, podendo chegar até oito. }\end{array}$ \\
\hline pregos & $\begin{array}{l}\text { Os pregos devem ser pequenos e finos. Serão usados } \\
\text { dois pregos para prender os fios na madeira. }\end{array}$ \\
\hline fita adesiva & $\begin{array}{l}\text { Pode ser encontrada em papelarias, bazares, } \\
\text { supermercados, lojas do tipo R } \$ 1,99, \text { etc. }\end{array}$ \\
\hline
\end{tabular}

Montagem

- Corte as duas extremidades dos fios de um fone de ouvido de "walkman" e separe-os de forma que fiquem com dois pedaços de fio com aproximadamente $70 \mathrm{~cm}$ cada. Veja a figura abaixo.

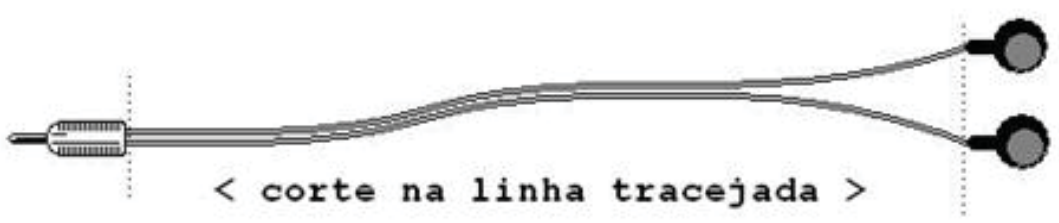

Fone de ouvido de walkman.

Disponível em: < http://www2.fc.unesp.br/experimentosdefisica/ele20.htm>

- Desencape as duas extremidades dos dois fios.

- Coloque os fios em paralelos e una as extremidades, enrolando junto suas pontas desencapadas, como mostra a figura (a) abaixo.

- Pregue dois pregos na régua de madeira de $60 \mathrm{~cm}$, mais ou menos a $10 \mathrm{~cm}$ das extremidades.

- Lace as extremidades dos fios já enrolados nos pregos. Enrole mais 
o fio, um pouco de cada lado, até que os fios desencostem da madeira e fiquem um pouco esticados.

- Caso as extremidades desencapadas dos fios de "walkman" não forem suficientes para alcançar as extremidades da associação de pilhas, faça a conexão de um pedaço de fio elétrico nas extremidades do fio de "walkman" e nas extremidades da associação de pilhas. Como mostra a figura (b) abaixo.

- A associação de pilhas é montada conectando-se o pólo positivo de uma pilha com o pólo negativo de outra. Como mostra a figura (b) abaixo. Para se manter fixa a associação de pilhas, grude fita adesiva em torno das pilhas na região de seus contatos.

- Afixa-se com fita adesiva o contato dos fios elétricos com a associação de pilhas.

\section{(a)}

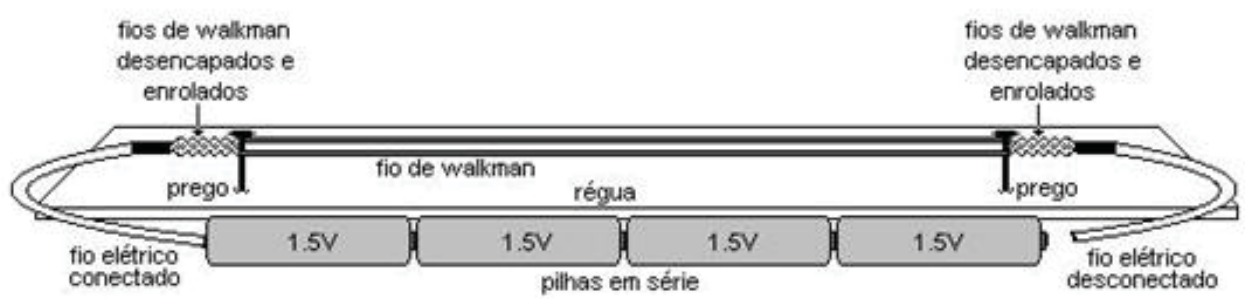

(b)

\section{COMENTÁRIOS SOBRE AS ATIVIDADES}

- Este experimento pode apresentar um inconveniente: a tensão necessária para a realização do experimento. A tensão mínima para fazer com que os fios se atraiam vai depender principalmente da escolha do(s) fio(s). Quanto mais resistentes eles forem, menor será a corrente elétrica que passará por eles e consequentemente, menor será o campo magnético gerado. Neste experimento, conseguimos provocar pequenas oscilações nos fios - no sentido da atração - com uma tensão de 6 volts (4 pilhas). No nosso entender, essas oscilações já demonstram que os fios vão se atrair. Mas, se você realmente quer vêlos "grudados" como mostra a figura do esquema geral de montagem, talvez você precise aumentar a tensão para um valor entre 9 e 15 volts. As figuras deste texto mostram uma associação em série de 4 pilhas comuns, com 1,5 volts cada, gerando uma tensão resultante de 6 volts. Para se produzir 9 volts, por exemplo, acrescente mais duas pilhas à série. - Tome cuidado ao escolher o fio de "walkman". O bom funcionamento 
deste experimento depende quase que exclusivamente dessa escolha. Este fio deve ser bem fino e muito maleável. A maleabilidade é importante para que os fios possam se curvar no momento da atração e também para que eles não se deformem enquanto são manipulados. No término da montagem os fios devem estar retos, paralelos e um pouco esticados. Quando dizemos, um pouco esticados, queremos dizer que eles devem estar esticados o suficiente para se manterem retos, paralelos e também para se apoiarem suspensos nos pregos e não encostarem-se à régua. Pois se isso acontece, aparece o atrito entre eles e a régua, o que não é desejável. Por outro lado, não podem estar muito esticados, pois se estiverem, a força magnética gerada não conseguirá vencer a tensão dos fios.

Esquema Geral de Montagem:

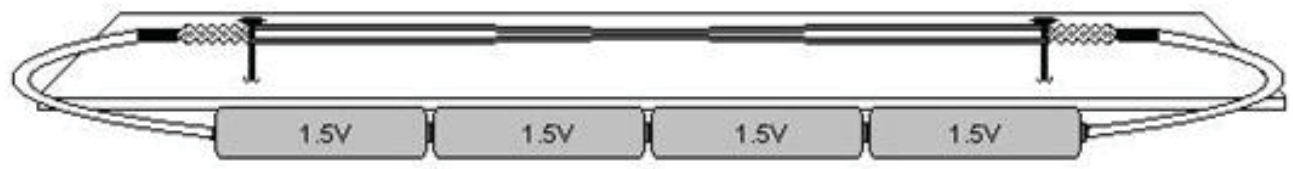

Esquema geral de montagem

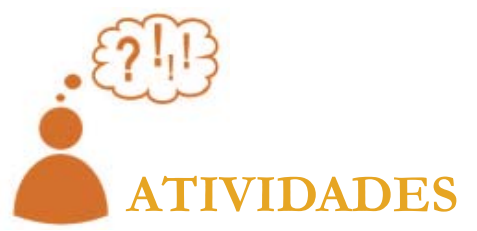

1. Você vê muita diferença entre o material produzido para os projetos Harvard e PSSC? Comente.

2. Você vê muita diferença entre o material produzido para os projetos Harvard e PEF? Comente.

3. Você vê muita diferença entre o material produzido para o projeto Harvard e o seu livro didático? Comente.

4. Como você analisa a transposição didática destes projetos com relação a um texto universitário do ciclo básico (por exemplo Halliday)?

5. Do seu ponto de vista qual é o conceito mais intuitivo para os estudantes do $2^{\circ}$ grau: Força ou campo? Como você explicaria a experiência de Oersted ora usando o conceito de força ora de campo?

6. Como você ilustraria o conceito de campo magnético para seus (futuros) alunos?

7. O que você acha do texto do Harvard? Você acha que poderíamos usá-lo como livro texto? 
8. Alguns livros textos trazem a experiência de Oersted como se ele estivesse intencionalmente procurando demonstrar o efeito da corrente elétrica sobre um imã permanente, quando o fato foi acidental. Isso aparece mesmo em livros textos aprovados pelo PNLEM, por exemplo, o Bonjorno. Pesquise os livros textos que você tem a disposição e relate como eles narram estes fatos. 9. Devido ao alto grau de abstração, muitos físicos e grupos de ensino estão fazendo animações gráficas e applets que demonstram virtualmente as linhas de campo. Colocamos alguns links acima para você explorá-los. Faça um comentário a respeito deles.

10. Com o advento da televisão alguns grupos de ensino e ou instituições estão fazendo vídeos aulas sobre temas interessantes e complexos de Física. Colocamos alguns links acima para você explorá-los. Faça um comentário a respeito deles.

11. Colocamos acima alguns exemplos e/ou links de experimentos de baixo custo para analisar a possibilidade de usá-los em sala de aula. Comente se você os usaria ou não como recurso didático em sala de aula?

\section{CONCLUSÃO}

O estudante de licenciatura deve ter ficado ciente do processo de evolução dos projetos de ensino de Física e do livro didático. Deve ter aprendido que existem várias formas de se ensinar Física e de como enriquecer sua aula. Devem ter percebido o papel fundamental que o projeto Harvard teve sobre o PEF e sobre vários autores de livros didáticos.

Com a análise dos experimentos de baixo custo e dos recursos de multimídias que colocamos no final da aula o futuro professor deve ter ficado com algumas boas ideias de como este pode enriquecer uma aula sobre o tema Lei de Coulomb.

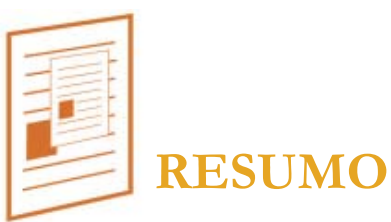

Completando a nossa análise dos projetos de ensino de física apresentamos o projeto Harvard. Contamos um resumo de sua história e o papel muito importante que os seus mentores e autores, os Professores Holton e Conant tiveram no seu sucesso. Apresentamos a lei de Àmpere através do material do projeto Harvard, e o analisamos.

Em seguida apresentamos vários experimentos de baixo custo para que explore as possibilidades que estes oferecem para se ministrar um curso usando mais ferramentas fenomenológicas e menos formais. Colocamos excelentes applets de ensino como recurso de simulação de fenômeno físico para ser explorado. 
Como há ótimos vídeos de ensino colocamos alguns deles como referência, e deixamos sua exploração como atividade, pois no curso de Instrumentação I não usamos os vídeos didáticos como ferramenta didática principal.

\section{REFERÊNCIAS}

EXPERIMENTOS DE FÍSICA PARA O ENSINO MÉDIO E FUNDAMENTAL COM MATERIAIS DO DIA-A-DIA. Eletricidade - Lei de Àmpere. UNESP -Universidade Estadual Paulista - Faculdade de Ciências - Câmpus de Bauru - Departamento de Física. Disponível em: $<$ http://www2.fc.unesp.br/experimentosdefisica/ele20.htm> Acesso em: $16 / 10 / 2011$

OLIVEIRA, J.O; FREIRE JUNIOR, O. Uma conversa com Gerald Holton. Cad. Bras. Ens. Fís., v. 23, n. 3: p. 315-328, dez. 2006. Disponível em: <http://www.fsc.ufsc.br/cbef/port/23-3/artpdf/a1.pdf>

PROJETO DE ENSINO DE FÍSICA. Cargas e Estrutura da Matéria, vol. Eletricidade, fasc. 01. Disponível em: <http://www.cienciamao.usp. br/tudo/exibir.php?midia=pef\&cod=_eletricidadecargaseestru $>$. Acesso em: 16/10/2011.

PROJETO HARVARD. Campos elétricos e magnéticos. Disponível em: $<$ http://www.cienciamao.usp.br/dados/hpp/_camposeletricosemagnetic. arquivopdf.pdf $>$. Acesso em 16/10/2011

PROJETO WEBPHYSICS. The Field from a Long Straight Wire. Disponível em: <http://webphysics.davidson.edu/physlet_resources/ bu_semester2/c15_ampere_long.html>. Acesso em 16/10/2011

The Field from a Solenoid. Disponível em: <http://webphysics. davidson.edu/physlet_resources/bu_semester2/c15_solenoid.html $>$. Acesso em 16/10/2011

YOUTUBE. 1 - ELETRICIDADE - Campo Magnético Gerado por Corrente Elétrica. Disponível em: <http://www.youtube.com/ watch?v=6DjHQmtz2UQ>. Acesso em: 16/10/2011.

Física Animada- Interação Entre Campo Magnético e Corrente Elétrica (Eletromagnetismo). Disponível em: <http://www.youtube. com/watch?v=p9aciGjJ6nA>. Acesso em: 16/10/2011. 



\section{Aula10}

\section{CORRENTE E FEM INDUZIDA}

META

Fazer com que o estudante comece a pensar no ensino de ciências como algo "orgânico"

que está em profunda transformação.

Fazer com que os alunos percebam, através de um texto básico complementado com atividades lúdicas, applets de ensino, vídeos, que a lei de Faraday e a Lei de Lenz podem ser apreendidas de forma simples e divertida. Levantar a discussão se podemos começar ensinando a partir de experimentos simples, e só depois apresentar a teoria.

\section{OBJETIVOS}

Ao final desta aula, o aluno deverá: estar ciente das novas possibilidades e dos desafios que envolvem o ensino de ciências em

geral.

Ter compreendido que as ciências naturais estão baseadas na experimentação e que esta é feita de ensaios, experiências e medidas e que estas levam a compreensão e matematização dos conceitos físicos (naturais em geral).

Estar ciente que para se ensinar conceitos de Física, não é necessário que se apresente a teoria para depois procurar exemplos para elas, pois pode começar apresentando os fenômenos e só depois apresentar a teoria

PRÉ-REQUISITOS Os alunos deverão ter cursado as disciplinas Psicologia da Educação, Física A e B. 


\section{INTRODUÇÃO}

Chegamos a nossa última aula. Vamos agora, fazer um breve resumo do que foi visto e apresentaremos aqui o que ficou faltando. O tema principal desse curso, como você notou, foi o da transposição didática. Assim, na $1^{\mathrm{a}}$ aula apresentamos um texto sobre eletrização que usa o modelo atômico e em seguida fizemos uma adaptação desse mesmo texto tirando o modelo atômico de sua explicação para que você avaliasse as vantagens e desvantagens de se fazer uma abordagem mais próxima dos fatos históricos e de uma que leve em conta mais os fatos atuais.

$\mathrm{Na} 2^{\mathrm{a}}$ aula apresentamos o material didático produzido para o projeto de ensino PSSC para discutíssemos a questão de que os livros textos devem ou não ensinar Física dentro do contexto histórico, com muito texto e experiências de apoio.

$\mathrm{Na} 3^{a}$ aula apresentamos a história de um cientista, Faraday, que apesar de seus parcos (muito pouco) conhecimentos e domínio de Matemática se tornou um dos mais importantes e celebres cientistas modernos. Através dessa biografia discutimos se a matemática possui tanta importância assim na Física do ensino médio. Discutimos o problema de se ensinar o conceito de campo em vez de força.

$\mathrm{Na} 4^{a}$ aula apresentamos três textos sobre a definição de potencial elétrico. O primeiro foi extraído do curso de EAD da Universidade de Brasília em que o conceito de potencial elétrico é apresentado em nível da Física básica do curso universitário. Depois apresentamos um texto que faz a transposição direta desse material para o ensino médio e por último o material do GREF que ensina o conceito de potencial elétrico a partir da "Física das coisas".

$\mathrm{Na} 5^{a}$ aula usamos o curso "Eletrotécnica Básica - Instrumentação", preparado pelo professor Jader de Oliveira para o SENAI/CST (Companhia Siderúrgica de Tubarão), com o intuito de levantarmos a questão pedagógica: por que não ensinar circuitos elétricos como estivéssemos preparando nossos alunos para a atividade profissional e não para passar de ano?

$\mathrm{Na} \sigma^{a}$ aula comparamos um tópico do curso do eletromagnetismo tirado de um livro texto e comparamos com o mesmo tópico de um projeto de ensino em particular. Nessa aula começamos com o capítulo do efeito Joule do projeto PEF.

$\mathrm{Na} 7^{\mathrm{a}}$ e $8^{\mathrm{a}}$ aulas abordamos novamente o problema da transposição científica, só que dessa vez, analisando o problema de se introduzir um pouco de história da ciência nos livros didáticos em geral. Refletimos se há necessidade de no ensino médio e fundamental, carregar os livros textos com nomes e datas.

$\mathrm{Na} 7^{\mathrm{a}}$ aula analisamos o material de ensino do projeto GREF, onde se ensina o conceito de campo e força magnética a partir de experimentos 
simples tirados de objetos do cotidiano e a completamos com várias atividades experimentais. $\mathrm{Na} 8^{a}$ aula analisamos o material de ensino do livro aprovado pelo PNLEM "Física ensino médio" dos autores Beatriz Alvarenga e Antônio Máximo, onde se ensina o conceito de campo magnético usando história da ciência.

$\mathrm{Na} 9^{a}$ aula apresentamos o projeto Harvard. Nela abordamos o famoso experimento de Oersted e a Lei de Ampere. Nessa aula fechamos a discussão sobre o uso da história da ciência no ensino de Física do ensino médio e convidamos você a fazer uma análise comparativa entre os quatro projetos.

Nessa última aula vamos seguir a cartilha do método de ensino do GREF. Começaremos com as atividades exploratórias e experimentais sugeridas e somente depois colocaremos a definição das leis de Faraday e de Lenz tirado do GEF da UFSM. Deixaremos o veredito sobre a praticidade e eficiência desse método para você. Finalizando, faremos uma breve revisão do que é um motor elétrico, segundo uma apostila de máquinas elétricas do Professor Jorge Eduardo Uliana.

No livro de GREF se começa com a observação, na sequência a prática e por último dá-se a explicação, ou seja, nessa filosofia o adolescente dever iniciar explorando o fenômeno físico e por último é apresentada a explicação em termos de leis físicas.

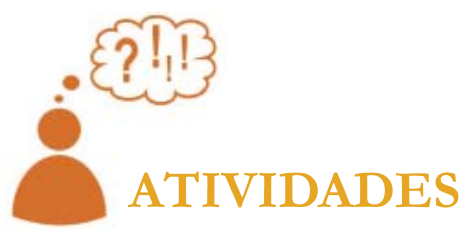

1. Faça os experimentos sugeridos abaixo pelo material do GREF (disponível em <http://fisica.cdcc.usp.br/GREF/eletro03.pdf> pág. 54)

\section{O MOTOR DE UM LIQUIDIFICADOR}

A parte externa de um liquidificador é geralmente de plástico, que é um material eletricamente isolante. É no interior dessa carcaça que encontramos o motor, conforme ilustra a figura abaixo.

\section{ROTEIRO}

1. Acompanhe os fios do plugue em direção à parte interna do motor. Em qual das partes do motor eles são ligados?

2. Gire o eixo do motor com a mão e identifique os materiais que se encontram na parte que gira junto com o eixo do motor. 
3. Identifique os materiais que se encontram na parte do motor que não gira com o eixo do motor.

4. Verifique se existe alguma ligação elétrica entre as duas partes que formam o motor. De que materiais eles são feitos?

5. Identifique no motor as partes indicadas com as setas na figura ao lado.

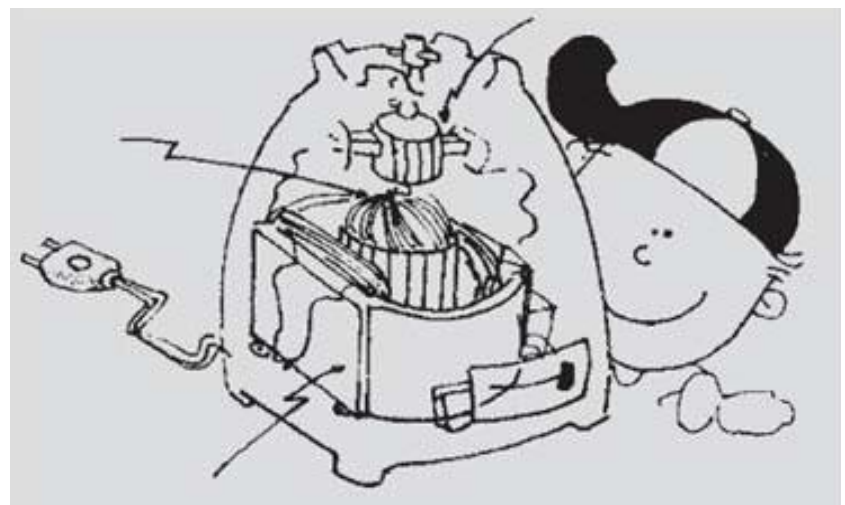

GREF - Eletromagnetismo , cap. 14 a 19 , p. 54.

Disponível em <http://www.cienciamao.usp.br/dados/grf/_eletromagnetismogrefcapitulos14a19-leiturasdefisica.arquivo.pdf $>$

Construa você mesmo um motor elétrico (disponível em <http:// fisica.cdcc.usp.br/GREF/eletro03.pdf> pág. 56)

Para construir um pequeno motor elétrico vai ser necessário um pedaço de $90 \mathrm{~cm}$ de fio de cobre esmaltado número 26 para fazer uma bobina. Ela será o eixo do motor, por isso deixe aproximadamente $3 \mathrm{~cm}$ em cada extremidade do fio.

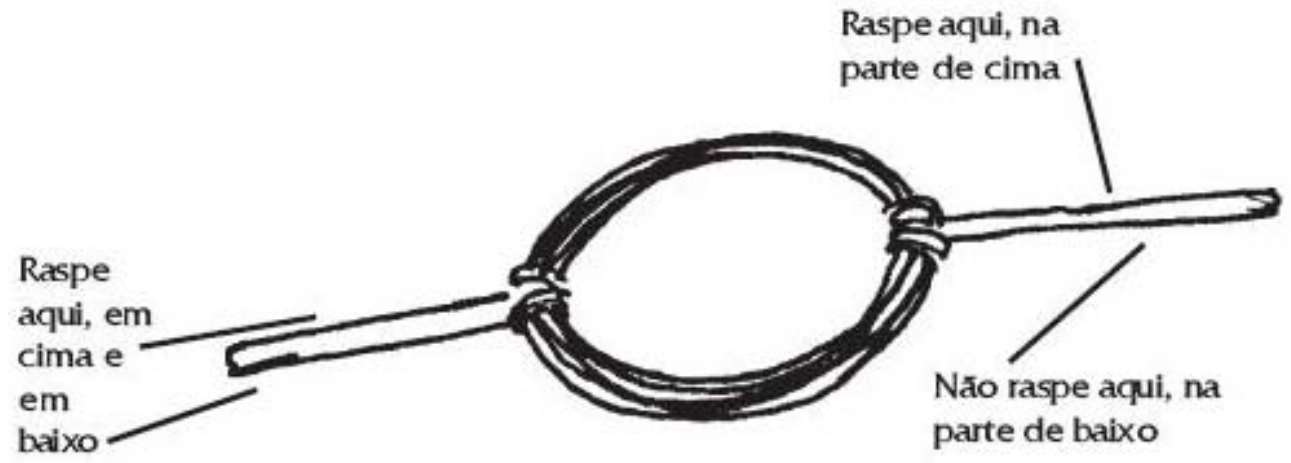

GREF - Eletromagnetismo , cap. 14 a 19, p. 56.

Disponível em < http://www.cienciamao.usp.br/dados/grf/_eletromagnetismogrefcapitulos14a19leiturasdefisica.arquivo.pdf $>$ 
Como o esmalte do fio da bobina é isolante elétrico, você deve raspá-lo para que o contato elétrico seja possível. De um dos lados da bobina, você deve raspar em cima e em baixo; do outro lado, só em cima.

A bobina será apoiada em duas hastes feitas de metal, presilhas de pasta de cartolina, por exemplo, dando-lhes o formato indicado na figura e, posteriormente, encaixadas num pedaço de madeira.

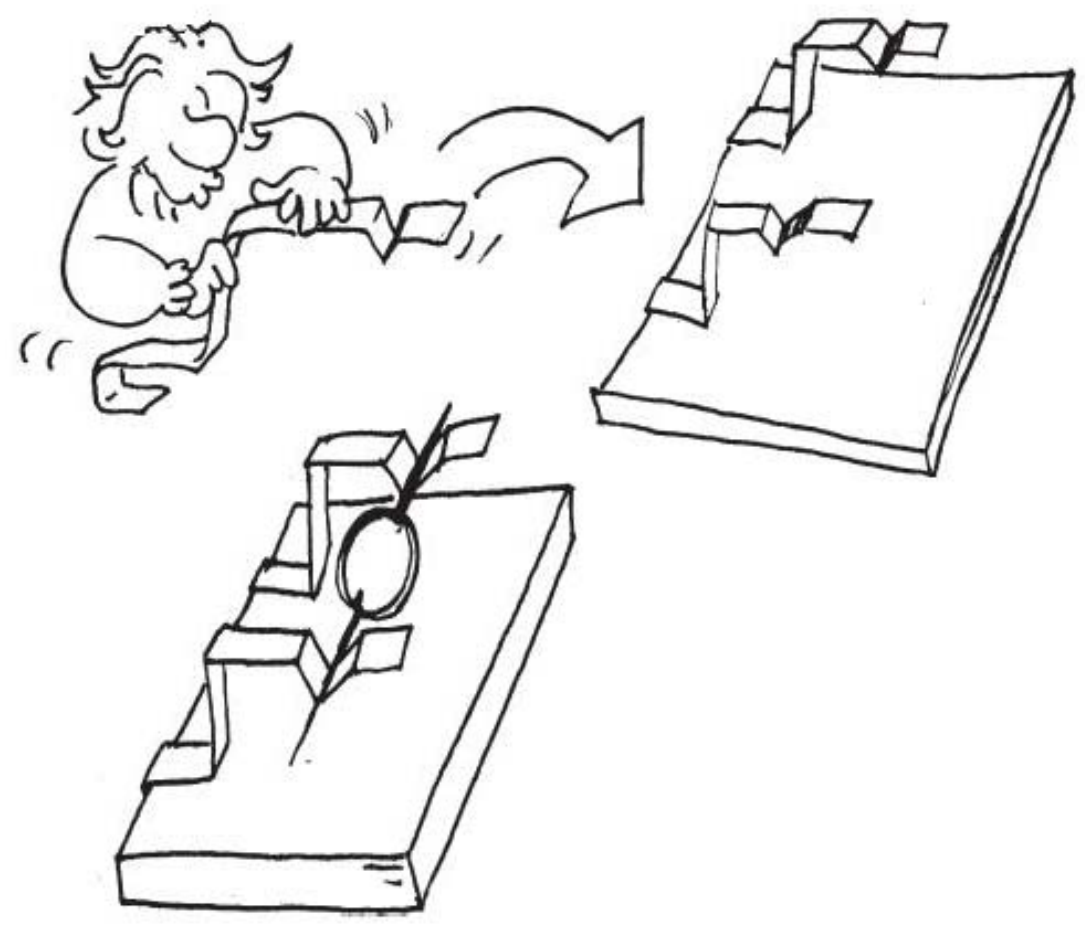

Figura 3 - GREF - Eletromagnetismo, cap. 14 a 19, p. 56.

Disponível em < http://www.cienciamao.usp.br/dados/grf/_eletromagnetismogrefcapitulos14a19-leiturasdefisica.arquivo.pdf $>$

A fonte de energia elétrica será uma pilha comum, que será conectada à bobina através de dois pedaços de fio ligados nas presilhas.

A parte fixa do motor será constituída de um ímã permanente, que será colocado sobre a tábua, conforme indica a figura. Dependendo do ímã utilizado, será necessário usar um pequeno suporte para aproximá-lo da bobina.

Para colocar o motor em funcionamento, não esqueça que é necessário um impulso inicial para dar a partida.

\section{ATENÇÃO}

- veja se os contatos elétricos estão perfeitos

- observe se a bobina pode girar livremente 
- fixe os fios de ligação na pilha com fita adesiva

Feitos esses ajustes necessários, observe:

1) o que acontece quando o ímã é retirado do local?

2) inverta a pilha e refaça as ligações.

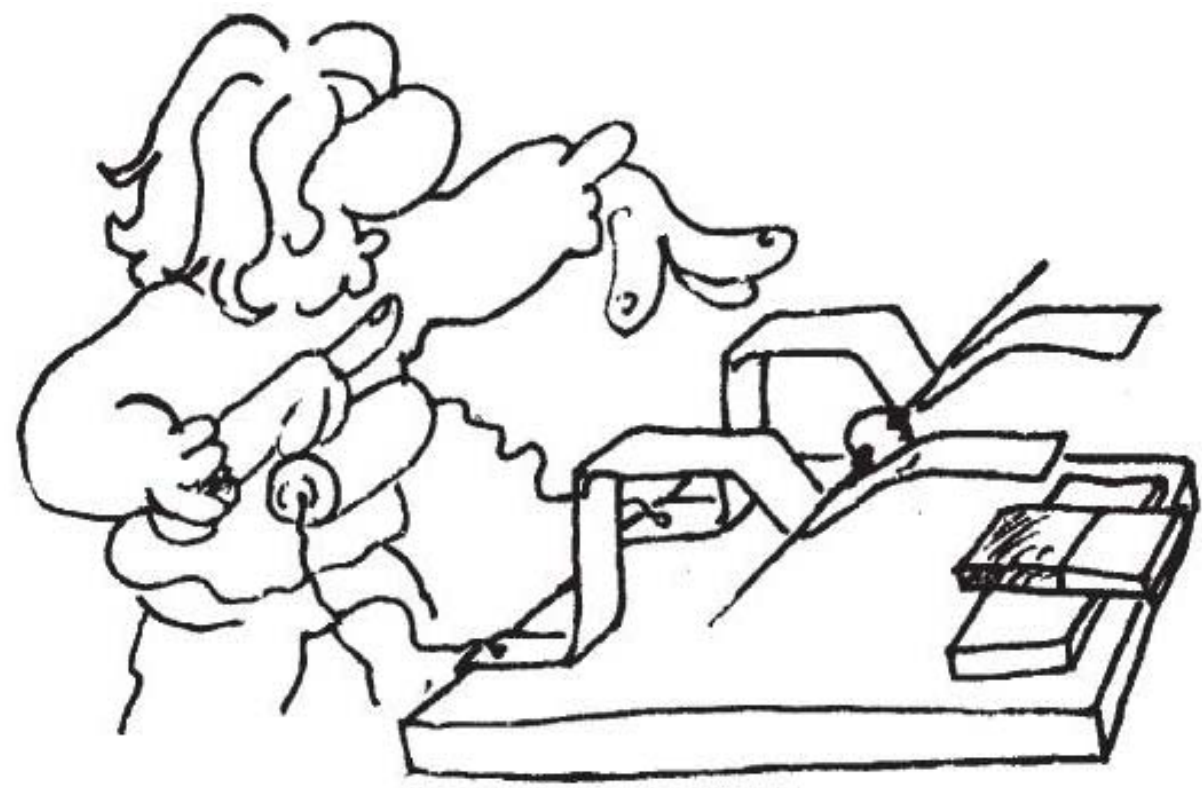

GREF - Eletromagnetismo, cap. 14 a 19, p. 56.

Disponível em <http://www.cienciamao.usp.br/dados/grf/_eletromagnetismogrefcapitulos14a19-leiturasdefisica.arquivo.pdf $>$

\section{FORÇA ELÉTRICA E CORRENTE ELE'TRICA - GREF}

(disponível em < http:// fisica.cdcc.usp.br/GREF/eletro03.pdf> pág. 66)

\section{FORÇAS MAGNÉTICA E CORRENTE ELÉTRICA}

Nas aulas anteriores estudamos o princípio de funcionamento dos motores elétricos, da campainha e do galvanômetro. Em todos eles está presente o efeito magnético da corrente elétrica. Vejamos agora com mais detalhes, o conteúdo físico envolvido.

O giro do eixo dos motores elétricos e também o do ponteiro do galvanômetro indica uma interação entre uma bobina com um ímã ou entre uma bobina com uma outra bobina, dependendo das partes de que eles são feitos.

Essa interação decorre do fato de que tanto um ímã como uma bobina com corrente elétrica criam no espaço ao redor um campo magnético. 
Em razão disso, a interação entre eles, que torna possível a obtenção do movimento, se dá ainda que não haja contato. Do mesmo modo podemos entender a atração ou a repulsão observada entre dois ímãs.

\section{INTERAÇÃO BOBINA-ÍMÃ}

1. Quando em um motorzinho de brinquedo, encontramos um ímã fixado à carcaça do motor e uma bobina fixada ao eixo, o primeiro cria campo magnético na região onde se encontra a bobina.

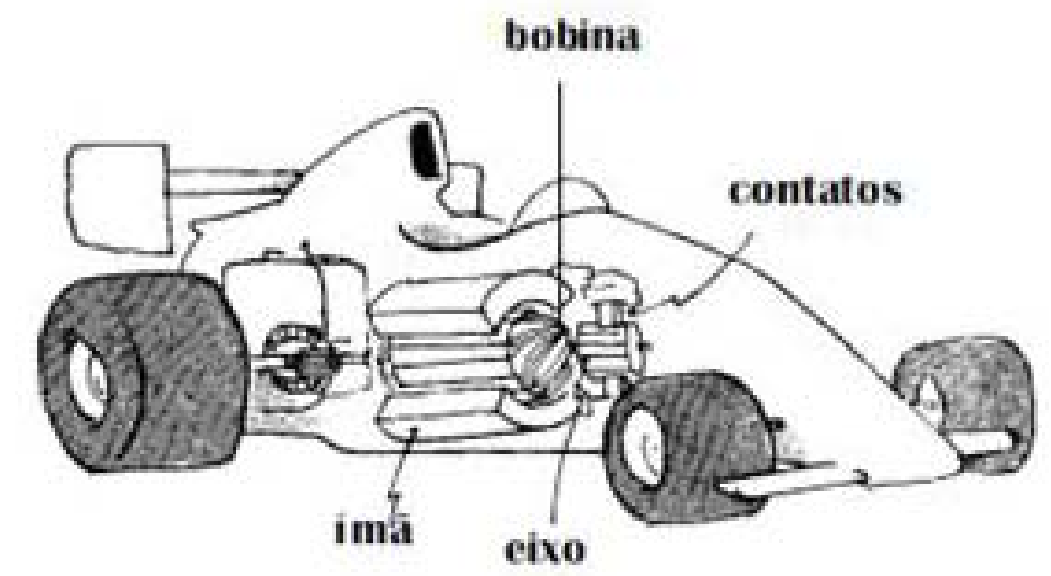

GREF - Eletromagnetismo , cap. 14 a 19 , p. 66.

Disponível em <http://www.cienciamao.usp.br/dados/grf/_eletromagnetismogrefcapitulos14a19-leiturasdefisica.arquivo.pdf $>$

Quando o circuito é fechado uma corrente passa a existir na bobina, criando um outro campo magnético na região onde encontra-se o ímã.

A partir desse momento há interação entre o ímã e a bobina com corrente, isto é, cada um "sente" o campo magnético criado pelo outro. Isso significa que cada um deles fica sujeito a uma força cuja natureza é magnética.

Como somente o que está fixado ao eixo tem mobilidade para se mover, no caso do motor do carrinho, é a bobina junto com o eixo que gira. E esse movimento é efeito da ação da força magnética sobre a bobina.

2. No galvanômetro como o montado na aula 16 , bobina era fixada à base e o ímã colocado junto ao ponteiro e ambos fixados ao eixo. 


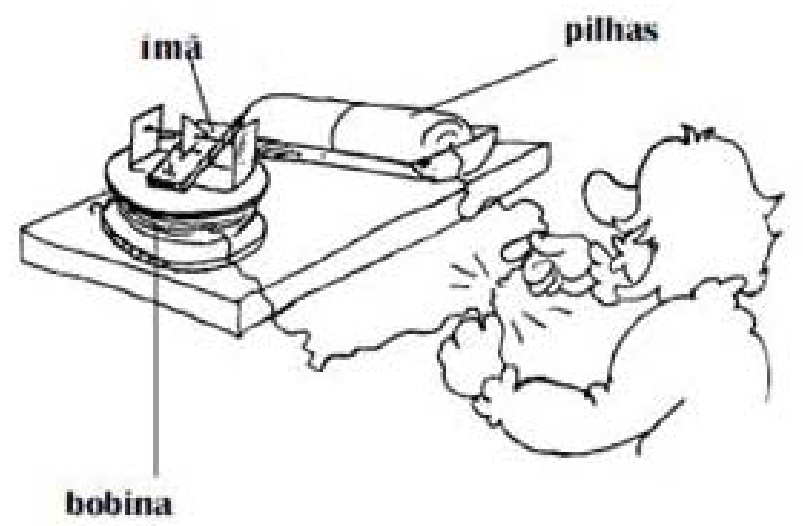

GREF - Eletromagnetismo, cap. 14 a 19, p. 66.

Disponível em <http://www.cienciamao.usp.br/dados/grf/_eletromagnetismogrefcapitulos14a19-leiturasdefisica.arquivo.pdf $>$

O ímã já criava um campo magnético na região onde se encontra a bobina e a partir do momento em que há corrente elétrica nela, tem início a interação entre eles. Ambos ficam sujeitos a uma força de natureza magnética e como a bobina está fixada ela não se move. Já o ímã entra em movimento e como ele está preso ao eixo, ele gira.

Comparando-se o princípio de funcionamento do motorzinho do carrinho e do galvanômetro, podemos perceber que tanto o ímã permanente como a bobina com corrente podem entrar em movimento quando estão próximos um do outro. Nos dois casos, é a ação da força magnética que os movimenta.

Vejamos agora como a Lei de Faraday e de Lenz são formuladas em nível de Ensino Médio. Usaremos o texto do GEF para isto. Você pode acessar este mesmo texto no link <http://www.ufsm.br/gef/Eletro/eletro18.pdf>

\section{LEI DE FARADAY}

Segundo a lei de Faraday, se o fluxo do campo magnético através da superfície limitada por um circuito varia com o tempo, aparece nesse circuito uma força eletromotriz (fem) induzida. Matematicamente:

$$
\varepsilon=-\frac{\Delta \phi}{\Delta t}
$$


O sinal negativo que aparece nessa expressão representa matematicamente a lei de Lenæ. Esta lei está relacionada ao princípio de conservação da energia, conforme se discute adiante.

Deve-se observar, de passagem, que o nome força eletromotriz, dado a essa grandeza, é mantido por questões históricas. Essa grandeza não representa fisicamente uma força e sim, uma diferença de potencial elétrico. Assim, tem como unidade no SI, o volt $(\mathrm{V})$.

Exercício Prático

Com o objetivo de estudar a lei de Faraday, mova um imã permanente em forma de barra em relação a uma espira ligada a um amperímetro A (Fig. 8(a)). Conforme o movimento do imã em relação à espira, se de aproximação ou afastamento, o sentido da corrente é diferente. Além disso, conforme a velocidade relativa, a intensidade da corrente varia: quanto maior a velocidade, maior a intensidade da corrente.

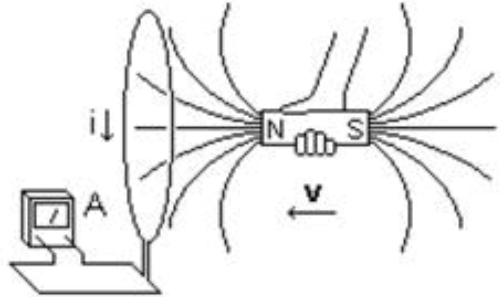

(a)

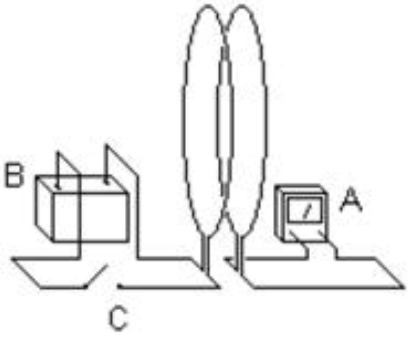

(b)

Fig. 8 Disponível em <http://www.ufsm.br/gef/Eletro/eletro18.pdf>

Por outro lado, você pode também, para estudar a lei de Faraday, fazer variar a corrente em uma espira ligada a uma bateria $\mathrm{B}$, ligando e desligando uma chave $C$ colocada em série no circuito, e observar a corrente em outra espira próxima, essa ligada a um amperímetro A (Fig. 8 (b)). A corrente na segunda espira só aparece nos instantes que se seguem aos atos de ligar e desligar a chave no circuito da primeira espira e, em cada caso, com um sentido diferente. Observe que, enquanto a chave no circuito da primeira espira permanecer desligada ou ligada, não aparece corrente na segunda espira.

Como exemplo de aplicação da lei de Faraday pode-se calcular a fem induzida em uma espira retangular que se movimenta entrando ou saindo, com velocidade constante, de uma região de campo magnético uniforme (Fig.9). A área da parte da espira que está na região de campo magnético é xL e como o campo é uniforme, o fluxo do campo magnético através da superfície limitada pela espira vale: 
$\phi=x L B$

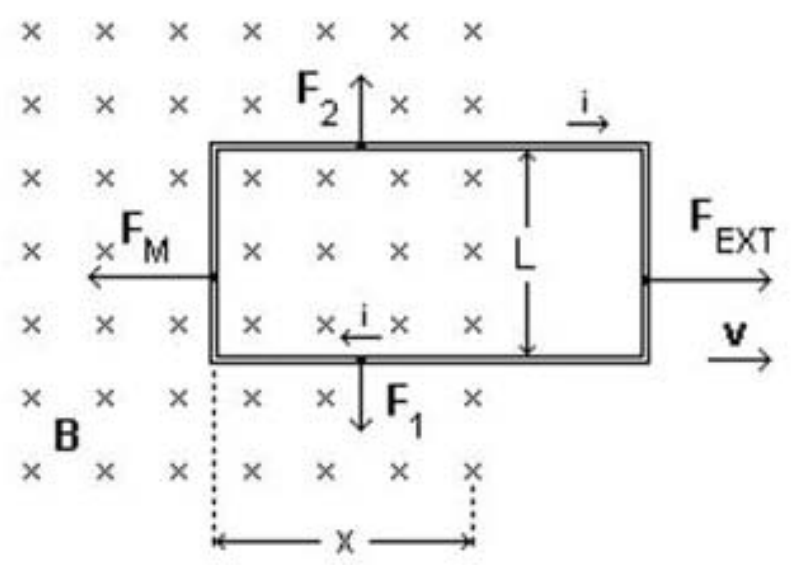

Espira

Disponível em <http://www.ufsm.br/gef/Eletro/eletro18.pdf>

Agora, levando em conta que L e B são constantes e que $\Delta x / \Delta t=v$, tem-se, para a variação do fluxo no tempo:

$$
\frac{\Delta \phi}{\Delta t}=\frac{\Delta(\mathrm{xLB})}{\Delta \mathrm{t}}=\left(\frac{\Delta \mathrm{x}}{\Delta \mathrm{t}}\right) \mathrm{LB}=\mathrm{vLB}
$$

Disponível em <http://www.ufsm.br/gef/Eletro/eletro18.pdf>

e, finalmente, pela lei de Faraday:

$$
\varepsilon=\mathrm{VLB}
$$

Disponível em <http://www.ufsm.br/gef/Eletro/eletro18.pdf>

Se a espira tem uma resistência $\mathrm{R}$, a corrente induzida é:

$$
\mathrm{i}=\frac{\varepsilon}{\mathrm{R}}=\frac{\mathrm{VLB}}{\mathrm{R}}
$$

Disponível em <http://www.ufsm.br/gef/Eletro/eletro18.pdf> 
Deve-se observar novamente que esta corrente induzida na espira existe apenas em dois intervalos de tempo: enquanto a espira está entrando na região de campo magnético e enquanto está saindo. Apenas durante estes intervalos de tempo o fluxo magnético através da superfície limitada pela espira varia.

Um condutor percorrido por corrente elétrica mergulhado numa região de campo magnético fica sob a ação de uma força dada por F = i L x B. Assim, por efeito da corrente induzida na espira aparecem as forças $F_{1}, F_{2}$ e $\mathrm{F}_{\mathrm{M}}$. As duas primeiras se cancelam mutuamente. A terceira é cancelada por uma força externa, necessária para manter a espira com velocidade constante. Como a força $\mathrm{F}_{\mathrm{M}}$ deve se opor à força $\mathrm{F}_{\mathrm{EXT}}$, a corrente induzida na espira pela variação do fluxo magnético deve ter o sentido indicado na Fig. 9. Esse fato constitui um exemplo particular de aplicação da lei de Lenz. (GEF - Lei de Faraday. Disponível em < http://www.ufsm.br/gef/Eletro/eletro18.pdf>)

\section{LEI DE LENZ}

Segundo a lei de Len₹, qualquer corrente induzida tem um sentido tal que o campo magnético que ela gera se opõe à variação do fluxo magnético que a produziu.

Matematicamente, a lei de Lenzé expressa pelo sinal negativo que aparece na expressão matemática da Lei de Faraday. Para entender o conteúdo da lei de Lenzpode-se considerá-la no contexto da atividade proposta com a lei de Faraday.

Quando um imã é aproximado de uma espira (Fig. 8(a)), a corrente induzida que aparece na espira tem o sentido indicado porque, assim, ela gera um campo magnético cujo polo norte se confronta com o polo norte do imã. Os dois polos se repelem, ou seja, o campo gerado pela corrente induzida na espira se opõe ao movimento do imã.
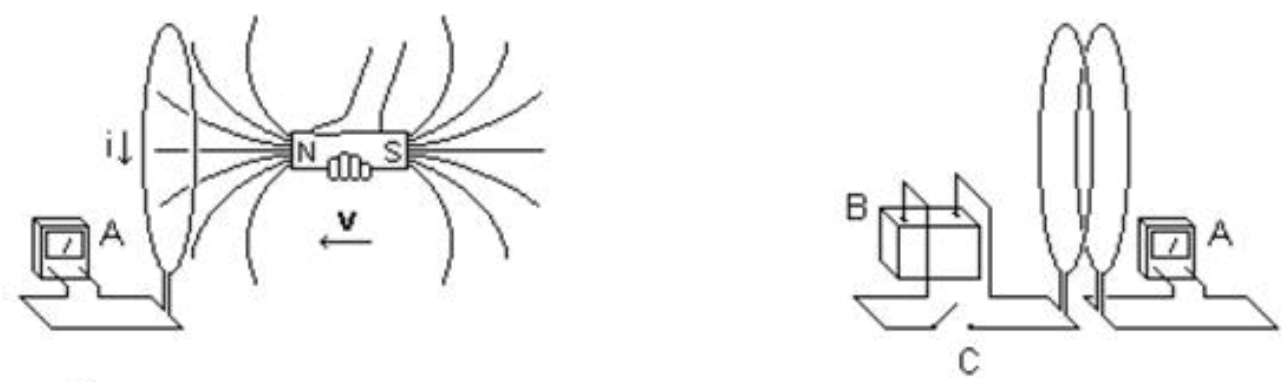

Disponível em <http://www.ufsm.br/gef/Eletro/eletro19.pdf>

Quando o imã é afastado da espira, a corrente induzida tem sentido contrário àquele indicado porque, assim, gera um campo magnético cujo polo sul se confronta com o polo norte do imã. Os dois polos se atraem, ou seja, o campo gerado pela corrente induzida na espira se opõe ao movimento de afastamento do imã. 
Quando duas bobinas são colocadas frente a frente (Fig. 8(b)) não existe corrente em qualquer delas. No instante em que a chave é fechada, aparece uma corrente na correspondente bobina. Então, uma corrente induzida aparece na segunda bobina. Ao se fechar a chave, a corrente da bobina correspondente vai de zero até um certo valor máximo que, a partir daí, permanece constante. Dessa forma, enquanto a corrente está mudando, o campo magnético que ela gera, com polo norte confrontando a segunda bobina, também está mudando, e o mesmo acontece com o fluxo desse campo através dessa segunda bobina. Então, aparece uma corrente induzida na segunda bobina cujo sentido é tal que o campo magnético que ela gera tende a diminuir o fluxo mencionado, ou seja, apresenta um polo norte confrontando o polo norte do campo da primeira bobina.

A partir do instante em que a corrente na primeira bobina atinge o seu valor máximo e fica constante, o campo magnético que ela gera também fica constante e também fica constante o fluxo desse campo através da segunda bobina. Nessas condições, não existe corrente induzida na segunda bobina. Quando a chave é aberta, a corrente na primeira bobina vai do valor máximo dado até zero, a intensidade do campo correspondente diminui e o fluxo desse campo na segunda espira também diminui, de modo que a corrente induzida na segunda bobina tem, agora, sentido contrário, sentido esse que é tal que o campo magnético que a corrente induzida gera se soma àquele, ou seja, apresenta um polo sul confrontando o pólo norte daquele campo.

O fato expresso na lei de Lenz, de que qualquer corrente induzida tem um efeito que se opõe à causa que a produziu é uma relação, nesse contexto, do princípio de conservação da energia. Se a corrente induzida atuasse no sentido de favorecer a variação do fluxo magnético que a produziu, o campo magnético da espira (Fig. 26(a)) teria um pólo sul confrontando o pólo norte do imã que se aproxima, com o que o imã seria atraído no sentido da bobina. Se o imã fosse, então, abandonado, seria acelerado na direção da bobina, aumentado a intensidade da corrente induzida, que geraria um campo cada vez maior que, por sua vez, atrairia o imã com uma força cada vez maior, e assim sucessivamente, com um aumento cada vez maior na energia cinética do imã. Se fosse retirada energia do sistema imã-espira na mesma taxa com que a energia cinética do imã aumenta, haveria um fornecimento infindável de energia às custas do nada. Um dispositivo que operasse desse modo seria um moto-perpétuo. Tal dispositivo não pode existir porque seria violado o princípio da conservação da energia.

(GEF - Lei de Len₹. Disponível em < http://www.ufsm.br/gef/Eletro/eletro19.pdf>)

\section{Outro exemplo:}

Considere uma barra metálica que pode se deslocar sobre um trilho metálico (ver figura a seguir). A direção tanto da fem induzida como da corrente induzida, podem ser achadas pela Lei de Lenæ: a polaridade da fem 
induzida é tal que ela tende a provocar uma corrente que irá gerar um fluxo magnético que se opõe à variação do fluxo magnético através do circuito fechado $\rightarrow$ é uma consequência da Lei de conservação da energia.

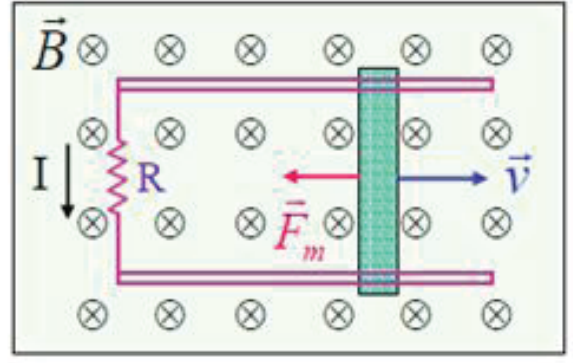

(A)

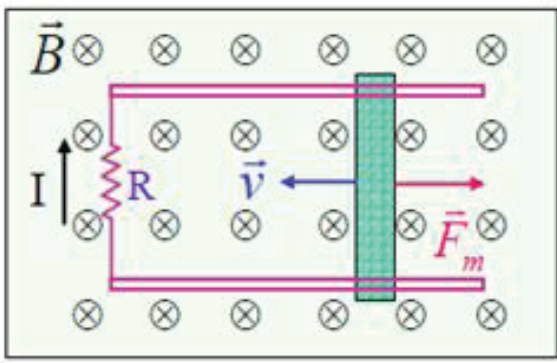

B

A Lei de Lenza afirma que a corrente I induzida deve ter uma direção tal que o fluxo que ela gera se oponha à variação do $\varphi$ m externo. A I induzida tende a manter o fluxo original através do circuito.

$\Phi \mathrm{m}$ externo crescendo $\otimes \Rightarrow \mathrm{I}$ anti horário

بm externo diminuindo $\otimes \Rightarrow I$ horário.

Do ponto de vista da conservação da energia temos: Se I tivesse o sentido horário $\Rightarrow \mathrm{F}_{\mathrm{m}}$ para a direita $\Rightarrow$ aceleração da barra $\Rightarrow$ no aumento da $\mathrm{V} \Rightarrow$ no aumento mais rápido da área do circuito $\Rightarrow$ aumento da I induzida $\Rightarrow$ no aumento da $\mathrm{Fm} \Rightarrow$ aumento da $\mathrm{I} \Rightarrow \ldots \Rightarrow$ O sistema adquiriria energia sem injeção adicional de energia. Logo $\Rightarrow$ I sentido anti-horário.
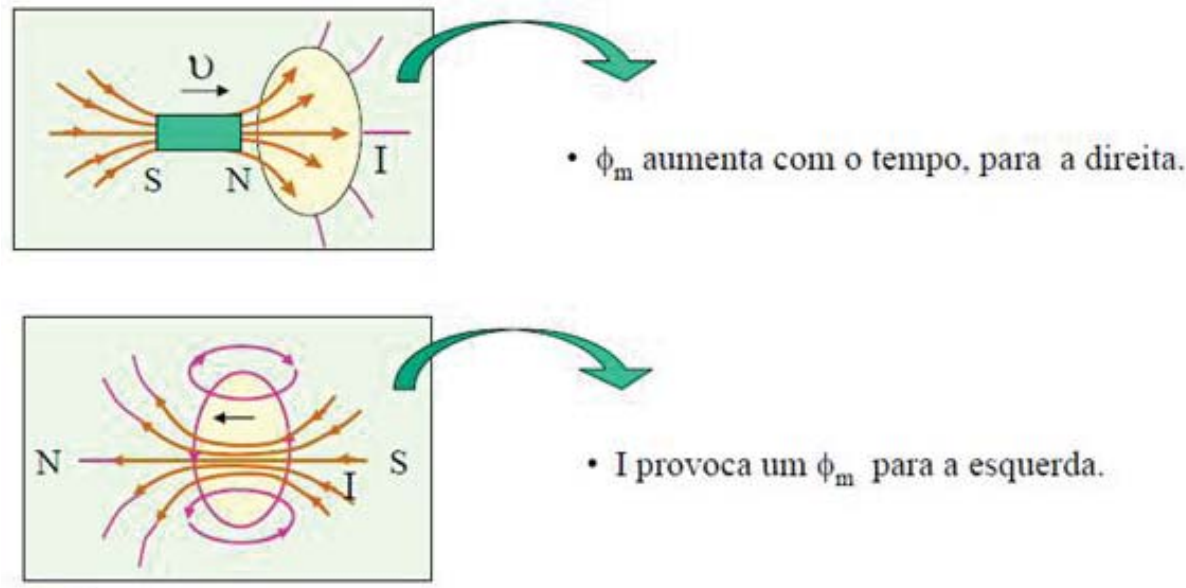

A maior aplicação das descobertas de Faraday e de Lenz são os motores elétricos. Vejamos o que é um motor elétrico segundo a referência. 


\section{MOTOR ELÉTRICO}

É uma máquina que converte a energia elétrica e energia mecânica (movimento rotativo), possui construção simples e custo reduzido, além de ser muito versátil e não poluente. $\mathrm{O}$ motor elétrico tornou-se um dos mais notórios inventos do homem ao longo de seu desenvolvimento tecnológico. A finalidade básica dos motores é o acionamento de máquinas, equipamentos mecânicos, eletrodomésticos, entre outros, não menos importantes. Seu princípio de funcionamento será conhecido ao longo desta disciplina.

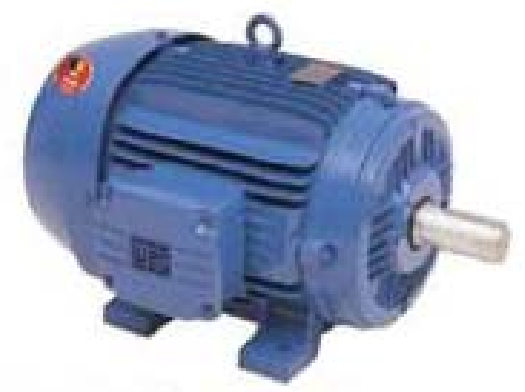

Motor elétrico

\section{MO'TORES ELÉTRICOS}

Motor elétrico é a máquina destinada a transformar energia elétrica em energia mecânica. O motor de indução é o mais usado de todos os tipos de motores, pois combina as vantagens da utilização de energia elétrica, baixo custo, facilidade de transporte, limpeza e simplicidade de comando com sua construção simples, custo reduzido, grande versatilidade de adaptação às cargas dos mais diversos tipos e melhores rendimentos. Os tipos mais comuns de motores elétricos são:

\section{MOTORES DE CORRENTE CONTÍNUA}

São motores de custo mais elevado e, além disso, precisam de uma fonte de corrente contínua, ou de um dispositivo que converta a corrente alternada comum em contínua. Podem funcionar com velocidade ajustável entre amplos limites e se prestam a controles de grande flexibilidade e precisão. Por isso, seu uso é restrito a casos especiais em que estas exigências compensam o custo muito mais alto da instalação.

\section{MOTORES DE CORRENTE ALTERNADA}

São os mais utilizados, porque a distribuição de energia elétrica é feita normalmente em corrente alternada. Os principais tipos são: 
- Motor síncrono: Funciona com velocidade fixa, utilizado somente para grandes potências (devido ao seu alto custo em tamanhos menores) ou quando se necessita de velocidade invariável.

- Motor de indução: Funciona normalmente com velocidade constante, que varia ligeiramente com a carga mecânica aplicada ao eixo. Devido a sua grande simplicidade, robustez e baixo custo é o motor mais utilizado de todos, sendo adequado para quase todos os tipos de máquinas acionadas, encontradas na prática. Atualmente é possível controlarmos a velocidade dos motores de indução com o auxílio de inversores de freqüência.

\section{FUNCIONAMENTO DE UM MOTOR ASSÍNCRONO}

A partir do momento que os enrolamentos localizados nas cavidades do estator são sujeitos a uma corrente alternada, gera-se um campo magnético no estator, consequentemente, no rotor surge uma força eletromotriz induzida devido ao fluxo magnético variável que atravessa o rotor. A fem. induzida dá origem a uma corrente induzida no rotor que tende a opor-se à causa que lhe deu origem, criando assim um movimento giratório no rotor.

Como podemos constatar o princípio de funcionamento do motor de indução baseia-se em duas leis do Eletromagnetismo, a Lei de Lenz e a Lei de Faraday.

Faraday: "Sempre que através da superfície abraçada por um circuito tiver lugar uma variação de fluxo, gera-se nesse circuito uma força eletromotriz induzida. Se o circuito é fechado será percorrido por uma corrente induzida".

Lenz: "O sentido da corrente induzida é tal que esta pelas suas ações magnéticas tende sempre a opor-se à causa que lhe deu origem".

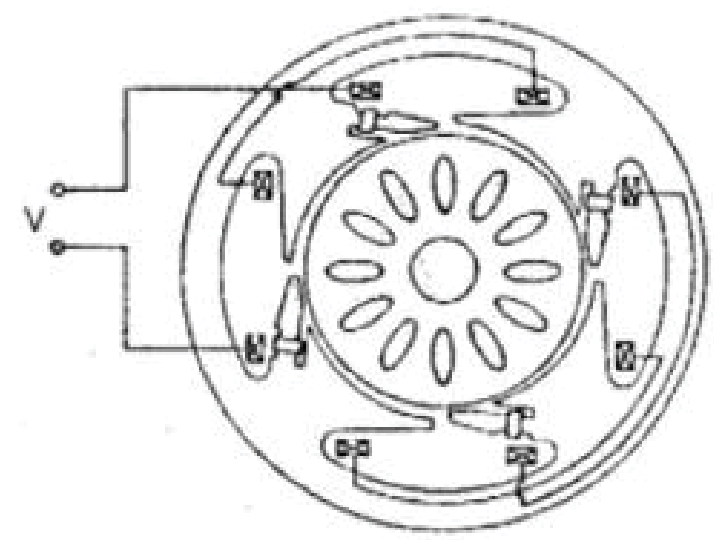

Motor elétrico

Colocamos no final da aula, como apêndice, a Constituição do Motor de Indução. 


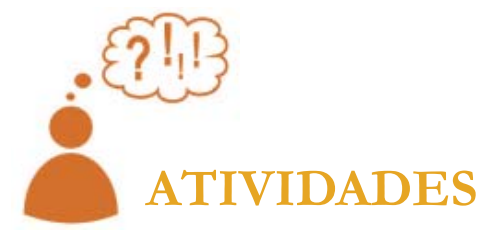

\section{APPLETS DE ENSINO}

1. Explique o princípio de funcionamento do applet abaixo do curso da Universidade do Colorado. Acesse o link < https:// sites.google.com/site/ professorpifer/Home/fisica-mix/eletromagnetismo $>$.

Note que você têm que abrir a torneira (cursor para o imã girar)

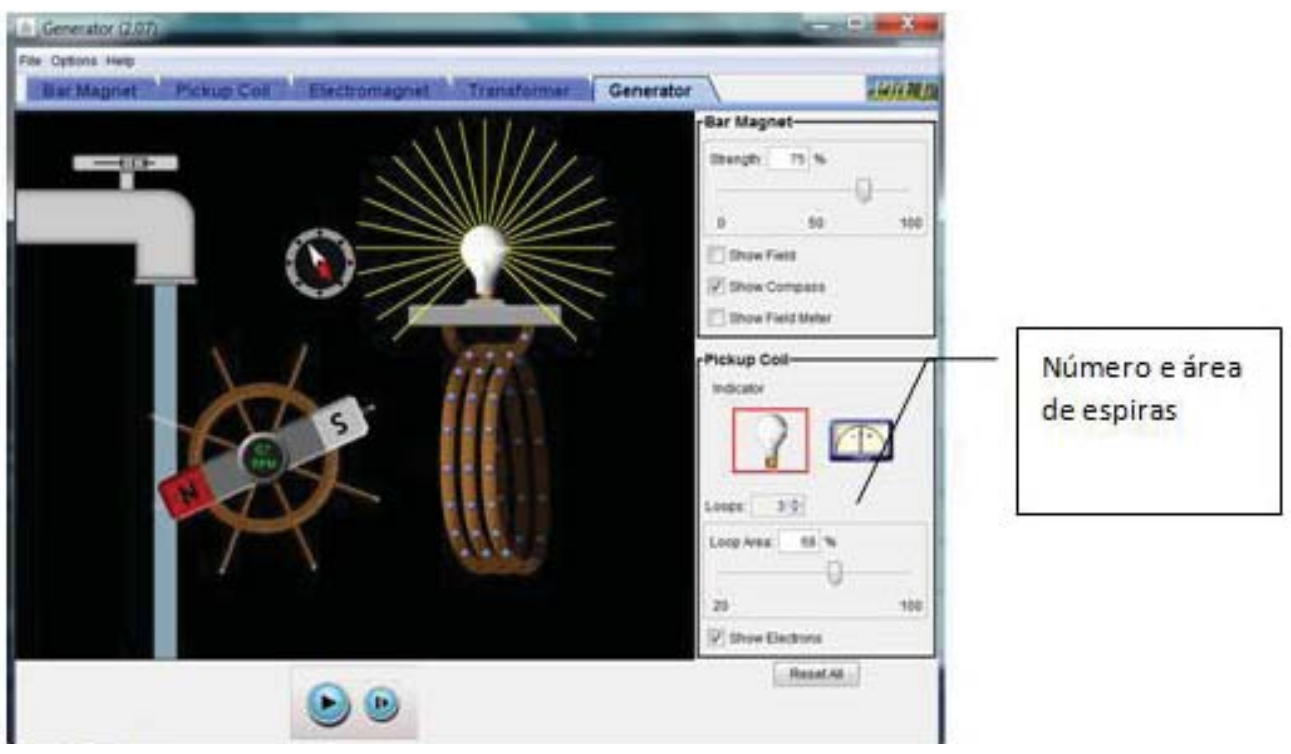

Disponível em https://sites.google.com/site/professorpifer/Home/fisica-mix/eletromagnetismo

\section{Botão: GENERATOR}

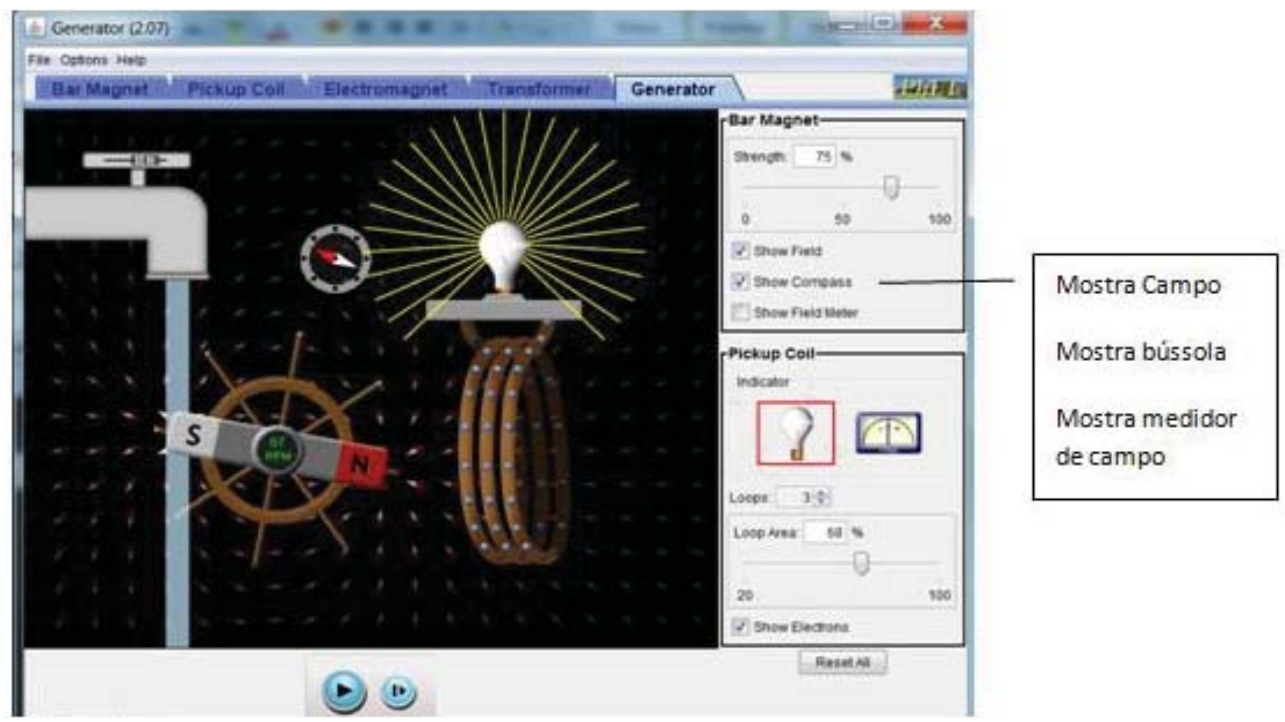


2.- Explique o princípio de funcionamento do applet abaixo do curso da Universidade do Colorado. Acesse o link <https:// sites.google.com/site/ professorpifer/Home/fisica-mix/eletromagnetismo $>$.

Note que é o mesmo applet, porém foi mudado de gerador para transformador

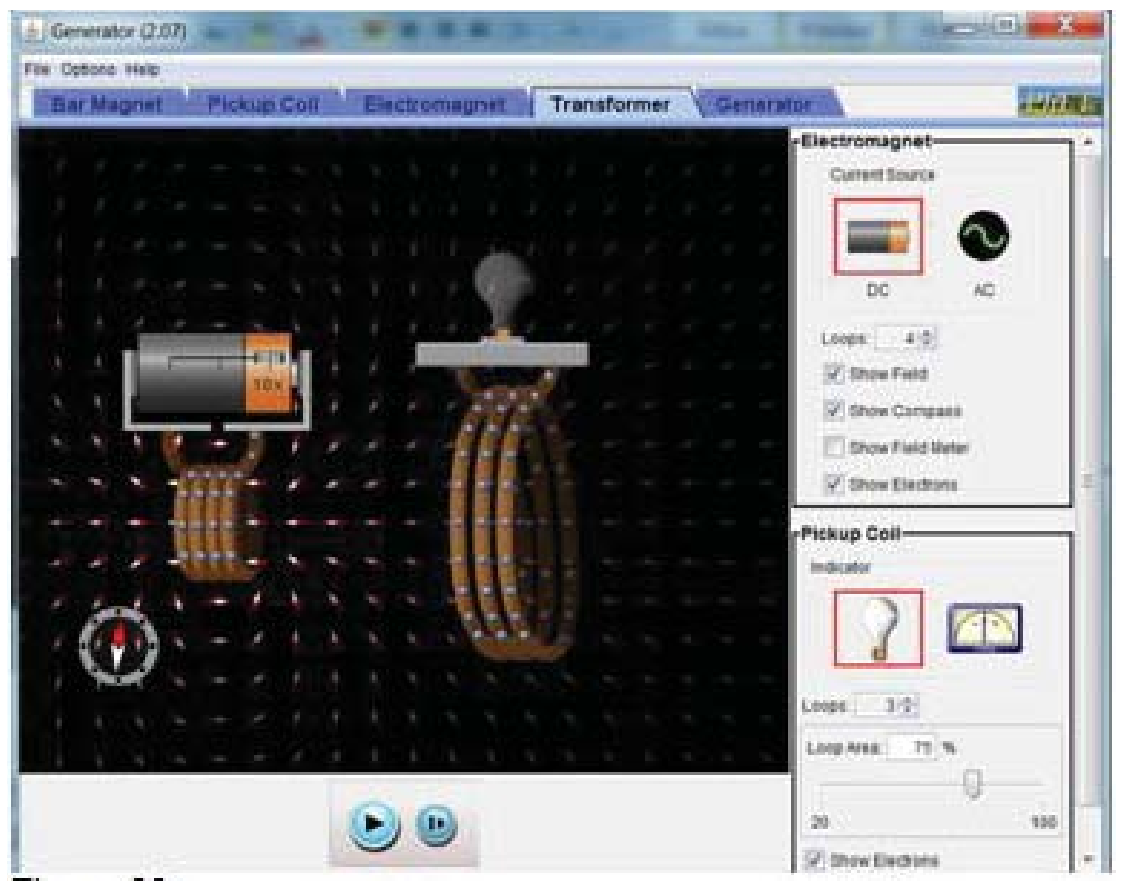

3. Explique o princípio de funcionamento do applet abaixo do curso da Universidade do Colorado. Acesse o link: <https://sites.google.com/site/ professorpifer/Home/fisica-mix/eletromagnetismo>

Você tem que ficar arrastando o imã como fosse de verdade (mouse)

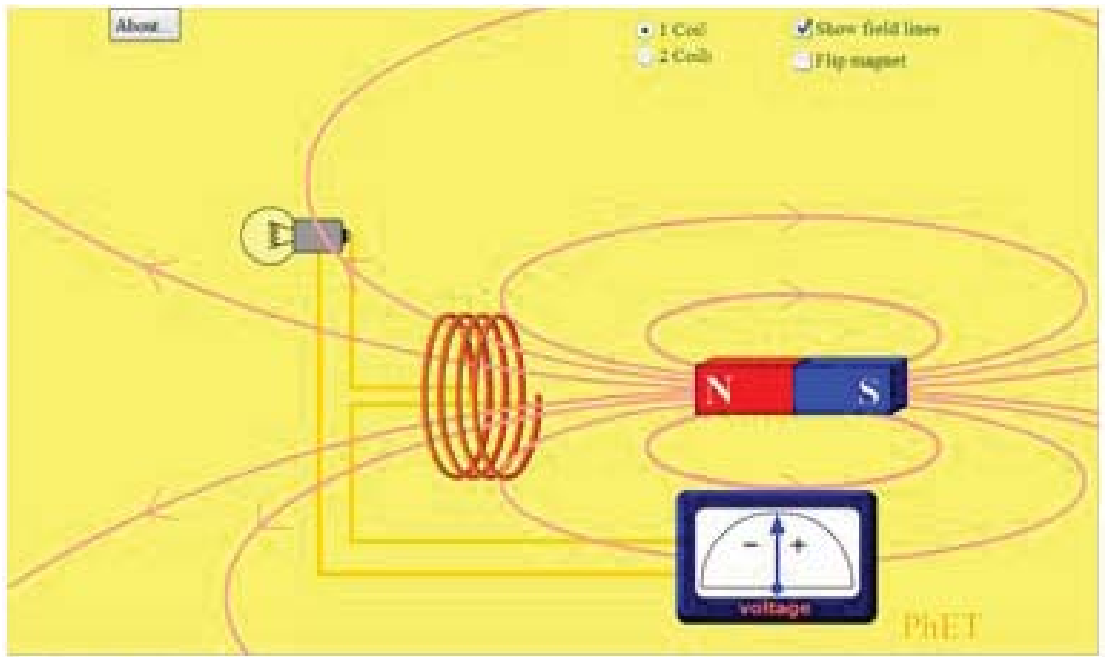

Disponível em: http://phet.colorado.edu/sims/faradays-law/faradays-law_en.html> 
4. Explore esse excelente applet do site lecture on line. Aqui podemos simular os resultados de algumas das experiências que Michael Farday feitos para descobrir a lei de indução. Você pode arrastar o espira vermelha com o mouse. Este laço é acoplado ao galvanômetro no fundo com fios elétricos invisíveis. No entanto, estes cabos para não obstruir a visão são representados por pontos verde e amarelo dos dois cabos. Cabos transparente! Outro triunfo do mundo virtual!

Mova a espira para dentro ou para fora do ímã, e o galvanômetro indica uma corrente. Quanto vai depender da velocidade com que você move o loop.

Você também pode inverter a polaridade do imã, basta clicar sobre as áreas cinza frente da ferradura. Como é que esta mudança afetará o movimento da agulha do galvanômetro quando você mover o loop dentro e fora do ímã?

Link: <http://lectureonline.cl.msu.edu/ mmp/applist/induct/faraday.htm $>$

\section{Applet: Induction}

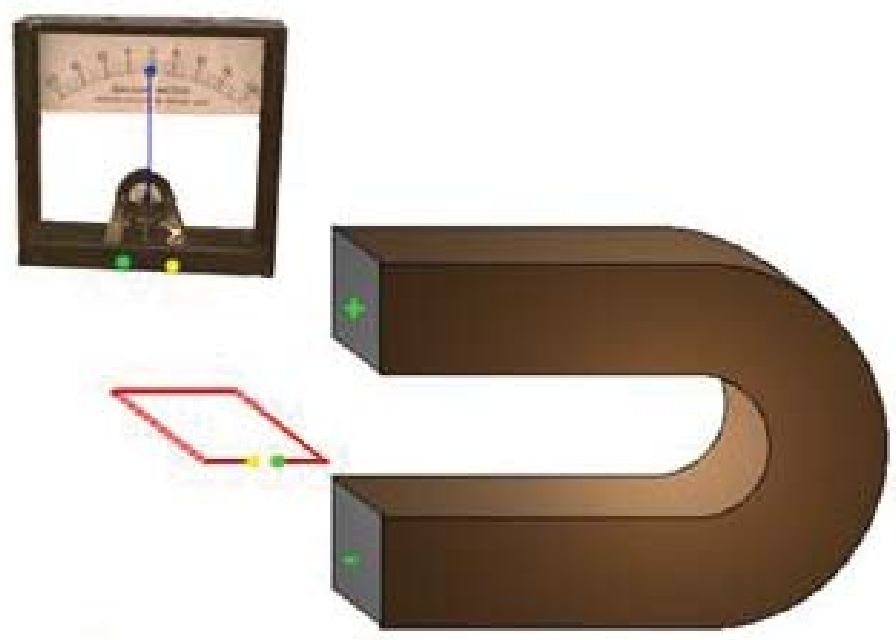

5 - Motor Elétrico. Applet do site do prof. Walter-Fendt. Esta pequena aplicação em Java mostra um motor elétrico funcionando com corrente contínua, com a imagem reduzida aos componentes essenciais para clareza da observação. Por exemplo, em vez de uma armadura com um enrolamento, observamos uma espira simples em rotação, do mesmo modo que não se observa o suporte e eixo do enrolamento.

As setas vermelhas indicam a direção convencional da corrente. Podem-se reconhecer as linhas do campo magnético (do pólo Norte em vermelho, para o pólo Sul em verde) marcadas em azul. As setas em negro representam a força de Lorent\%: 
A força de Lorentz é ortogonal em relação à direção da corrente e às linhas de campo magnético. A orientação desta força pode ser encontrada através da conhecida regra dos três dedos (ou regra da mão direita):

Polegar: Direção (convencional) da corrente

Indicador: Campo Magético

Médio: Força de Lorentz.

Os botões e as caixas que surgem na zona verde são de ação indutiva, permitindo ao utilizador manipular a aplicação quer ao nível da observação, (vetores) quer ao nível do funcionamento (rotações e polaridade).

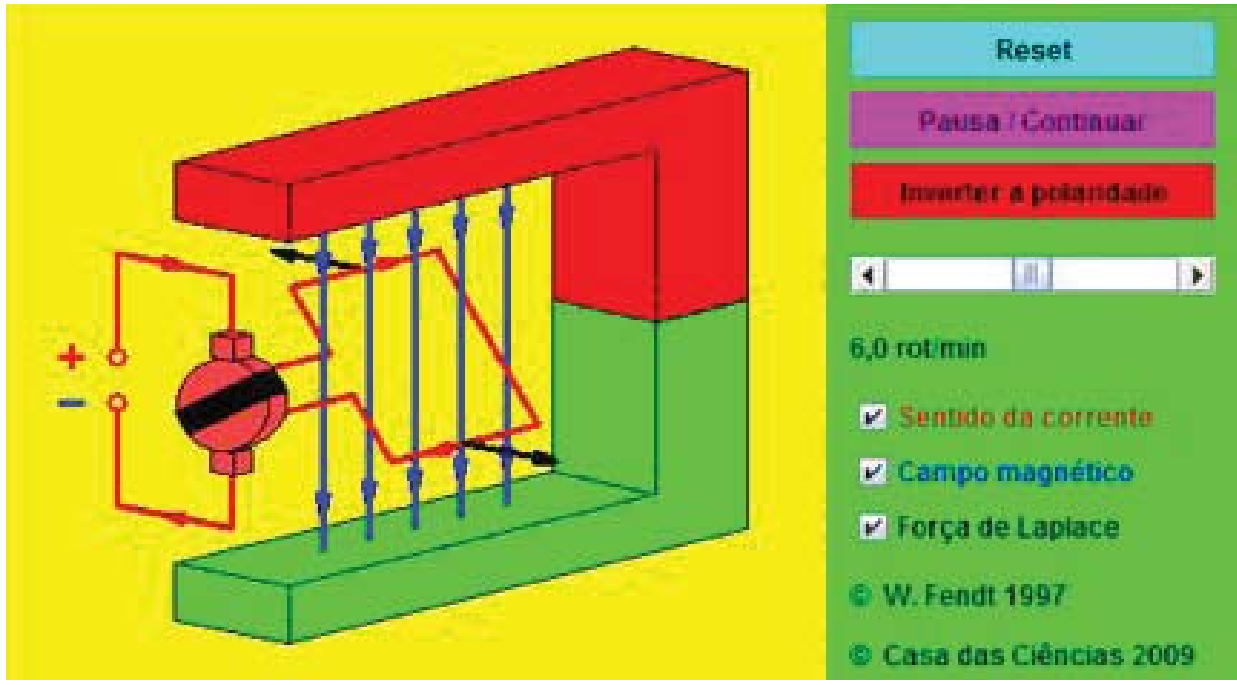

\section{VIDEOS AULAS}

1. Vídeo de aula simples. Força Magnética e funcionamento do motor elétrico

Link: <http:/ www.youtube.com/watch?v $=\mathrm{m} 4-8 \mathrm{OscX}-\mathrm{Xw}>$

2. Aula muito boa, mas está em espanhol. Funcionamiento Paso a Paso Del Motor Eléctrico: Motor De Corriente Continua. Para assistir acesse o link: $<$ http:/ / www.youtube.com/ watch?v=6JGyXDZBagg\&feature= related $>$ 3. Aula muito boa, mas está em espanhol. Generador eléctrico de corriente alterna Encarta. Para assistir acesse o link: <http://www.youtube.com/wa

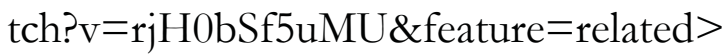

\section{EXPERIMENTOS DE BAIXO CUSTO}

Experimentos de Eletromagnetismo (disponível em: <http://www2. fc.unesp.br/experimentosdefisica/ele_list.htm>).

Variação do Campo Magnético Cria Corrente Elétrica 
Objetivo:

Neste experimento vamos mostrar que é possível criar corrente elétrica usando o magnetismo.

\section{Contexto:}

Quando uma corrente elétrica atravessa um fio condutor, cria em torno dele um campo magnético. Este efeito foi verificado pela primeira vez por Hans Christian Oersted em abril de 1820. Ele observou que a agulha de uma bússola defletia de sua posição de equilíbrio quando havia próximo a ela um fio condutor pelo qual passava uma corrente elétrica.

Usando esse resultado, Michael Faraday perseguiu a ideia de que o contrário poderia ser verdade: um campo magnético poderia induzir uma corrente elétrica num fio condutor.

Faraday montou um circuito fechado composto de um galvanômetro (medidor de corrente elétrica) e uma bobina (fio condutor enrolado, formando um conjunto de espiras superpostas). Ele observou que quando um ímã é posto em movimento próximo desse circuito elétrico, o galvanômetro oscilava seu ponteiro. Se o ímã era empurrado para dentro da bobina, o galvanômetro acusava corrente elétrica percorrida num sentido. Se o ímã era puxado de dentro da bobina, o galvanômetro acusava corrente no sentido contrário. Faraday observou também que se o ímã estivesse parado em relação à bobina, o galvanômetro não acusava nenhuma corrente elétrica.

Este fenômeno ocorre para qualquer circuito elétrico fechado. Porém a existência de uma bobina neste circuito é fundamental para a sua detecção, pois ela multiplica a intensidade do efeito proporcionalmente ao número de espiras que a constitui.

Este fenômeno, hoje conhecido como indução magnética, foi explicado pelo físico Heinrich Emil Lenz, baseado no Princípio da Conservação da Energia.

Lenz estabeleceu que a indução magnética ocorre quando há uma variação (aumento ou diminuição) do campo magnético no interior da bobina e a corrente induzida nesta é tal que o campo magnético por ela criado anula o efeito do campo magnético variável que iniciou o processo. Assim, se um campo magnético externo estiver aumentando de intensidade no interior de um circuito fechado, será criada neste circuito uma corrente tal que o campo magnético criado por ela tentará anular o campo magnético externo. As linhas de campo dos dois campos magnéticos são opostas. Em oposição, se o campo magnético externo estiver diminuindo de intensidade, a corrente induzida (criada) no circuito criará um campo magnético que tentará manter constante o campo magnético externo, somando-se a ele. Agora, as linhas de campo dos dois campos magnéticos são de mesma direção e sentido.

Para relacionar a direção da corrente induzida com a do campo induzido, veja o experimento "Fio vira Ímã". 


\section{Ideia do Experimento}

Vamos reproduzir e analisar o experimento de Faraday, na tentativa de provar que a variação de um campo magnético próximo a um circuito produz corrente elétrica. Mas haverá uma diferença entre o experimento original de Faraday e o que faremos aqui. Misturaremos elementos do experimento de Oersted, a fim de substituirmos o galvanômetro (ou medidor de corrente). Entendemos que nem todas as escolas ou professores terão um medidor de corrente, por isso resolvemos substituí-lo por uma bússola, que apesar de não ser um medidor de corrente, poderá identificar sua existência nesta montagem.

Então a ideia desse experimento é criar uma corrente elétrica, variando o campo magnético dentro de uma bobina (experimento proposto por Faraday), que possa gerar um campo magnético em torno do fio e defletir a agulha de uma bússola (experimento proposto por Oersted). Ou seja, o movimento de um ímã numa extremidade do circuito com a conseqüente deflexão da bússola na outra extremidade, só pode ser explicada se desse movimento for gerada uma corrente elétrica.

Ao invertermos a polaridade do ímã, observaremos uma inversão na deflexão da bússola.

Tabela do Material

\begin{tabular}{|l|l|}
\hline \multicolumn{1}{|c|}{ Item } & \multicolumn{1}{c|}{ Observações } \\
\hline Um ímã & $\begin{array}{l}\text { Ímãs são encontrados em alto falantes, ferro velho, } \\
\text { lojas de materiais elétricos, em alguns brinquedos, em } \\
\text { objetos de decoração como os ímãs de geladeira, etc. }\end{array}$ \\
\hline $\begin{array}{l}\text { Fio metálico } \\
\text { Condutor }\end{array}$ & $\begin{array}{l}\text { Qualquer fio condutor serve. Obtém-se melhores re- } \\
\text { sultados com fios de cobres esmaltados. Estes fios são } \\
\text { encontrados em casa de materiais elétricos, ou retirados } \\
\text { de aparelhos elétricos velhos. }\end{array}$ \\
\hline Bússola & $\begin{array}{l}\text { Verifique o funcionamento da bússola antes de usá-la } \\
\text { ou faça uma (veja a seção de comentários). }\end{array}$ \\
\hline
\end{tabular}

Montagem:

- Enrole o fio esmaltado no formato de uma bobina, com mais ou menos cinqüenta voltas. A bobina terá duas extremidades.

- Uma extremidade da bobina deverá ter mais ou menos dois metros. Desencape uns três centímetros dessa extremidade.

- Com a outra extremidade faremos o enrolamento da bússola. Deixe mais ou menos dois metros de fio, a partir da bobina, antes de fazê-lo. Veja a figura abaixo. 


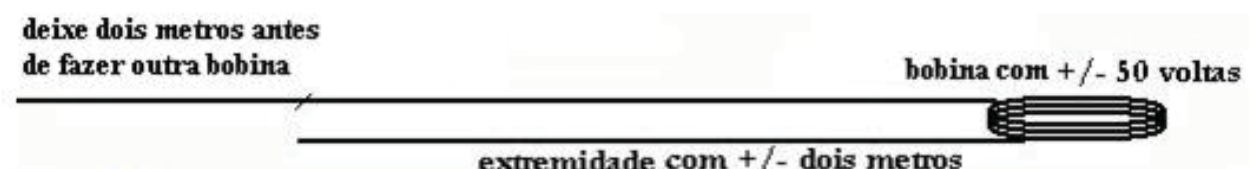

- Enrole outra bobina de mais ou menos cinqüenta voltas, de forma que a bússola entre em seu interior.

- Desencape e una as extremidades das bobinas.

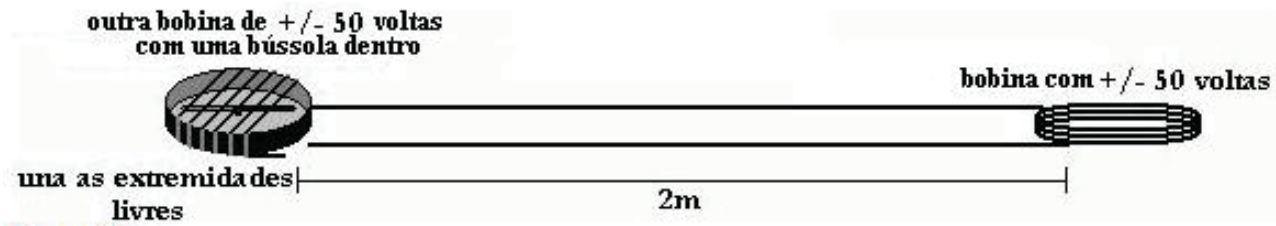

- Faça com que a direção da agulha da bússola seja paralela às espiras da bobina, antes de iniciar o experimento.

- Coloque a montagem sobre uma mesa. Se o ímã utilizado for em barra é recomendado deixar a bobina um pouco fora da mesa para que o imã possa atravessá-lo. Veja o esquema geral de montagem.

- Aproxime e afaste o ímã da bobina. Inverta a polaridade e repita este procedimento.

Comentários

- Tome cuidado com os alto-falantes, pois eles contêm ímãs bastante fortes e o campo gerado por eles atrapalhará o experimento, caso haja algum por perto.

- Quanto maior a intensidade do campo magnético, melhores serão os resultados obtidos no experimento. Procure retirar imãs de alto-falantes grandes e potentes, pois, em geral, quanto maior o alto-falante mais forte é o ímã.

- Mantenha a bússola suficientemente longe do ímã que gerará a corrente para que não haja interferência (atração da agulha da bússola pelo ímã). Foi sugerido dois metros durante a montagem, pois foi a medida em que o ímã deixou de interferir na bússola em nossa montagem. Esta distância pode variar dependendo da intensidade do campo do ímã utilizado.

- Caso você não consiga uma bússola para a realização do experimento, é possível construir uma. Para isso você vai precisar de um copo comum com água, uma agulha de costura fina, um pedaço de papel e um ímã natural. Siga os passos seguintes:

1 - Primeiro deve-se imantar a agulha de costura, passando-se o ímã natural várias vezes na agulha de costura, sempre na direção do seu comprimento e no mesmo sentido. Para saber se agulha já está bem imantada, aproxime-a de algum objeto metálico e verifique se há atração ou repulsão.

2 - Corte um pedaço de papel de aproximadamente $2 \mathrm{~cm}$ quadrado. Este 
pedaço de papel serve para permitir que a agulha de costura possa flutuar sobre a água.

3 - Atravesse ou cole no pedaço de papel já cortado, a agulha.

4 - Coloque o pedaço de papel com agulha em um copo cheio de água.

5 - Verifique por algum método se sua bússola está funcionando, comparando a direção para onde a agulha está apontando com alguma referência. Sem outros campos magnéticos por perto, ela deve se orientar na direção norte-sul.

6 - Veja a figura de como fica a construção desta bússola.

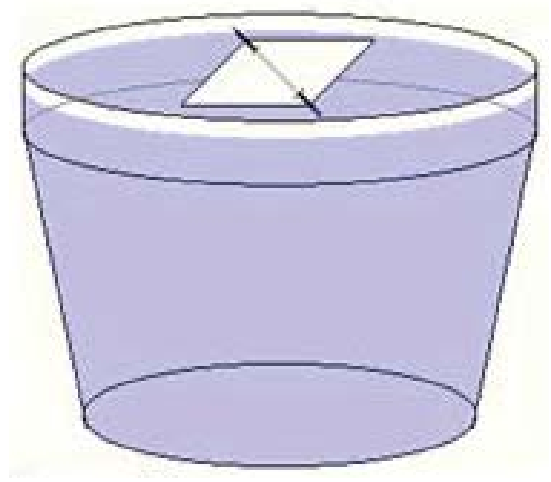

Esquema Geral de Montagem

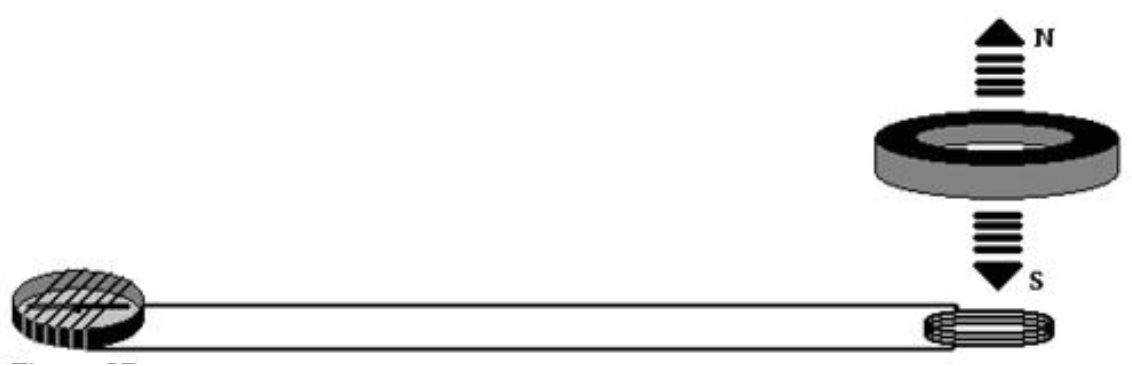

Projeto Experimentos de Física com Materiais do Dia-a-Dia - UNESP/Bauru

Motor Elétrico

Objetivo

Neste experimento vamos construir um sistema simplificado de motor de corrente contínua. Trata-se de uma aplicação de grande importância de eletricidade e magnetismo. 
Contexto

O motor elétrico funciona com base na repulsão entre imãs, um natural e outro não-natural, neste nosso exemplo.

Ideia do Experimento

O imã não-natural neste experimento é uma bobina.

O conveniente de se usar imãs não naturais num motor elétrico é a possibilidade de se manipular (inverter) os polos magnéticos.

O funcionamento deste motor elétrico pode ser explicado em alguns passos (acompanhe pela figura abaixo):

1. Num primeiro momento, os fios raspados estão em contato com as tiras e a corrente elétrica cria um campo magnético na bobina. Esta bobina por ter liberdade de rotação entra em movimento, para se livrar da repulsão do imã comum, que está fixo à sua frente.

2. Em um quarto de volta, a bobina está parcialmente em contato com as tiras e o campo magnético começa a perder sua força. Não deixando assim que a atração do polo sul da bobina pelo polo norte do imã comum seja forte o suficiente para frear o movimento.

3. Quando a bobina completa meia volta, começaria o processo inverso. Ou seja, deveria existir um campo atrativo entre a bobina e o imã. Mas isso só aconteceria se os contatos estivessem ligados. Este contato não é estabelecido, pois, esta atração frearia ou cessaria o movimento adquirido no primeiro momento.

4. Completando-se mais um quarto de volta, o contato com as tiras começa a se reestabelecer e o campo magnético a ganhar força. Neste momento a bobina começa a ser repelida pelo imã comum. Dado o movimento que a bobina já possui este ganha nova aceleração.

5. Volta-se à posição inicial e o ciclo recomeça.

Assim o processo continua periodicamente, enquanto existir corrente elétrica passando pela bobina.

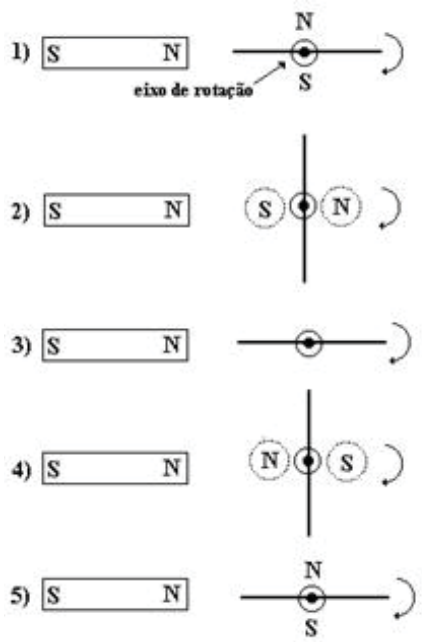




\begin{tabular}{|l|l|}
\hline \multicolumn{1}{|c|}{ Item } & \multicolumn{1}{|c|}{ Observações } \\
\hline $\begin{array}{l}\text { Um pedaço de fio de } \\
\text { cobre esmaltado }\end{array}$ & $\begin{array}{l}\text { Aproximadamente um metro de fio }\left(\mathrm{n}^{\circ} \text { 26). Pode }\right. \\
\text { ser encontrado em casa de materiais elétricos ou } \\
\text { eletrônicos ou então retirados de enrolamentos } \\
\text { elétricos velhos. }\end{array}$ \\
\hline Tiras de lata & $\begin{array}{l}\text { Neste experimento foi utilizado presilhas de lata das } \\
\text { pastas de cartolina que são vendidas em papelarias. }\end{array}$ \\
\hline Pilhas & $\begin{array}{l}\text { Acrescentar pilhas, ligadas em série, conforme a } \\
\text { necessidade da montagem. }\end{array}$ \\
\hline Imã & $\begin{array}{l}\text { Quanto mais intenso for o campo magnético } \\
\text { melhor. Pode ser retirado de alto falantes velhos } \\
\text { ou encontrado em lojas de ferro velho. }\end{array}$ \\
\hline Pedaço de madeira & Servirá como base para a montagem. \\
\hline
\end{tabular}

\section{Montagem}

- Para fazer a bobina enrola-se o fio de cobre num cano ou qualquer outro objeto cilíndrico, com cerca de $3 \mathrm{~cm}$ de diâmetro. Deve-se deixar livre duas pontas de aproximadamente $2 \mathrm{~cm}$ de comprimento, em cada extremidade.

- A raspagem do esmalte do fio de cobre nas extremidades, deve ser feito da seguinte maneira: primeiro, deve-se raspar com uma lâmina todo o esmalte de uma das extremidades, dando uma volta completa. A outra extremidade, só é raspado o esmalte de meia volta do fio. Isso porque em um plano, ambas as extremidades estão raspadas, e em contato com as tiras, dando contato para a passagem de corrente elétrica. E consequentemente no outro plano, somente uma das extremidades em contato com as tiras estará raspada, não permitindo assim a passagem de corrente elétrica. E consequentemente não gerando campo magnético em torno da bobina.

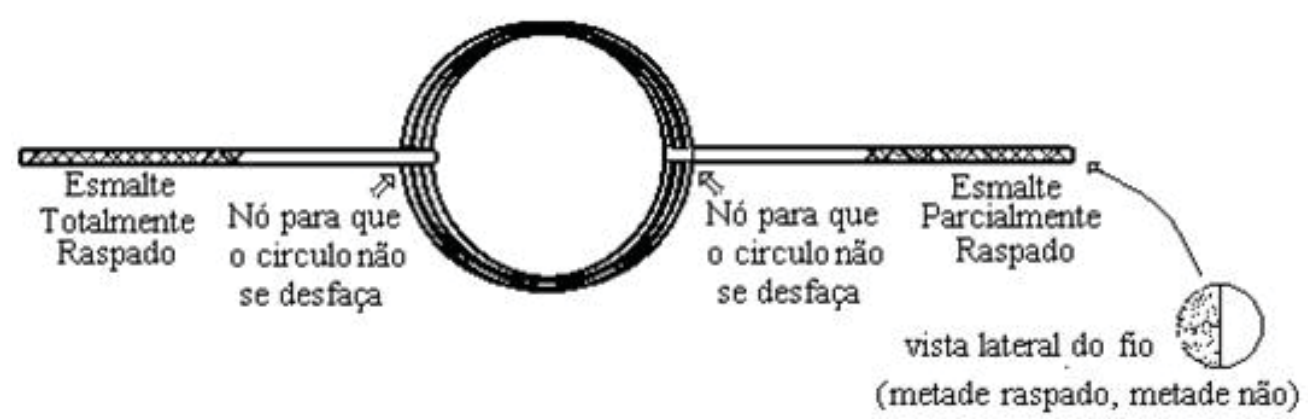

- Para fazer os suportes da bobina utiliza-se tiras de lata, dando-lhes o formato indicado na figura a seguir e prendendo-as a uma base de madeira; 


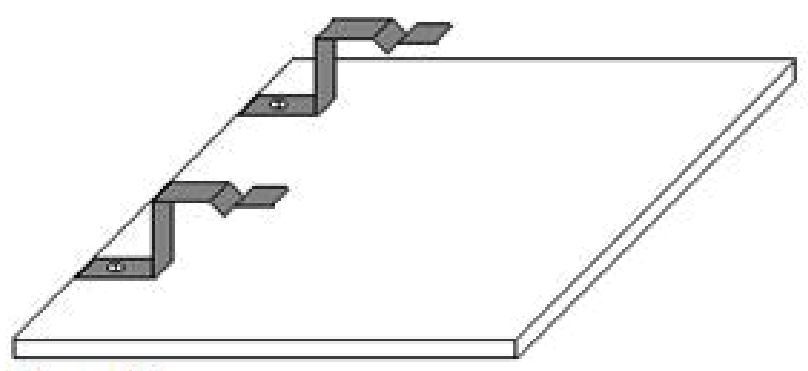

- Coloque a bobina sobre o suporte, verificando se ela pode girar livremente. Se isso não ocorrer, alinhe as extremidades da bobina de modo que elas fiquem bem retas e opostas e veja se as depressões nos suportes estão em linha reta, no mesmo nível e do mesmo tamanho;

- Ligue com fios de cobre cada uma das lâminas do suporte a uma extremidade da(s) pilha(s), prestando atenção para não deixar a faixa esmaltada das extremidades da bobina em contato com o suporte.

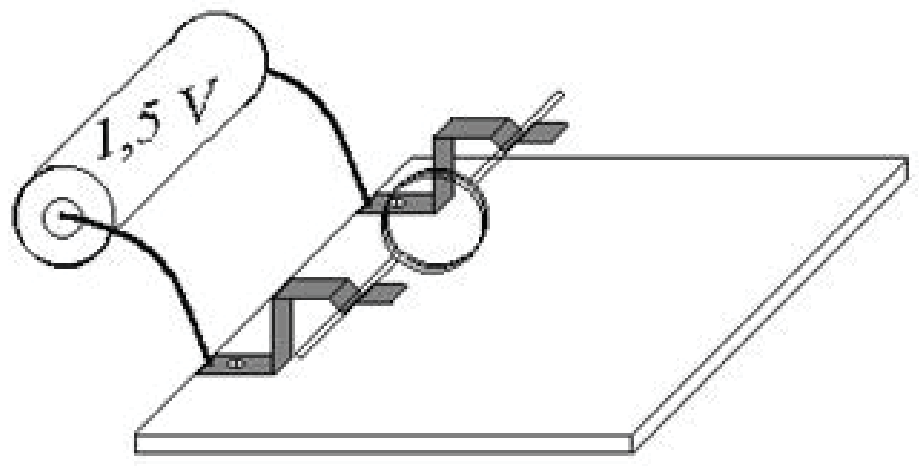

- Posiciona-se um imã sobre um suporte qualquer de forma que fique aproximadamente na mesma altura da bobina. Se o contato com a pilha for estabelecido e a bobina não girar, talvez seja preciso, no início, girar a bobina manualmente (dar um empurrãozinho).

Comentários

- Dada a simplicidade do motor, para funcionar, ele é dependente das dimensões e materiais usados. Portanto, algumas tentativas talvez sejam necessárias até que o motor funcione adequadamente.

- Outra característica deste motor é que há determinadas combinações de formas diferentes de se ligar os polos da bateria às tiras e mesmo da posição da espira sobre as tiras. Mas algumas poucas tentativas devem levar a uma das combinações corretas. 
Esquema Geral de Montagem:

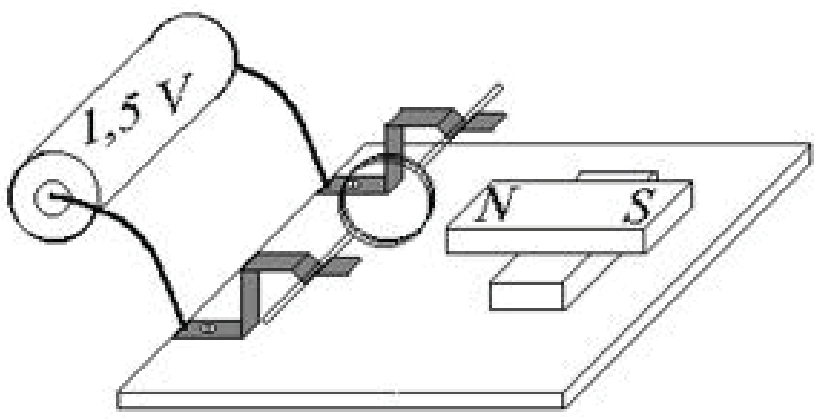

Projeto Experimentos de Física com Materiais do Dia-a-Dia - UNESP/Bauru

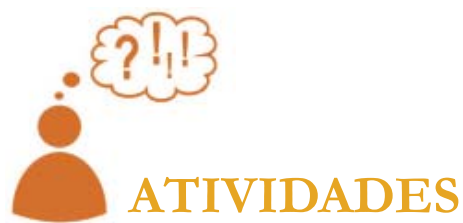

1. Você acha meio confuso começar mostrando os fenômenos só depois introduzindo a teoria, explicação?

2. O que você pensa sobre o trocadilho: ensinar a física das coisas e não as coisas da física.

3. Você vê muita diferença entre o material produzido para o projeto GREF e o seu livro didático? Comente.

4. Você vê muita diferença entre o material produzido para o projeto GREF (UFSM) e o seu livro didático? Comente.

5. Como você analisa a transposição didática destes projetos com relação a um texto universitário do ciclo básico (por exemplo Halliday)?

6. Como você ilustraria o conceito de campo magnético para seus (futuros) alunos depois dessa ultima aula?

7. Você usaria esse material que eu preparei para essa aula para ministrar um curso sobre as leis de Faraday e de Lenz? Comente.

8. Devido ao alto grau de abstração muitos físicos e grupos de ensino estão fazendo animações gráficas e applets que demonstram virtualmente a lei de Lenz e de Faraday. Colocamos alguns links para você abaixo para você poder explorar alguns deles.

9. Com o advento da televisão alguns grupos de ensino e ou instituições estão fazendo vídeos aulas sobre temas interessantes e complexos de física. Colocamos alguns links para você acima para você poder explorar alguns deles. Faça um comentário a respeito deles.

10. Colocamos acima alguns exemplos e/ou links de experimentos de baixo custo para você analisar a possibilidade de usá-los em sala de aula. Comente se você os usaria ou não como recurso didático em sala de aula? Comente. 


\section{CONCLUSÃO}

Depois dessa aula o futuro professor deve ter entrado em contato com uma forma mais lúdica e motivante de se ensinar Física. Deve estar se perguntando se temos que ficar presos ao método tradicional de se ensinar Física. Deve estar imaginando quantas possibilidades temos para ensinar Física.

Com a análise dos experimentos de baixo custo e dos recursos de multimídias que colocamos no final da aula o futuro professor deve ter ficado com algumas boas idéias de como este pode enriquecer uma aula sobre o tema Lei de Coulomb.

Com essa última aula o estudante deve ter ficado como uma boa visão do papel dos projetos de ensino de Física, e seu papel na formação dos primeiros físicos no Brasil. Deve ter notado como estes influenciaram a estrutura dos nossos livros didáticos.

\section{COMENTÁRIOS SOBRE AS ATIVIDADES}

É muito comum as queixas dos alunos de licenciatura com respeito de como um curso de Física é ministrado ou desenvolvido e do porque da estrutura do curso. E o que ocorre em geral é que ao sair da universidade se acaba sucumbindo às pressões da vida e repetindo à mesma forma de ensinar Física (erros!). Com essa aula, continuamos a levantar e discutir os problemas de se ministrar um "bom" curso de Física e de suas limitações. O mais importante é que estamos tentando, como em muitos outros lugares, a incentivar o futuro professor repensar, reavaliar e criar uma nova forma de ministar um curso de Física.

Em geral os alunos que fazem o curso de licenciatura em Física têm um curso muito superficial ou não têm nenhuma aula de Física. Se têm, usam algum livro texto tradicional, onde a Física é apresentada como uma coleção de definições e fórmulas para ser aplicada em problemas e exercícios. Assim, a maioria só possui o conhecimento de Física dado na universidade. A apresentação do projeto Havard deve ter dado uma visão geral de toda a complexidade de se montar um curso de Física e como esse pode se tornar mais atraente.

O aluno deve começar a se ver como futuro professor. Isto é, ele deve começar a ver a Física não como matéria a ser aprendida e sim como a ser ensinada. Aqui ele deve começar a enxergar as diversas possibilidades que o mundo moderno lhe oferece como educador. Os futuros professores devem ter compreendido o papel central que eles têm na escolha do conteúdo, da técnica e da didática ser utilizada em sala de aula. Este deve ter adquirido uma ideia de como se deve preparar um curso ou apenas uma aula. Eles devem compreender que uma aula é um processo dinâmico e orgânico. 


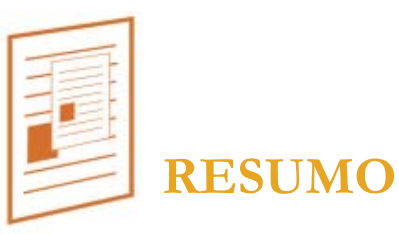

Nessa última aula, seguimos a cartilha do método de ensino do GREF. Iniciamos com as atividades exploratórias e experimentais sugeridas, e somente depois colocamos a definição das leis de Faraday e de Lenz tirado do GEF da UFSM. Deixamos o veredito sobre a praticidade e eficiência desse método para você. E encerramos fazendo uma breve revisão do que é um motor elétrico, segundo uma apostila de máquinas elétricas do Professor Jorge Eduardo Uliana.

Em seguida apresentamos vários experimentos de baixo custo para que o aluno explore as possibilidades que estes oferecem para se ministrar um curso usando mais ferramentas fenomenológicas e menos formais. Colocamos vários e excelentes applets de ensino como recurso de simulação de fenômeno físico para ser explorado pelo futuro professor.

Como há ótimos vídeos de ensino colocamos alguns deles como referência, e deixamos sua exploração como atividade, pois no curso de Instrumentação I não usamos os vídeos didáticos como ferramenta didática principal.

\section{RESPOSTA ÀS ATIVIDADES}

1. A resposta é um pouco subjetiva. Mas, esperamos que ele responda que não.

2. Espero que eles tenham gostado.

3. Sim, os materiais são muito diferentes. Eles têm que fazer uma avaliação dos métodos de ensino.

4. Não. Eles têm muita coisa em comum. Ambos começam pela teoria e depois partem para a explicação.

5. O livro didático e o material do GEF são uma simplificação do livro didático, enquanto o GREF não.

6. Resposta pessoal. Ele tem que fornecer um exemplo.

7. Espero que sim, mas com ressalvas.

8. Fazer uma resenha do filme assistido.

9. Fazer uma resenha do filme assistido.

10. Fazer uma resenha do filme assistido. 


\section{REFERÊNCIAS}

APPLETS-ELETROMAGNETISMO. Universidade do Colorado. Disponível em: <https:// sites.google.com/site/professorpifer/Home/fisicamix/eletromagnetismo>. Acesso em 15/10/2011.

GEF-UFSM - Grupo de Ensino de Física da Universidade Federal de Santa Maria. Disponível em: <http://www.ufsm.br/gef/>. Acesso em 16/10/2011.

GREF - Grupo de Reelaboração do Ensino de Física, Instituto de Física da USP - Leituras de física - Gref - Eletromagnetismo para ler, fazer e pensar - versão preliminar 14-19. Disponível em: <http://www.if.usp. br/gref/eletro/eletro1.pdf>. Acesso em 15/10/2011.

Projeto de ensino da UNESP Bauru. Experimentos de física para o ensino médio e fundamental com materiais do dia-a-dia. Disponível em: $<$ http://www2.fc.unesp.br/experimentosdefisica/ele_list.htm > . Acesso em 16/10/2011.

PSSC, Física - Parte I, Parte II, Parte III, Parte IV, Editora Universidade de Brasília, tradução autorizada com direitos reservados para o Brasil pelo IBECC-UNESCO.

PSSC, Guia do Professor de Física- Parte I, Parte II, Parte III, Parte IV, EDART, SP, traduzido e adaptado pela Fundação Brasileira para o Desenvolvimento do Ensino de Ciências e pelo Centro de Treinamento de Professores de Ciências de São Paulo(CECISP).

PSSC PHYSICS: A Personal Perspective, by Uri Haber-Schaim. Disponível em <http://www.compadre.org/portal/pssc/docs/Haber-Schaim.pdf> PSSC in Historical Context: Science, National Security, and American Culture during the Cold War, by John L. Rudolph”. Disponível em < http:/ / www.-compadre. $\neg$ org $/ \neg$ portal $/ \neg$ pssc $/ \neg$ docs $/ \neg$ Rudolph. $\neg$ pdf $>$ ULIANA, Jorge Eduardo. Comandos e motores elétricos. Apostila disponível em: http://apostilas.netsaber.com.br/apostilas/1077.pdf. Acesso em 16/10/2011.

Youtube. Força Magnética e funcionamento do motor elétrico. Disponível em: <http://www.youtube.com/watch?v=m4-8OscX-Xw>. Acesso em 16/10/2011.

. Funcionamiento Paso a Paso Del Motor Eléctrico: Motor de Corriente Continua. Disponível em:

$<$ http: / / www.youtube.com/ watch?v=6JGyXDZBagg\&feature= related $>$. Acesso em 16/10/2011.

Generador eléctrico de corriente alterna Encarta. Disponível em:

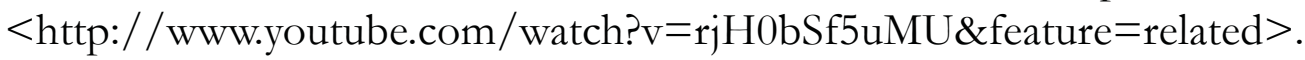
Acesso em 16/10/2011. 


\section{APÊNDICE - CONSTITUIÇÃO DO MOTOR DE INDUÇÃO}

O motor assíncrono é constituído basicamente pelos seguintes elementos: um circuito magnético estático, constituído por chapas ferromagnéticas empilhadas e isoladas entre si, ao qual se dá o nome de estator; por bobinas localizadas em cavidades abertas no estator e alimentadas pela rede de corrente alternada; por um rotor constituído por um núcleo ferromagnético, também laminado, sobre o qual se encontra um enrolamento ou um conjunto de condutores paralelos, nos quais são induzidas correntes provocadas pela corrente alternada das bobinas do estator.

O rotor é apoiado num veio, que por sua vez transmite à carga a energia mecânica produzida. O entreferro (distância entre o rotor e o estator) é bastante reduzido, de forma a reduzir a corrente em vazio e, portanto as perdas, mas também para aumentar o fator de potência em vazio.

Como exemplo, apresentamos a "projeção" dos diversos elementos o motor assíncrono de rotor em gaiola de esquilo.

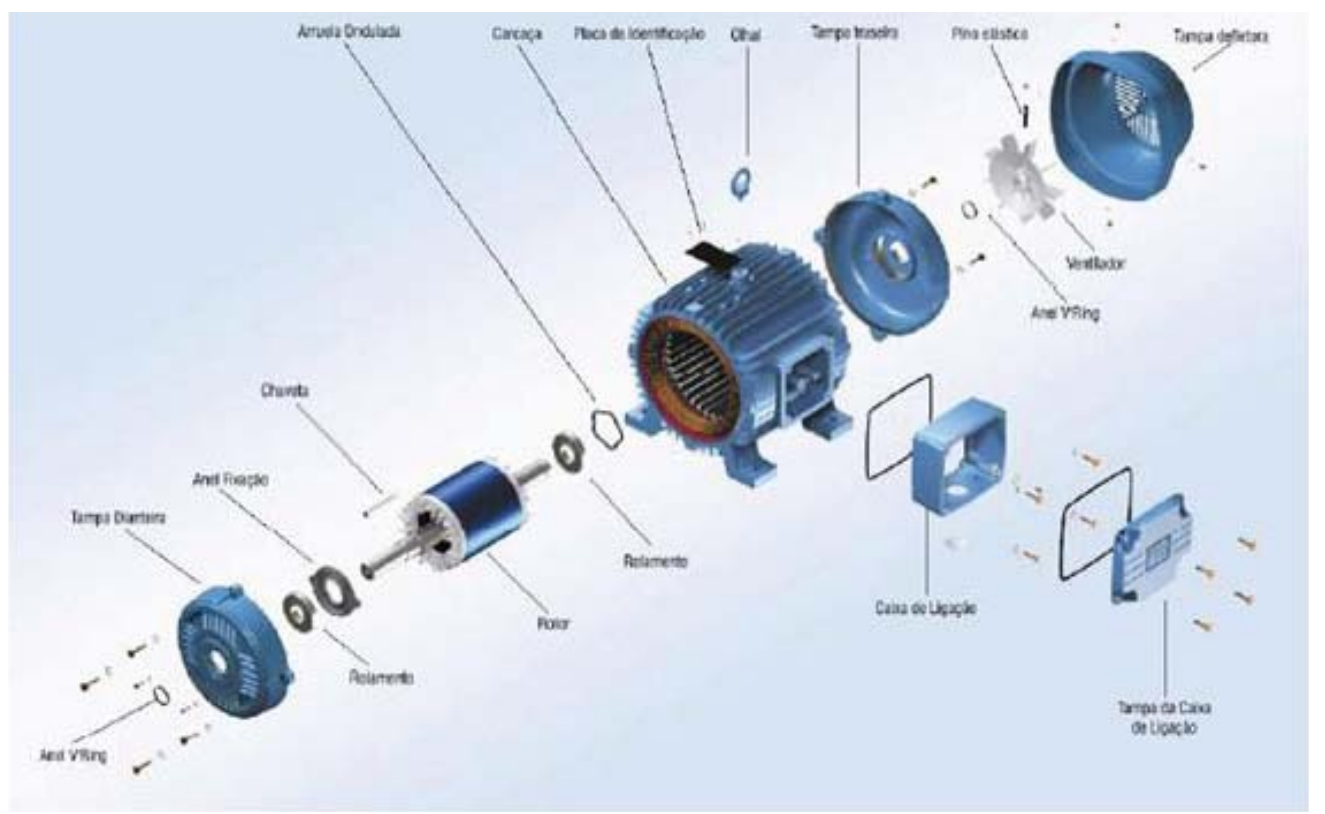

